\title{
VEGETABLE GARDENING.
}

SAMUEL B. GREEN. 

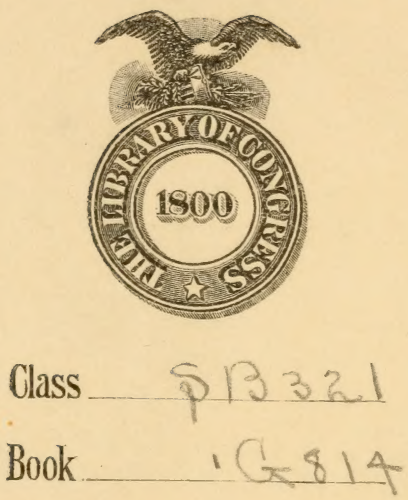

Copyright $\mathrm{N}^{0}$.

COPYRIGHT DEPOSIT. 




\section{VEGETABLE GARDi NING.}

A Manual on the Growing of Vegetables for Home Use and Marketing.

Prepared for the Classes of the School of Agriculture of the University of Minnesota,

BY

SAMUEL B. GREEN,

Professor of Horticulture in the University of Minnesota.

Author of

"Amateur Fruit Growing" and "Forestry in Minnesota."

WITH I23 ILLUSTRATI NS.

FIFTH EDITION

REVISED.

ST. PAUL.

WEBB PUBLISHING COMPANY.

1903. 


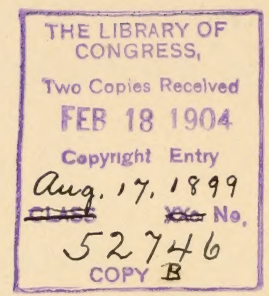

COPYRIGHT, 1901,

BY

SAMUEL B. GREEN.

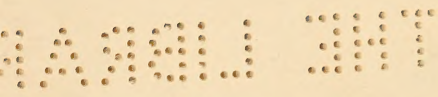

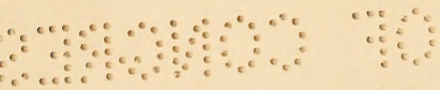




\section{Preface to Fifth Edition.}

This book was prepared primarily for the School of Agriculture of the University of Minnesota, where it has been used as a text book for four years. In this edition some changes have been made to bring it up to date in the matter of methods of culture and varieties recommended. The material has also been re-arranged and more attention paid to the classification of vegetables than in the first edition. A few other new minor features have also been introduced which experience seemed to show desirable.

I wish to acknowledge the kind assistance received in the preparation of this manuscript from Prof. Harry Snyder and my assistant, R. S. Mackintosh. In previous editions I have taken pleasure, as I do now, in acknowledging the assistance which I have received in many ways from Dr. Otto Lugger and Major A. G. Wilcox, and it pains me now to have to record the death of both within the past year, but the memory of the many pleasant associations with them will always be fresh in my mind.

Figures numbered 52, 67, 69 and 121 are from D. Landreth \& Sons; 26, 27, 31, 32 and 92 are from W. Atlee Burpee; Nos. 22, 23, 81 and 96 are reproduced from publications of the Department of Agriculture; No. 5 is from Bateman Manufacturing Co.; Nos. $34,35,36,37,38,39,41,42$ and 43 were loaned by Dr. Lugger; Nos. 58, 61, 63, 65, 66, 106, 108, 112, 119, 120 and 122 from various sources. All other figures are original.

SAMUEL B. GREEN.

St. Anthony Park, Minn., February 1, 1903. 


\section{CONTENTS.}

\section{CHAPTER I.}

The Vegetable Garden.-Location and soil for early crops. Location and soil for late crops.

Irrigation.-Cultivation and irrigation. Humus an aid to irrigation. Amount of water required for irrigating different crops. Pumping water for irrigation. Making reservoirs. Application of water. Rules for applying water. Sub-irrigation.

Rotation of Crops.-Reasons for.

\section{CHAPTER II.}

Manures.-Most valuable elements in manures. Direct and indirect manures. Composition of vegetables. Manures and fertilizers.

Animal Manures.-Horse manure. Hen manure. Cow and swine manure. Sheep manure. The manure pile. The compost heap. Commercial manures. Tankage. Ground blood. Ground bone. Nitrate of soda. Sulphate of ammonia. Superphosphate. Wood ashes. Kainite. Lime. Land plaster. Effect of manures on crops. Manures for early and late crops. Manures for leguminous crops. Manuring the growing crops. Liquid manure.

CHAPTER III.

Garden Tillage.-Prevention and killing of weeds. Importance of not allowing weeds to go to seed. Weed seeds in manure for the garden. Plowing. Subsoil plowing. Ridging land. General cultivation of garden crops. Cultivation to develop plant food.

Garden Implements.-Horse hoes and horse cultivators. Hand cultivators. Seed drills. Combination seed drills and cultivators. Markers. Scuffle attachment to hand garden cultivators. Scuffle hoe. Plant drag. Potato diggers. Spray pumps. 
CHAPTER IV.

Seed Sowing.-Depth to plant. Time for sowing. Sowing in stiff clay soils. Sowing seed with machine. Sowing seed by hand. Using the feet for firming the soil around seeds. Thinning. Protecting seeds against insects and birds. Transplanting. Avoid transplanting as much as possible. Conditions of success. Shortening the tops of plants. Firming the soil about the roots of plants. Tomato cans for flower pots. The Farmer's Kitchen Garden.-Arrangement of.

\section{CHAPTER V.}

Seeds and Seed Growing.-Good pedigrees in seeds. Testing seeds. Simple germinating apparatus. Curing and storing seeds. Changing seed. Stock seed. Seedsmen's specialties. Seedsmen's humbugs. Novelties. Development of varieties.Rules for improving plants. Cross and self-pollination of plants. Mixing of varieties. Distance between varieties to prevent mixing.

CHAPTER VI.

Glass Structures.-Cold frames. Hotbeds. Hotbed manure. Fire hotbeds. A greenhouse hotbed.

Greenhouses.-Cheap kinds of. Methods of heating. Sash for hotbeds and cold frames. Shutters. Mats. Ventilation and temperature. Watering. Soil. Boxes. Substitutes for glass. Shading the glass. Fifteen things to remember in connection with building glass strucures.

\section{CHAPTER VII.}

Insects Injurious to Vegetables.-Insecticides and methods of destroying insects. Pyrethrum. Paris green. London purple. Tobacco. Keroserie emulsion with soap and with milk. Carbon bisulphide. Catching insects by light at night. Application of insecticides.

Common Garden Insects and Methods of Destroying Them.Colorado Potato Beetle. Imported and Native Cabbage Worms. Cabbage Plusia. Wire Worms or Drill Worms. Cutworms. Striped Cucumber Beetle. White Grub or May Beetle. Maggots. Cabbage Flea Beetle. Leaf Lice or Aphis. Cabbage Lice or Aphis. Sweet Corn Moth or Tassel Worm. Parsley Worm or Celery Caterpillar. Chinch Bugs. Bean and Pea Weevil. Squash Vine Borer. Squash Bug. 


\section{CHAPTER VIII.}

Classification of Vegetables.-Warm and cold climate vegetables. Frost tender and frost hardy vegetables. Botanical classification. Characteristics and directions for the cultivation of vegetables. Mushrooms. Corn. Asparagus. Onions. Leeks. Garlic. Rhubarb. Beets. Swiss Chard. Spinach. Cabbage. Cauliflower. Radishes. Rutabaga. Turnip. Brussels Sprouts. Kale. Kohlrabi. Horseradish. Cress. Water Cress. Beans. Peas. Okra. Parsnip. Parsley. Carrot. Celery. Celariac. Sweet Potato. Tomato. Potato. Egg Plant. Peppers. Strawberry Tomato. Martynia. Cucumber. Squash. Muskmelon. Watermelon. Pumpkin. Gourds. Lettuce. Salsify. Endive. Dandelion.

Garden Herbs.-Balm. Catnip. Lavender. Peppermint. Sage. Sweet Basil. Sweet Marjoram. Spearmint. Summer Savory. Thyme. Winter Savory. Anise. Caraway. Coriander. Dill. Borage. Rue.

Tables.-I. Weight of one quart of seeds and a number of seeds. in one ounce. II. Longevity of garden seeds. III. Amount of seed required to sow one acre. IV. Average time required for garden seeds to germinate. V. Standards of Purity and Germination of Agricultural Seeds.

Monthly Calendar of Garden Operations. 


\section{Vegetable Gardening.}

\section{CHAPTER I. \\ THE VEGETABLE GARDEN.}

Location and Soil.-The land for vegetable gardening should be free from stones and stumps, and easily cultivated. Wet land should be avoided unless it can be drained at a reasonable outlay; if it cannot be drained it is of little worth as scarcely anything of value can be raised on it. All land for vegetable gardening should be well drained either naturally or artificially, since crops on well drained land suffer less from drought as well as from excess of water. Drained land also gives best and most uniform returns from the manure applied to it. When drainage is lacking in the land, the raising of plants on it is so very much a matter of chance that in the long run it will generally prove unprofitable. Most of the land in cultivation is sufficiently drained naturally, while some land that needs no drainage when used for grass or grain would be greatly improved by being under-drained when it is to be used for some garden crops. Land which has a gently rolling or undulating surface with a southern exposure is the most desirable for general gardening operations, since it receives the full sunlight and allows the most perfect control of the water that falls upon it. When irrigation is to be practiced, such sloping surface aids very much in the distribution of the water. For a few crops, such as celery, cabbage, etc., the slope makes very little difference, as flat and even very moist (not wet) land is best. There is a very great difference in the value of northern and southern slopes for various crops. This difference will frequently amount to one crop a year where the soil is closely tilled The soil on a southern slope can be worked much earlier in the spring than that having a northern exposure, and often by proper management two crops may be grown in one year in such places, while on a northern 
slope perhaps only one crop could be raised. Then again, such crops as melons and tomatoes that require a long season and a warm location to mature could do so on a southern slope, while on a northern slope they might not ripen.

Location and Soil for Early Crops.-When the object in vegetable gardening is to grow very early crops, it is important to have quick-acting land. Such a soil contains a large amount of sand in its composition. Soils of this class warm up very quickly, and decomposition goes on very rapidly in them. They also give the quickest returns from manures. If such land has a southern slope, and, in addition, is protected from the north and west winds, the situation will be an ideal one for the early vegetable garden and for tropical plants, such as tomatoes, beans, corn, etc. However, land and locations of this character suffer most from drought, therefore every precaution should be taken to protect them from it. Sandy soils are especially arlapted to irrigation, and sometimes what were barren sands become very fertile when irrigated.

Location and Soil for Late Crops.-When the intention is to raise cabbages, potatoes, turnips, beets, etc., for marketing in ine autumn and for crops that require but a short time to mature or that prefer a cool location, a good clayey loam is generally the best, and if it has a northern exposure so much the better. If obliged to use a stiff clay soil, it will be found to give best results if subsoiled and drained. Such land should be fall-plowed and left in ridges. It will also be improved if coarse manure is worked into it, since this has a tendency to make the land open and more easily worked. A retentive clayey loam will be more difficult to work than a sandy soil, but will generally withstand drought much better, although a somewhat sandy loam with a retentive, porous clay sub-soil is often considered more desirable on account of the greater ease with which it is worked, and it resists drought nearly as well as a clayey loam if proper precautions are used in its management.

\section{IRRIGATION.}

Irrigation is generally considered unnecessary in this section, since we raise fair and even abundant crops nearly every year without its aid, but in almost any season there are periods 
when if water could be applied to growing crops it would improve them. It will seldom if ever pay to irrigate ordinary farm crops, if it is necessary to pump the water used. In order to have irrigation practical for farm crops the water should be carried and distributed on the land by the force of gravity. It may pay to pump water to irrigate some garden crops if the conditions are favorable and the work is done intelligently. In this section irrigation should be used to supplement the rainfall which should ordinarily be kept from running off the surface of the land by every possible precaution.

Mulching the surface of the soil is practicable only around trees and in the case of a very few garden crops, such as strawberries and raspberries. The intelligent use of mulch on land in well known cases has caused the soil under it to hold an amount of water equal to thirty-three per cent more than was retained in soil near by not mulched, the amount in one case being equal to an increase of over two quarts of water to every cubic foot of soil, or to an increase of over 680 barrels in the upper one foot of soil of one acre. If this amount of water had been applied at the critical stage in the growth of some crops suffering for moisture, it might have made a success of what would otherwise have been a failure. Where practicable it is always desirable to have a good mulch on land that is watered, since it retards evaporation and prevents the surface soil from baking.

Cultivation of the land prevents evaporaticri and so saves the moisture in it. In one instance the amount of increase of water in a good soil due to cultivation was equal to thirtythree per cent of what it contained when not cultivated. This increase, however, is somewhat more than was found in other trials, but in every instance there has been a marked increase in the drought resisting qualities of the soil due to continued cultivation. In some experiments made by Professor Levi Stockbridge in 1878 , it was clearly shown that on one occasion in eight days of very dry summer weather thorough cultivation of the land resulted in saving 256 barrels of water in an acre of heavy loam by preventing evaporation from its surface. These facts show the great value of cultivation as an aid in 
irrigating operations. Cultivation of the land or mulching should always go with irrigation.

Humus is rotten organic matter. In the soil it increases its retentive qualities. On this account new land which contains much organic matter does not suffer as seriously from irought as that which has been cultivated for some time without manure. Liliewise, land, heavily manured with rotten manure, which is largely humus, has its drought resisting qualities increased, while the application of undecayed manure to the land has a directly opposite result until it has been in the soil long enough to become thoroughly rotted.

Amount of Water Required for Irrigating Different Crops.Sometimes a very small amount of water applied at the right time will make the difference between a good crop and a total failure, as, for instance, when dry weather comes on just as the strawberry crop is almost ripe, when it has happened that so small a quantity as 600 barrels of water per acre has been sufficient to ripen the crop. In western Kansas it is estimater that a storage capacity of 5,000 barrels per acre in arldition to the ordinary rain supply is needed to mature a crop in dry scasons. In this section a storage capacity of 1,500 barrels per acre would probably be enough to insure against scrious injury from drought in any but very exceptionally dry rears. Enough water to corer an acre one inch deep is termed an acre inch. About 900 barrels equal one acre inch.

Pumping Water for Irrigation.-Where valuable crops are grown, it will sometimes ray to pump water for them. There are many localities in this section where a large amount of water may be controlled by lifting it less than thirty feet. In such places windmills may be successfully used for pumping the water, providing reservoirs of large capacity can be cheaply made into which water may be pumped the year around to be used as necled. Thresher engines, which are seldom used except in the late summer and fall, may sometimes be used in arrantage for pumping water and often at very low cost. Casoline engines are occasionally used in some irrigation works. They are very desirable, but at present the price is too high to warrant their general use. In putting in a pumping plant the pump should be put as near the water supply as possible. 
Reservoirs should be on some elevated point. They are easily made by digging out the earth and puddling the bottom and sides with thick clay, which should be at least one foot in thickness anrl well packed when wet. A good way to pack it is to drive horses over it. When clay cannot be obtained the bottom may be made tight with a thin coating of coal tar and sand, but clay is preferable, and what is known as blue clay is generally best. Cement is liable to crack badly from frost and is not adlapterl to this purpose. Made in this way, reserroir's are very cheap and easily repaired. It is important to have them very large where the supply of water is limited; where the supply is large, the reservoir may be much smaller.

Application of Water.-Sloping land is necessary for most successful irrigation, as it is very difficult to apply water to the surface of level land. The slope should be sufficient to permit the water to flow quickly along its surface and yet not enough to cause it to wash. For irrigation purposes the rows should not be over 300 feet long. The best results are gener ally obtained from soils having considerable sand in their composition. Drifting sands may often be made to produce good crops by irrigating and manuring, and lands having some sand in their composition are much better adapted to irrigation than clay soils, since the latter often bake badly or become sticky so that they cannot be cultivated immediately after applying water.

Rules for Applying Water to Land.-Water should not be applied unless the crop is suffering for it, but the soil should be cultivated thoroughly and frequently, and thus waste by evaporation may be saved.

Cultivate at once after irrigating, if the land will permit of it, so that the soil will not bake; evaporation will thus be prevented, and water will be saved in the soil.

Do not apply more than enough water to nicely moisten the land and avoid getting it water-soaked.

Do not think that irrigation will take the place of cultiration, for it will not, since without cultivation irrigation is seldom successful.

Water for irrigating purposes should be somewhat wam when applied. Cold springs do not afford a satisfactory supply 
for some crops unless first pumped into a reservoir. A temperature of 60 degrees is desirable, though not always necessary for the best results.

Aim to wet the roots of the plants and avoid getting water on the leaves.

Wooden troughs afford the cheapest conduits for water and

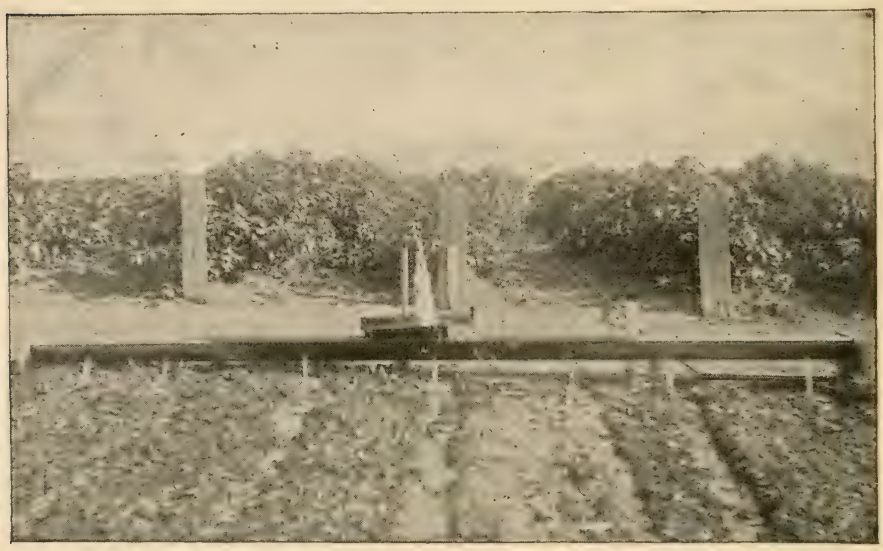

Figure 1.-One method of irrigating crop planted in rows.

should be used whenever practicable. Iron pipe is expensive and much more difficult to manage than wooden troughs.

Sub-irrigation is a new term that refers to the application of water to the roots of plants by means of underground channels, such as tile or other drains. It works best in sandy soils. In clayey soil the water runs too slowly through the sides of the tiles. Land tiles make as good channels as any for this purpose. They should be buried a few inches below or by the side of the plants to be watered, being laid level with open joints. Some experiments seem to show that it is a very wasteful way of using water, while others have shown this system to be economical. As practiced for watering plants in greenhouse benches, especially for lettuce, it has given excellent results. 
ROTATION OF CROPS.

By rotation is meant the special succession of crops growing upon the land for a series of years. This is very desirable even on land in the highest state of cultivation, but it is very difficult to lay down exact rules to be followed.

Reasons for Rotating Crops.-We rotate crops for at least six reasons. (1) To avoid insect enemies, as in the case of onions and turnips, which are often liable to serious insect injuries when grown more than one year on the same land. Turnips are especially liable to injury from insects when grown in the same place successively. (2) To avoid injuries from fungous diseases, i. e., in case of potato and beet scab, onion and melon rust, corn smut, etc. (3) To increase the amount of humus in the soil, and for this purpose we may seed down the land to grass or clover. (4) To deepen the soil and add nitrogen to it as well as humus, as when clover is grown on the land. (5) To get rid of weed seeds in the soil. (6) To use the plant food in the land to best advantage, since crops vary very much in the amount of the different elements which enter into their composition. Leguminous crops, like clover, peas, beans, etc., improve the land on which they grow, while most other crops exhaust the soil. Some plants excel others in their power to search for plant food, or to take plant food from the soil. Some plants feed near the surface largely, while others take their food mostly from a lower level. Root crops should not follow root crops, nor should vines follow vines for many years in succession on the same land. 


\section{CHAPTER II.}

\section{MANURES.}

Most Valuable Elements in Manures.-While there are twelve or more elements that enter into the composition of uur cultivated plants, yet only nitrogen, phosphorus and potash, and in a few cases lime, are lacking from our agricultural soils. These three elements enter largely into all our cultivated crops and are necessary for their growth. The other elements are usually present in abundance.

Humus.-While humus in itself is not a plant food, it is of great importance in the soil. It is formed by the decay of organic matter and is composed principally of carbon. It promotes chemical action by which plant food is set free in the soil, and it increases the power of the soil for holding the water and gases which it gives up slowly to the roots of plants. Rotten stable manure contains a large amount of humusforming materials, which undoubtedly add very much to its value, and it is probably on this account that it often gives better returns than commercial fertilizers containing the same quantities of what are termed the essential elements.

The Action of Manures in the Soil can be and generally is both direct and indirect. They act directly when they contain actual available plant food or when by their decay they yield it to the plant; they act indirectly when they start chemical action in the soil and thus set free soluble plant food in the soil itself. Almost all manures act in this indirect way to some extent. A moderate application of stable manure by its (lecomposition (which is chemical action) in the soil has been known to increase the temperature of the soil by three degrees. Lime in itself is a plant food and is largely used by some crops. Most soils, however, contain it in great abundance, yet if quick lime be added to a soil already rich in common limestone it generally serves to increase growth. This is not due to the ylant taking up more lime, but rather to the fact that the quick lime starts chemical action in the soil by which some 
of the locked-up stores of plant food are made availabs The same may be said of unleached ashes, though it contains much more valuable fertilizing material than lime. Common salt also acts to some extent indirectly as a fertilizer, while it is of very little value as a plant food.

COMPOSITION OF VEGETABLES, MANURES AND FERTILIZERS.

In the following tables is shown the amount of fertilizing elements required by vegetables and the amount of these materials which is contained in the various farm manures and commercial fertilizer's. These figures are from eastern United States and European sources. The climatic conditions in thes places are quite different from those in many sections of the Trestern states where the actual amount of ash ingredients in plants, especially in dry years, may greatiy exceed the amounts here given. The relation of these tables to one another is worthy of special study, since they show what the plants need and what the fertilizing materials supply.

TABLE I.-Composition of Vegetables.+

\begin{tabular}{|c|c|c|c|c|c|}
\hline & Water. & Ash. & $\begin{array}{c}\text { Nitro- } \\
\text { gen. }\end{array}$ & $\begin{array}{c}\text { Phos- } \\
\text { phoric } \\
\text { acid. }\end{array}$ & Potash \\
\hline 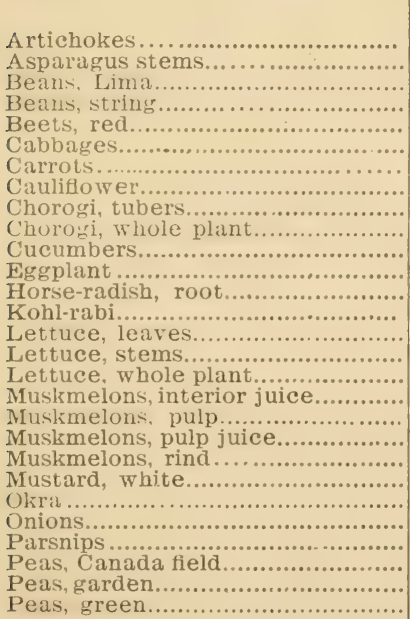 & $\begin{array}{c}\text { Per ct. } \\
81.50 \\
93.96 \\
68.40 \\
87.23 \\
88,47 \\
90.52 \\
88.59 \\
90.82 \\
78.90 \\
78.33 \\
95.99 \\
92.93 \\
76.68 \\
91.08 \\
86.28 \\
88.46 \\
93.68 \\
92.61 \\
76.41 \\
90.53 \\
91.15 \\
81.19 \\
87.41 \\
87.55 \\
80.34 \\
12.48 \\
12.62 \\
79.93\end{array}$ & $\begin{array}{c}\text { Per ct. } \\
0.99 \\
0.67 \\
1.69 \\
0.76 \\
1.04 \\
1.40 \\
1.02 \\
0.81 \\
1.09 \\
1.02 \\
0.46 \\
0.50 \\
1.87 \\
1.27 \\
1.71 \\
1.18 \\
1.61 \\
1.01 \\
1.49 \\
0.56 \\
0.68 \\
2.25 \\
0.74 \\
0.57 \\
1.03 \\
2.36 \\
3.11 \\
0.78\end{array}$ & 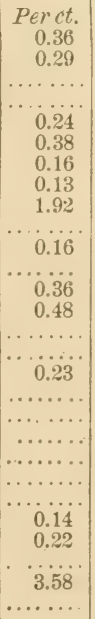 & 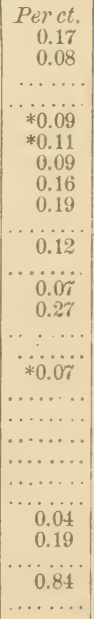 & 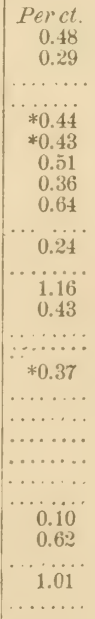 \\
\hline
\end{tabular}


Composition of Vegetables. $+-($ Continued.)

Peas, smail (Lathyrus sativus), whole plant.

Pumpkins, flesh

Pumpkins, rind....................................

Pumpkins, seeds and string,

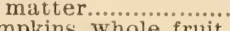

Pumpkins, whole fruit..................

Rhubarb, roots

Rhubarb, stems.........................

Rhubarb, stems and leaves.

Rutabagas.

Spinach

Squashes. flesh.

Squashes, rind.

Squashes, seeds and stringy

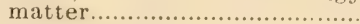

Squashes, whole fruit

Sweet corn, cobs.

$\mathrm{S}$ weet corn, husks.

Sweet corn, kernels

Sw eet corn, stalks.

Sweet potatoes. tubers.

Sweet potatoes, vines

Tomatoes, fruitt.

Tomatoes, roots.

Tomatoes, vines

Turnips.

Watermelons, juice

W atermelons, pulp.

W atermelons, rind.

\begin{tabular}{|c|c|c|c|c|}
\hline Water & Ash. & $\begin{array}{c}\text { Nitro- } \\
\text { gen. }\end{array}$ & $\begin{array}{l}\text { Phos- } \\
\text { phoric } \\
\text { A cid. }\end{array}$ & Potash \\
\hline Per ct. & Per ct. & Per ct. & Per ct, & Per ct. \\
\hline 5.80 & 5.94 & 2.50 & 0.59 & 1.99 \\
\hline $\begin{array}{l}93.39 \\
86.23\end{array}$ & $\begin{array}{l}0.67 \\
1.36\end{array}$ & …..... & $\cdots \cdots$ & $\cdots \cdots$ \\
\hline 86 & (5) & & & \\
\hline 92.27 & $\begin{array}{l}1.0163 \\
\end{array}$ & $* 0.11$ & $* 0.16$ & $* 0.09$ \\
\hline 74.35 & 2.28 & 0.55 & 0.06 & 0.53 \\
\hline 92.67 & 0.94 & 0.8 & & \\
\hline $91.6 \pi$ & 1.72 & 0.13 & 0.02 & 0.36 \\
\hline 88.61 & 1.94 & 0.19 & 0.12 & 49 \\
\hline $9: .42$ & $\begin{array}{l}1.94 \\
1.7 .2\end{array}$ & 0.49 & 0.16 & 0.27 \\
\hline 82.00 & 21 & $\cdots$ & $\cdots \cdots \cdots$ & ..... \\
\hline$\tau$ & 39 & & & \\
\hline & 0 & & & \\
\hline 10 & 0.59 & 0.21 & 0.05 & 0.22 \\
\hline 86.19 & 0.56 & 0.1 & 0.07 & 0.22 \\
\hline 8 & 0.56 & 0.4 & 0.07 & 0.24 \\
\hline 80.8 & 1. & 0.28 & 0.14 & 0.41 \\
\hline 71.26 & $\begin{array}{l}1.00 \\
5.70\end{array}$ & $* 0.24$ & $* 0.08$ & $* 0.3 \pi$ \\
\hline $\begin{array}{l}41.55 \\
93.64\end{array}$ & $\begin{array}{l}5.79 \\
0.47\end{array}$ & i & 0.05 & 0.27 \\
\hline & 11.7 & 0.2 & 0.0 & 0.29 \\
\hline 83.6 & a & 0.3 & 0.0 & 0.50 \\
\hline 90.46 & 0.80 & 0.18 & 0.10 & 0.39 \\
\hline 93.05 & 0.20 & $\ldots \ldots \ldots$ & $\ldots \ldots$ & $\ldots \ldots \ldots$ \\
\hline 91.87 & 0.33 & & t... & \\
\hline $\begin{array}{l}89.97 \\
48.37\end{array}$ & $\begin{array}{l}1.24 \\
1.34\end{array}$ & & 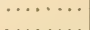 & \\
\hline & & & & \\
\hline
\end{tabular}

*Wolff. +Sugar in fruit, 3.05 per cent; acid (malic), 0.46 per cent. ${ }_{+}$Compiled by office of Experiment Station.

TABLE II.-Composition of Farm Manures.

\begin{tabular}{|c|c|c|c|c|c|}
\hline & $\begin{array}{l}\text { Mois- } \\
\text { ture. }\end{array}$ & $\begin{array}{l}\text { Nitro- } \\
\text { gen. }\end{array}$ & $\begin{array}{l}\text { Pot- } \\
\text { ash. }\end{array}$ & $\begin{array}{l}\text { Phos- } \\
\text { phoric } \\
\text { acid. }\end{array}$ & Lime. \\
\hline & Perct. & Perct. & Perct. & Perct. & Perct. \\
\hline $\begin{array}{l}\text { Cattle excrement (solid, fresh)....... } \\
\text { ('attle urine (fresh) }\end{array}$ & & 0.29 & 0.10 & 0.17 & \\
\hline Hen manure (fresb) ............ & 60.00 & 1.1 & $\begin{array}{l}0.49 \\
0.56\end{array}$ & 0.85 & \\
\hline Horse excrement (solid) ... & ........... & 0.4 & 0.35 & 0.17 & \\
\hline Horse urine (fresh) .............. & & 1. & 1.50 & & \\
\hline $\begin{array}{l}\text { Human excrement (soli } \\
\text { Human urine................ }\end{array}$ & 95 & $\begin{array}{l}1.00 \\
0.60\end{array}$ & 0.25 & 1.09 & \\
\hline $\begin{array}{l}\text { Human urine............... } \\
\text { Pigeon manure (dry)... }\end{array}$ & 10.00 & 3. & 1.0 & 1.90 & $\dddot{2} \ddot{1}$ \\
\hline Poudrette (night soil).......... & 50.00 & 0.80 & 0.30 & 1.40 & 0.80 \\
\hline
\end{tabular}


Composition of Farm Manures.-(Continued)

\begin{tabular}{|c|c|c|c|c|c|c|c|}
\hline & \multirow[b]{2}{*}{$\begin{array}{l}\text { Mois- } \\
\text { ture. }\end{array}$} & \multirow[b]{2}{*}{$\begin{array}{l}\text { Nitro- } \\
\text { gen. }\end{array}$} & \multirow[b]{2}{*}{$\begin{array}{l}\text { Pot- } \\
\text { ash. }\end{array}$} & \multicolumn{3}{|c|}{ Phosphoric acid. } & \multirow[b]{2}{*}{ Lime. } \\
\hline & & & & $\begin{array}{c}\text { Solu- } \\
\text { ble. }\end{array}$ & $\begin{array}{c}\text { Re- } \\
\text { verted. }\end{array}$ & Total. & \\
\hline $\begin{array}{l}\text { Sheep excrement } \\
\text { (solid, fresh) .......... } \\
\text { Sheep urine (fresh) } \\
\text { Stable m a nure } \\
\text { (mixed) ............... } \\
\text { Swine excrement } \\
\text { (solid. fresh)........ } \\
\text { Swine urine (fresh) } \\
\text { Barnyard manure } \\
\text { (average) ............... }\end{array}$ & 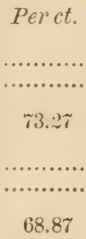 & $\begin{array}{r}\text { Perct. } \\
0.5 .5 \\
1.95 \\
0.50 \\
0.60 \\
0.43 \\
0.49\end{array}$ & $\begin{array}{r}\text { Perct. } \\
0.15 \\
2.26 \\
0.60 \\
\\
0.13 \\
0.83 \\
0.43\end{array}$ & Perct. & Perct. & $\begin{array}{c}\text { Perct. } \\
0.31 \\
0.01^{\circ} \\
0.30 \\
0.41 \\
0.07 \\
0.32\end{array}$ & Perct- \\
\hline
\end{tabular}

TABLE III.-Composition of Commercial Fertilizing Materials.

\begin{tabular}{|c|c|c|c|c|c|c|c|}
\hline Apatite & & & & & & 36.08 & \\
\hline $\begin{array}{c}\text { Ashes (anthraicte } \\
\text { coal) .................... }\end{array}$ & & & 0.10 & & & 0.10 & \\
\hline Ashes (bituminous & & & 0.40 & & & 0.40 & \\
\hline Ashes (lime kiln)... & 15.45 & ...... & 1.20 & & & 1.14 & 48.50 \\
\hline $\begin{array}{l}\text { A shes (w } 0 \text { o } \\
\text { leached) }\end{array}$ & 30.22 & & 1.27 & & & 1.51 & 28.08 \\
\hline $\begin{array}{r}\text { Ashes (wood, un- } \\
\text { leached) ........... }\end{array}$ & 12.50 & & 5.25 & & & 1.70 & 34.00 \\
\hline $\begin{array}{l}\text { Bat guano................... } \\
\text { Bone ash }\end{array}$ & 40.09 & 8.20 & 1.31 & 2.37 & 1.24 & 3.80 & 1480 \\
\hline $\begin{array}{l}\text { Bone ash.............. } \\
\text { Bone black........... }\end{array}$ & $\begin{array}{l}7.00 \\
4.60\end{array}$ & ....... & & & & $\begin{array}{l}35.89 \\
28.28\end{array}$ & 44.89 \\
\hline Bone black (dis- & & & & & & & \\
\hline Bonemeal................. & 7.50 & 4.05 & & $\begin{array}{r}15.40 \\
0.40\end{array}$ & $\begin{array}{l}1.30 \\
7.60\end{array}$ & $\begin{array}{l}17.00 \\
23.25\end{array}$ & \\
\hline $\begin{array}{c}\text { Bone meal (dis- } \\
\text { solved)............... }\end{array}$ & & 2.60 & & & .53 & 17.60 & \\
\hline $\begin{array}{l}\text { Bone meal (free } \\
\text { from fat) ......... }\end{array}$ & & 6.20 & & & & $\approx 0.10$ & \\
\hline $\begin{array}{l}\text { Bone meal (from } \\
\text { glue factory)... }\end{array}$ & & 1.70 & & & & 29.90 & \\
\hline Carribean guano... & 7.31 & & & & & $26.7 \%$ & 39.95 \\
\hline $\begin{array}{l}\text { Castor pomace..... } \\
\text { Cotton-hull ashes... }\end{array}$ & $\begin{array}{l}9.50 \\
7.80\end{array}$ & 5.50 & $\begin{array}{r}1.10 \\
2 \% .75\end{array}$ & 1.25 & 6.50 & $\begin{array}{l}1.75 \\
8.85\end{array}$ & 9.60 \\
\hline $\begin{array}{c}\text { Cotton-seed meal } \\
\text { (decort) }\end{array}$ & & & & & & & \\
\hline $\begin{array}{l}\text { (decort) ........... } \\
\text { Cotton-seed meal }\end{array}$ & 7.75 & 7.10 & 1.80 & & & 3.10 & \\
\hline (undecort) ....... & & 430 & 1.50 & & & 3.10 & \\
\hline $\begin{array}{l}\text { Cuba guano .............. } \\
\text { Dried blood........... }\end{array}$ & $\begin{array}{l}24.27 \\
12.50\end{array}$ & $1.6 \%$ & * & & & 13.35 & $\cdots$ \\
\hline 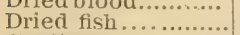 & $\begin{array}{l}12.50 \\
12.75\end{array}$ & $\begin{array}{r}10.53 \\
7.25\end{array}$ & ........ & 0.55 & 2.60 & $\begin{array}{l}1.91 \\
8.25\end{array}$ & \\
\hline Gaslime.... & 92.28 & ..... & & & & & 43.66 \\
\hline $\begin{array}{r}\text { Horn and hoof } \\
\text { waste................ }\end{array}$ & 10.17 & 13.25 & & & & 1.83 & \\
\hline Kainit ............... & 3.20 & $\cdots$ & $\begin{array}{r}13.54 \\
8.40\end{array}$ & & & n......... & $\begin{array}{l}1.15 \\
12.45\end{array}$ \\
\hline 110 & 2 & & & & & & \\
\hline
\end{tabular}




\section{Composition of Commercial Fertilizing Materials.-(Continued.)}

\begin{tabular}{|c|c|c|c|c|c|c|c|}
\hline & \multirow[b]{2}{*}{$\begin{array}{l}\text { Mois- } \\
\text { ture }\end{array}$} & \multirow[b]{2}{*}{$\begin{array}{l}\text { Nitro- } \\
\text { 'gen. }\end{array}$} & \multirow[b]{2}{*}{$\begin{array}{l}\text { Pot. } \\
\text { ash. }\end{array}$} & \multicolumn{3}{|c|}{ Phosphoric acid. } & \multirow[b]{2}{*}{ Lime. } \\
\hline & & & & $\begin{array}{l}\text { Solu- } \\
\text { ble. }\end{array}$ & $\begin{array}{c}\text { Re- } \\
\text { verted. }\end{array}$ & Total. & \\
\hline & Per ct. & Per ct. & Per ct. & Per ct. & Per ct. & Per ct. & Per ct. \\
\hline Meat scrap............ & 12.09 & 10.44 & & & & 2.07 & \\
\hline Mono Island Guano. & 13.32 & 0.76 & & & 7.55 & 21.88 & 37.49 \\
\hline $\begin{array}{l}\text { Muek..................... } \\
\text { Mud (sait) }\end{array}$ & $\begin{array}{l}50.00 \\
60.00\end{array}$ & $\begin{array}{l}1.10 \\
0.40\end{array}$ & 0.15 & & s. & $\begin{array}{l}0.10 \\
0.10\end{array}$ & 0.90 \\
\hline Muriate of potash.. & $\begin{array}{r}60.00 \\
2.00\end{array}$ & & $\begin{array}{r}0.35 \\
51.48\end{array}$ & & $\begin{array}{l}\cdots \cdot \cdot \\
\cdots . .\end{array}$ & & 0.80 \\
\hline Navassa phosphate & 7.60 & & & & & 34.27 & 37.45 \\
\hline Nitrate of potash... & 1.93 & 13.09 & 45.19 & & & (........... & ............ \\
\hline $\begin{array}{l}\text { Nitrate of soda...... } \\
\text { Oleomargarine re- }\end{array}$ & 1.40 & 15.70 & & & & ............. & (............. \\
\hline fuse................ & 8.54 & 12.12 & & & & 0.88 & \\
\hline Peat......................... & 61.50 & 0.85 & 0.18 & & & 0.08 & \\
\hline Peruvianguano...... & 14.81 & 7.35 & 2.65 & 3.20 & 4.10 & 15.30 & \\
\hline Phosphates from & & & & & & & \\
\hline $\begin{array}{l}\text { Florida.............. } \\
\text { Plaster (pure) }+\ldots \ldots .\end{array}$ & 2.25 & & & & & 24.50 & $\begin{array}{l}28.50 \\
20.93\end{array}$ \\
\hline Sewage sludge & & & & & & & \\
\hline 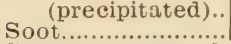 & $\begin{array}{r}88.49 \\
5.54\end{array}$ & 0.05 & $\begin{array}{l}0.05 \\
1.83\end{array}$ & & & 0.10 & 1.58 \\
\hline Spent tanbark & & & & & & & \\
\hline $\begin{array}{l}\text { ashes............... } \\
\text { Sumate waste...... }\end{array}$ & 3.61 & & 2.04 & & & 1.61 & 33.46 \\
\hline $\begin{array}{l}\text { Sumatc waste....... } \\
\text { Sulphate of am- }\end{array}$ & 63.06 & 1.19 & 3,25 & & & $\cdots$ & \\
\hline monia............... & 1.00 & 20.50 & & & & & \\
\hline $\begin{array}{l}\text { Sulphate of potash } \\
\text { and magnesia... }\end{array}$ & 475 & & 25,50 & & & & 257 \\
\hline Sulphate of potash & 4.65 & & & & & & 2.58 \\
\hline $\begin{array}{r}\text { (high grade).... } \\
\text { Tankage................ }\end{array}$ & 2.54 & & 33.40 & & & & \\
\hline $\begin{array}{l}\text { Tankage ................. } \\
\text { Tobaceo stalks...... }\end{array}$ & 10.00 & 6.70 & $0 ?$ & 0.30 & 5.10 & $\begin{array}{r}11.80 \\
0.65\end{array}$ & $\dddot{700}$ \\
\hline $\begin{array}{l}\text { Tobaceo stalks...... } \\
\text { Tobacco stems...... }\end{array}$ & $\begin{array}{r}0.18 \\
10.00\end{array}$ & $\begin{array}{l}3.41 \\
2.35\end{array}$ & 8.20 & & & $\begin{array}{l}0.02 \\
0.70\end{array}$ & 4.20 \\
\hline Wool washings...... & & & 3.92 & & & & \\
\hline Wool waste............ & 15.80 & 6.50 & $* 1.20$ & (.......... & $|\ldots \ldots \ldots \ldots|$ & 0.35 & 0.11 \\
\hline
\end{tabular}

*Sometimes as high as 5 per cent.

$\uparrow$ Nova Scotia plaster contains 94 per cent pure gypsum and 4 per (ent carbonate of lime; Onondaga and Cayuga, 65-75 per cent gypsum and 1S-28 per cent carbonate of lime.

Animal Manures.-Manure from the same animals may vary greatly in quality according to the kind of food and the condition and age of the animals from which it comes. Fat animals fed on food rich in nitrogen (grains) produce the best manures. Young growing animals that are fed on poor food, such as straw, swale hay, etc, produce very inferior manure. The manure from young growing animals n from milking cows is much inferior to that from fat steers, since, in the case of 
the young animals, a large amount of nitrogen and phosphoric acid is required to build up the animal body. In the case of the milking cow a large amount of nitrogen is required for the production of the casein of the milk, while very little of the nitrogen in the food is retained in the body of the fattening animal. The fats, oils and starchy materials which animals use largely are of no value as manures. The nitrogen, potash and phosphorus are thrown off by the fat animal in the waste products. Manures rich in nitrogen ferment most rapidly, other things being equal. The urine is generally rich in nitrogen, and since all it contains is soluble it is of more value than the solid excrements of animals, and special effort should be made to save it.

The Heating of Manures and other organic material is generally due to the presence of ferments which are minute organisms that break down the composition of the materials in which they grow and produce chemical changes that result in the formation of heat. They are nearly allied to the yeast that is used in bread-making. Fire fanged is a term applied to manure which has heated to a very high temperature without sufficient moisture and has dried out. It is generally white in color and has lost much of its texture, and parts of it may appear to have been burned to ashes. When in this condition manure is of little value, for it has lost much if not all of its nitrogen and all the ferments which it contained are destroyed. And it is probable that the ferments which are added to soils by manure are often of much importance to them.

Horse Manure is loose and light, and ferments very quickly. On this account it is especially valuable for early spring crops, as it makes the soil loose, thus permitting the air to easily penetrate it, while by its rapid fermentation it warms the land. It is valuable to mix with cow and swine manure on account of its hastening fermentation. On account of its heating qualities it is used to warm hotbeds.

Hen Manure is one of the richest manures formed by any of our domestic animals, for the reason that poultry live on highly concentrated foods and the liquid and solid excrements are voided together. It heats quite readily and violently and should be used very sparingly and with caution, 
since if put in contact with the roots or stems of plants it is very liable to burn them. It should be handled with great care and be kept dry. If wet it ferments and parts with its nitrogen in the form of ammonia gas, which is readily perceptible to the nose. For the same reason it should not be mixed with lime or wood ashes unless used at once. It ar.ts very quickiy and on this account is valuable for early crops or to apply during the growth of a crop when the available manure in the lind appears to have been exhausted. It may be composted with dry peat or muck when it is more safely applied than if clear and there is less danger of loss from heating. Twenty to thirty bushels of hen mamue is generally considered sufficient for one acre when used with stable manure.

Cow and Swine Manures are rather slow in action, consequently they are not as desirable for early crops as horse manure, while they are excellent for late crops. For this latter purpose they are often better than horse manure. If they are mixed with horse manure they ferment very rapidly.

Sheep Manure is a very concentrated manure which heats rapidly. It is one of the best farm manures.

Mixing Manures.-It may often be a good plan to mix the different linds of animal manues for gencral appliration, as in this way all seem to be improved. Hen manure is an exception and, as a rule, should be applied separately. Limc, wood ashes or other matcrial of an allialine nature should never be mixed with stable manure of any lind unless a considerable anount of loam, peat or other material is arlder to absorb the ammonia, which is always liberater why nitrogenous and alkaline substances are thus mixed. It is a good plan to mix ground bone, tankage and other slow acting fertilizers with heating stable manure, as by so doing the plant food they contain is made more available and the stable manure is greatly improved in quality.

The Manure Pile.-If early garden crops are to be grown, it is neressary to have fine, well rotted manure, and this makes the manure pile neessary. It should be placed so that as little waste as possible will occur from leaching by rains. When a manure pile is to remain in one place for a considerable time it should be made upon a bed of leaves, peat, loam, rotted sods 
or other absorbent, about one foot in thickness, which will catch and rotain any fertilizing mateial that may leach through the pile. If practicable, the pile should be made where it will be protected from the sun and drying winds. The height of the pile should repend somewhat on the kind of manure and the season of the year when it is marle. Manme that will heat readily should be piled about six feet deep. When the pile is quite warm the nuanule should be turner over. This operition should be performed very thoroughly as often as the pile gets very hot. All the lumps should be broken up and the whole pile turined to the bottom of the ved on which it is placed. The absorberits of the bed should be nised evenly thoughout ti. pile and the cold manne flom the ontside be put on the in....... of the pile so that it may heat the more rapicly. If the pile appear's dry on the inside water or, what is better, the urine from the stable should be added to assist fermentation, as this cannot take place satisfactorily in dry manure, and the lack of water liay lesult in serious loss. The nuinber of times a manure pile should be turned over will depend on the crop to which it is to he applied and the lind and condition of the manure. This is a matter which must be left to the good judgment of the inclividual manager, but some of the factors bearing on this will be found discussed farther on.

The Compost Heap can be macle a prolific source of home made manure. Every farm and garden should have ons of sufficiently large proportion to take care of all refuse organic material about the place. It should be macle about as follows: Select a place hamiy to get at but where there is no stanring water and put down first a bed one foot deep of old sods or muck and on this pile all the refuse material as it collects in various places. It may consist of old straw, leaves, an occasional loar of heating manure, rotten vegetables, etc. This should be turned over occasicnally, by hanrl if necessary, but the best jlan is to have the compost heap in a hog yard and to it haul manure as it collects near the stables. If manure is piled upon a good bed of rotten sod it will not lose much by leaching, nor will it lose anything by heating if a sufficient number of hogs have the run of it to keep it well worlice up. Commercial Manuies.-By commercial manures is meant 
those manures which are commonly sold by the trade. When of a high price they are generally of a guaranteed composition and they should be bought at a valuation based on the amount of nitrogen, potash and phosphoric acid which they contain in condition arailable to the roots of the plants. The most available the form in which these materials exist in the fertilizer, the more valuable it is generally considered. Most of the older states require a guaranteed analysis to accompany the packages in which the fertilizel's are sold and exercise some supervision over the business. Among the most common of this class of fertilizers are the following:

Tankage.-This is the refuse product from slaughtering establishments, which after being reliever of its fat is brought to dryness and ground. It is very rich in nitrogen and phosphoric acil, but contains very little potash. Most of the nitrogen and phosphoric acid which it contains is available to the roots of plants. It is probal,ly the cheapest source of nitrogen and phosphoric acid to be found in the western states. It varies considerably in composition, and this may sometimes be accounted for by the fact that in some establishments the blood is separated from the other offal, thus reducing the percentage of nitrogen in the tankage. It is rather a slow acting fertilizer. Tankage may be safely used in quantities of less than 1,000 pounds per acre if applied broadcast and worked into the soil. Four hundred poundis per acre is gencrally consiclered a good application. It may be safely used in these quantities around growing plants of cabbage, corn, lettuce, etc., provided it is spread out evenly and does not come in contact with the roots of the plants.

Ground Blood is very rich in nitrogen and quite difficult to dry thoroughly. If it is at all moist it is likely to heat badly. It is a quick acting fertilizer, and is seldom used without being mixed with other materials.

Ground Eones are always rich in phosphoric acid, but sround fresh bones are better than dry bones since in addition to phosphoric acid they have quite a large percentage of nitrogen, which amount is very small in bones that are old and dry. It is always best to break or grind the bones that are to be used on the land and in many cases to then mix them with fer- 
menting stable manure. Ground bone is said to be a lasting fertilizer because its effect can be seen for several years. If bones are burned the nitrogen is wasted. If fresh bones are mixed with unleached wood ashes they will be made soft so they can be easily broken up. It is generally applied in mush the same way and for the same purposes as tankage.

Nitrate of Soda, called also Chili saltpeter, is imported from Chili. It looks like common salt and contains about 16 per cent of nitrogen that is perfectly soluble and in form most available for the plant. On this account only very small quantities should be applied at one time, because if not taken uI by the plant it may be washed deep into the soil out of reach of the roots. It is especially desirable for early leaf crops such as early spinach, cabbage and lettuce, and to apply when a cron comes to a standstill. It acts with wonderfui quickness--almost like magic. It may be applied several times to the growing crop at intervals of two weeks, using from 75 to 100 pounds per acre at each application. It may be sown near the hills if applied to cabbage, but for spinach or similar crops it should be

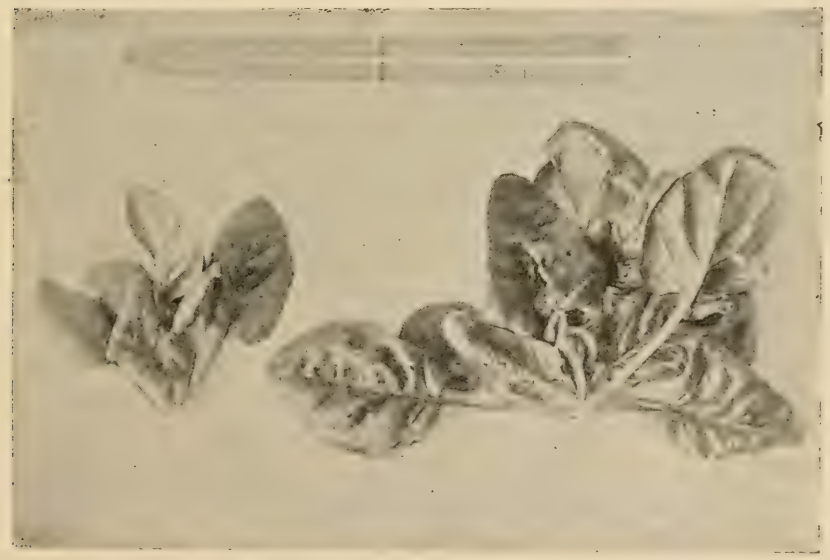

Figure 2.-Spinach plants grown on land rich in rotten stable manure. The larger plant receised in addition to the stable manure nitrate of soda at the rate of one hundred and fifty pounds per acre. 
sown broadcast when the plants are perfectly dry or duriuf a hard rain. If it sticks to the leaves it is liable to burn them. If sown during a hard rain it is quickly dissolved and washed to the roots of the plants without injury to the leaves. It is expensive and should never be used when a cheaper supply of nitrogenous manure will do just as well. It may occasionally be used to good advantage in water at the rate of one-half an ounce of nitrate of soda to one gallon of water. Such a solution will not injure the foliage and is of sufficient strength.

The use of very large quantities of nitrate of soda on the land has been found to make it necessary to continue using it in large quantities, while if used at the rate given it is not followed by such consequences. The supposed reason for this is that so much nitric acid in the soil destroys the nitric acidforming ferments, and these must be slowiy replenished before the soil is able to continue yielding its ordinary supply of nitrogen.

Sulphate of Ammonia is a by-product from gas works and contains about 20 per cent of nitrogen. It does not act as quickly as nitrate of soda, but for late crops, to be applied dur. ing warm weather, it is one of the best sources of nitrogen.

Superphosphate is made by treating ground bone or nodu. lar phosphate with sulphuric acid to render the phosphates soluble. It is rich in phosphoric acid, and some kinds contain a considerable quantity of nitrogen. They vary much in quality The better kinds are generally used at the rate of about 400 pounds per acre.

Wood Ashes is rich in potash and a valuable fertilizer in many cases provided it has not been leached; if it has been leached it is practically worthless as a fertilizer. Ashes from hard wood is much more valuable than that from soft woor on arcount of its containing much more potash. Ashes is one of the best fertilizers for fruit trees and plants. About twenty bushels of unleached hard wood ashes is generally sufficient for one acre. but much more may be safely used.

Kainit.-Potash is also applied to the land in the form of German Potash salts. a grade of which. known as kainit. is very commonly used as a fertilizer. These salts are more or less mixed with common table salt and other impurities and form 
a cheap and very useful supply of potash. They are generally sold on a valuation based on the percentage of actual potash they contain. Kainit contains 13 per cent of poiash which is more than twice as much as there is in ordinary unleached rood ashes. From 200 to 600 pounds of liainit is generally applied per acre.

Lime is found in abundance in most western soils, but burned limestone. whether as freshly slacked or as quick lime. may often be usei to adrantage in small quantities when largy amounts of stable manure have been used upon the lamt ior a number of years. It should not be used alone, because it exhausts the soil.

Land Plaster is a sulphate of lime. It is not a direct fertilizer, and its method of action is not txartly known. It may occasionally be used to advantage for $1 \in$ guminons crop-; such as clorer, beans. peas, etc., in applications of from 20010 600 pounds per acre spread broadcast.

There is Little Need for Commercial Fertilizers at present in most of the western states and they should never be used until the home sources of manure hare been exhausted, and then the? should be used to supplement rather than replace farm manures. and as aids in close cultivation of gardens. They ale generall: expensive, and results from their use here have not been as satisfactory as in the eastern states. Only the more common kinds to be met with here have been mentioned.

Those who use commercial fertilizers of the better kinds for the first time are very likely to use too inuch ani seriously injure the crops to which they are applied. It is much betier to use too little than too much, and to experiment along this line in a small and inexpensive way to begin with.

Effect of Manure on Crops.-The proportion of the various plant foods used by different crops varies considerably, som" using a larger amount of one element and some of another. Their visible effects when in excess are also quite differen: Garden plants that are grown especially for their foliage us large quantities of nitrogen and require it in ordis to be pe:fectly healthy, and seed producing plants use large quartities $v$ : phosphoric acid and potash. Where nitrogen in a soluhle forn is very abundant so as to be in excess in the soil it will bs 
found that the plants growing on it are noted for their dark green color and rank leaf and stem growth, and for late maturity of fruit and seed. In the case of small grain, it may result in such a weak, soft, succulent growth that the stems cannot support themselves and they become "lodged," and such growth may be gained without an increase in the yield of grain. In the case of lawns a soft, thick sod is made; in the case of spinach, cabbage and other leaf crops, vigorous, large plants result; while tree and bush fruits, under such conditions, make a soft, late-maturing growth that easily winter kills.

On the contrary, when soluble potash and phosphoric acid are in excess in the soil, the plants will have a tendency to produce a large amount of seed and fruit in proportion to straw or wood and to mature early. This is a desirable condition for heaviest grain and seed crops. In the case of bush and tree fruits, it conduces to fruitfulness, early maturity of wood and hardiness. These qualities will be most evident if the nitrogen is under a normal quantity in the soil.

It must not be understood from this that any of these elements are hurtful, for they a"e absolutely necessary in proper proportions to secure best results; but these effects follow when they are greatly in excess.

Except in few instances, fresh manure in the soil is not beneficial, and its presence prevents close cultivation and causes the land to dry out very quickly. Such manure does not afford plant food for some time, since it must first be thoroughly decayed before it is of any value to plants. Rotten manure has much of its plant food in an available condition.

Manure for Early and Late Crops.-Much more manure and more thoroughly rotted manure is required for early than for late crops. This is undoubtedly due to the fact that early in the season fermentation goes on very slowly, and unless plant food is supplied in a quickly available form it is of no immediate use to the plant. On account of the rapid fermentation which goes on in the soil later in the season, crops that mature later than the middle of the summer may be able to use the plant food that was locked up in fresh manure in the spring. For instance, the results from fresh cow manure may be almost nothing if applied in the spring to a crop of early 
cabbage or spinach, while for a late crop of cabbage or for corn it may answer very well. Where an abundance of wellrotted manure cannot be obtained in the spring and it becomes necessary to use partially rotted manure for an early crop, it is a good plan to use nitrate of soda or some other quick acting fertilizer to afford plant food until the manure has rotted.

Manures for Leguminous Crops.-Leguminous crops, such as peas, beans, clover, alfalfa, etc., do not need as much nitrogenous manure as most other crops that are so rich in nitrogen, since their presence encourages the growth of nitric acid ferments in the soil. Such crops improve the land on which they grow by increasing the amount of nitrogen in it, and in this respect they are different from all other garden crops, and are sometimes referred to as nitrogen producers and other crops as nitrogen consumers.

Animal Manure should generally be spread evenly on the land and then be thinly covered with the soil; yet for some crops it may sometimes be most desirable to apply the manure in the hill or furrow. The amount that should be applied per acre varies with the crop, soil and manure, so no exact rule can be given. For a midsummer or late maturing crop, probably eight cords of well rotted stable manule per acre would be sufficient in almost any case, and much less will sometimes be enough, while for an early crop twice as much rotter manure might be used to advantage. Well rotted manure should be corered with soil soon after it is applied to the land, or it may waste by drying. If it is put on frozen land it may waste by the soluble parts being washed away. Bitt in the case of fresh animal manures there is little chance of loss in these ways.

The effect of the application of animal manures to the land will remain apparent for several years. It is generally considered safe to estimate that not more than one-third the full value of these manures is taken up by the crop growing on the land the year it is applied.

Manure the Growing Crop.-Sometimes a crop comes to a standstill on account of having exhausted the available fertilizing material in the soil. In such cases it may be a good plan to fertilize the growing crop with hen manure, nitrate of soda or other quick acting fertilizer and cultivate the land at 
once. This may be done in many cases by applying such materials to the crop during a hard rain or in a dry time by plowing a furrow near the crop and placing the fertilizer in the furrow. But in any case it should be cultivated into the soil so as to become well mixed through it, and much care must be takien to prevent the dry fertilizer from coming in contact with the roots of the plants.

Rotating Manures.-It is a good plan to occasionally change the manures applied to land, i. e. when stable manure has been largely used for some years apply some commercial fertilizer, lime or land plaster, and when commercial fertilizer's have been used for some time recourse should be had to stable manure.

Liquid Manure.-Liquid manure is sometimes used for enconraging the growth of plants. It should never be macle from fresh manure, but from that which is thoroughly rotted. Urine may be used as a liquid manure if well decomposed, but it should always be used with great caution and never applied to plants if fresh or unliluted. Cow and horse manure are generally preferred for making liquid manure. The vessel in which it is to be marle should be one-third full of manure and filled up with water. The whole should then be stirred and allowed to settle. The clear water is then used for watering plants.

Liquir fertilizer is also made by dissolving nitrate of soda in water as mentioned under that head. Ammonia is somerimes used in rery smail quantities in water applied to plants, especially to house plants, with good result.6. 


\section{CHAPTER III.}

\section{GARDEN TILLAGE.}

By the proper cultivation of the garden we accomplish three things: (1) The weeds are kept out so that they do not shade or take away valuable plant food and moisture from the plants which we desire to perfect. (2) The surface soil is brought into best condition to resist drought, that is, into the best condition to avail itself to the utmost of the stores of water in the subsoil and to prevent the evaporation of this water from the surface soil. (3) The inert plant food in the soil is made soluble by cnemical action, which is increased by the cultivation of the soil.

Prevention and Killing of Weeds.-The methods best adapted for keeping weeds out of the garden are many and varied. They depend much upon the condition and kind of soil in which the weeds grow, and upon the lind of crop and the habits of the weerls themselves. The most important step in making easy the prevention of weeds in the garden is the harrowing or other thorough cultivation of the land just before the planting of the seed, to kill the young weeds. If this is done thoroughly the weeds do not have any better chance than the crop. If this is not done the weeds will be ahead of the crop in growth, and if started ever so little when the (rop is planted the result generally is that the crop is seriously orergrown by them before it is large enough to be cultivated.

When garden seeds that require a long time to germinate are sown, it is an excellent plan to lightly rake over the land with an ordinary fine-toothed rake even before the crop appears above the ground, providing the work is so carefully done as not to distrirb the seeds. This is an easy matter in case of the larger garden seeds, while it would be impossible with the finer sects, as they are invariably planted shallow. When the seer? is sown with a drill the line of the row may be plainly seen even before the plants come up, thus making it easy to commence cul- 
tivating in advance of the weeds. In case of such crops as carrots, onions, beets and parsnips, which are quite delicate when young, cultivation should begin with some hand garden cultivator, even if it is intended later on to cultivate it with a horse implement and the crop is planted with this purpose in view. Such close and careful work cannot be done with any horse implement now in use as with the best hand implements. Careful early cultivation is of the utmost importance, since if the weeds are removed when they are young the work of weeding is small. If allowed to remain until well rooted, their removal is often a very serious matter, and frequently, if neglected at this early stage, the weeds become so firmly established as to make it a question whether to remove them or to plow under the whole crop; and often it is the part of wisdom to adopt the latter alternative. Aside from its effect in the prevention of weeds, early cultivation is of the greatest value in breaking up the crust that packs firmly around the tender growing stems of plants and which seriously interferes with their growth. Like all surface cultivation it is also an aid in the conservation of moisture in the soil.

Importance of Not Allowing Weeds to go to Seed-A common source of weed infection is often found in the few weeds that are allowed to go to seed toward the end of the growing season in the maturing crop or after the crop has been gathered. To some persons it often seems a small matter to allow a few plants of pig-weed, purslane, tumble weed and weeds of other kinds to go to seed in the garden, but absolute cleanliness should be the rule in this particular, and it is by far the most economical in practice in the long rum. It requires but little labor and saves much useless expense if the weeds that are going to seed are destroyed. If the preventives for weeds here suggested are closely followed hand weeding will be reduced to a minimum and will often be unnecessary with any crop.

Weed Seeds in Manure for the Garden.-While the discussion of the subject of manures for the garien is not the special object of this chapter, yet some reference to the subject is quite necessary in considering the subject of weed eradication. The people of this sertion have not yet learned the great value of barnyar manure and its proper preparation for best 
results in the soil. This is a subject of vast importance and one that in the future will receive far more thought than at present. The manure applied to the garden is often coarse and contains many weed seeds and is a fruitful source of weed infection. If the manure intended for the garden contains the seeds of weeds it should be piled up and allowed to ferment until the whole mass is thoroughly rotted, which process will kill the weed seeds in it. It is seldom advisable to use fresh manure in the garden, and it should only be applied in this condition when free from weeds and then only for some late maturing crops, in which case there will be time for it to rot before the crops need it.

Plowing.-In the western states, where the summers are often very dry, vegetable land should generally be plowed in the autumn so that the subsoil may become sufficiently compacted by spring to readily transmit the subsoil moisture to the surface. Such treatment, by forming a dust blanket, retards evaporation from the land during dry autumns and dry winters when there is no snow on the ground. Fall plowing also puts the land in the best shape for the action of the elements and the development of plant food, and may we a means of killing very many cut worms, white grubs and other insects that winter over in the soil. If plowing is left until spring in this climate it should be done as early as practicable and not so deep as when done in the fall. Deep spring plowing leaves too much of the upper soil loose and not sufficiently compact to enable the subsoil water to easily reach the surface roots-but where irrigation is practiced there is not much difference in this respect. The soil for the garden should ordinarily be plowed to a depth of about eight inches, yet in the case of some light soils half this depth may be preferable.

Subsoil Plowing or Subsoiling, are terms applied to the loosening of the land just below where the plow ordinarily goes. In doing this, the subsoil is not brought to the surface, but a special plow is used which follows an ordinary plow. This has no mold board, but has a good point and shoe, and these loosen the subsoil without raising it. This process may be hurtful or of no value to subsoils already so loose as to permit the roots of plants to readily push into them, and should not 
be applied to them, but for some of the very stiff subsoils of this section it is a great improvement, since it deepens the tillable land so that the roots of the plants can push more readily into it. This loosening of the stiff subsoil also puts it into just the right condition for receiving and holding water. It is thus sometimes a great help in carrying plants over droughty periods. Subsoiling gives best results when performed in the autumn. If done in the spring and the operation is follower by dry weather, tho land is ant to be left too loose to hold moisture well that year and consequently will suffer from drought. It is sclitom. cren on stiff land, that subsoiling is necied more than

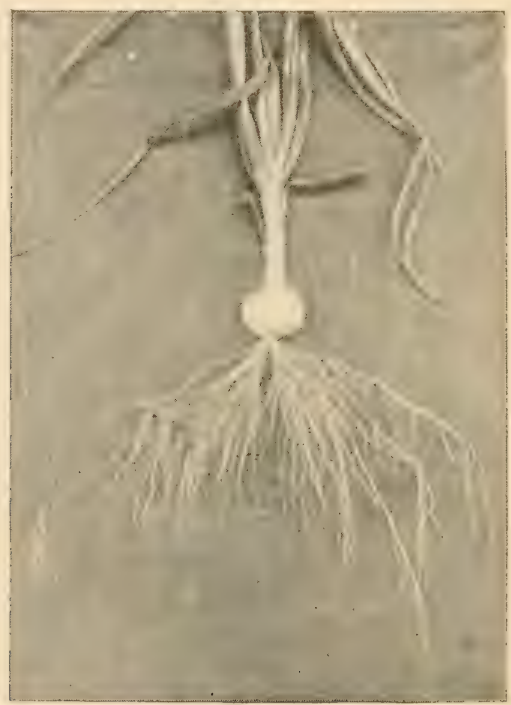

Figure 3.-Root of onion plant with earth washed off. The roots went to the depth of eighteen inches in the earth.

once in four or five years, for after being once loosened the roots of plants penctrate it and keep it open. The roots of our garden (rops push deeper into the land than is generally known; eren the onion, which is, perhaps, as shallow rooted as any garden (rop) slown. often pushes its roots to a depth of eighteen ink hes in good soil, while corn roots have been followed to a 
depth of four feet. It is probable that in good land almost any of our garden crops will send their roots eighteen or more inches deep.

Ridging the Land.-If the land is liable to be too wet for planting in early spring, it is sometimes a good practice in plowing it to turn several furrows back to back and thus leave the land in ridges over winter. If these ridges or "lands" are made fifteen or twenty feet wide, they may be dragged and planted in the spring without further plowing. For some crops it is often best to open the furrows again in the spring and thus leave the land level. This method of treatment permits of working

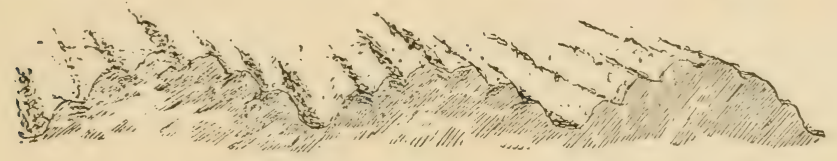

Figure 4-Cross section of ridged land.

the land much earlier in the spring than it otherwise could be worked if plowed flat. It also leaves the soil in very good shape for the action of frost on its particles during the winter. For early crops on flat or heavy soils it is a most desirable treatment. The objection to it is that if not turned back in the spring the dead furrows interfere with cultivation; if the land is thus turned back in the spring, it may be left too loose. But admitting these objections, even then there are often cases where this treatment would be very desirable. It snould be borne in mind, too, in cultivating the garden that. while the soil in it may be too loose, it cannot be too rich nor too deep, nor can the subscil, if not of too impervious a nature, be too compact, and yet it must be loose enough to permit of the roots entering it and the water percolating through it.

General Cultivation of Garden Crops.-The methods to be pursued in the general cultivation of garden crops vary somewhat according to the soil, season and crop. Howerer, it is very important to remember that the destruction of weeds is but a small part of the work of cultivation. The most important part in this section is to so fit the soil that it may best with. 
stand drought. This is accomplished by frequent shallow cultivation during the period of drought. The first implements to use in the care of such crops as are generally cultivated by hand are those that work the soil to only a very slight depth close to the plants. Such implements may be used just as the seedlings are breaking ground. As soon as the plants have gained some little strength, implements should be used that will go deeper, until a depth of two or three inches can be easily worked without endangering the safety of the crop by covering the plants with dirt. It is doubtful if any of our garden crops should ever be cultivated more than three inches deep, and it is very certain that many crops are injured by cultivating deeply very close to the plants, in which case the roots are cut ofi near their upper ends and thus wholly destroyed. Cultivation in a period of drought results in forming a mulch or blanket of dry earth on the surface of the land, which prevents the moisture from passing into the atmosphere, and a rather shallow dust blanket, say three inches deep, accomplishes this purpose. A compact subsoil readily transmits the water upwards to the surface soil in

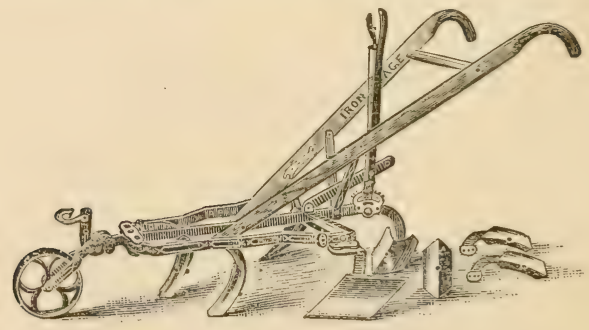

Figure 5.-Iron Age horse hoe.

the same manner that a lamp wick carries the oil to the flame. At the surface the soil water is prevented from evaporating by the blanket of loose earth, and is thus saved in the upper subsoil and lower and middle parts of the furrow slice for the roots of the crop. Loose surface soil is a good non-conductor of water. During the growth of a crop the surface soil should never be left long with a crust on it, but should be stirred after each rain or artificial watering. 
Cultivation to Develop Plant Food.-Nearly all land in this section contains immense quantities of plant food. Professor Snyder has shown that our average wheat-producing soils contain enough nitrogen to raise one hundred and twenty-five successive crops of wheat. But only a very little of this material is ever at one time in a condition in which the plant can take it up; nearly all of it is insoluble. By chemical action and fermentation in the soil, plant food is set free. This is increased and made more complete by admitting air into the soil. Hence the reason for deep plowing in the fall, which allows the air and water to enter and thus develop plant food. This, also, is an important fact to be kept in mind in cultivating land. Where the soil can be kept moist through the summer deep spring plowing is an advantage as it opens the soil to the air; but on account of the liability to injury from droughts to soils thus worked the practice is generally a poor one for this section.

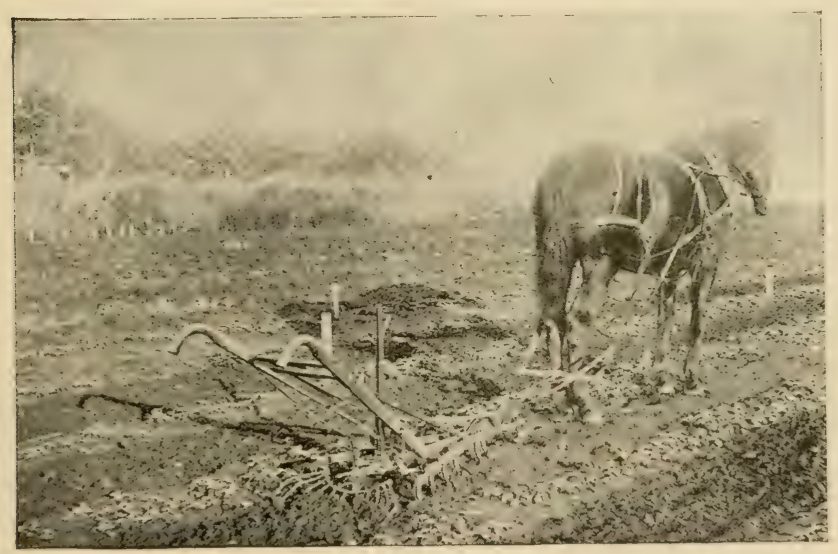

Figure 6.-P1anet Jr. fine tooth cultivator.

\section{GARDEN IMPLEMENTS.}

Implements, such as plows, harrows, etc., used for preparing the land for ordinary farm crops are also used in fitting the land for garden crops. In addition, however, there are a 
number of tools and implements which are not commonly used in growing the farm crops. These may be roughly classed as follows:

Horse Hoes and Horse Cultivators are much alike in general construction, but each is adapted to special purposes; and both are very desirable. The horse hoes are for use when the land is very hard and weedy; they may also be used for ridging the land and drawing the earth from or harrowing it towards the plants. For this purpose they have various attachments.

The cultivators are especially for the purpose of stirring the surface soil and ping a dust blanket; they do not remove weeds that are well established. They throw very little soil sideways and on this account may be used for cultivating very close to small plants. Among the best of these are those known under the names of Planet Jr. and Iron Age.

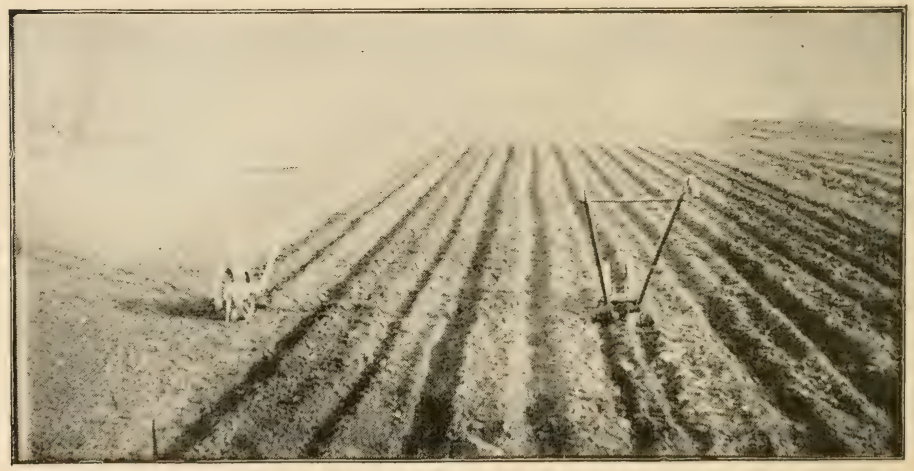

Figure $\tau$.-Openiug and closing furrows with hand garden cultivators.

Hand Cultivators.-There are many good forms of hand cultivators on the market, and they are a necessity in every garden containing over a quarter of an acre. They are made so as to be adjusted to various widths between the rows, and kinds called "straddle cultivators" are made so as to cut on two sides of a row of plants at one time, which is often quite an advantage. They also have various attachments for special purposes. Among 
the best of these are Jewel wheel hoe, New Univer'sal whcel hoe, Gem garden cultivator and the several kinds manufactured by the Planet Jr. Co.

Seed Drills.-These are necessary in every garden. There are many good kinds offered by dealers. Among the best are the New Model drill, Planet Jr. Hill-Dropping drill and Mat. thews drill.

Combined Seed Drills and Cultivators.-These are very eco. nomical and useful implements for a small garden; for a large garden it is important to have the seed drill and cultivator sep-

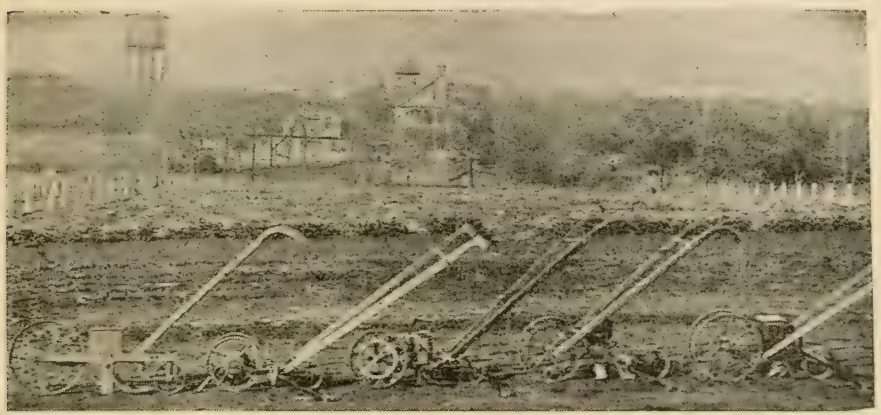

Figure 8.-Garden drills. (1) A. H. Mathews. (2) Planet Jr. combined drill. (2) Mathews combined drill. (4) New Model drill. (5) Planet Jr. Hill Dropping drill.

arate, but in a small garden these combined machines can be used to good advantage, and thereby make a saving in first cost. Among the best of these is the combination drill and cultivator made by the Ames Plow Co., of Boston, Mass., and the Planet Jr. combined drill and cultivator.

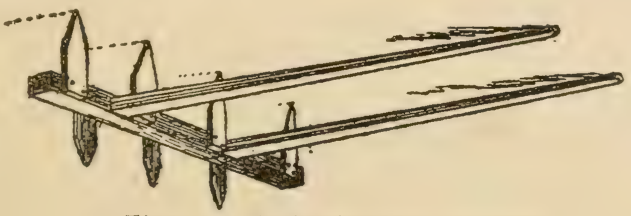

Figure 9.-A simple garden marker. 
Marker.-The illustration shows a good form of a marker for the garden. It is easily made by any one who is handy with tonls and is used for marking out rows.

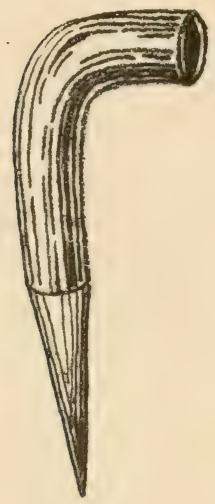

Figure 10.-Common wooden dibber.

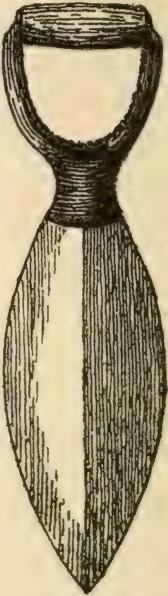

Figure 11.-Improved flat steel dibber.

Dibbers are generally made from a crooked stick shod with iron and are very useful in transplanting (Fig. 10). A better form made of steel is shown in figure 11.

Scuffle Attachments for Hand Garden Cultivators.-Fig. 11 shows two sets of implements designed to be attached to the

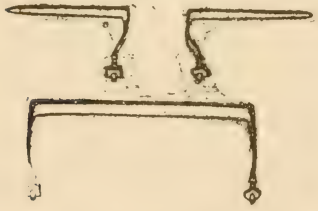

Figure 12.-Home made attachments for garden cultiva ors.

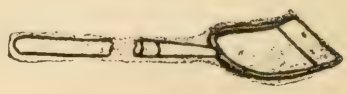

Figure 13.-Scuffle hoe.

ordinary wheel cultivators which will work close up to the young plants so as to cut off the weeds just under the surface of the soil, and will be found very useful in many places. They 
should be made out of tool steel and any gcod blacksmith can make them. The length of blades may be made to suit the work.

The Scuffle Hoe, shown in Fig. 13, is an excellent old-fashioned implement for shallow cultivation, such as is needed in early spring in the garden. Besides, it is very cheap and simple and can be made by any handy blacksmith. It cannot be recommended to take the place of the improved wheel hoes for large gardens, but in small gardens it may be used for the work of shallow cultivation to good advantage. It does not work the soil deep enough for the best summer cultivation.

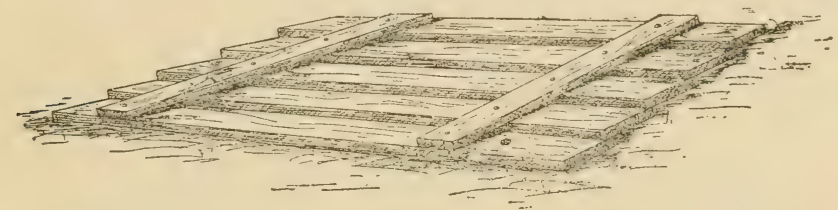

Figure 14.-Plank drag for smoothing the surface of land.

Plank Drag or Smoothing Board.-The form of this is clearly shown in Fig. 14. It is used for crushing lumpy soil and smoothing off and levelling the land preparatory to seed sowing or planting and will be found very useful. It can be made by any one. The planks are two by ten inches on the ends and eight feet long, lapped two inches and nailed. These are strengthened by two six-inch cleats securely bolted on. It is drawn by a chain fastened at the front corners.

Potato Diggers.-Of the cheaper forms of potato diggers, probably the Hallock Improved is the most perfect. It does very good work, and where not over five acres of potatoes are to be dug it is probably all that is needed. Where the potato is raised on a large scale, however, it is generally desirable to use an elevating digger. Of these the Hoover and the Dowden are probably the best to be had. They both work on the same principle.

Spray Pumps.-Almost every farmer and gardener needs a good spray pump for applying Paris green to potatoes and vines and for spraying trees, vines, etc., with fungicides or insecticides. For this purpose some form of the knapsack spray 
pump is most desirable where the work to be done is not very extensive. For applying these subtances on a large scale some special apparatus is needed, and there are many kinds offered by manufacturers. In Fig. 15 is shown the barrel spray pump, which has been found most convenient at the Minnesota Experiment Station for general work about the grounds, such as spraying trees of different kinds where the knapsack sprayer is

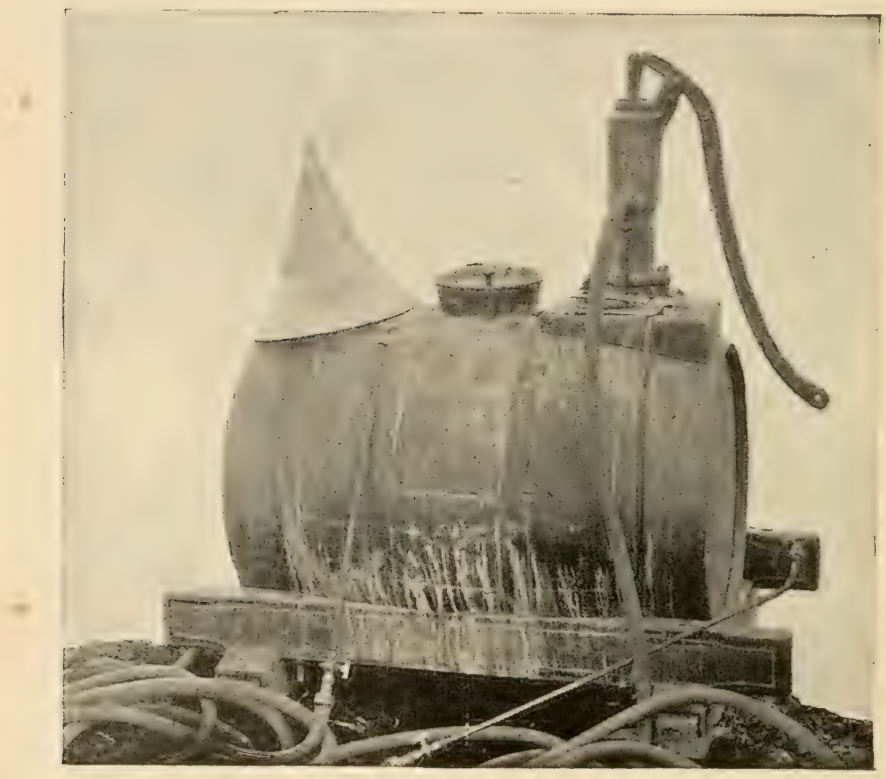

Figure 15-Barrel spray pump, showing cone shaped strainer to the left. insufficient. The barrel is fastened to a wooden frame and may be placed in a wagon or on a stone boat when it is to be used.

The essential parts are a good hardwood barrel, such as a linseed oil barrel mounted on and securely fastened to a light framework of oak. At one end of the barrel is mounted a powerful force pump with attachments capable of throwing two 
or three fine strong sprays at one time. The liquid in the barrel is kept agitated by a small stream of water passing through a one-fourth inch pipe, having a one-sixteenth inch wide opening near the feed p pe of the pump, in the bottom of the barrel. On one end of the barrel is shown a cone shaped strainer which is much the best form to use. There are many styles of spray nozzles on the market. For general use the McGowen, Vermorel or Bordeaux are best.

The lower end of the feed pipe is covered with a fine brass screen. In the center of the side of the barrel is an opening eight inches in diameter with a tight fitting cover. This is so large that the barrel may be easily cleaned. The whole expense of making this machine was as follows: One linseed oil barrel, $\$ 1$; pump, $\$ 6.50$; 50 feet of one-half inch hose, $\$ 3$; strainer, $\$ 1.50$; two nozzles, $\$ 1.25$; bolts, etc., 50 cents. Total cost, not including labor, $\$ 13.75$.

In buying machinery it is well to regard with suspicion those that are very complicated, as the simplest is generally the most durable in the end. 


\section{CHAPTER IV.}

\section{SEED SOWING AND TRANSPLANTING FARMER'S KITCHEN GARDEN.}

For the Successful Germination of Seed in the land it should be placed so as to have a reasonable amount of heat, moisture and air. To secure these conditions in practice, the seed should be imbedded in mellow soil, and this packed around it just firm enough to bring it into actual contact with and make sure capillary action in tne soil. If the soil is left loose over and around the seed, capillary action cannot continue, and the seed is liable to dry out unless the season is very wet; on the other hand, the soil must not be allowed to become too compact over the seed, or the young seedling will not be able to push through it. No matter how carefully the sowing may have been done, the successful germination of the seed is largely dependent upon the condition of the ground. Unless the seed is carefully and properly placed and covered, the crop cannot get a good start no matter how well the land has been prepared or how good the seed is. Seed will not sprout in the absence of air, and on this account when deeply buried some weed seeds may retain their germinating power for many years. Cases are on record of yellow mustard seeds germinating after remaining in the land for eighteen years. Very frequently, on plowing land that has not been stirred for a long time, the weeds of certain kinds are very abundant, showing that they must have been in the soil a long time, but could not germinate away from the air.

Depth to Plant.-Most of the common, smaller garden seeds are planted one inch deep; celery and some other fine seeds cannot be planted nearly so deep. Peas and corn are generally planted from two to three inches deep. Peas, however, are sometimes planted as deep as six inches. These matters will be found referred to under their respective heads.

Always Sow in Freshly Stirred Ground, as the seed is far 
more liable to get a good start in it than in soil that has lain untilled long enough to become crusty and lumpy. Then, if the seeds are planted immediately after cultivation has been given and while the soil is still moist, the weeds will hardly get the start of the crop planted if reasonable care is used. In fact, following this rule will generally insure success as long as there is life in the seed and moisture in the soil. Again, it is preferable to sow seeds immediately after a rain rather than just before it comes, since in the case of the finer seeds the crust which forms immediately after a rain may be so compact that the young seedlings cannot push through. When a crust thus forms over seeds it is sometimes a good plan to go over the land before the crust is very compact and break it up with rakes, but this should be done in a most careful manner so as not to disturb the seeds. If a crust forms over fine seeds, such as celery, tobacco and others, it is a good plan to keep the crust moist, at least, until the seeds have pushed through it. Soil that is much dried out in midsummer is often quite an obstacle to the ready germination of seed sown at that time, but if the seed is sown shortly after the ground is plowed and somewhat deeper than it is generally sown, in the early spring and care is taken to firm the earth very carefully immediately after sowing, the seed will generally come up very quickly at this season. But the land should not be worked for seed sowing or for any other purpose when very wet and sticky, as seeds cannot be properly planted in soil in such condition.

The Time for Sowing the various seeds varies greatly and will be founnd referred to separately under the several heads. Some seeds, such as spinach, onion, lettuce and radish may be sown as soon is the ground can be worked, while the seed of such tropical plants as corn, cucumber and squash should not be sown until the ground is well warmed. The early sown hardier seeds are often frozen up in the ground and, perhaps, covered with snow without injury; in fact, a covering of snow seems to help seeds of the hardy kinds to grow.

Sowing in Stiff Clay Soils.-It is comparatively easy to make seeds germinate in sand, sandy loam, muck or soil rich in humus, provided they contain a reasonable amount of moisture, but in stiff clay soils this is often quite a different matter, as the land 
becomes crusted over so completely as to prevent the smaller seedlings from pushing through. For such land it is desirable to use rather more seed than would be needed in more porous soil for the reason that while a few plants could not push up the crusted surface yet the many can do so; and while thick seeding increases the total cost of seeci, yet the certainty of thus securing a full stand is so great an advantage as to well repay this additional outlay and the expense for thinning, if it has to be done at all, is about the same for thick as for thin seeding.

Sowing Seed With Machine.-When the soil is prepared for best work with a garden drill it is generally in the best condition for the germination of seeds. The whole surface should be fine, mellow and even. There are only one or two garden seeds that cannot readily be sown with any of the half dozen good garden drills that are offered in the market. Garden drills when properly used will sow and cover seed much more uniformly than it can possibly be sown and covered by hand, and they are a necessity in any well-managed garden. It is of the utmost importance to have straight rows in the garden, for they are more economical of space than crooked rows and are more perfectly cultivated with the wheel hoes and cultivator, besides, crooked rows are unsightly and slovenly. It is generally desirable in using a garden drill to mark off the first row with a line to get it straight. If this is done to begin with the subsequent rows may be kept parallel by using the marker always found on such machines, providing constant care is used. Some growers prefer to mark out all the rows with a marker and then run the seed sower in the marks, but for a careful workman this is useless labor. Seed drills are made with a point to open furrows, a coverer for filling in after the drill, a wheel for compacting the soil on the seed and a marker for the next row. To use a garden seed drill most successfully requires good judgment, but a little careful experimenting will soon enable any one accustomed to tools to handle these most useful implements to good advantage. Sometimes it is desirable to sow. seed when the ground is so wet that it is not safe to firm the soil over it. When such is the case the rear wheel is removed in sowing. In other cases when it is desirable to firm the soil more compactly, the press wheel may be used for this purpose, by going 
over the rows a second time. It is a good plan in doing this to remove the drill point or else tip the machine until the point is off the ground. In the case of a few seeds that are rather delicate about germinating, it is a good plan to sow the rows a second time with the seed drill and thus mix the seed up with the soil. This method puts in a large amount of seed, leaves the seed at various depths, and some of it is sure to grow.

Sowing Seed by Hand.-When only a very small quantity of seed is to be sown it is often best to sow it by hand. When this is the plan the rows are made by the garden maker and the seed distributed in them evenly by hand. The rows are then covered by the soil being drawn into them with a rake and are firmed by passing over the seed with the feet. If the soil is dry it cannot be made too firm; if moist, care must be used to prevent packing it too hard. In the case of very fine seed sown in dry weather, many devices are used to bring about germination such as watering, shading the soil with boards, covering the earth with cloths and the like.

Using the Feet for Firming the Soil Around the Seeds.Many seeds are lost from the failure to properly firm the soil over those sown during dry weather. Many devices have been suggested and used for securing this desirable condition, but for general garden purposes no method or implement ever used can vie with the proper use of the feet for this purpose. While this matter is referred to elsewhere, it is put under this special head to call attention to this useful fact. Peter Henderson was the first to call attention to the importance of this method, and describes it as follows: "After plowing, harrowing and leveling the land smoothly, lines are drawn by the 'markers,' which make furrows about two inches deep and a foot apart. After the man who sows the seed follows another who, with the ball of his right foot, presses down his full weight on every inch of soil where the seed has been sown; the rows are then slightly levelled longitudinally with the rake, a light roller is passed over them and the work is done." Those who have practiced this method know it gives most excellent results. In my own practice, in sowing seed in dry weather, even with a 
seed drill which has a wheel for firming the soil, I have frequently, and to advantage, walked the rows with the heel of one foot close to and in front of the toe of the other, pressing down on the row.

Thinning.-It is generally best to sow the seed of most garden vegetables much more thickly than the plants should stand when mature. This is done to make sure of having enough plants to stock the land, and it is a good practice. It is important, also, to let every young plant in the garden have room enough for perfect development, and this can only be secured, where thick seeding is practiced, by thinning out. It is a very general fault of beginners in gardening that they try to grow too many plants on their land. This is a common mistake and is no better in result than permitting weeds to grow. Every plant in excess of what can properly mature on the land is in its effect a weed and should be treated as such. In the home gaiden, where the thinnings are valuable, as in the case of beets, lettuce, etc., the work of thinning need not be done all at once but as the plants need room. In the market garden it is best to thin out the full distance at one time. Do not allow the seedlings to get drawn and spindling before thinning, but do it while they are young and before they crowd one another. The proper distances between plants seem very large when the plants are small, but it must be remembered that later on any. thing less than the proper distance injures the crop. One must have determination enough to throw away many nice plants in order to make room for those that are to mature. It is better to give too much than too little room to plants.

Protection to Newly Planted Seeds against insects and birds may often be given by slightly moistening them and then stirring in red lead until all the seeds are thoroughly coatel. The seed should be dried before sowing.

Crows and Gophers May be Kept From Eating Corn by coating it with coal tar as follows: Wet the corn with hot water and drain off all surplus. Spread it out about four inches deep on the floor of a warm room and sprinkle it with hot coal tar using about a tablespoonful to a half bushel of corn and stir ihoroughly until every kernel has a thin coat of tar on it. Then 
dry the corn by coating it with dry ground plaster or other fine absorbent. This treatment does not seem to hinder germination.

\section{TRANSPLANTING.}

Avoid transplanting as much as possible.- Whatever may be said of its merits elsewhere does not apply in this section, since the dry weather so common here in the season when transplanting is done often makes the operation unsuccessful. Undoubtedly one of the reasons why transplanted plants sometimes give better results than seedlings allowed to grow where the seed is sown, is that they are allowed more room to develop in, but if seedlings that are not moved are given the proper room to develop they are just as good and generally far superior to those that are transplanted. Transplanting, as a rule, is an injury to plants and yet it is a necessary operation in the growing of some of our most valuable vegetables.

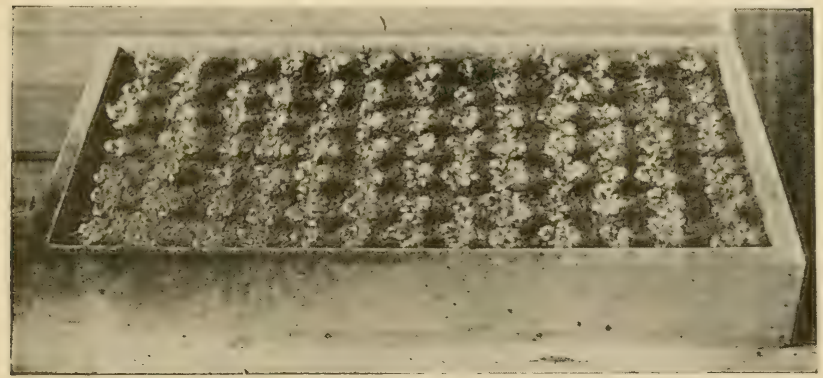

Figure 16.-A box of young lettuce plants after being transplanted from the seed box. These plants may be moved to the open ground or to hotbeds or cold frames as soon as they crowd one another. This is a conrenient way to grow plants in dwelling houses and in front of windows. This style of box is often referred to as a "flat."

Success in Transplanting is dependent on a variety of con ditions. In moist weather the setting of plants in the open ground is a very simple operation and any one can succeed with it without much effort, but during dry weather the gardener's skill is taxed to the utmost to move plants successfully. One of the most important elements for success in transplanting is a 
supply of first-class stocky plants that have not been crowded in the seed bed. Such plants make success reasonably certain. A most important requirement in any case is that the soil be moist and not wet and sticky. If it is very dry it must be watered or failure will be a sure result.

Shortening the Tops of Plants.-It is a good plan to shorten the tops of cabbage, celery, cauliflower and similar plants when they are to be moved. This may be done by twisting or cutting off a third or even one-half of the tops. If the plants have excessively long roots it is a good plan to shorten them enough to permit of their being handled easily.

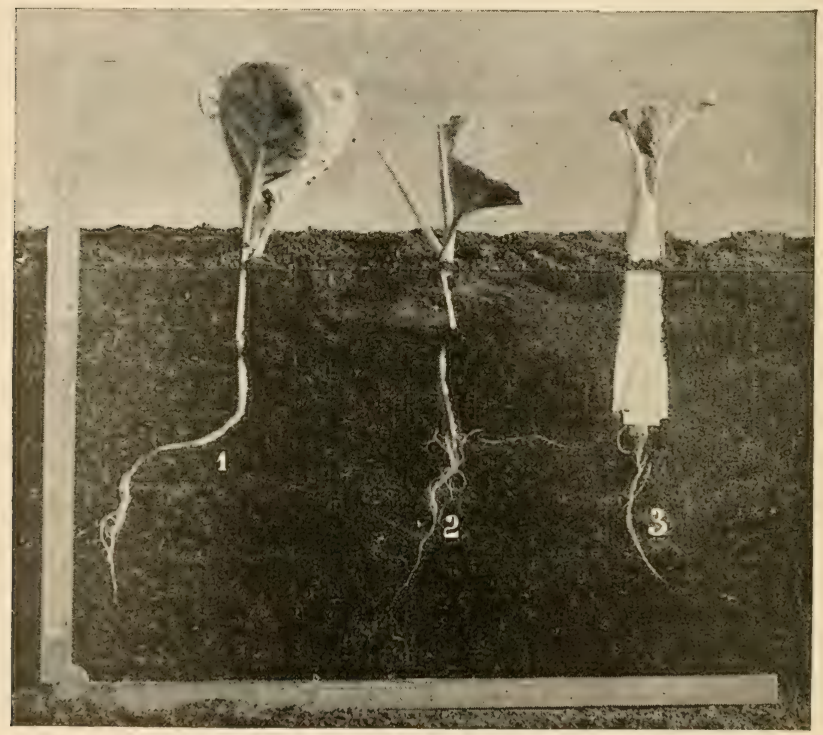

Figure 17.-1.-Cabbage plant with long stem set deen. 2-Cabbage plant with top twisted off before planting. 3-Cabbage plant wrapped in manilla paper to protect from cut worms.

The Digging of Plants should be done carefully and every precaution taken to get good roots. If the bed is very dry the 
soll should be thoroughly wet before digging so that the small roots will not be broken in separating the plants. The best time of day for transplanting is generally after 4 p. m., as after that time the moisture in the air increases rapidly and the plants have the cool night air in which to recorer before being subjected to the intense rays of the sun. Of course if the weather is cloudy the plants may be set out at any time of the day. If a little shade can be provided for the newly set plants so much the better. This may consist of boxes, boards slightly raised from the ground, shingles, inverted flower pots, paper bags,

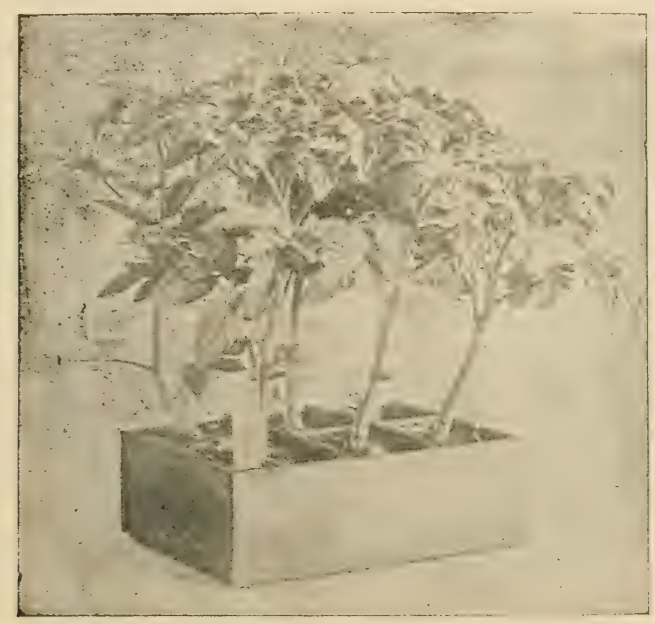

Figure 18.-Tomato plants grown in a compartment box to facilitate transplanting. Such boxes can be bought for a very low price and are very convenient aids for transplanting many kinds of plants. They are especially desirable when plants are to be sold at retail.

a handful of green grass, strawberry boxes or similar material that will protect the plants from the fierce rays of the sun.

Firming the soil about the roots is fully as important as firming the soil over the seeds and for the same reasons. It should be so firmly and closely packed that the plants cannot be pulled up without considerable effort. The drier the soil 
the greater the necessity for packing it firmly about the roots. If the soil is wet and inclined to pack hard it should receive only moderate pressure until somewhat dried out. The firming is generally done by pressing with a dibber or the ball of the foot against the soil on one side of the roots of the plant. When the transplanting is finished it is a good plan to give the plants a good hoeing at once, drawing a little loose, dry soil around them to act as mulch and prevent evaporation. The holes for the plants are generally made with a dibber (Fig. 10 or 11.) A spade is often used for this purpose and such plants as small onions are most conveniently set in small furrows made with a wheel hoe. In every case, however, the plants should be set a little deeper than they grew in the seed bed and in the case of spindling tomato, cabbage and some other p1ants it is a good plan to bend the stems and bury a large part of them in the soil as shown in figure 17 .

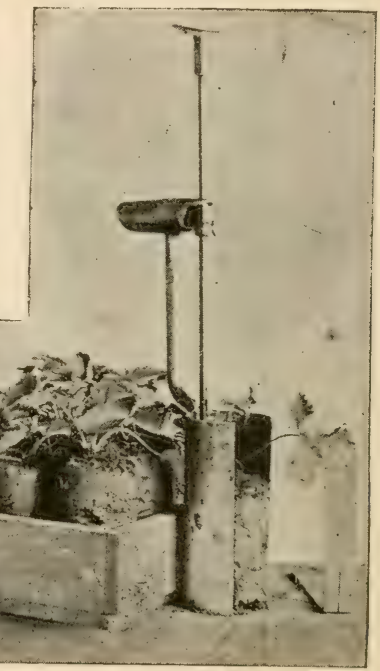

Figure 19.-Transplanting aided by the Balbridge transplanter, which takes up a ball of earth with each plant. The illustration shows a box of strawberry plants just taken up and ready for planting out. In planting out the holes are made with the same implement. There are several other similar implements for the same purpose.

Hardening off the Plants.-Hardening off is a term used to denote the checking of the growth of plants in such a way as to cause their tissues to become firm and hard. It is very important to have the plants accustomed to cold weather when they are transplanted to the open ground, or they may be killed by a frost that otherwise wo:ld do them no harm. This is true of the 
cauliflower, celery and of course of all our native frost tender trees and many other plants. When cabbage plants are properly hardened they take on a dull blue color that at once indicates their condition to one acquainted with their peculiarities. This hardening off of the plants is accomplished by gradually subjecting them to a lower temperature than that in which they grow freely or by drying them a little, and, finally, thus nearly checking their growth. The result is a sort of ripening up of the tissues of the plants and, in consequence, they will stand great hardship.

Tomato Cans are very convenient substitutes for flower pots when plants are grown for transfrlanting. The cover on the end openod may be melted off and a half inch hole made in the

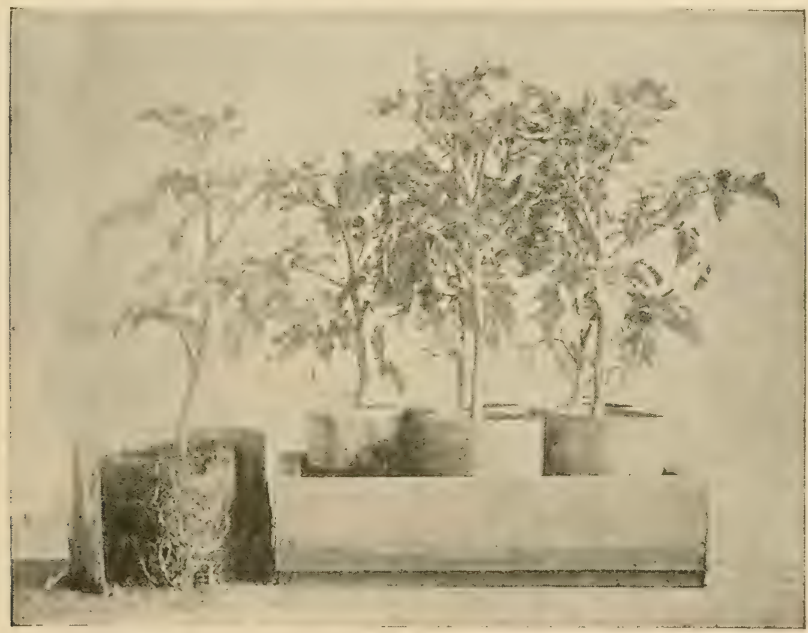

Figure 20.-Use of tomato cans as an aid in transplanting. A box of plants in the cans, ready for removal to the field and one can opened, showing the ball of roots. The cans are held together by wire twisted around them.

bottom for drainage. Another way to use them is to melt all the joints and use the body of the can by tying it together with a piece of wire. Thus prepared the tins may be set in the hotbed or cold frame and filled with earth into which the seed or 


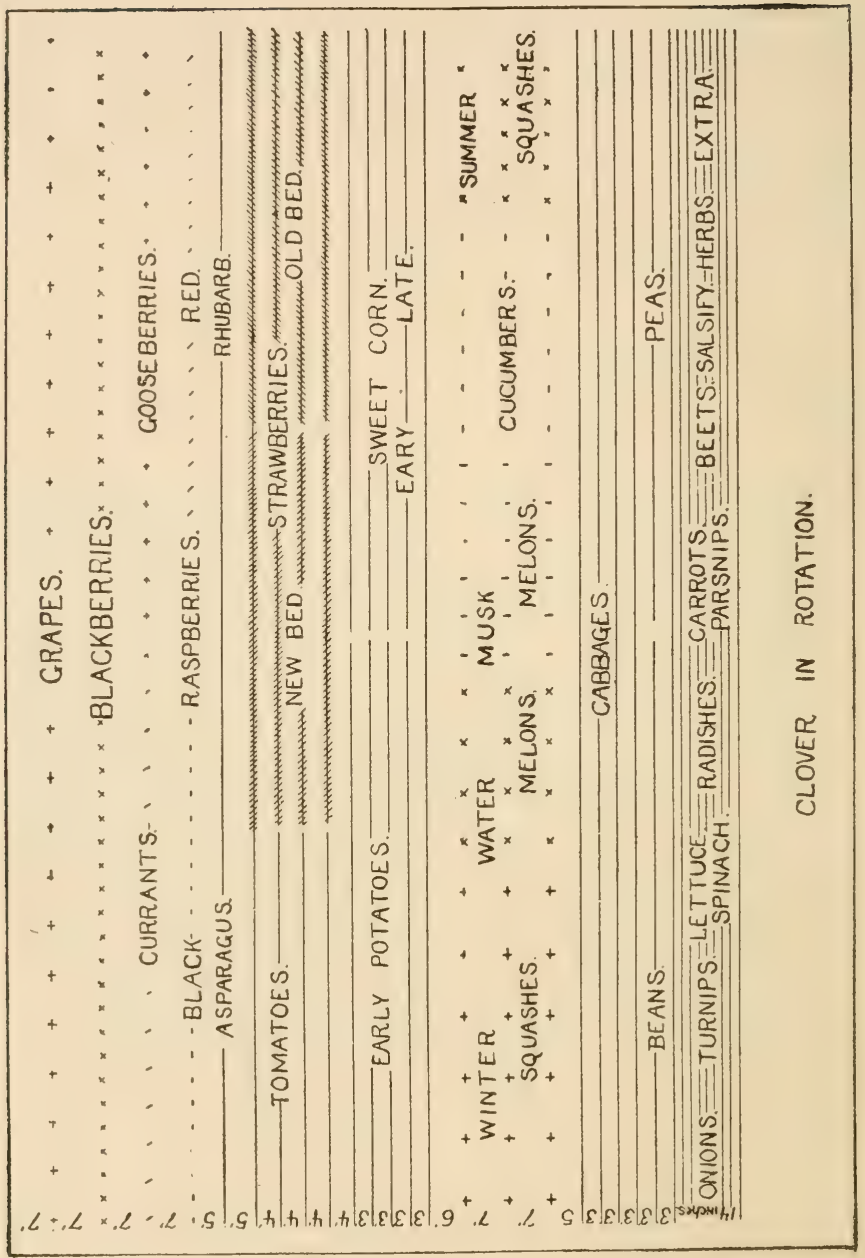

Figure 21.-Plan for farmer's kitchen garden. 
the plants may be placed. When the time comes for planting into the open ground the tine with the plants in them may be lifted with a trowel and placed in boxes, to be carried to the field where the plants are easily placed in the ground. The tins may also be set around the plans on top of the ground to protect them from the sun and wind. (See Fig. 20.)

\section{FARMER'S KITCHEN GARDEN.}

When Properly Conducted the kitchen garden should be the most profitable part of the farm. Too often its confined area and the laborious methods employed in its management makes the labor of cultivating it out of all proportion to the returns. Instead of confining the garden to a small area, it is better to enclose one or two acres of good rich land with a good windbreak of some kind so that it will make a garden plot twice as long as wide. Leave a headland in grass about fifteen feet wide all around as good crops cannot be grown next to a windbreak. The rows should run the long way of the land, somewhat as shown in figure 21. If the garden is surrounded by a fence it is found a good plan to have the part at the ends of the rows made of movable panels, so they may be removed when cultivating.

The Arrangement of a vegetable garden in the manner shown in figure 21 makes it large enough for practicing something of a rotation of crops in it and permits of hand labor being reduced to a minimum by the use of horse implements. The land should be cultivated flat, except for a few special crops such as celery. There is no advantage to be gained from hilling up around plants and it is a laborious process that can be dispensed with as well as not. When irrigation cannot be practiced it is important to have such crops as celery and late cabbage on moist soil, but for general gardening purposes a porous clay soil overlaid with a sandy loam is best, although a good clay loam will do very well when properly cultivated. Light sandy soils, especially those that are underlaid with sand or gravel, are too liable to injury from drought to be reliable for general garden operations. The garden should be near the house, so as to be easily accessible.

In planning the garden it is important to put all the perennial crops together, and so arrange the other crops that those 
that grow best in rows of the same width will come together. The accompanying figure shows one plan by which this may be done; it also provides for a part of the garden to be kept in clover, to be broken up about once in three or four years and used for vegetables in alternation with that shown laid out in rows, which part should then be seeded down for a while. This is a very desirable feature of this plan. 


\section{CHAPTER V.}

SEEDS AND SEED GROWING. DEVELOPMENT OF VARIETIES.

Good pedigrees in seeds are of the utmost importance in order to grow good crops. No single factor that enters into production of a crop is more important. Where many kinds of plants are grown it is better and cheaper as a rule to depend on some careful seed grower for seeds than to go to the expense of raising them, although it may be best to raise a few of the more important kinds of seeds for which one's conditions are best adapted. When one makes a specialty of crops like onions, cabbage and some other vegetables, it is often advantageous to raise the seed oneself, since their purity and pedigree are then known and no risk is taken about it.

Some seeds can be grown to better advantage in one section than in another. For instance, cauliflower seed cannot be raised profitably in many parts of the United States, but near Puget Sound and in a few other places in this country it can be raised to good advantage. Most of the cauliflower seed used in this country is still imported from southern Europe. As a general rule, however, the seeds raised in one's own vicinity or in a similar climate elsewhere are best to plant if they are properly selected. Experience seems to show that seed grown in cold climates generally produces an earlier crop than seed grown in warm sections.

Testing Seeds.-No matter how carefully our seeds may have been raised or who the person is from whom we received , them it may save much trouble and loss to test them before sowing. This may be done by sowing them in a box of fine loam kept at a temperature of from 60 to 70 degrees. The temperature of an ordinary living room is about right. For this purpose use a box about four inches deep and the size of a soap box; sow the seed in shallow drills and cover the box 
with grass to prevent rapid evaporation. One hundred seed should be counted out just as they come, and be sown. By counting the seedlings the per cent of germination of the seed is easily obtained.

A Simple Germinating Apparatus.-A simple method of testing seed is as follows:-Take two plates and in one of them

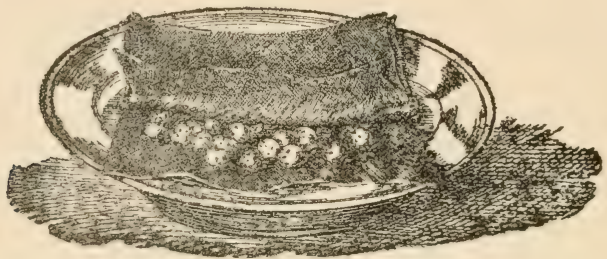

Figure 22.-Simple device for seed testing (open).

place a folded cloth, woolen flannel is preferable, since it must remain moist for a long time, but any cloth will do. The cloth should be free from dye stuffs since they may contain injurious chemicals. Wet the cloth, pressing out the surplus water, leaving it very lamp, but not soaked. Place the counted seeds between its folds and mark plainly with a pencil on a piece of paper the number of seeds put in and the date. Then cover with the second plate, as shown in figure 23. Plenty of air will get in

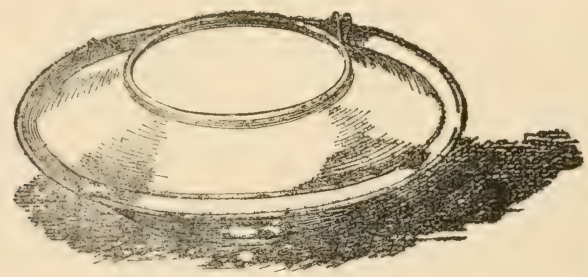

Figure 23.--Simple device for seed testing (closed).

between the plates, and the upper one will prevent evaporation. The temperature should average as recommended. Common newspaper or wrapping paper may take the place of the cloth, but requires much more attention. 
Sometimes seeds that barely germinate under the excep. tionally good conditions that exist in a sitting room or greenhouse will not grow readily when planted outdoors, so that in testing seeds it is very important to note the vigor of the sprouts. Seeds that start strongly in the house may be safely planted at their proper season outdoors, while those that start only weak sprouts indoors may be worthless for outdoor planting. An instance bearing on this occurred a few years ago at Chester, N. Y., where an onion grower planted seeds three years old which germinated fairly well in his conservatory but failed to grow outdoors, while fresher onion seed sown at the same time grew perfectiy.

The Curing and Storing of Seeds are matters of much im. portance and greatly influence their germinating qualities. Seeds should be thoroughly ventilated while being cured, or they will mould or sprout, either of which seriously injures their value. Seeds of some kinds will sprout several times before entirely losing their germinating qualities, but they lose much of their vitality, even by once sprouting. Moulded seeds may some. times retain their vitality unimpaired, but if to be offered for sale their dark color is objectionable, for it must always be re. garded as an eridence of neglect in curing. It is important also to prevent seeds, especially tropical seeds as those of melons, squashes, corn, cucumbers, tomatoes, etc., from being frozen un. til fully dry. The freezing of green or half cured seeds in. jures their vitality and often destroys it. This is well known in the case of corn where the seed taken from an orcinary crib in the spring often fails to grow while seed corn from the same crop properly cured in a dry warm room grows perfectly.

Seeds are much influenced by the temperature and humidity of the place in which they are kept. A dry place is absolutely necessary for successfully keeping garden seeds, and if warm so much the better for tropical seeds The temperature and condition of a good living room are almost ideal for storing all kinds of garden seeds. Most if not all our garden seeds are unimpair. ed by even severe freezing while perfectly dry. In a moist place garden seeds lose their germinating qualities much quicker than when they are kept dry.

Changing Seed.-There are locations so well adapted to cer- 
tain particular crops that some varieties seem to lose nothing of their pristine vigor and productiveness when grown there for many years, or they may be greatly improved in such locations; but, as a rule it is a good plan to change seed occasionally and it often results in increased productiveness. This sems to be a fact while the reason for it is not so plain.

Stock Seed.-When seed raising is a large business it is out of the question to have all the specimens planted, perfect in every respect, but nothing should be planted except it is near the desired type. Each year enough perfect specimens, or those closely approximating perfection, should be selected to raise the seed for the grower's use the following season. In this way the quality of the grower's seed stock is kept up and without such care the stock of seed is liable to seriously deteriorate. Seed so selected and improved from year to year is termed stock seed.

Seedsmen's Specialties.-Most seed growers and dealers have some few kinds of seed in which they are especially interested. These they select with more than ordinary care. It is always desirable to order seed of our specialties from those making a specialty of our favorite kinds unless we raise them ourselves. To secure the best it is well to order early in the season.

Seedsmen's Humbugs.-Almost without exception every dealer in seeds sells humbugs, that is, worthless or very inferior varieties. If he is honest he offers them simply because his customers want them. If he is dishonest he is very apt to misrepresent and praise them in order to make customers pay a big profit.

Novelties.-It is desirable to test novelties in seeds and plants, but this should be done cautiously and, as a rule, it is best not to be in too great haste to try new things. It is the general experience of growers that not more than one in ten of the novelties in seeds, fruits and plants is any better than those generally cultivated. In the history of the Minnesota Experiment Station the average of desirable seed novelties has been even less than this.

THE DEVELOPMENT OF VARIETIES.

There are laws that govern heredity and descent in planta 
as well as in animals, and by intelligent selectiow and breeding one may greatly improve or even originate new varieties of vegetable as well as of other plants. The seed stock of desirable new or improved varieties may often be sold at profitable prices, or by retaining the sole ownership of sucl new or improved kinds, one may perhaps raise crops that have highly esteemed qualities as to size, shape, color, flavor, hardiness, season of maturity or other features, and so command an advanced price. Thus a grower may sometimes be well rewarded for his care and attention in improving his specialties, but careful study and persistence is necessary to success and few persons are keen enough in their powers of observation. to succeed in this line of work.

There is constant tendency for cultivated plants to vary widely from the original form, though this feature may not manifest itself for many generations after cultivation has commenced. The higher the state of cultivation to which a plant is subjected, the higher are the chances of its producing new features. In nature plants grow under fixed conditions, so they do not vary much. When a plant once commences to vary from the original type, the changes ofttimes come very rapidly, and the possibilities are endless. Thus from a wild plant two or more feet high with only a few leaves has been developed (1) the modern cabbage of (a) the wrinkled, (b) the smooth, (c) the red-leaved, and (d) the many ornamental kinds; (2) Brussels sprouts with numerous small cabbage heads on a stem two or more feet high; (3) cauliflowers, in which the inflorescence becomes thick and fleshy; (4) the various kinds of kale; and (5) cow cabbage, which in the Jersey Islands has been known to grow to the height of sixteen feet and strong enough for rafters of cow sheds. The many varieties of garden and field plants are conclusive evidence of the variation of plants under cultivation.

All of our valuable garden vegetables are the result of almost endless care in selection and in a few cases of artificial as well as chance crossing. They must be regarded as artificial productions having a constant tendency to revert to the inferior wild state, which we must constantly try to overcome if their desirable qualities are to be maintained. 
It is necessary for the most successful breedinng of plants to have in vieiv a well defined purpose and in selecting seed not to vary the ideal standard of excellence sought, for such variation increases the difficulty of fixing desired characteristics.

It is found to be quite a general law obtaining among plants that the qualities of the parent are much more potent and thus more liable to be transmitted than some especially desirable qualities of a few individual fruits, which may occur on a plant otherwise defective. For instance, Liivingstone, who has done much to improve the tomato, selected seed for fifteen years from the best tomatoes that approached most nearly in size and other qualities the best modern tomatoes without noting much improvement. He says, "I was then no nearer the goal than when I started. Such stock seed would reproduce every trace of their ancestry, viz: thin fleshed, rough, undesirable fruits." It finally occurred to him to select from the special merits of the plants as a whole instead of from the best fruits without regard to the plants on which they grew. Improvement then came easily and rapidly and in a few years he obtained the Paragon, Acme and Perfection, varieties which were vastly superior to and have entirely supplanted the old varieties of tomatoes. Again, in selecting seed corn it is more important to save seed from plants having ears approaching the desired size of cob, kernel, etc., rather than to select the largest kernels alone or to select from ears after they have been pulled.

When it is desired to hasten the ripening period of a variety, only the seed from the earliest maturing specimens from a plant having the largest number of early specimens should be planted. In order to fix late maturing qualities, seed should be saved from the late maturing fruits on plants possessing these features to the greatest extent.

The continued selection of any seed from inferior specimens results in the fixing of the poorer quatities even more surely than the selection of seed from the better plants results in im. provement. By judicious selection the cabbage has sometimes been cbanged from a biennial to an annual producing no head at all but going to seed the first year. When cabbage has been grown for several generations from stem sprouts and not from 
head sprouts the effect has sometimes been to lengthen the stem at the expense of the head, until the seed stock becomes run out entirely and is in effect no longer true modern cabbage seed, since it has partly reverted to the original type. An instance of this occurred in a neighborhood in Nova Scotia where, for the sake of economy for a number of years cabbage seed was grown by cutting off the heads and planting out the stumps only until the stems became nearly two feet long and the heads not much bigger than twice the size of a man's fist.

The practice of sowing the seed from plants remaining in the garden after the best specimens have been gathered for home use, as often happens, is a very poor one. Under such treatment there is a very general tendency for the stock to degenerate. Where seed is to be saved in a mixed garden, a few hills of plants should be allowed to go to seed for this special purpose, without being picked at all. It is very important to save seed from well ripened fruits Very immature seeds will often grow but they give a weak though perhaps very early maturing plant and are very liable to disease. According to Professor Arthur, it is not the slightly unripe seeds that give a noticeable increase in earliness but very unripe seeds gathered from fruit (tomatoes) scarcely of full size and still very green. Such seeds weigh scarcely more than two-thirds as much as those fully ripe; they grow readily but lack constitutional vigor. Professor E. S. Goff has made a great number of experiments along this line and remarks that the increase in earliness in tomatoes following the use of very immature seeds, "is accompanied by a marked decrease in the vigor of the plant and in the size, firmness and keeping quality of the fruit."

A few years of careful observation and experience in following out these principles in the breeding of plants with a special object in view, will convince the most skeptical of the wonderful power which man possesses to adapt plants to his needs.

Cross and Self-pollination of Plants.- The flowers of plants are said to be either elf-pollenized or crossed. By self-pollination is meant the pollination of the female organ (pistil) by the male element (pollen) of the same flower or, in some cases of the same plant but different flowers as in corn and 
squashes, which have two kinds of flowers. By crossing or cross-pollination is meant the pollinization of the female organ by pollen from another plant. The crossing of different varieties generally gives increased vigor in the progeny, but its effect is variable and may result in the loss as well as in the increase of their desirable qualities. Most of our cultivated plants are crossed by natural processes. The crossing of different seed stocks of the same varieties of plants is generally a great advantage, since it generally results in increased vigor without loss of desirable qualities. Seeds from self-pollenized flowers are not as productive as crossed flowers. Darwin found that cabbage plants from seeds that had been crossed produced nearly three times the weight produced by self-pollenized seeds. In the case of Indian corn, experiments made at the Illinois Experiment Station show that while cross-fertilization is not necessary, it is very desirable. Corn grown from crossed seed in nearly all cases was clearly increased in size as the result of crossing. "Plants grown from self-fertilized seed corn were in most cases notably inferior in size and vigor to the plants grown from hand crossed seed or from seed simply selected which was probably naturally crossed." "One plat from selffertilized seed had nearly half the stalks deformed in such a manner that instead of standing ui straight they turned off at a right angle at or near the point where the ear was produced. thus showing the tassel on a level with the ear. Many of the tassels were very deficient in pollen." In another plot from self-fertilized seed, nearly all the tassels were abortive. All the plants from self-fertilized seed produced a greater proportion of barren stalks or poorly filled ears than plants of the same varieties from hand crossed seed or from seed naturally fertilized. On the other hand the flowers of barley and wheat are so constructed that their flowers seldom open and hence are naturally self-fertilized, but even here artificial crossing results in increased productiveness.

The Effect of Cross-pollination is not always apparent in the progeny of the first generation, but is frequently plainly to be seen in the crossed fruit or seed the first year. However, differences may appear as the result of the cross the second or later generation which were not suspected. When corn is crossed it 
Is generally believed that the effect of the cross is apparent the first year in the grain, but careful experiments plainly show that this is not so, and that flint corn grains which do not show a trace of the admixture of sweet corn the first generation may produce ears the second generation, showing some of the characteristics of the sweet corn, and the same is true of other kinds that are crossed. The same truth undoubtedly holds as good in the case of other plants.

Mixing Varieties.-Practically varieties of plants can be mixed only in the blossom; and in order to mix the different varieties both must be in blossom at the same time. On this account potatoes do not mix in the hill. The varieties of some species of plants are much inclined to mix. Any two varieties of corn, melons, squashes and cucumbers are especially liable to be crossed if growing in the same field and in flower at the same time. However, two kinds of corn, of beans and of other plants may be grown on adjoining pieces of land withut danger of mixing, providing that they are not in flower at the same time: e. g., Cory and Evergreen sweet corn if planted at the same time may be grown for seed close together and will not mix, since the Cory would be entirely out of flower when the Evergreen came into flower. Melons and squashes never mix together, for although this belief is widespread the most careful experiments have failed in getting any fruit when the one has been pollenized by the other. Neither do musk-melons and water-melons mix together.

Distance Between Varieties.-The distance which should intervene between varieties liable to mix is variously estimated by different growers and is influenced by various conditions. The pollen of corn, grasses and many other plants is moved by the wind; and when different varieties of corn flowering at the same time are planted for seed there will be more liablity of their mixing when the pieces of land on which they grow are in line of the prevailing winds than when east and west of each other. If a grove or hill intervenes between varieties it will often prevent crossing. When varieties of each plant are not on a line of prevailing winds, they are reasonably free from mixing if 500 feet apart: otherwise, at least $1,0 \cap n$ feet should intervene. 
Such plants as melons, cucumbers, squashes and onions and most other plants with conspicuous flowers, are pollenized by insects to whose borlies the pollen becomes attached and is thus carried from one flower to another. This pollen is not light and powdery as in corn and many other plants but is rather heavy. It is obvious then that the direction of the wind has little effect in crossing such plants. It is generally agreed that different varieties of plants pollenized by insects should have at least 1,000 feet between them to prevent mixing, but which will often occur to some extent even with these precautions. The greatest care should be taken to keep stock seed from being mixed. 


\section{CHAPTER VI.}

\section{GLASS STRUCTURES.}

Glass structures are becoming more numerous each season for raising vegetables and flowers, and are destined to continue to increase in use as the wealth of the country increases. They are referred to here under the head of cold frames, hotbeds and greenhouses.

Cold Frames.-The term cold frame is applied to frames covered with glass and used to protect plants in winter, or for forwarding them without any heat other than that derived from the sun. It is the simplest form of glass structure. They are

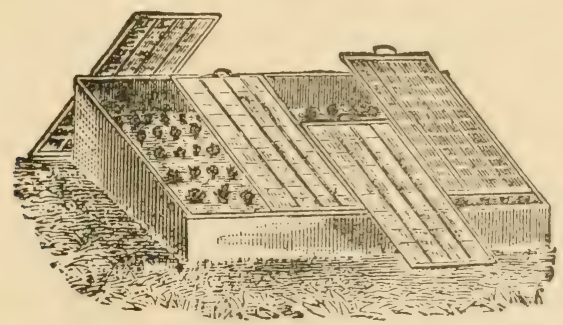

Figure 24.-Morable frame which may be stored out of the way in the summer. It is generally made of one inch boards and is very cunvenient for those using only a few sashes.

generally made $4 \frac{1}{2}$ or 6 feet wide and of any length or depth which convenience may suggest. The sashes for covering them are generally $4 \times 4 \frac{1}{2}$ feet or $3 \times 6$ in size. The location should be near to water and the house, preferably sloping to the south and well protected on the north and west by buildings, trees, etc. If there is no protection on the north and west, a tight board fence six feet high will answer the purpose. In making the bed the following are requisites: Enough $2 \times 12$ in. plank to go the length of the north side and the same length of $2 \times 6$ in. plank for the south side of the bed and $2 \times 4$ in. stakes, two or more feet long, 
for each corner and to support the sides firmly in place and sash and shutters to cover. The plants should be made into a box with its width equal to the length of the sash and extending east and west. See figure 24. Those forming the north side should be six inches above ground, and the top edge of the plank forming the southerly side should be five inches lower. Thus when the sash is put on, it will slope five inches to the south, as shown in figure. The planks should be nailed to the stakes, and end pieces put in. The earth inside the frame should be thrown out to the bottom of the planks and used to bank up the outside of the frame. The soil of the frame should be of the best quality if plants are to be grown in it. The frame is now ready for the sash and plants. More durable and expensive frames are sometimes made of brick or stone for the sides, and sometimes four-inch strips are put on wherever two of the sashes come together, to serve as a support. Frames are also frequently made several feet deep, but the same general rule applies in the building of them as are here given.

Cold frames are used in the middle states to winter over cabbage and lettuce plants. The plants are started in September and planted into them when grown to a good transplanting size. In severe climates this is not a safe method.

Cold frames are used here in the spring for forwarding lettuce and other early crops, and still later for melons, cucumbers and other tropical plants. They are also used to extend the season of growth during the autumn months and to protect some of the half-hardy plants, such as spinach, during the winter. They require ventilation during the day in mild weather, and on cold nights should be covered with mats and shutters or shutters alone. They are very inexpensive and very useful in the garden. but where the materials for making them can be had at low cost hotberls are much more satisfactory for forcing vegetables.

Hotbeds.-Hotbeds are made very much like cold frames, only they are warmed by fermenting horse manure or other material placed under the soil, and hence they must be dug out deep enough to make room for it. The amount of manure necessary to properly warm a hotbed will depend very much on the season of the year at which the bed is made up and the crop to be grown. In the colder northern states when the hotbeds are 
made up at the beginning of March from 24 to 30 inches of manure should be used, and covered with six or eight inches of rich soil. Later in the season 18 inches or even one foot of manure

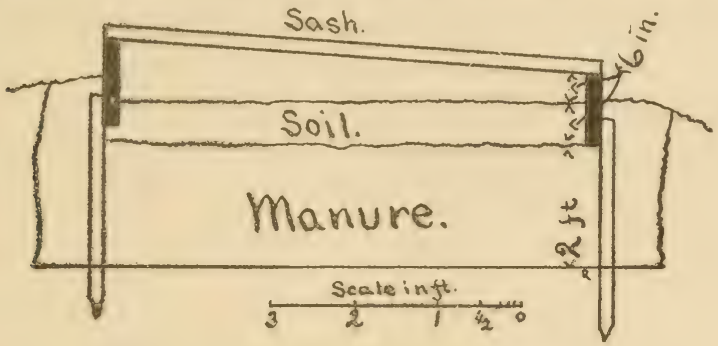

Figure 25.-Cross section of hotbed.

may be sufficient. In farorable locations hotberls may be used all winter for growing lettuce, radishes, etc. This is not often practicable in the exireme northern states anc? cheap greenhouses are generally used there during winter and hotbeds only during the spring.

The Hotbed and Frames for Early Spring Use should be prepared in the autumn, so that no digging will have to be done in the spring. The soil for spring use should generally be put into them, covered with leaves, and the shutters and mats put on to keep out the frost. If this has not been done the sash may be put on in the early spring, which will partially thaw out the soil in the bed; or, by another method, more manure may be used, putting it on the surface of the frozen land, and the frame may be set on top of it. In the latter case the manure should extend at least one loot beyond the sides of the frame and be onehalf again as deep as when placed in a pit and the frame should be banked up with manure. It is quite common practice to make morable frames of one-inch hoards large enough for three or four sash, as shown in figure $2 \frac{4}{2}$. These are liept from year to year, being set on top of the manure and the earth put into them.

Hotbed Manure.-The naterial generally used for heating hotbeds is fresh horse manure, but sheep manure and even spent hops may serve the punpose. Of animal manures, that from horses fed on highly nitrogenous foocis, i. e., on grain foods, will 
heat best. The preparation of the manure is very simple. It should be gathered together in a pile, as fresh as may be, when if moist it will generally heat, no matter how cold the weather. If it does not start to heat readily, a few buckets of hot water poured into the center of the pile will often start it. When it gets nicely started the pile should be turned over, throwing the outside manure into the center of the pile and breaking up all the lumps. In a few days it will heat again and will then be ready to go into the frames, but do not put it into the frames until it is heating thoroughly. Clear horse manure heats too violently and should be mixed with about its own bulk of leaves or fine straw. The leaves used to keep frost out of the frames during winter now come in to good advantage for mixing with the manure. Of course, if the manure gathered has considerable straw in it this admixture is not necessary.

The way of putting manure in the frames calls for some little care. It should be broken up very fine, mixed with leaves or other material and spread as evenly as possible over the whole bed, taking special pains to have the frame well filled in the center, as it settles there much quicker than at the sides. is the manure is put in it should be packed down quite firmly by the feet, taking great care to have it evenly packed throughout. Now put on the sash and cover until it heats well all through the bed. If it does not start to heating quickly enough, a few buckets of hot water should be added. When well warmedi through, level off the top of the manure and cover with soil six inches deep. This soil should have been prepared in the autumn and protected from frost by mulching or put under the leaves in the bed; but if this provision has not been made the soil may be scarched for in cellars, under strawstacks, in the woods under leaves or elsewhere, or the soil may be thawed out by the use of sash and manure. As this latter process is tedious all expericnced growers prepare their soil in autumn.

After the soil is put on it should be left until it is warmed through and the weed seeds near the surface have germinated. Then remove the sashes and make the surface fine with a rake and the bed is ready to receive the seed. A hotbed made up in this way in Mar'ch will continue to give out heat five or six weeks, after which it will be practically a cold frame, but since 
after the middle of April the sun is pretty high and the bed well warmed, the plants will continue to flourish.

Hotbeds require more water than cold frames and more care in the matter of ventilation. They should not be started until a short time before one is ready to use them. If seedlings are to be raised in them to be later on transplanted, start only enough sashes to grow the seedlings and do not start other hotbeds until the seedlings are big enough to be removed into them.

For the ordinary farm garden four or five hotbed sashes are a great plenty and no more should be started than can be prop-

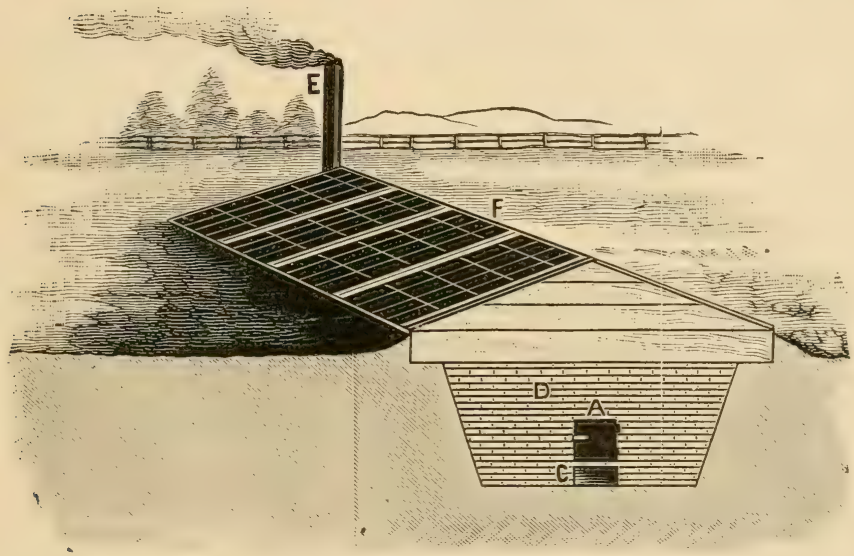

Figure 26.-Fire hotbed.

erly attended to. These should be started about the first of March. This number will be found sufficient for all the early radishes, onions, lettuce, cress and other greens for the table in early spring, and for raising tomatoes, cabbage and other vegetable plants to be set out later in the open ground.

Shutters and mats are used for covering the sash of hotbeds and cold frames at night to prevent too rapid radiation of the heat.

Fire Hotbeds.-Horse manure will undoubtedly continue to 
be used for warming hotbeds, no matter how much greenhouse construction or means of artificial heating may be cheapened, but there are some situations where it may be more economical and convenient to use a forcing bed or what is sometimes called a fire hotbed. This closely resembles a hotbed in outward appearance, but instead of being heated with manure a

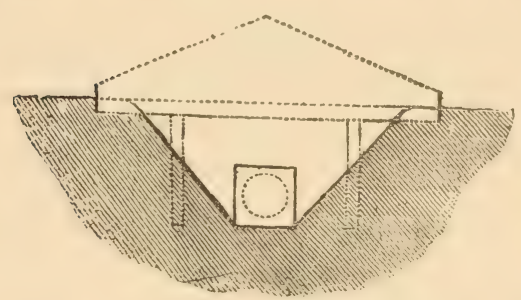
flue is used to take its place, and it is warmed by the smoke of wood, coal or other fuel. In this case a pit should be excavated, furnished with permanent walls and a good strong floor to support the soil in which the crops grow. Ten inch terra cotta or glazed drain tile is a cheap materiai for the flue, or brick may be used for this purpose. The furnace and the first eight or ten feet of the flue should be made of common hard brick and have a lining of fire brick set in fire clay. If the pit is not over thirty feet long the fire box should be at one end and the chimney at the other'; but if much longer it is better to have the chimmey orer the fire-box and to run the tile to the end of the house and return back to the chimney. This chimney should have dampers so arranged that when kindling the fire a drrect draft may be had into it, and after starting the fire the heat and smoke can then be forced to go through the whoie length of the pipe. This arrangement is desirable on account of the clifficulty in getting a draft through a long, flat, cold flue. In laying such a flue, it should rise slightly throughout its whole length fron firelox to chimney. The furnace should vary in sizo accorcinig to whether coal or wood is to be used for fucl. For wood the firmace should be 18 inches wide and arched over the required length. generally $4 \frac{1}{2}$ feet, with cast iron grate bars set in the walls. There should be an ash pit of suitable size, and both it and the fire-lox should have suitable iron doors set in brick. The illustrations llerewith show the general arrangement of such a house. It is a good plan to build a low shed for fuel on the enci where the furnace is located. 
The heat from a flue is very dry, and much more water is required when hotbeds are heated in this way than when manure is used as the source of heat.

A Greenhouse Hotbed.-A greenhouse may be heated by manure or a combination of manure and other artificial heat. In the following lines and illustrations is given the plan of what may be called a greenhouse hotbed which has been in very successiul operation at the Minnesota Agriculaural School. The description is from an article on the subject by R. S. Mackintosh, of the Division of Horticulture.

"There are disadvantages in hotbeds, as, for instance, the transplanting, ventilating, watering, etc., must be done from the outside even in severe weather, while in a house like thc one
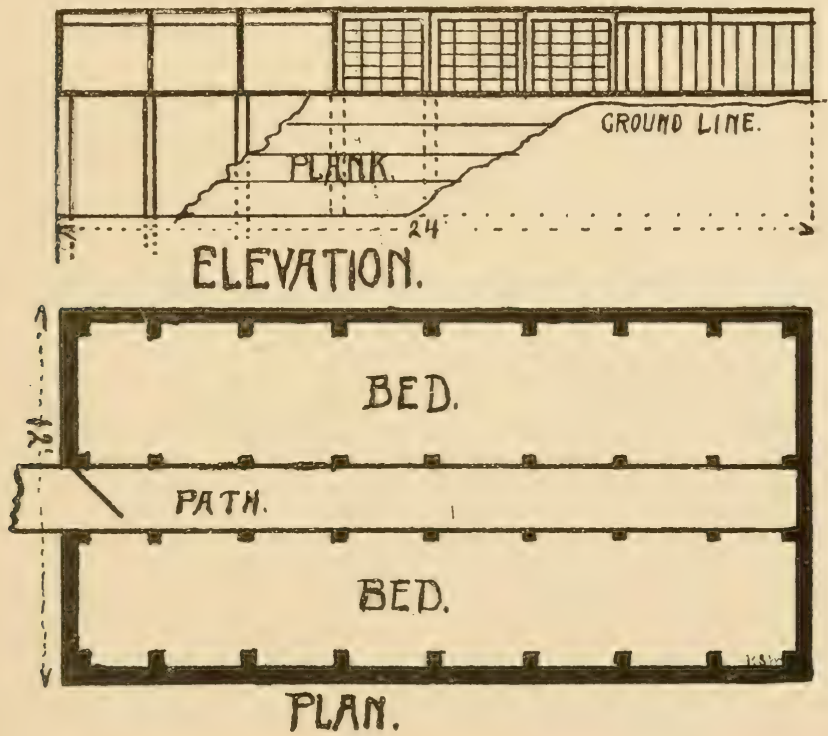

Figure 28.-Plan and elevation of hotbed greenhouse.

shown in the figure these operations can be carried on easily. The house is simply a hotbed built so as to allow a person to go 
inside to do all the work of caring for the plants. Figure 28 shows the general plan of the house. The size is $12 \times 24$ feet. The roof consists of sixteen sashes, each $3 \times 6$ feet. Any number of sashes may be used according to the size of the house desired. To receive the most sunlight the house should extend north and south; the light will then strike both sides of the plants. The south end of the house is glazed from the surface of the bed up to the rafter's. It is not necessary to excavate the full depth of four feet, because the earth that is thrown out can be used to bank up with on either side, making a terrace as sloping as desired.

The heat is furnished by two to three feet of well prepared manure in each bed, over which is placed five inches of soil.

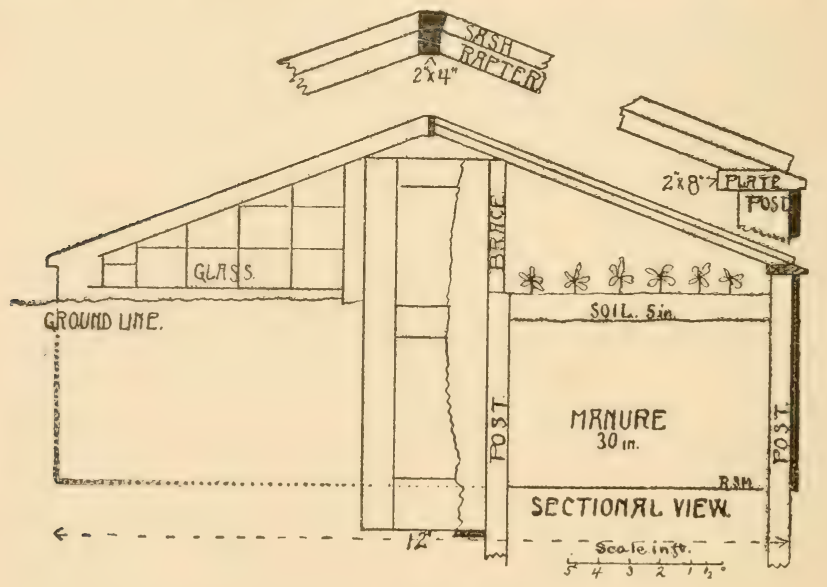

Figure 29.-Sectional view of hotbed greenhouse.

The sashes are iastened to the rafters by screws which prevents their being lifted by heavy winds and at the same time allows them to be removed very easily when desired to replace soil or manure. Ventilation is provided for by fastening one or more sashes with hinges at the bottom so they may be raiged as high as necessary at the top.

Many kinds of building material may be used in the con: 
struction of the wall, beds, etc. Lumber is used in the building shown in the figure, but brick or stone would be more durable, though it would add considerable to the first cost. The posts are three feet apart, extend about two feet below the planlis and are braced. The inside rows of posts need not be quite so strong as the outside ones, and need not be braced. When a house is not more than twenty-four feet long it will not be necessary to support the roof in more than one place. This is done by extending two of the middle posts to the rafters.

In figure 29 is shown a cross section of this greenhouse and the way the sashes and rafter's are joined at top and bottom. The sashes are cut so as to fit tightly at the top and the plate is beveled a little so as to allow water to run off quickly.

There are sixteen wooden shutters for covering the sashes on cold nights. These are made the same width as the sashes

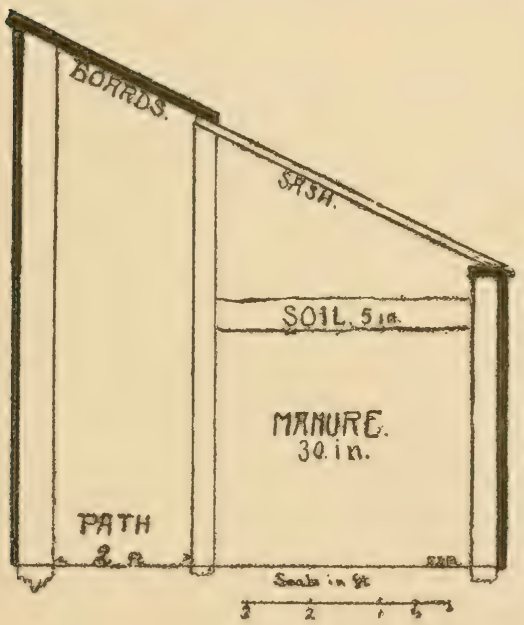

Figure 30-Cross section of lean-to greenhouse hotbed.

the glass as may be, and this fact should be carefully borne in mind. This style of house is susceptible of many modifications. It may be used as a lean-to on the south side of the dwelling, 
where it may receive a little heat from the houss. Its limitations are about the same as those of hotbeds. When such a house is intencled for use in winter, it might be an advantage to so plan it that the manure from one-half could be renewsd every five or six weeks.

\section{GREENHOUSES.}

Greenhouse is a term applied rather loosely to glass struotures of the larger sort having special heating apparatus, and used for growing plants. The more expensive structures are not referred to here, but only the simpler ones such as are most economical for use in the market and home garden.

A Very Cheap, and Yet Withal Serviceable Greenhouse, is described in "How to Make the Garden Pay" and the publishers

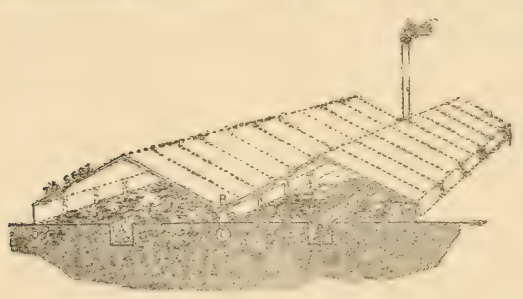

igure 31.-Market gardeners greenhouse. of it have kindly consented to the use of it here. It is called the "Model Forcing Pit." Figure 13 shows a cross section of this house which is made with a valley in the center, so that in point of fact it is two houses. The total width of both houses is twenty-six feet. The alleys are dug into the ground in each house eighteen inches wide and eighteen inches deep and boaried up on each side. The beds on each side are four fect wide, and the attendant can cultivate them when standing in the alley. The peak of the greenhouse is only four and a half feet above the ground level or six feet from the bottom of the alleys. The sides are only one foot ábove the ground, and are made of plank nailed to cedar posts and banked upon the outsile with horse manure in winter. The roof is covered wilh movale sashes 7 or $7 \frac{1}{2}$ feet long and of any convenient width. Common hotbed sash ( $3 \times 6$ feet) might be made to answer. but sash having larger glass than is generally put in them is best. Large sized glass is preferable, $12 \times 16$ inches being a good size. A light framework for the sash to rest on, similar in construction to that shown in figure 
of a greenhouse hotbed is necessary, and the sashes should be screwed down and renilation secured in the same way as there explained. In the center of $B$, where the two roof sections meet, the sashes rest on a plank 12 inches wicle cut out 3/4 by 8 inches, to form a gutter to carry off water as shown in figure 32 . The center planks rest on two rows of $2 \times 3$ inch posts, two and a half feet long and twelve inches above the beds; these posts are four feet apart in each row. The total length of the houses here described may vary according to circumstances. The house from which this plan is taken was 100 reet long. It was heated with a second hand tubular steam boiler which at an outside temperature of zero, has to carry about five pounds pressure to maintain a temperature of 65 or 70 degrees. Two inch pipes conduct the heat from the boiler, one line of pipe running up each side of the house and both returning through the center a.t $\mathrm{B}$, back to the boiler. The furnace room is an excavation 10x12 feet and six feet

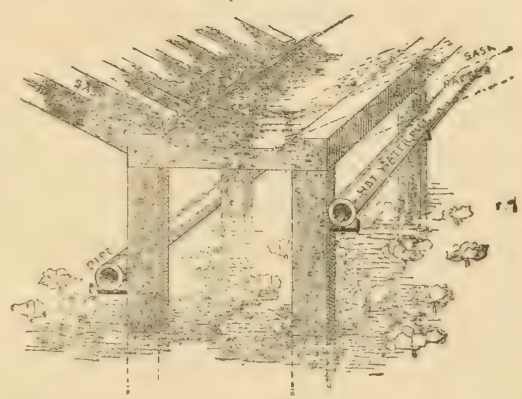

Figure 32.-Valley in market gardener's' greenhouse showing the way the sashbars are attached to the plate. deep at the northerly $\in$ nd of the house, built with a good wall and roof. The length of pipe required is 450 feet. In the extreme northern states mole pipe radiating surface would perhaps be required for best resilts. The entire cost of material for a structure of these dimensions, boiler and pipes included, amounts to about $\$ 450$. The cost of steam fitting will have to be acided to this, but the rest of the Work can be done by any man of ordinaly intelligence. Mr. Greiner, whose description has been largely followed in the above, says that he likes the pipes all above ground as here recommended for forcing vegetables, but if wanted for starting seedlings and for general propagating purposes the pipe had better be placed ten to twelve inches under the surface, and encased in an ordinary three inch drain 
tile as shown at $\mathrm{D}$, figure 31 . In sections where fuel is high priced the beds might be partially heated with manure.

Figure 33 shows a cross section of a lean-to house that is easily adapted to most locations, but especially suited to sidehills. It is twenty feet wide and may be made of any length desired. It should have a boiler room on one end or at the back side as is most convenient. It should, of course, extend east and west so that the slope will be entirely to the south or southeast. The walls are made of cedar posts tightly boarded up on both sides. The alleys are two feet wide and planked on each side. The roof is shown made of permanent sash bars but these

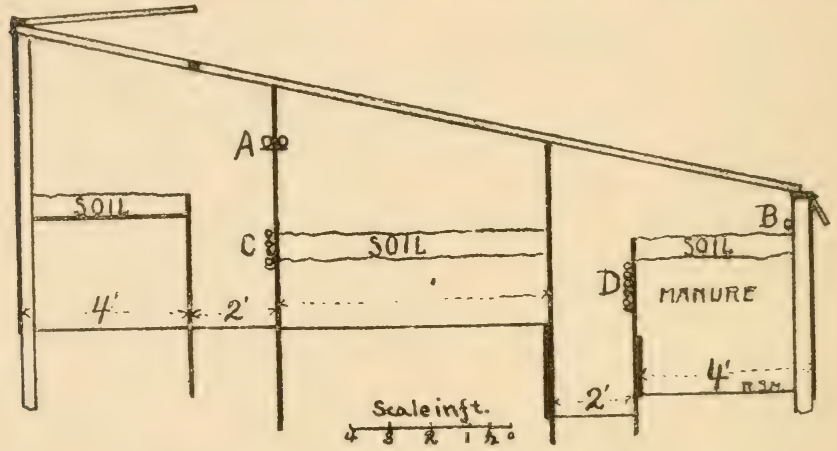

Figure 33.-Cross section of lean-to greenhouse.

might be made of movable sash as recommended for the model forcing pit. One ventilator is at the top of the roof and another is in the side wall. Two purlins extending the length of the house are supported by small gas pipe posts. The northerly bench is four feet wide, raised three feet above the alley and is filled with six inches of soil or it may be used for seed boxes. The center bench is eight feet wide and may be solid or raised. The southerly bench is shown filled with stable manure and is practically a hotbed. The same treatment may also be given the center bench. But where the plan is followed of making up a part of the benches with manure, it is well to have some or all of the roof glazed with movable sash, to facilitate the work of 
putting in and taking out the manure. The use of stable manure to supplement the heating apparatus is a practice that may be economically followed in locations where coal is high priced and stable manure abundant. The heating arrangement could bẽ either steam or hot water with the flow pipes high up near the roof, as shown at $\mathrm{A}$ and $\mathrm{B}$ and the returns at $\mathrm{C}$ and $\mathrm{D}$.

Methods of Heating.-There are practically three methods of heating greenhouses, viz.: by smoke flue, by hot water and by steam. Heating by smoke flue is described under the head of fire hotbeds. It has the merit of being easily and cheaply constructed by anyone having some little ingenuity. Even when made on the best principles it is probably more wasteful of fuel than a good steam or hot water apparatus, but where inferior fuel can be cheaply obtained a smoke flue may often be used to advantage. As for the relative merits of hot water and steam apparatus for heating, it is probably enough to say that each system nas its earnest advocates and that very often there is little advantage in favor of either. Where a very large heating plant must be used, making a night watchman necessary, it is best to plan for steam heating at low pressure. For small greenhouses perhaps a hot water plant is best. It costs more to put in the hot water apparatus because it requires more radiating surface since the pipes are not heated as hot as when steam is used. Some exclusive merits are perhaps justly claimed for a combination of hot water and steam, in which system hot water is used for heating in mild weather, while in severe weather the water is lowered in the boiler, a regulator is put on and the pipes are filled with steam. It is probable that an ordinary tubular steam boiler is the most practical kind to use either for a hot water or steam heating apparatus.

The amount of radiating surface necessary for heating a greenhouse wul depend on the temperature to be maintained and the location of the house. In a general way, one should figure that glass houses will require at least four times as much radisting surface as an ordinary dwelling house similarly situated and enclosing the same number of cubic feet of space. In estrmating the amount of radiating surface necessary it is always adrisable to consult some practical person acquainted with such problems. 


\section{MISCELLANEOUS MATTERS CONNECTED WITH THE} BUILDING AND CARE OF HOTBEDS AND GREENHOUSES.

The Sash for Hotbeds or Cold Frames should be about $3 \times 6$ feet or $4 \times 1 \frac{1}{2}$ feet in size; the glass free from blisters, of double strength and lapped not more than one-fourth of an inch. If lapped more than this water is liable to freeze the laps and crack the glass, and dirt will collect largcly becween the glass. It should be bedded in putty and mailed in, not puttied in. Common window sash might be used for the purpose in a small way and temporarily, but it is not strong enough to last well and besides as the sash bar's lun both ways and project beyond the glass the rain water cannot run off, but soaks the wood and leaks through into the hotbed, making it too wet in places. Also, the cross bars in common window sash make a needless extra shadow that is objectionable. Regular hotbed sash is made with sash bars running only one way so that the water falling on it runs off easily and quickly. Hotbed sash can be bought of sash manufacturer's or may be made at home by any person having a fair amount of mechanical ingenuity.

Shutters are desirable for covering the glass of hotbeds and cold frames. 'I'hey are generally made of second fencing, matched and dressed, and in size of the same width as the sash but about six inches longer with a six-inch cleat on each end.

The Mats are often made of straw, but cloth and burlap mats are sometimes userl. Straw mats are probably as goor as any kind and are easily made as follows Make a frame of $2 \mathrm{x} 4$ inch lumber the size of the mats desired; four feet wide and one foot longer than the sash is a convenient size. Stand this frame up against a wall and tightly stretch four or five tarred strings eight to ten inches apart from top to bottom so as to evenly divide the four feet of width. Have as many balls of lighter tarred strings as there are strings fastened to the frame and fasten one to each upright string at the bottom. Commence at the lower end by laying a wisp of straw, cut ends out, on the string at the bottom and fasten it there by twisting each of the smaller strings once around the straw and the upright strings. Next put on another wisp of straw and so continue until the frame is corered. Nats thus made are an admirable protection 
against frost and far better than shutlers alone. The advantage of having shutters in addition to the luats is that they keep the mats from getting wet. which makes tnem so heavy that they break easily in handling or they freeze solid and do not lie close or are clumsy to handle. Rye straw is best for mats and it is most tough and durable when cut partially green. It is often threshed by hand so that the straw can be kept straight, but it may be cleaned by a threshing machine by holding the bundle and only putting the heads into the machine.

Ventilation and Temperature are subjects of gieatest importance in growing plants under glass. The various classes of plants require different degrees of heat to reach their best development. For instance, lettuce, radish, cress and similar plants grow best at a low temperature, say about 75 degrees in the day and 40 to 50 degrees at night, and may even be frozen without serious injury, while tomatoes, egg plants, cucumbers and melons grow best at the higher temperature of 85 to 90 degrees in the day and 60 degrees at night. If the former plants are kept at a higher temperature than that given they are liable to become diseased and infested with insects. This is especially true of lettuce. On the other hand if the high temperature plants are kept much cooler they become sickly and weak, although tomato plants will grow in quite cool temperature. In admitting air to glass structures care shoulr be taken that the wind does not blow in on the plants. This is generally best accomplished in hotbeds and frames by blocking up the sash at the ends or sides with notched pieces of wood.

The temperature of any place, unless otherwise specified, is the temperature there of a thermometer in the shade. A thermometer with the full sunlight shining on it, will record about fifteen degrees higher than in the shade, which is a point always to be borne in mind in ventilating.

In the weather of early spring when the sun is getting high the middle of the days will be very warm and the nights still quite cool and frostr. It is then that a heginner often makes the mistake of learing the sashes of his hotbeds open late in the afternoon, and the beds cool off more than is desirable. At this season of the year but little rentilation is necessary, and frames and greenhouses should he shut up quite early in the 
afternoon, and the coveling put on to retain the heat as soon as the sun is low. In the warm weather of later spring, the sash of the hotbeds and frames may be removed in the day and kept on only at night. No exact rules can be laid down for ventilating, but it is quite a simple matter to learn, if one is observant and uses constant vigilance. Many persons just beginning to use greenhouses and hotbeds fail to get best results from them because they neglect the matter of ventilation. On cloudy mornings it may not be needed, but if the sun comes through the clouds it may warm the house or the beds in a very short time. so that when they are examined the whole crop has been injured by the heat. This is a most common cause of failure by amateur's in charge of greenhouses and hotbeds.

In nature the night temperature in which plants grow averages from fifteen to twenty degrees below that of the day, and it has been found in practice that when this condition is reverser the plants do not do well. This, of course, can be easily avoided by a little forethought. It is a bad plan, generally speaking, to ventilate much in cold weather, when the leaves are wet. On this account it is best to vater early in the day, so that the leaves may dry off before much ventilation is required.

Watering.-Plants that are growing slowly do not need much water, while those that are growing vigorously need a great deal of it. Growing plants need water whenever they are dry. In bright warm weather a rapid growing crop in hotbed or cold frame will need watering every day while in cloudy moist weather perhaps no water will be needed for a week. In fact, watering in cloudy weather seems to encourage disease. When applying water see that the soil is wet as far down as the roots extend. It is only the beginner who just wets the surface soil and thinks the plants sufficiently watered. If plants are wilting for want of water in the soil give it to them no matter what time of day, but it is always a great advantage in such cases to sharle as well as water them if the sun is shining. If a long continued spell of clouly weather is followed by a period of bright sumshine it is not uncommon to see plants wilting that have plenty of water in the soil surrounding them. In such a case it may be desirable to shade them somewhat in the middle of the day until they get use t to the sunlight. In cold weather 
it is a poor plan to water most of our plants at night since the water will cool off the air and the plants may be cnecked in growth, but in hot weather the reverse is true and plants seem to get more benefit from a good soaking in the evening, when they can have all night to take the water in, than if it is applied in the morning and followed by a hot sun. In watering hotbeds in very cold weather use a fine rose sprinkler and if practicable tepid water. At other seasons good lake or cistern water is perfectly safe, and is generally used by commercial grower's at all seasons of the year. Avoid getting the soil water-soaked.

The leaves of lettuce and some other plants are liable to burn if watered when the sun is shining brightly on them.

The Soil should vary somewhat in texture for different plants, but all garden vegetables will flourish in much the same lind of soil. For use in glass structures a light, friable rich, sandy loam is best. This is easily obtained when one has been using hotbeds by mixing some of the old rotted manure which has been used for heating them the preceding year with any good sandy loam. If sandy loam cannot be hadl, clay loam may be used and sand added to the mixture. The manure from old hotbeds is especially good for this purpose and should form about one-third of the bulk of the soil.

Boxes.-In the case of many plants having small seeds, it is a good plan to start them in boxes instead of growing them in beds, on account of the better care that may thus be given them. When plants are to be marketed it is often best to grow them in the boxes in which they are to be sold. Frequently, too, where plants are started in the greenhouse and then moved is the open ground it is must convenient to have them in boxes. For this purpose boxes should be about four inches deep and the size of a soap or cracker box, which may be cut down for the pinpose and thus make very cheap boxes. Of course where the market demands a certain number of plants in boxes, they will have to be made for the purpose. The lumber for these can be obtained at any box factory and what would perhaps be otherwise idle moments may be used in putting it together at trifling expense.

Substitutes for Glass.-Frames of the same size as hotberi sash are sometimes covered with prepared cloth or paper sub. 
stitutes for glass. Such covering, however, will not allow the sun's rays to penetrate it easily nor is it so effective in preventing radiation of the heat as glass, but under some circumstances it may be very desirable. Sash thus covered may often be used to advantage in the latter part of spring by alternating it on the frames and thus doubling the amount of sash at small expense. Or, they may be used in the warm weather of spring when the sash needs to be removed entirely in the middle of the day. They are excellent for covering beds filled with recently transplanted crops, since the light is less intense and evaporation less under them than under glass. A convenient way of forming these sashes is to make frames without sash bars but with one or two wires stretched across them to support the cloth or paper covering. Unbleached heavy cotton cloth may be used for this purpose, and the material for dressing it should be made of three pints pale linseed oil, one ounce acetate of lead and four ounces white resin. Grind the acetate in a little oil, then add the resin and the rest of the oil. Melt in an iron kettle over a gentle fire until well mixed and apply warm to the cloth. When paper is used it should be what is known as manilla wrapping paper. Paste this firmly and tightly on the frame with fresh flour paste. Dry in a warm place. Then wipe the whole of the paper with a damp sponge to cause it to stretch evenly. Dry it again, and apply boiled linseed oil to both sides of it and dry in a warm place. Use linseed oil that is free from cotton seed oil.

Shading the Glass.-In the hot weather of late spring or summer the sunlight is too warm for many plants in the greenhouse and it is customary to shade them. The amount of shade necessary will depend somewhat on circumstances. This shade may consist of lath screens laid on the roof, but more commonly it is given by sprinkling the glass on the outside, with a wash made of white lead and gasoline, put on with a spray pump or syringe. This is easily and cheaply done. It will generally come off by autumn or may be rubbed off with a coarse rag or brush. Whitewash is sometimes used for this purpose but it is too easily washed off by heavy rains to be desirable. 
SOME THINGS TO REMEMBER IN CONNECTION WITH BUILDING GLASS HOUSES FOR PLANTS.

(1) That all joints should be made tight and so far as possible so placed that water will not lodge in them.

(2) There should be just as much room in the beds and as little in the paths as possible.

(3) The glass should be as close to the beds as it can be and allow room to manage the crops grown in them. It should be of larger size for greenhouses than for hotbeds and in size not smaller than 10x12 inches, laid on sash bars 11 inches apart. The larger the glass the better. There is not so much breakage in large as in small glass.

(4) A permanent water supply is very desirable.

(5) The glass should be of good quality, free from blisters, bad waves or other imperfections and what is known as double strength glass.

(6) The heating arrangements should be sufficient to heat the house easily in coldest weather; in other words, it should be more than sufficient to maintain the proper temperature if crowded.

(7) Having the heating plant insufficient and then crowding it in severe weather, injures the heating plant and wastes fuel besides being a trial of patience.

(8) The ventilators should be large and carefully fitted so they will close tightly. When in the roof they should be open at the top. If they open at the bottom the moisture that condenses on the glass forms an ice ridge on them in cold weather and prevents their shutting tight.

(9) The smaller the sash bars and framing material in the roof the more sunlight can reach the crop.

(10) The greenhouse roof may be covered with movable sash, but it is generally found most desirable to use permanent sash bars. Where severe hail storms are frequent it might be well to use movable sash and take them off in the summer, but such places are rare exceptions. It requires a very severe hailstorm to break double strength glass, when at an angle, as in a roof, and practically there is little risk from this source.

(11) In the framing of greenhouses, for instances for pur- 
lins and posts, gas pipe can be used to good advantage. It is cheap and durable.

(12) All joints should be painted beîore being put together; all wood and iron work should be kept well painted.

(13) If putty is used in glazing the glass it should be bedded in it and nailed in, in this way: paint the sash bars, then run a thin coat of putty along them; bed the glass in it commencing at the bottom of the sash and lapping the glass onefourth of an inch, on the same plan that shingles are laid on a roof. Fasten the glass with round three-quarter inch brads, using four to each glass; put more liquid putty along the glass next to the sash bars and smooth it off with a knife even with the glass.

(14) Liquid putty is made by mixing one-third boiled linseed oil, one-third white lead and one-third common putty. If too thick, as may be the case in cold weather, add a little turpentine or benzine. It may be applied with a brush but the best way is to put it on with a bulb bought for the purpose; or a bulb may be made with leather, having a large quill through which to squeeze the putty. In the latter case there must be a hole in the side or end by which the bulb is filled and which may be drawn together by a string.

(15) Perhaps the most popular way of setting glass in greenhouses at present is by using square glass and butting the ends together. To do this to kist advantage no nails or putty are used and a special wooden cap is put on the sash bar which holds the glass in place. If destred to have the glass tight the abutting edges may be just touched with white lead before being put together. This makes a very satisfactory roof. 


\section{CHAPTER VII.}

\section{INSECTS INJURIOUS TO VEGETABLES.}

In this chapter only the more common insects infesting garden vegetables are referred to. There are many others that almost yearly cause some damage to our crops and which in occasional years cause serious loss. But to enumerate them would require more space than can be afforded here. In dealing with them it is well to remember that biting insects, such as potato beetles and blister beetles, are generally most surely destroyed by arsenical poisons such as Paris green and London purple; while sucking insects, such as plant lice and chinch bugs are not affected by them but are most readily destroyed by external applications such as tobacco water and kerosene emulsion. We should also remember that in our war upon injurious insects we have the support of most of the birds and of the moles and shrews, and these should be protected as the friends of man rather than be destroyed as is too often the case among thoughtless or ignorant people. Moles and shrews are especially useful since they work under ground, and feed largely on various insects that are difficult to destroy on account of their living in the soil. It is perhaps no exaggeration to say that the shrew (often called mole) will eat its weight of insects each day. Insects are also liable to attacks of parasites or of fungus and other diseases, which destroy them in large numbers and often in a very short time.

When insects appear in small numbers hand picking is often a very efficient remedy, but when they become very abundant some other method of destroying them must be devised.

INSECTICIDES AND METHODS OF DESTROYING INSECTS.

Pyrethrum is the insect powder of the stores. It is made by grinding the flowers of the pyrethrum plant which closely resembles the common oxeye daisy. It is not poisonous to higher organized animals although very destructive to many kinds of insects. It is frequently adulterated and can seldom be obtained 
of good quality. It also deteriorates very quickly when exposed to the air. On these accounts it is often very difficult to get satisfactory results from that obtained at the stores. When used it should be diluted with about five times its bulk of flour, with which it should be kept in a tight vessel for at least twenty-four hours before using in order to get best results. When thus confined it takes up the poisonous principle of the pyrethrum. It should always be kept in an air-tight receptacle.

Paris green is a refuse product composed of ar'senious acid and copper and is probably as safe as any arsenic compound. It is only very slightly soluble in water, and is used with water at the rate of one pound to one hundred or more gallons of water; it is also used when mixed with dry substances, at the rate of one pound to fifty pounds of flour or one hundred pounds of land plaster, road dust or sifted coal ashes. In using it with water the addition of an equal amount of milk of lime often prevents injury to leaves.

London purple is composed of arsenious acid and lime. It is often much cheaper than Paris green but varies more in its composition. On account of its being lighter than Paris green it does not settle so quickly when put in water. It is used in the same manner as that substance. When used in water an equal amount of milk of lime should always be added to neutralize the free acid which it sometimes contains in injurious quantities, and which may burn the foilage of tender plants. London purple adheres to the foilage of plants longer than Paris green.

Tobacco is very useful for destroying some kinds of insects in the garden and greenhouse. It is especially effective aginst plant lice and soft-skinned hairless caterpillar's. Where smoke from it can be confined around the plants, as in greenhouses and hotbeds, it is common to use it in a smurge, but when thus used it should be kept from blazing. It is also used in powdered form to keep off some insects. A more common and effective way of using it, is as a decoction in water at the rate of one pound of tobacco stems, leaves or dust to two gallons of water. The tobacco should be boiled in the water for twenty minutes. When cold the decoction should be used undiluted with a syringe, spray or otherwise. The decoction will not keep more than a few days 
without spoiling. Tobacco is an excellent fertilizer as well as insecticide.

Kerosene emulsion is a valuable insecticide. It kills by contact and is of greatest importance for destroying sucking insects such as lice, scale insects and soft caterpillars, but also kills many biting insects. It is made as follows:

Kerosene oil, 2 gallons, 67 per cent; common soap, or whale oil soap; $1 / 2$ pound, 33 per cent.

Two pounds of soft soap may be used in place of the soap recommended.

Dissolve the soap over a brisk fire, remove and add the kerosene while the water is hot. Churn the mixture or stir rapidly until a creamlike emulsion is secured. If well made the kerosene will not separate but on cooling the emulsion will thicken into a jelly-like paste that adheres without oiliness to the surface of glass. Soft water will give far better results than hard water for making kerosene emulsion, and soap that is made with potash $\mathrm{Oi}^{\prime}$ soda lye, such as home made soap, is far better than most of the soap of the stores, as they do not emulsify easily. For plant lice, dilute the emulsion recommended with from twenty to twenty-five parts of cold water. The strength of the application will necessarily depend on the insects to which it is to be applied. For such insects as soft-slinned caterpillars the emulsion should be diluted with not more than ten parts of water.

Kerosene and milk emulsion may be used as follows:

Kerosene ................... gallons.

Sour milk ................... gallon.

These readily form an emulsion when thoroughly churned together. It should be used the same as other soap and kerosene emulsion mentioned. Sweet milk does not emulsify readily but if a little sour or even if very sour, it unites easily with the kerosene. This is the best emulsion where the water is very hard.

Carbon bisulphide is a very inflammable material with a disagreeble odor and readily vaporizes. It should be handled with the same precaution as gasoline which resembles it in appearance. The fumes which it gives off are very heavy and are poisonous to animal life when confined with it. On account of these properties it is used for lilling weevils in grain or peas, 
beans and other seeds, and for killing gophers, mice or other creatures in their holes. The method of using it for grain weevils, is to fill a barrel or other tight receptacle nearly full of seed, then sprinkle on an ounce of the liquid for each one hundred pounds of seed and cover the vessel tightly for several hours. It does not hurt the grain which is just as good and looks as nice as ever after being treated. The germinating qualities of the seed are not injured by this treatment. When used for killing moles, gophers and mice, the material should be put on cotton or other absorbent and placed in their holes closed with earth over the cotton.

Catching Insects by Light at Night.-By suspending a lantern at night over a tub of water having its surface coated with kerosene many night flying insects can be destroyed. Among those that can be caught in this way are cut worm moths, the clicking beetle (which is the mature form of the wire worm), and the May beetle (which is the mature form of the white grub). When these insects become especially abundant this method of catching them is worthy of trial. The objections to it are: (1) that it is the larvae and not the flying form of these insects that do serious injury; (2) few persons are so far sighted that they can be persuaded to attack insect enemies until they are suffering from their ravages, and the benefits of this method will not be felt until perhaps the following year. (3) The observations of Dr. Otto Lugger show that insects have generally laid their eggs before they fly much, and only the male insects of some species fly, and the females are nearly or quite wingless. It is obvious that in such cases catching the flying insects will do little if any good.

Applications of Insecticides.-In applying insecticiles it is generally important to begin their use as soon as the insects appear and not wait until the plants have been weakened and set back by their attacks. There are many and various machines for distributing insecticides. The machine best adapted to this purpose will c.epend much on the insecticide used and the extent of the operations contemplated. For applying liquid compounds some of the many forms of spray pumps will be found best. For the small garden where there is a variety of crops grown, 
perhaps what is known as knapsack spray pump is as convenient

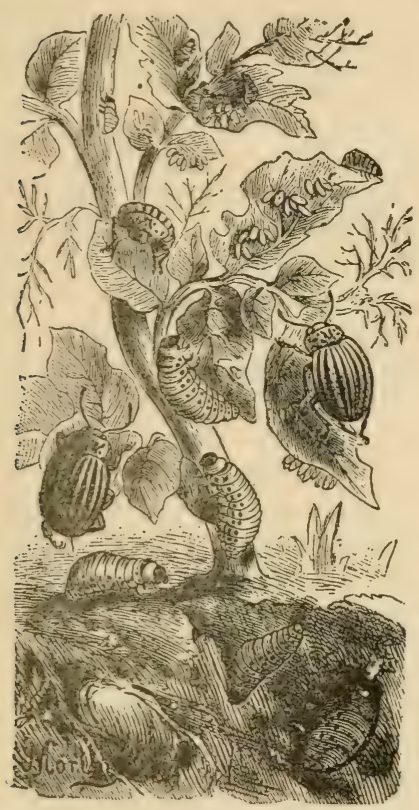

Figure 34.-Colorado potato beetle in all stages. as any general purpose machine. Where potatoes are grown on a large scale some special spray pump that can be geared to the wheels of a wagon may often be the best to use. Where insecticides are used in powder form it is a good plan to scatter them on the plants through a coarse linen bag or fine wire cloth. When such material needs to be ejected with force, a fan or bellows may be used. It is always best to use poisons in a liquid form when practicable since it is the most economical and effective method of applying them. No insecticide should ever be used in a large way, until it has been tried on a small scale to see what its effect will be on the crop to be treated, since plants may be more susceptible at one time than at another to applications of this nature.

\section{COMMON GARDEN INSECTS AND METHODS OF} DESTROYING THEM.

The Colorado Potato Beetle (Doryphora decemlineata.) The Colorado potato beetle is so common and so well known by every farmer and gardener in this country that it needs no description here. It came originally from the Rocky Mountain region where it fed on the native sandbur (Solanum rostratum) which is closely allied to the potato, but when this insect came to know the cultivated potato it preferred it to its original food and has since become a very dangerous pest to this vegetable. The orange colored eggs, varying in number from a dozen to fifty, are generally laid on the under side of the potato leaf. 
They hatch in about a week into sluggish larvae which feed upon the leaves, never leaving a plant until all the leaves are gone. They also feed to some extent upon tomato and egg plants. When fully developed the larvae descend to the ground where they pupate and emerge as perfect beetles. There are three broods each season. The beelles winter over in potato fields.

Remedies.-The number of these pests varies greatly from year to year. The chief remedies are arsenical poisons applied to the foilage. For this purpose Paris green and London purple are commonly used. The method of applying them varies much. It is a common practice to use one pound of Paris green to 150 gallons of water. This must be constantly agitated while in use or the poison will settle to the bottom of the vessel. London purple may also be applied in water, but as it varies somewhat in composition and is liable to contain a dangerous amount of free acid, it is safest to use with it an equal amount of milk of lime. It is also a good plan to use milk of lime with Paris green. Some experiments show that about one pound of lime, one pound London purple and about seventy gallons of water, is a safe and satisfactory formula to use for this crop. When thus applied the work may be done with a spraying machine, a watering pot or brush broom, but the spray pump is the most economical. On a large scale, some kind of a spraying apparatus is necessary.

These poisons may also be safely applied when mixed with one hundred times their bulk of flour, sifted ashes or road dust or mixed with one hundred pounds of land plaster. When thus used they are easily applied by means of a coarse linen bag. There are a number of proprietary insecticides for the potato beetle but they generally depend for their success on the arsenic they contain. But no matter what insecticide is applied, in order to do the most good it should be used as soon as the young larvae can be seen on the leaves.

The Imported and Native Cabbage Worm (Pieris sp.).The imported cabbage worm resembles our native species and both of them are very destructive to cabbage, turnip, caulifiower and similar vezetables and to such flowering plants as mignonette, stocks and nasturtiums. They feed on the leaves and will often destroy the cabbage crop unless preventive measures 
are taken. The worms of the imported species are green in color, while our native species are bluish with yellow stripes. The butterflies of both species are much alike. They are gener-

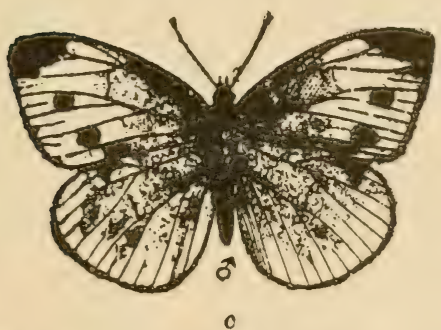

Fig. 35. 'Imported Cabbage Wórm. (a) Lapræ

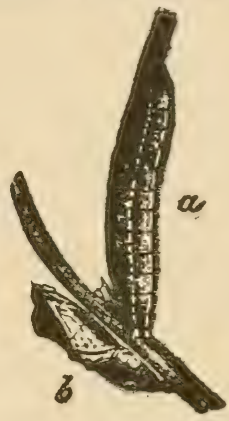

(b) Chrssalis. ic) Male butterfis.

ally white with indefinite black marks above and yellow or green markings on the underside, and are commonly seen flitting over fields of cabbage or of other of its food plants during the day time. The full grown caterpillar is about an inch and a half long. The winter is passed in the chrysalis stage hidden away in sheltered places and from

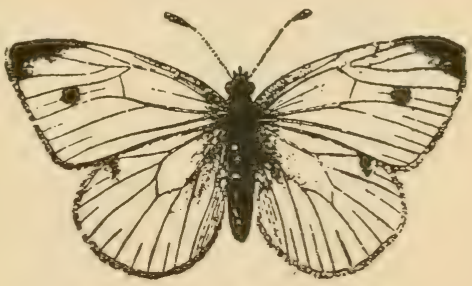
these the adult butterfly emerges in the spring and lays her eggs on the under side of the leaves where they hatch in about one week. There are several broods in a season.

Remedies.-Pyrethrum powder, mixed with five times its bulk of flour and dusted into the cabbage just at nightfall is a good remedy. The flour should be mixed with the pyrethrum overnight. In a small way hand picking may be successfully resorted to. If the worms are troublesome where cabbage is grown on a large scale it is customary to use arsenical poison mixed with flour as recommended for the potato bug. The poison cannot be applied in water as it will not stick to the leaves. 
These, it is evident to anyone, can be safely applied before the plants commence to head, and recent careful trials and analyses of cabbage thus treated with Paris green, show there is very little danger in using it at any stage of the plants. It is the simplest of remedies and effective yet not dangerous. There are parasites that attack and kill the worms and chrysalides, and Dr. Lugger has shown clearly that they sometimes may be destroyed very rapidly by disease as well as insect parasites. It is not uncommon to have nearly all these worms die in the latter part of any season from one or both of these causes.

Cabbage Plusia. (Plusia brassicae.)-The cabbage plusia eats irregular holes in the leaves, and burrows into the heads of the cabbage. The parent insect is a moth of a dark-gray color

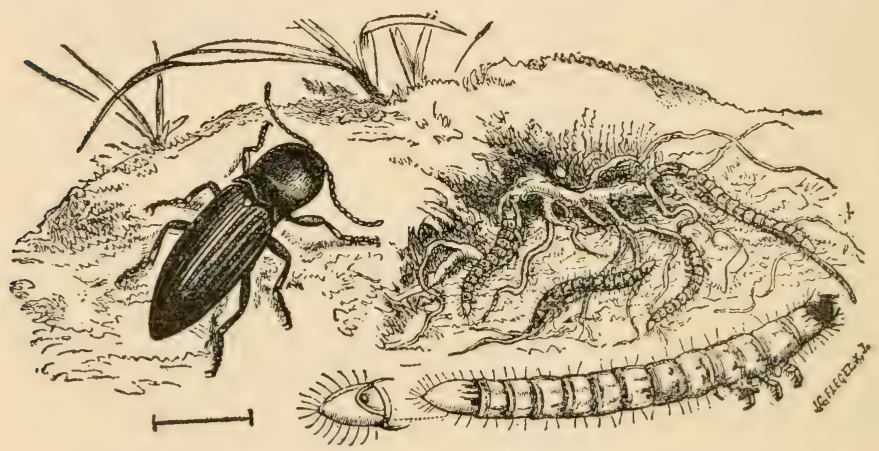

Figure 37.-Snapping beetle or wire worm with larvae.

distinguished by a silver mark on each wing. The eggs are laid on the upper surface of the leaves singly or in clusters. They soon hatch into pale green translucent worms, marked with paler longitudinal stripes on the back and sides. When fuil grown these are about two inches long. They resemble spain worms in their mode of locomotion, hence are easily distinguished from the cabbage worm. The full grown caterpillar spins a cocoon, generally on the under side of the cabbage leaf, in which it undergoes its changes. The insect winters over in the pupal state. The remedies for this pest are the same as those 
recommended for cabbage worms and it is also subject to diseases and parasites.

Wire Worms or Drill Worms (Elator).-Wire worms cause damage by boring into potatoes and some seeds in the ground. They are the larvae of a snapping or clicking beetle, so called from the ease with which, if laid on their backs, they spring into the air with a clicking noise. The larvae are slender wirelike worms having a glassy tough skin of a yellowish or brownish color. The larvae stage lasts for two and possibly five years; it is therefore no small job to clear a piece of land badly infested with the pest. Naturally, wire worms live in grass land where the harm they do is not apparent, but when such land is planted to corn or potatoes and the worms are thus depived of their natural food they may become very troublesome.

Remedies.-Late fall plowing is desirable for land infested with wire worms since it exposes and thus kills all that are leady to pupate. By clean summer fallowing the land one season the worms are starved out, if no plants whatever are permitted to grow on it.

Cut Worms (Agrotis sp.).-Cut worms often cause serious injury by eating vegetable plants. They are generally most in-
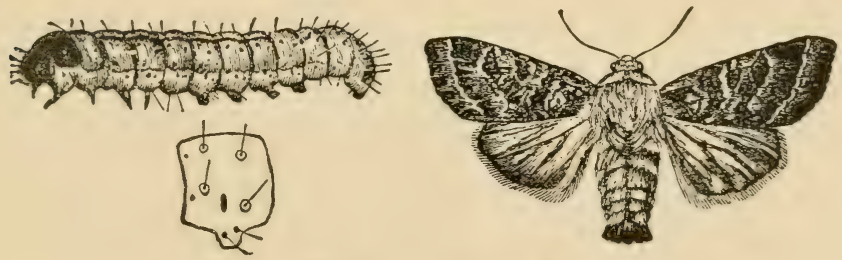

Figure 38.-Cut worm and moth.

jurious while the plants are small, when they often bite off young cabbage, bean, corn or other plants close to or just under the ground and thus destroy them. Their work is most perceptible in the spring on account of the small amount of growing vegetation at that time, yet they also work in the autumn. True cut worms are the larvae of several night flying moths which appear late in summer. The female deposits her eggs late in the summer. These soon hatch into worms which enter the 
ground and live near the surface on the tender nots of grass and other plants until the approach of cold weather. They then descend deeper into the ground and remain torpid until spring, when they come to the surface and again commence their depredations. Cut worms when full grown, are from one and a quarter to one and three-quarter inches long and rather large in diameter as compared with the length. Their skin is of some dull color, smooth, with often dull stripes and bands.

Remedies.-Cut worms are most injurious in sod land or land on which weeds have been permitted to grow in autumn, or in land adjacent thereto. They are not liable to winter over on any land that is kept free from weeds and grass in autumn, since there is no food for them in such places. The worms feed almost entirely by night and hide during the day time under clods or just under the surface of the ground near where they have been working. In a small way they may be dug out and destroyed, but in fields and on a large scale this is impossible and a good remedy is to scatter baits of poisoned clover through the fields. This is easily prepared by dipping clover into Paris green or London purple and water. A dough made of bran and Paris green sprinkled about the plants will often be found very satisfactory in destroying cut worms, and sometimes will work even better than clover for this purpose. Where cut worms are abundant a larger amount than usual of seed should be planted that a good stand may be secured even if the worms do get some of it. When plants such as cabbage, cauliflower and tomatoes are planted out, it is a good plan to wrap the plants with pieces of stout paper extending about an inch below and three inches above the ground. When boxes or tomato cans are set around plants for shade, they afford a good protection from this pest. Protection from cut worms to hills of melons, cucumbers and similar plants, may be given by pieces of pasteboard or tin. These should be cut about three inches wide and sufficiently long to encircle the hill. They should be set about an inch deep in the ground. Spraying the plants with London purple or Paris green is a good remedy. The moths of cut worms, as well as such insects as adult wire worms and grub worms may be killed at night by means of a lantern suspended over a tub of water having a little kerosene on its surface. This should be done late in the summer when the moths of cut worms are abundant. 
Striped Cucumber Beetle. (Diabrotica vittata.)-This little

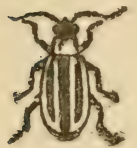

beetle attacks squashes, cucumbers and melons when they are young. By eating the foliage and tender stems they may cause the death of the young plants. When abundant it is a very difficult pest to combat. It appears in the spring

Figure 39-Striped cucumber beetle.

at just about the time the young squash plants are out of the ground, having wintered over in brush piles or other places affording protection. The beetle lays its eggs on the roots of corn where the young do considerable damage. These worms, are full grown in about one month from hatching They then leave the roots, make a little cavity in the earth near by, and undergo their changes. The insects spend the winter in the beetle stage. The beetle is about a quarter of $a n$ inch long and is striped with yellow and black. It is very quick in its movements but does not fiy much except in the middle of the day.

Remedies.-An extra amount of seed should be sown so as to secure a good stand

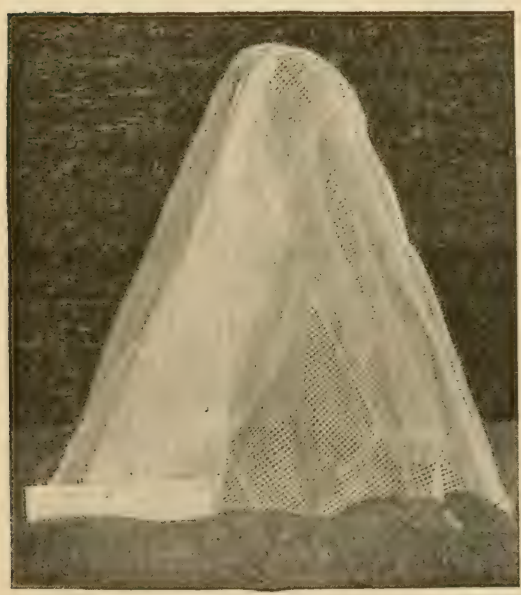

Figure 40-Cheese cloth screen for protecting cucumber, squashes and melon vines from the striped beetle when young. and still allow some for the beetles. Dusting the vines, stems and leaves when they are moist, with air slaked lime, road dust or similar material containing a little Paris green or other poison, is quite a protection, and if persistently followed up after every rain will generally prevent serious loss. But care should be taken to put the dust on the stems as well as the leaves. Paris green and water is also a good remedy and is applied the same as for the 
potato beetle. Tobacco dust is also an excellent preventative used in this way. Some gardeners having quite extensive plantings, and many who are working in a small way, prefer to cover each hill with a box or frame covered with cheese cloth. In this case, the edges of the box or frame should be sunk an inch or so in the ground to keep out the bugs. Frames for this purpose are readily made of barrel hoops cut in halves and fastened together or of three slender sticks forming a sort of tent. This method allows the light and air to circulate freely around the plants, while at the same time they are perfectly protected and at slight cost.

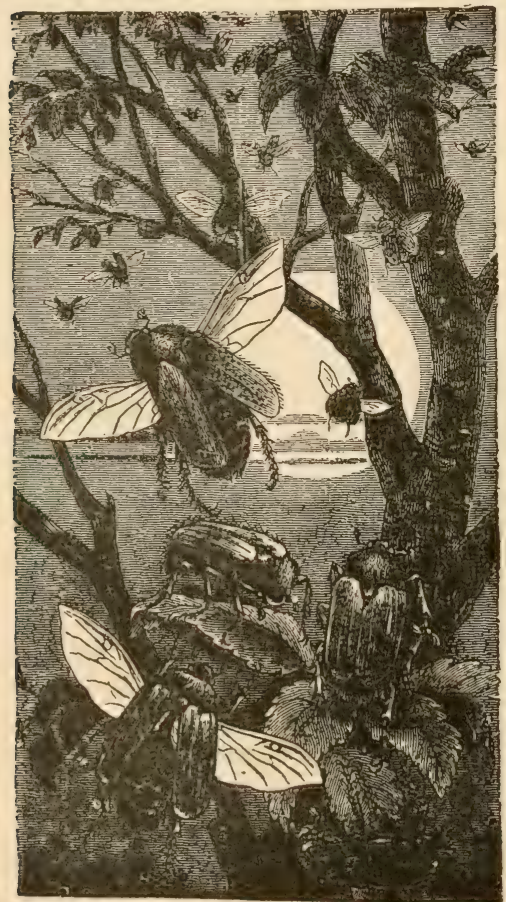

Figure 41.-May beetles at night.
White Grub or May Beetles (Lachnosterna fus ca. - The in sect known as the white grub is the larval stage of the May beetle. It lives in the land where it feeds on the roots of plants. The mature insect is a dark brown beetle, often nearly black with breast covered with yellowish hairs. The body is threefourths of an inch long and about a half inch in diameter. They fly at night and are wellknown insects of the spring of the year. As beetles they feed on the leaves of various plants. The females lay their eggs among the grass roots in a ball of earth. These hatch in about a month and the grubs be

gin to feed on the roots near by. It requires two or three years for the grubs to get their full growth and they then undergo their 
changes and emerge in the spring of the third or fourth year as the beetle described.

Remedies.-The grubs are eaten by birds, moles and skunks. They are not apt to be abundant in any but grass land recent?y broken up. They are exceedingly hard to destroy on account of their remaining so long in the soil. When young plants are seen to be wilting from the effects of the grub, they may sometimes be taken up, the grub removed and the plant reset. When lawns or other grass lands are badly affected they should be broken up and grown in some cultivated crop for two years. The beetles should be trapped when they become very abunclant as recommended for cut worm moths. Such animals as moles and shrews should generally be permitted or even encouraged in our lawns and gardens and the little damage they generally do suffered patiently, since they are among our best friends and destroy immense numbers of white grubs and other insects that live in the ground and are difficult for us to reach. They are seldom abundant except where insects are numerous.

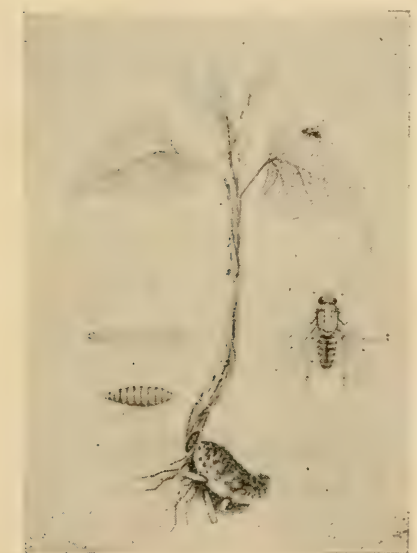

Figure 42.-Bean and onion mag. gots on young bean plants.

Maggots (Anthomyia sp.)-They are often de structive to the seed or roots of a variety of plants including onions, cabbage, cauliflower and similar plants; they also attack the seed of corn, peas, beans and other vegetables in some seasons.

Life History. - The maggot here referred to is the larvae of a fly somewhat resembling the house fly, but brown in color. The eggs are laid in or near the surface of the ground, generally on the food plants and hatch out in about two weels into maggots, that commence to feed at once and finally become one-half inch long; these 
change in two weeks more to flies. This insect winters over in the pupa state in the ground.

Remedies.-When this insect attacks onions the infested plant turns yellow and looks sickly and they should be pulled and destroyed. The same treatment should be given to any onions that may be found infested at harvest time. When onion land becomes badly infested with this pest crop rotation should be practiced and no onions should be raised near it for a year or two. When beans, corn and peas are affected, the seed should be treated with a very thin coating of coal tar and afterwards rolled in plaster or other dust. The coal tar may be applied as follows: Spread the grain out in a warm room on the floor about six inches deep and wet it with warm water; sprinkle on a very little warm coal tar (about one tablespoonful to one-half bushel) until each grain is coated; then roll it in plaster to dry it off. If this is carefully done the grains will not stick together and may be planted by seed planter. This treatment also prevents crows, gophers and squirrels from pulling newly planted corn.

When it attacks cabbage, cauliflower and similar plants it may be destroyed by kerosene emulsion, since the maggots work on the stem and roots of the plant near the surface of the ground and such an application would be practicable in this case, while in the case of many other crops such as onions, beans, etc., it might be quite out of the question on account of the large number of plants that would have to be treated to make it effectual. In the case of cabbage however it may be prevented from entering by inserting the plant through a small piece of tarred paper, that is allowed to remain flat on the surface of the ground.

Cabbage Flea Beetle (Halticus sp.) - There are several in. sects closely resembling each other and known as cabbage flea beetles that feed on the surface of the leaves of cabbage, turnips, radish, cauliflower, etc., and various wild plants. They are very injurious to the very young plants if allowed to have their way, but when the plants are nicely started they do not seem to be seriously incommoded by this pest. These beetles are very small and move very quickly. The adult insect is black or nearly so; some of them lay their eggs near the roots 
of the food plants, where the larvae do some damage; in other cases the eggs are laid on the under side of the leaves and the larvae mine into them and live between the upper and lower surfaces. But their chief damage is as heetles, in which form they pass the winter. One species of flea beetle is sometimes destructive to potato vines.

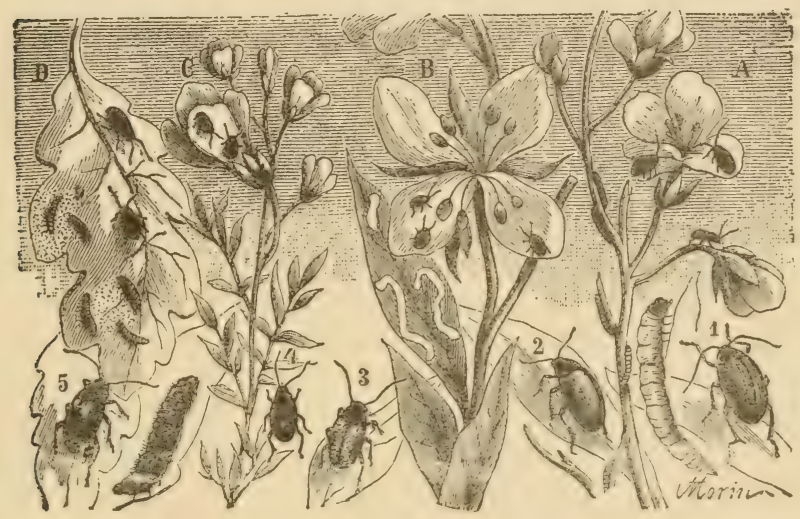

Figure 43.-Different species of flea beetles with their larvae.

Remedies.-Since these are biting insects they are readily killed by Paris green or London purple in the usual proportions. If the plants are kept dusted with air slaked lime or plaster they are measurably protected from this insect. But the latter applications are greatly improved by adding a little poison to them.

Leaf Lice or Aphides (Aphis sp.)-The varions kinds of leaf lice, otherwise called aphides, that live on plants have very much the same general habits. They are all sucking insects and increase with great rapidity when their fool plants are abund- 
ant. They generally winter over in the egg state. The summer broods are often brought forth alive without the intervention of the egg state. Kerosene emulsion and tobacco water are the usual remedies, but hot water and pyrethrum will also destroy them. Leaf lice are eaten by the larvae of lady bugs and they are also subject to attacks of parasites. When the lice are coated with a meal-like covering that sheds water and prevents their being wet by insectides, they should first be sprayed with strong soal) suds to remove the mealy covering and then the insecticide may be applied successfully.

Cabbage Lice or Aphides (Aphis brassicae).-These are light brown insects covered with a floury substance. They attack turnips, caulifiower, rutabagas and similar plants, as well as the cabbage. They work generally on the lower sicle of the leaves where they collect most abundantly. They are most numerous in dry seasons. The lemedies for them are those given under the general head of leaf lice but in ardition to those it is a good plan to burn or compost all the old (ab)age leaves and stumps, since the eggs winter over attached to them.

Sweet Corn Moth or Tassel Worm (Heliophila unipucta.) This is the boll-worm of the south. It eats into the green grain of the corn. But is seldom very troublesome at the north. Dr. Lugger thinlis that it does not winter over in the extreme northern states, but that the moths come from the south each year. The only remedy is hand picking. It is doubtful if they will ever become very injurious in the northern states, since they do not begin their work there until late in the season.

Parsley Worm or Celery Caterpillar (Papilio asterias.)-This worm eats the foliage of celery, carrot, parsley and allied plants, but is not very often injurious. The mature insect is a leautiful large black butterfly having yellow and blue spots on its wings. The eggs are laid on the foliage and hatch into small caterpillar's less than one-tenth of an inch long, which when full grown are one and a half inches long. It has bright yellow markings. The remedy is to hand pick the worms, which are seldom abundant. 
Chinch Bugs (Blissus leucopteris.)-The chinch bug does it trouble any of our garden products except corn, but is sometimes very injurious to this vegetable and

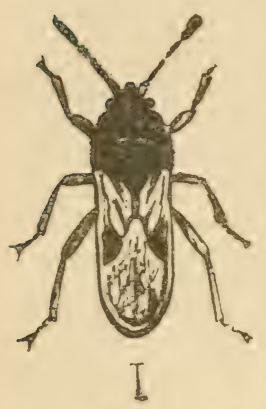
may kill it in a very few days if neglected. This is a sucking insect that winters over in the adult state under leaves and in dry protected places generally. When full grown it is about one-seventh of an inch long with white upper wings which have two well defined black spots on them. When crushed they have an offensive bed-bug-like odor, This insect is not affected vy cold weather, but succumbs quickly to moisture. The female deposits her eggs near the ground upon the stem or roots of wheat, oats, grasses, etc.

Re:nedies.-The burning of rubbish accumulations along headlands, fences, etc., in the winter or early spring in infested localities will destroy many. They always infest the small grains before they do corn.

While these insects have wings they use them but little in their migration in summer, but they travel on foot and often in sreat numbers. Taking adrantage of these peculiarities they may be kept from corn fields by piowing deep furrows in their way, which should be turned back as soon as filled with bugs and new furrows made. Fences of boards six inches high with the upper edge kept covered with tar will keep them out, but holes in the ground should be made at intervals along the line of the boards, which when full of bugs should ve filled in with earth, and new holes made. A dusty headland or road is rery difficult for them to go through. If they finally reach the corn they will readily succumb to kerosene emulsion. Much is being done to rid the grain fields of this pest by infecting the bugs with disease. This works most rapidly in moist weather, but other remedies should not be put aside for this one.

Bean and Pea Weevil (Bruchus sp.)-The insects known as weeril are quite common in some sections. They work in the seed of beans and peas. The adult insects are small beetles which lay their eggs in the flowers where they soon hatch and 
the young larrae eat their way into the immature seeds. The hole by which the larva enters the seed grows completely over, so that the seed appears unimpaired externally. In the seed the larva does not touch the germ, though it may eat up a large part of the starch. The larva undergoes its changes in the seed, and when these have been completed the beetles emerge through quite large holes in the shell of the seed. While seed that is infested may germinate it forms only weak plants that are very sure to fail to mature a full crop. Similar insects also attack corn. There is another species that breeds in stored grain, peas and beans, etc., but it is not common here as yet.

Remedies.-These insects are generally somewhat Iocal in range. Whenever any locality is infested the date of planting should be delayed two weeks, by which means the beetle fail to find the crop ready when they are ready to lay their eggs. This trouble generally comes from sowing infested seeds. These may be separated from the good seed by throwing them into water, when the good will sink, but those infested will float. Another method is to treat the seed with carbon bisulphide as recommended under that head. If the seed is kept over two years the beetles will have come out. The species that breeds in the grain is most easily destroyed and kept out of the seed by using bisulphide of carbon as recommended.

Squash Vine Borer (Aegeria cucurbitae.)--The squash vine borer is the larva of a moth. The eggs are laid on the stems of the young plants near the roots of cucumber, squash and melon vines. The larvae on hatching burrow into the stem and follow along the center, which causes the plants to wilt an finally to die. The full grown borer measures about one inch in length and has a whitish body with a brown head. The borers leave the stem the latter part of the summer and winter over near the surface of the ground in cocoons composed partly of earth. The moth emerges the following spring.

Remedies.-This insect is not yet found in this section but is common in the eastern states, and where it is found all withered or dead vines should be destroyed. When vines have only commenced to wilt the borer may often be cut out and the vine recover. It is also a good plan to cover several of the 
lower joints of squash vines with earth to encourage the formation of extra sets of roots at these places.

The Squash Bug (Anasa tristis.)-This insect makes its appearance the latter part of June or the first of July. The females deposit their brownish-yellow eggs in small patches on the under side of the leaves. These hatch into nymphs that suck the sap of the leaves, often seriously injuring them. The full grown bug is a little over one-half inch long and a rusty black color above and yellowish beneath. They emit a disagreeable odor when touched. They winter over in rubbish, under boards or anywhere they can find protection.

Remedies.-Hand picking in the morning and evening at which times the bugs are somewhat torpid, is the most practical remedy. Boards laid among the plants at night will be found to have many bugs under them in the morning, and these may be crushed or otherwise destroyed. Large numbers may be killed in this way. 


\section{CHAPTER VIII.}

\section{GARDEN VEGETABLES.}

\section{CLASSIFICATION OF VEGETABLES.}

Vegetables may be classified in many ways, but perhaps the most helpful way is to divide them according to the conditions under which they grow best into (1) warm and (2) cold climate vegetables:

(1) Among warm climate vegetables (often called tropical) we have tomato, corn, beans, pepper, egg plant, cucumber, musk melon, watermelon, squash, pumpkin, and okra. These plants all require hot weather for their growth, are severely injured by first hard frost and should not be planted in open ground until warm weather is assured. They are generally at their best on a warm southern exposure and in soil having a little sand in its composition. These plants are all natives of hot climates and will not survive long in cold climates when left to themselves.

(2) Among cold climate vegetables, we have practically all those commonly grown not mentioned above (1) such as asparagus, rhul)arb, horseradish, safsify and parsnip, which stand our seveiest winters without injury, and those that are less hardy, such as onions, leeks, peas, beets, spinach, cabbage, Brussels sprouts, cauliflower, cress, kale, kohl rabi, radishes, rutabaga, turnip, carrot, parsley, celery, celariac, lettuce, endive, potato, strawherry, tomato, and others. These all grow well at a cool temperature and most of them will stand some frost without injury. They may be divided into those with tops that are frost hardy or frost tender as follows:

By frost tender is meant those whose tops are injured by a light hard frost such as potato. asparagus, strawberry, tomato, and of course all the tropical plants mentioned above (1). Some plants like asparagus and our native oak tree may have foliage that is very susceptible to frost but are havdy in winter. 
By frost hardy is meant those having foliage that is not injured by light frost, such as horseradish, rhubarb, onions, leeks, garlic, peas, spinach, beets, cabbage, Brussels sprouts, canliforrer, cress, kale, kohl rabi, radishes, rutabaga, turnip, carrot, parsley, celery, lettuce, endive and most of the garden herus.

Botanical Classification.-All plants may be divided into families, each of which has its distinguishing features. Our garden vegetables and herbs belong to at least seventeen families. The special features of each of which will be found with the cuitural directions for the plants grouped under them, but for conrenience a list is here giren of all the vegetables referred to herein, arranged under their proper family names:

The Fungi Group or Family, mushrooms or toadstools.

The Grass Family (Gramineae), corn.

The Lily Family (Liliaceae) asparagus, onion, leeks, garlic.

The Buckwheat Family (Polygonaceae), rhubarb or pie plant.

The Goosefoot Family (Chenopodiaceae), beet, Swiss chard and spinach.

The Cabbage Family (Cruciferae), cabbage, cauliflower, raclishes, rutabaga, turnip, Brussels sprouts, kale, kohl rabi, horse radish, cress and watercress.

The Clover Family (Leguminosae), beans and peas.

The Mallow Family (Malvaceae), okra.

The Parsnip Family (Umbelliferae), parmip, parsley, carrot, celery, calariac, caraway, dill, anise, coriander and femnel.

The Morning Glory Family (Convolvulaceae), swect potato.

The Mint Family (Labiatae), sweet basil, lavencler, balm, spearmint, peppermint, summer savory, winter sarory, sweet marjoram, thyme, sage and catnip.

The Potato Family (Solanaceae), tomato, potato, egg plant, peppers and strawberry tomato.

The Martynia Family (Martiniaceae), Martynia.

The Gourd Family (Cucurbitaceae), cucumber, squash, muskmelons, watermelons, pumpkin and gourd.

The Sunflower Family (Compositae), lettuce, salisiry, endire and dantelion. 
The Rue Family (Rutaceae), rue.

The Borage Family (Boraginaceae), borage.

\section{THE FUNGI.}

The Fungi group includes a large number of flowerless plants which are propagated by division and by spores. Besides the cultivated and wild mushrooms, which are below referred to, this group includes some that are poisonous, although they form but a small proportion of the whole number of species that are liable to be taken for edible kinds. The wheat rusts, mildews, grain smuts and other similar diseases also come in under this head. The spores (seed bodies) are distributed in various ways, but very commonly by their becoming light and powdery and being blown about by the wind as in the case of the common puff ball and corn smut. There is no sure way of telling the poisonous mushroom from the edible kinds but most of the species have been studied and their value for food is well known.

\section{MUSHROOMS. (Agaricus campestris.)}

There are many edible wild mushrooms, and they differ in no particular from the so-called toadstools, but the species referred to above is the kind commonly cultivated. The part eaten is really the fruit bearing portion and not, as many suppose, the plant itself. The true plant is the white network of fibres which grow in the soil, and it is this part that is used in propagating them.

Culture.-The cultivation of the mushroom is often attended with uncertainty. It is, however, being grown on an increasingly larger scale, and the demand for it constantly increases. The conditions essential to success in growing it are a rich soil and a steady temperature of from 50 to 75 degrees. It is for the purpose of securing this latter requisite that cellars and old caves are often utilized in its culture, as light is not necessary. Horse manure is a practically indispensable material for the growth of mushrooms. If possible, it should be from animals fed on rich, nitrogenous food and as free from straw or other litter as it can be obtained. This should be thoroughly mixed with a fourth or fifth part of good garden soil and is then ready 
to go into the beds. Care should be taken that the beds are in a well drained damp place. They may be of any size or shape desired but should be about ten inches deep. Some of the largest growers use tiers of shelves or boxes, each one of which is eight or ten inches deep, into which they put the soil. Whatever the shape of the beds, the soil should be packed into them firmly and evenly and be left smooth on the outside. A thermometer should then be inserted in the center of the mass. As soon as fermentation sets in, the temperature will rise until probably over 100 degrees will be indicated, and when it falls to 80 degrees the bed is ready to receive the spawn. This may sometimes be obtained from old mushroom beds, but it is best to depend on that sold by seedsmen, as it is more certain to be free from other fungi. The operation of spawning consists in putting pieces of the spawn bricks the size of small hens' eggs in holes made about two inches deep and ten or twelve inches apart. Afterwards the holes should be filled with the soil and the surface firmed and smoothed off.

If the work has been well done and the conditions are favorable, the spawn should commence to grow in seven or eight days; at the end of that time it should be examined and any pieces that have not started should be removed and be replacec by fresh spawn. A failure in germination is indicated by thu absence of white threads in the manure around the spawn. When the spawn has nicely started and begins to show itself on the surface, the bed should be covered with a layer one inch thick of fine, slightly moist soil, which should be pressed down smoothly and firmly. In damp cellars mushroom beds do not need water, but if the surface gets dry they should be watered with tepid water from a fine rose watering pot. The mushrooms should show in from five to eight weeks, and the beĩ continue to yield for two or three months. The spawn bricks, as they are termed by seedsmen, are simply flat square pieces of a mixture of manure and loam into which spawn has been put and has grown until it fills the whole piece. Afterwards these bricks are dried and form the mushroom bricks or spawn of commerce.

Native Mushrooms.-There are quite a number of native 
inushrooms that are eiible, but since there are also several poisonous kinds one should be careful about trying unknown sorts. Among the edible kinds are the several sorts known as puff balls (Lycoperdon). When these first appear, they are white balls of a fleshy texture with little or no stalks; as they ipen the flesh turns gradually to a dark brown, and finally the spcres are ejected by the ball being crushed or naturally brealing open. They are not fit to eat after the flesh begins to turn brown. The smaller sorts are most common, but the giant puff ball is occasionally met with and is often ten or more inches in diameter.

Another common native mushroom is shown in figure 45 .

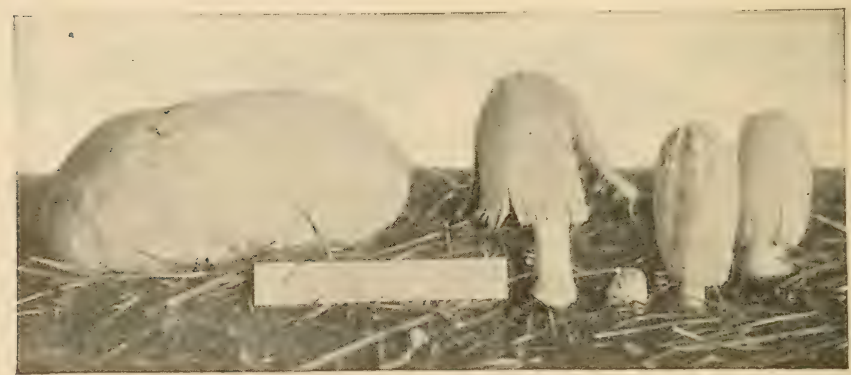

Figure 45.-Native Mushrooms. On the left is shown the giant puff ball (Lycoperdon giganteum); on the right Maned Agaric (Coprinus comatus), in rarious stages of maturity.

It has a stem several inches high. but the top does not expand and is one of the most delicious of all the mushroom tribe when joung. It is called the Maned Agaric (Coprinus comatus.) It grows in waste and grassy places, lawns and mealows. The ills (layers on the under part of the head) are at first white oi pink, melting into an inky, fluid-like substance when more mature.

Little attention has ever been paid in this country to growing our native species. They could undoubtedly be propagated by digging up some of the earth whcre they grow abundantly and mixing it with the soil where it is desired to grow 
them. The kinds mentioned mature in the latter part of summer and are especially abundant in old pastures or other places containing much decaying organic matter ant during moist weather. If an attempt was made to grow them, it would pro!s. ably be necessary to keep the ground moist all summer to sccure the best results.

\section{THE GRASS FAMILY. ( (Oder Gramineae.)}

The Grass Family has many well known general charactelistics. It includes many species and produces the greater pa:t of the food of the human race either directly as seed or inclirecily as meat and yet only corn is ordinarily grown in regetabl. gardens. Among the most important food plants belonging here are wheat, rye, oats, barley, rice, corn, sorghum and sugar can's. The wild rice grows in great abundance in some portions of this state and is an important article of food among the Inclians.

CORN. (Zea mays.)

Native of America.-Annual. The male flower's are in the tassel and the female flower on the cob. While cross-fertilization is not absolutely necessary far the production of seed, it is necessary for a good crop. The varieties of corn may be easily grouped under four classes: (1) Sweet corn, which includes varieties with soft and generally much wrinkled liernels, that are especially desirable for use in a gleen state on account of their being sweeter and more delicate in flaror than other kinds. (2) Flint corn, which includes field varieties having a very hard, smooth grain. (3) Dent corn, which includes field varieties rather softer in texture than the flint corn, each kernel having a depression in the end of it. (4) Pop corn, which has a liernel of flinty hardness and is used almost entirely tor popping purposes. These classes will all cross together. But there are numerous rerieties in each of the classes varying fioni one another in height of stalk, size and color of the ear and kernel, time of ripening and various minor particulars. The color of the grains may be white, yellow, red or purple, but white an l yellow are most common. Corn is quiclily improved by jur?... cious selection, and new varieties are frequently originater in this way. 
Cultivation.-For early use, the seed should be sown as soon as the ground begins to get warm in the spring. Very early planting is not desirable for the main crop, since in cold, wet weather the seed is liable to rot in the ground, or the plants may be frozen on coming up. It may, however, be desirable to plant some of the earliest kinds as soon as the weather is warm, and, selecting the most favorable location, run the risk of failure, as the profits are correspondingly large if the crop is very early, while the expense of planting is a small matter. The main crop of corn should be planted from the middle to the last of May. The land can hardly be too ric. for corn, and it should be in a finely pulverized condition. The seed may be planted in lows at about nine-inch intervals, with rows three to four feet apart, or in hills three to four feet apart each way, according to the growth of the plants and method of cultivation to be followed. It should be covereri above two inches. If grown in hills, three or four plants should be left in a place, which means planting about six seeds to the hill. If planted in hills, they may be cultivated both ways, which is an advantage over planting in rows. In rows, however, the plants develop rather better than in hills, and it is the method preferred by many good growers, though field corn is generally planted in hills. Corn should be cultivated shallow and never deep enough to cut the roots; until it is six inches high it may be harrowed with a slant tooth harrow. In order to have a long season of this vegetable in its best condition for table use, plantings of the very early and some good second early kind should be made at the same time; and then plantings of the second eariy kinds should be made once in two weeks, thereafter up to about the twentieth of June. If planted later than this there is much doubt about its getting large enough for table use before the autumn frosts set in. The very early kinds, however, may be planted in this section as late as the fourth of July, with good prospects of their becoming of marketable size; but the very early varieties are small in size and not as sweet and desirable as the larger second early or late linds, and a few varleties require the whole season in which to obtain table size. If properly planted, sweet corn may be had in a young and tender condition from the middle of July until the cold weather of autumn. 
Marketing.-There is a large demand for green corn in every city and village. It is marketable as soon as the kernels are well formed and is generally sold in the husk, by the dozen or by the barrel. There are several canning factories in this section and many in other parts of the country that make a specialty of canning sweet corn. Grown for this purpose or for evaporating, it is a farm crop that may be made to pay very well in some locations, and extensive tracts of land are devoted to raising it. Where the crop is marketed at canning factories the fodder is left on the farm and is in admirable condition for feeding. The ears are best for table use when first picked and quickly lose in quality after gathering; if they heat in piles or packages they are of very inferior quality.

Varieties.-For very early use the White or Red Cob Cory is a general favorite and is probably earlier than any other kind.

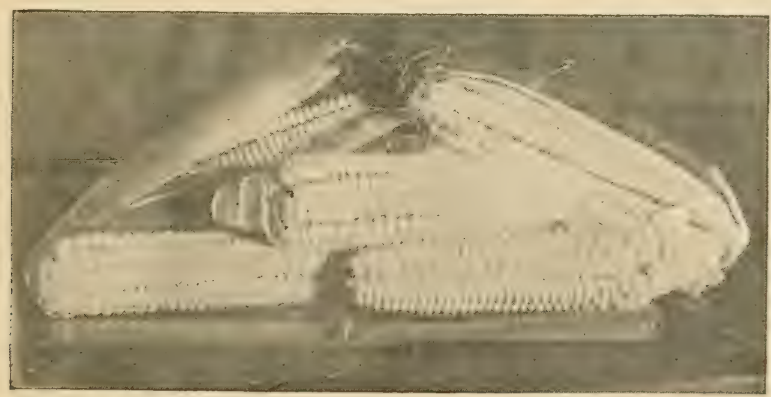

Figure 46.-Early Cory Corn.

It will often mature in eight weeks. Early Minnesota is a little later, but a much better table variety. For second early and mid-season use, Perry's Hybrid, Moore's Concord, Potter's Excelsior and Landreth's Sugar are excellent. Perhaps the Perry's Hybrid is the most popular second early market sort.

For late use, requiring a long season, Stowell's Evergreen, and Egyptian Mammoth are desirable. These kinds have large 'ears and are particularly desirable for canning purposes. The Country Gentleman is a peculiar late variety of great merit. The 
kernels are narrow and long and not arranged in rows but irregularly on the ear. It has, perhaps, the smallest cob of any known rariety. While it requires a long season to get it to

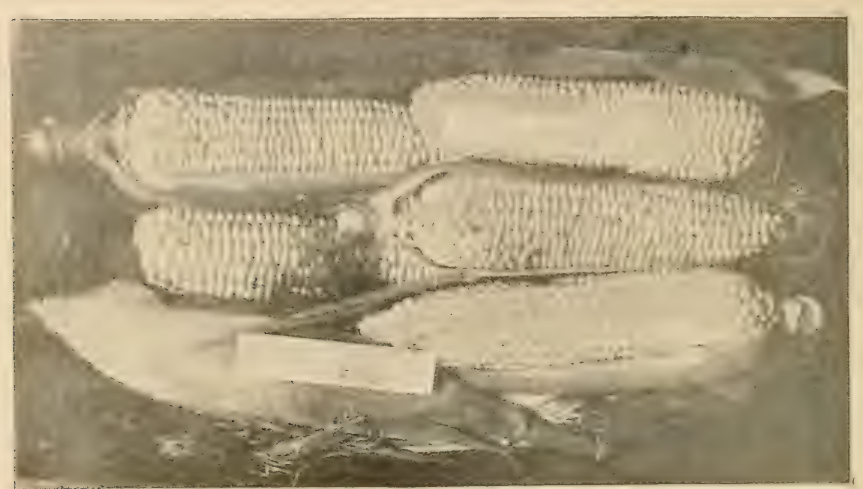

Figure 47.-Late Sweet Corn.

an edible size, it is of fine quality and very desirable for home use.

Pop corn is grown in the same way as sweet corn. For home use. a rery little will suffice; in some sections, however, it is raised in large quantities. It is usually marketed on the cob and is seldom salable until at least one year old. Among the best varieties are White Rice and Golden Pop.

Varieties of corn run out and change very quickly, and there is often much difference in the strains of different kinds. Those that it is desired to keep pure should be grown at least 1000 feet away from other kinds that flower at the same period. Varieties of corn of every description, including all those belonging to the sweet. dent. flint and pop corn classes, will mix together when near by each other.

Curing Seed of Sweet Coin.-The seed of the late varieties 
of sweet corn is difficult to cure thoroughly and is very liable to mould during drying process, unless it is given plenty of light and air. A good way is to tie the ears in small bunches and suspend in a dry, hot, airy room after it has ripened as nearly as may be on the stalk.

Preserving Green Corn.-Green corn is often preserved in a small way by cooking and then cutting it from the cob and drying it in the sun, oven or evaporator. It is also preserved in brine by first cooking it and then treating the same as recommended for cucumber pickles. It may also be cut from the cob after cooking and packed in a vessel in layer's alternating with salt, using about seven pounds of salt to a bushel of kernels.

Mrs. T. T. Batchelor has been very successful in canning corn for winter use as follows:

When the Stowell's Evergreen corn is ripe, the fresh pullerl ears are slightly shaved with a sharp knife, so as to take off the ends of the kernels. The corn is then scraped from the cob and packed solidly in Mason jars. The covers are put on, leaving them only a little lose so water will not get in. The cans are set in a boiler, covered with cold water, which is brought to the boiling point and allowed to boil for two hours. The tops are then screwed tight, and they are allowed to boil for two hours longer. No water is used with the corn, and no salt. They have been very successfull in keeping it when put up in this way.

Cutting off the Tassels. - It has been recommended to cut off half of the tassels from the young corn, on the ground that one-half the tassels would produce all the pollen needed by all the kernels. While some experiments have shown this to be true, many other experiments show there is little if anything to be gained by the practice.

Insects.-Corn is quite free from serious injury, either from insects or diseases. The most injurious insects are the cut worms and boll worms, for discussion of which see chapter on insects.

Smut (Ustilago maydis) is almost the only disease seriously 
injurious to corn. It is a fungous disease that works in almost

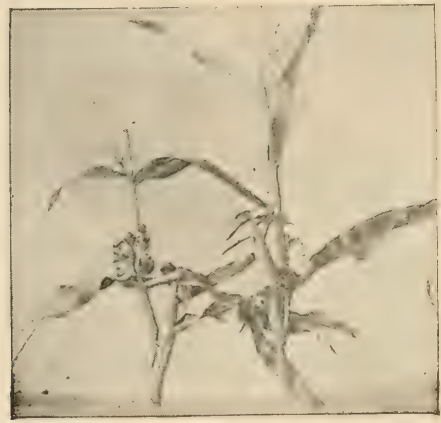

Figure 48.-Corn Snut. (Ustilago Maydis.) any part of the plant, causing swellings which contain black spores. When ripe, the swellings burst and the spores are scattered to continue the disease another year. There can be no question but that gathering and destroying the bunches of spores by burning or burying them deeply in the ground would result in greatly lessening the loss from this cause. It is, however, such an expensive remedy as to seem almost impracticable. Some experiments seem tc show that soaking the seed in a solution of sulphate of copper may assist in preventing this trouble in corn as well as smut ir wheat, but other experiments apparently prove the contrary and it may be taken as a doubtful matter at the best. Prac tically, then, we know of no sure remedy for smut in corn.

\section{THE LILY FAMILY. (Order Liliaceae.)}

The Lily Family is made up of plants that with few excep tions have parallel veined leaves. The flowers are regular and symmetrical with perianth of six parts, six stamens and a superior three-celled ovary. Fruit a many-seeded dry pod or soft berry. Besides the asparagus, onion, garlic and leek, whose cultural directions are here given, there occurs in this family the tiger and other lilies, the hyacinth, tulip, Spanish bayonet, century plant, smilax, lily of the valley and many other familiar flowering plants.

\section{ASPARAGUS. (Asparagus officinalis.)}

Native of Europe.-Perennial.-The asparagus is an herbaceous plant, growing to the height of about four feet. The 
flowars are small and generally yellow. They are perfect but in many plants the pistils are abor.

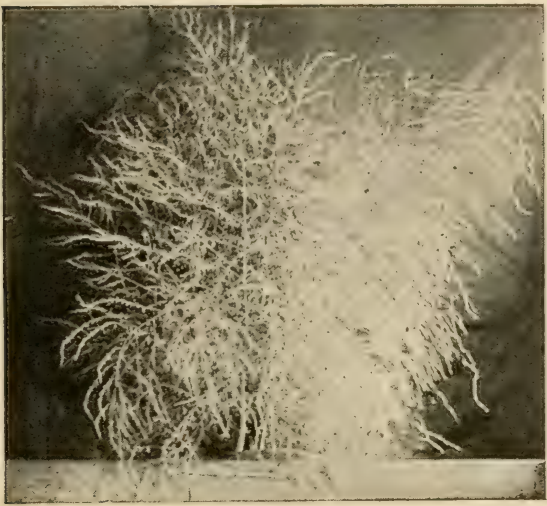

Figure 49.-Asparagus plant full grown. tive, so that only about half of the plants produce seed. The seed is produced in spherical berries, that are vermilion in color when they ripen in the autumn. The seeds are black and trlangular, numbering about 1400 to the ounce. Asparagus is one of the most valuable garden vegetables. It is perfectly hardy, never fails to produce a crop, is one of the first vegetables to be obtained in the spring and may be used until the middle of June. Perhaps, no other vegetable is more highly esteemed by those who are accustomed to its use. It may be grown with success in any good corn land, but is worthy of the best of care, as it responds readily to rich manure and high cultivation. On sandy loam the crop is much earlier than on clay soils; wet land is not suited to it.

Propagation.--It grows readily from seed, and one ounce of seed is sufficient for about fifty feet of drill and should produce with good care about iour hundred plants, though no particular care is necessary for success. The seed should be sown in good soil early in the spring, in drills which may be as close as sixteen inches, and it should be covered about one inch deep. As asparagus seed starts slowly, it is a good plan to sow radishes or other early appearing crops with it, so that the rows may be seen and weeding commenced early. This practice does not interfere with the growth of the asparagus as the radishes will be ready for use and out of the way before it needs much room. The seedling asparagus troots 
will be large enough for transplanting to the permanent plantation when one year old, and it is the best plan to do so: but they may be allowed tc stand two years in the seed bed. The young seedling plants which often come up in or near asparagus beds may be transplanted in July of the first year directly to the permanent bed and will do very well if handled carefuny. At whatever age they are transplanted the plants should be dug and set out in the spring or early summer, as they are likely to fail when removed in the autumn. Aspar-

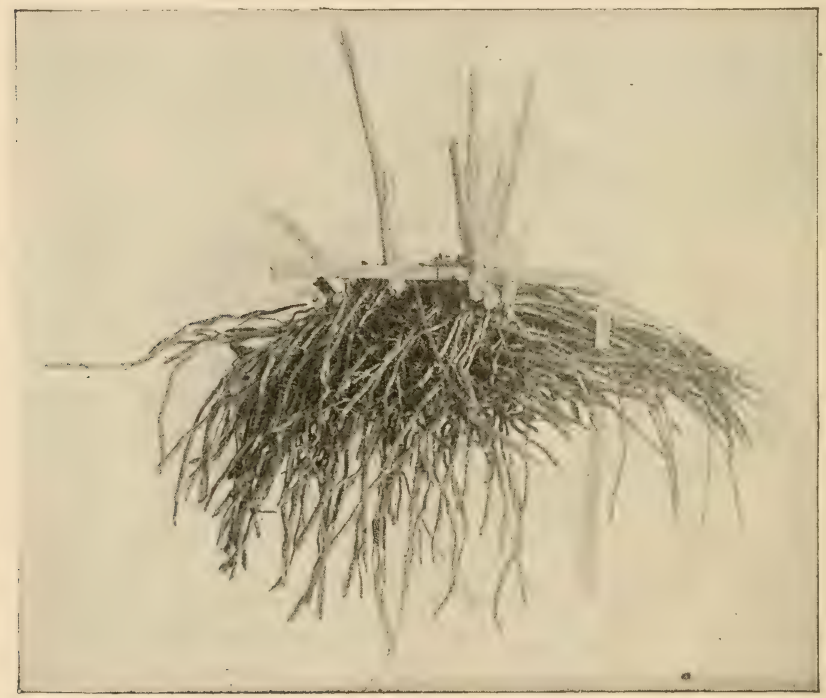

Figure 50,-Asparagus root with edible shoots.

agus may be increased by dividing the crowns, but this is an expensive process, and plants so grown have no peculiar merit over those from seed. By buying the plants instead of sowing the seed to start with, one or two years' time may be saved, and frequently it is cheaper to buy the plants than to raise them. It is said that plants that do not bear seed produce 
more sprouts than those that do. Such plants may be increased by divisions.

Planting.-While asparagus should always be moved in the spring, it is not necessary to move it very early, though it is better to do so; but it may be successfully transplanted as late as the first of June. Any long sprouts that may have started should be broken off when the plants are set out. The land for planting should be heavily manured, deeply plowed and finely pulverized, and it is important to do this work well, as asparagus beds well made should last at least twenty years. The opinions of different growers as to distance between plants vary much. It has been advocated to set the plants four feet apart each way and if the soil is remarkably fertile this distance will not be too great; if the land is not very rich, it is customary to put the plants at in. tervals of three feet in rows four feet apart. If a bed for a family garden is desired where space is limited, it is probably best to set the plants three by three feet apart. About 100 plants will produce all the sprouts needed in an ordinary home garden.

Depth to Plant.-For ordinary purposes asparagus roots should be planted about six inches deep; the deeper they are planted the later they will be about starting in the spring; if planted much less than six inches deep, the roots often push up to the surface and interfere with cultivation. The piants should not be coverce' to the full depth of six inches at once or the shoots may never be able to push up to the surface. The fur. rows should he made with a plow to the proper depth, the plauts placed in the bottom of the furrow and covered about three inches to begin with, and the furrows filled in by after cultivation as the tops grow. By the middle of the summer the furrows should be level full.

Cultivation during the first year can be done almost entirely with a horse, though some hand hoeing will be necessary between the plants. By autumn of the first year, the tops should be three feet high. As soon as they are dead they should be cut off close to the ground with a heavy, sharp hoe or similar tool, and then the land should have a light plowing or be worked 
u1) with a harrow to a depth of four inches. No care need to be talien about the plants when cultivating at this season of the year, but the whole surface may be cultivated or plowed three inches deep as though no crop was in the land. In the spring the land should be cultivated as soon as it will work well in order that it may warm up quickly. There will be no crop to cut until the spring of the third year; a very little, however, may be safely cut the second year after planting if the plants do well. The cultivation in subsequent years should be very much the same as that given above, but in addition, when the crop has been all harvested and cutting is to cease, which will be about the middle or last of June in the northern states, the whole bed should have a thorough cultivation to the depth of three inches without regard to the rows, and if manure is to be used it should be put on at this time. Under this method of treatment it is unnecessary to do much hand weeding, and it is very easy to keep the soil in the best condition by horse power. After the thorough cultivation in June, all the sprouts that come up from the roots should be permitted to grow until autumn, by that time they should be about five feet high if in good soil and will have ripe seed. It is necessary to allow the top to grow to this extent in order that plant food may be stored up in the roots. Very late cutting weakens the growth of the plants.

Cutting.-When the crop is grown for marketing, it is not desirable to cut the shoots until the third season after planting the roots; however, in the case of small beds in the garden where the planter is very anxious to test the fruit of his labor, it may be well to note that no harm is liable to come from a very slight cutting the second season. The sprouts should be cut as they appear in the spring, and all of them should be cut when of the proper size, although they may not be needed at that time. If permitted to grow they interfere with subsequent cutting and prevent the growth of new sprouts. They will also be in the way of cultivation later in the season. The sprouts are generally cut off about two inches below the surlace when they are about six inches high above the ground, and in this case all but two inches of the asparagus is green, 
which is the right condition for most markets. Some people prefer to have white sprouts and in such cases they should be cut four or five inches deep in the ground. In case white sprouts are wanted it is also a good plan to mound up around the hills or to cover them with fine manure to keep the sunlight away from the shoots. The time between the cuttings is largely dependent on the weather. In early spring, if the weather is rather cold, the plants may not give more than one cutting per week, but later in the season a good cutting will perhaps be secured once in two days. A severe frost will kill all the shoots above ground but will not injure subsequent cuttings. Asparagus is

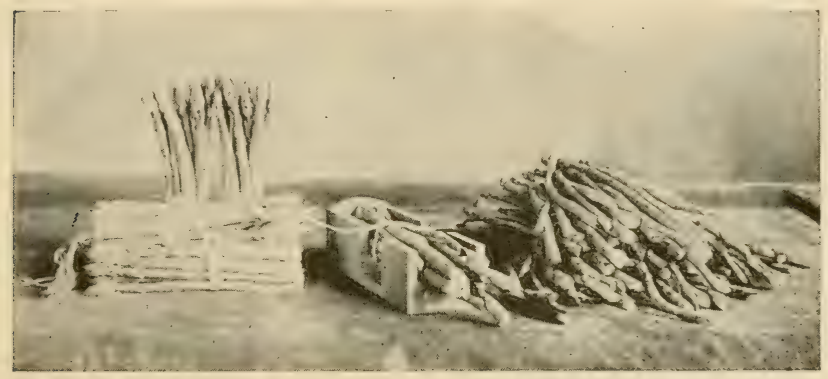

Fi ure 51.-Method of bunching asparagus, showing loose sprouts, boxes for tying up in and completed bunches.

marketed by tying the sprouts in bunches, and the size of the bunches depends much upon the market and, in some places, on the season and whether the supply is pientiful or not. It is very desirable, however, to have all the bunches of one size. It is preferable to tie the sprouts when they are just a little wilted and then set them in water to swell and make the bands tight. The shoots will easily keep for a week if kept cold and moist. It is customary to stand the bunches on end in water in keeping them.

Manuring.-If manure is applied to the asparagus bed in autumn or before the frost is out of the ground in the spring, it prevents the frost from coming out of the ground and so keeps back the growth unless the manure applied is very fine 
and is at once cultivated into the soil. Sometimes such treatment will keep the sprouts from starting for a week or more at a season when it is most relished and the market price is the highest. On this account it is an excellent plan to manure asparagus in June at the close of the cutting season, as it can then be thoroughly cultivated into the soil and does not interfere in any way with the growth of the plants in the spring. Asparagus is a rank feeder and needs lots of manure for the best results. Salt may be applied to asparagus to such an extent as to kill all the weeds without injuring the plants and yet careful experiments seem to show that salt is of no special value as a manure for this crop.

Asparagus seed is rearlily taken from the fruit in which it grows by macerating the fruit in water and then drying it.

Forcing Asparagus for early use is being done to some extent near large cities where it is often a profitable undertaking. For this purpose the roots must be dug in the fall and carefully stored in earth in a cellar. In March, make a good, slow hotbed and put the roots in it in good soil. It is important to start the roots slowly or the shoots will be spindling and weak. The roots stored as recommended may also be forced into growth in a warm cellar, shed, greenhousee, or a part of a permanent bed may be enclosed in glass or cotton sheeting.

Varieties.-There are a number of varieties, and they are all desirable when given good cultivation. Among the best kinds are Conover's Colossal, Moore's and Palmetto.

\section{ONIONS. (Allium Cepa.)}

Native of Central or Western Asia.-Biennial, sometimes perennial. The original home of the onion is not known. It has no true stem, but this is represented by the base of the bulb. The form, color and shape of onions vary greatly in different varieties. The free portion of the leaves is elongated and swollen in the lower part. The flowers, which are white or linac in color, are borne in dense, round heads on long, slender, hollow stalks; sometimes, instead of flowers, a head of small bulbs is produced and no seed at all. This may occur occasionally in all kinds, but is the almost invariable characteris- 
tic of the tree and top onions. The seeds are black, angular and flattish. Usually the plant after seeding dies and disappear's entirely, but sometimes seed onions produce pernliar pointed bulbs, called cloves, as well as seeds. Such plants may be considered perennial as well as the potato onion which never seeds and is propagated by the division of its bulbs. The onion has been cultivated from remote antiquity, and there are very many varieties that have been developed for different purposes. These are almost without exception grown for their bulbs, but in a few cases no bulbs are formed. The bulbs in color are white, red and yellow, with intermediate shades. In the successful raising of the onion, good judgment and experience play an important part. Perhaps no vegetable crop is more certain to pay the skillful grower for his time and labor and none more liable to cause trouble to the careless beginner, and yet its cultivation is quite simple. The prices for onions vary greatly. They seldom are so cheap as to make the crop unprofitable; but occasionally they get down to fifteen cents per bushel, at $\pi$ hich price they cannot be grown at a profit. There are few c.... nals that eat onions, and if not sold they cannot be fed to stock on a large scale, as is the case with most vegetables. As a money crop for careful growers in many sections they are among the most reliable, and if a reasonable amount of them is raised each year without regard to the price the preceding year, it is a crop that will generally average a good profit.

Land.-Onions may be raised on any good retentive soil. Sandy land is too apt to dry out in summer for best results. On drained muck land, large crops may be easily raised; although onions grown on such soil are often a little looser in texture than those raised on drier land. The land should be rich, fine and free from weeds and any strawy manure or other material that would interfere with close cultivation. Too much stress cannot be put on having the land free from weed seeds, since it is a crop that requires much hand weeding and the plants are quite delicate when young. The soil should be rather firm for onions and plowed in the fall rather than in the spring. Fall plowing leaves the soil firm and in excellent condition for the crop. Sometimes when the land is rich it is desirable not to plow at all, especially it is was in onions the preceding year, but instead 
to make a seed bed by the use of a disk or other good harrow and plant at once; in fact, better results will generally be obtained from spring harrowing than from spring plowing of land to be used for onions. Of course, if the land is to be harrowed only to prepare it for the crop, it is very important, if manure is to be used, that this be very fine, so that the harrow will cover it.

Old land is generally preferred for onions, and this crop is often successfully raised on the same land for many years. From the fact that onion land is always most carefully attended to and gets much manure and tillage, it is generally in better condition for onions than land used for almost any other crop. However, it is a good plan to occasionally change the land for onions, since on new land there is far less danger from disease and insect enemies than on old land. Land that has grown any crop requiring high culture and heavy manuring and is free from weed seeds will generally grow good onions. Sometimes onions are raised on newly cleared woodland or prairie sod with greatest success, simply by sowing the seed broadcast and harrowing it in; but this is seldom attempted.

Sowing the Seed.-Before sowing the seed the land should be made very smooth. It is very important to get the seed in the ground as early in the spring as possible. As soon as the land can be worlied in the spring, the seed should be sown and the earlier it is sown the better. The seed of some kinds can be sown in the autumn to advantage, but on land that is inclined to "bake," it is a bad practice and is seldom attempted. There is, however, a fair chance of a crop even if the seed is sown as late as the first of June, but a first-class crop from seed sown as late as this is almost out of the question. By the middle of May, all onion land should have been sown. The distance between the rows will depend somewhat on the variety grown, but for ordinary purposes the seed should be sown in rows fifteen inches apart and covered one inch deep. About eighteen good seed should be sown to each foot of row, which will make it necessary to use four or five pounds of seed per acre. If there is danger of much loss from the depredations of the onion maggot, more than this amount of seed should be used; where maggots are very troublesome some growers use as much as ais 
pounds per acre. The seed sower should be carefully tested on a floor or other smooth surface before using it in the field to see how it works. It is very important to know the germinating qualities of the seed sown, since if it is of low germination more must be used than if it is of best quality. Ninety per cent of good onion seed ought to germinate if the conditions are favorable. It is important to closely study these matters, as it is desirable to have the land well stocked with plants and yet not over stocked. It is better to fail of getting quite so much seed on the land as is desired than it is to get very much more than is wanted, for in the first case the onions, although somewhat scattering, will be of good size, while if the plants are too thick they must be thinned out, or the onions will be small and inferior. The work of thinning onions on a large scale is a ve:y expensive operation, and every precaution should be taken to avoid having to do it. If the seed is sown only a little thicker than the plants ought to stand, it is sometimes a good plan instead of thinning them out, to put on an extra dressing of some quick-acting, easily-applied manure, such as hen manure, which will probably make it possible for the land to mature the whole crop in good shape. Onions have the quality of crowding out to the sides of the rows and on top of one another, so that they may grow pretty thick and still be of good size, providing other conditions are favorable to their development. It is important to have the seed sown in straight rows. If the first row is laid off with a line or otherwise made straight, the subsequent rows are easily made parallel to it by means of the marker on the seed sower. If there are found to be some vacancies in the rows after the onions appear, these may be filled by sowing onion seed in them by hand; late in the season such vacancies may be sown with carrot seed.

Cultivation.-As soon as the plants commence to break the surface soil, cultivation should be commenced with a hand cultivator that will work both sides of the row at one time and throw a little earth from the plant; hand weeding should follow at once. At the second hoeing, the plants being now pretty strong, the soil should be cultivated somewhat deeper. This will enable a careful man to work the soil very close to the plants. Onions naturally grow in the surface of the land and 
not below it and should never be hilled up. The onion crop should be hoed and weeded as often as the weeds appear or whenever the ground packs hard around the growing plants. The weeds should be destroyed when small. This means that until early summer the onions should be hoed about once every two weeks. When the plants get so large that they will no longer pass under the straddle cultivator without being bruised the work of cultivation must be continued between the rows until the bulbs commence to form, after which it is not a good plan to work much among them, since pushing the tops about tends to make them die down quicker than otherwise. When the onions are about the size of a half dollar and before the tops fall over, it is a good plan, if the land is not very rich, to apply some quick-acting fertilizer such as hen manure or a commercial fertilizer broadcast over the crop. This should be done just before or during a rain if possible. For this purpose dry, fine hen manure is gooa, but any rich, nitrogenous fertilizer will answer.

If the plants are going to make good onions they will become weak in the neck just above the bulb when nearly grown and fall flat on the ground, where they should be allowed to lie undisturbed until the tops and roots are entirely dried, then the bulbs can be easily pulled out of the ground with a rake or onion puller. In the vicinity of St. Paul, this time will be in August or the early part of September. About four rows of bulbs should be thrown together, and they should be turned with a rake every few days until perfectly dry and then be put under cover to protect them from rain. If they are allowed to get wet several times after being pulled, the outer skins are liable to come off and thus make the bulbs unsightly. If not pulled for some little time after they are ripe, especially if the season is moist, new roots are very sure to start and the roots become grown so firmly into the soil that the work of pulling and drying them is increased. The work of cutting or twisting off the tops, called topping, may be left until the onions are marketed, but they will be found to keep much better if "topped," since if the tops aro left on they prevent a free circulation of the air through the bulbs.

"Scallions" or "Thick Necks."-Sometimes, too, the tops of 
the plant do not die down as they should, but remain green and continue to grow after the bulbs are well former, and become what are called "scallions" or "thick necks." This is generaily due to the planting of poorly selected seed, but sometimes it is not to be accounted for. In such cases it is generally recommended to break the tops down, which certainly does no harm, but it is of doubtful value. A better way is to pull such plants as soon as they begin to grow vigorously after once having formed good bulbs, dry them as much as possible and remove the tops. However, such onions do not generally keep well and had better be used during autumn and early winter.

Keeping Onions.-Onions should be kept in a dry, cool place. In a damp cellar they will sprout and grow no matter il the temperature there is near the freezing point. They will stand quite a little frost without much injury, but if frozen and thawed several times ihey become soft and do not keep well, but start to grow very quickly. The best way of keeping onions is in a cold, dry room in slatted bins or on shelves so arranged that the air can circulate through them. A very practical plan is to put them in barrels without heads, having holes in the bottom and sides and pile these on top of one another two tier's high, first putting down scantling or other material to allow the air to circulate under and around them. If our common onions are frozen solid in the autumn and kept so all winter, they will generally come out right in the spring. A good way to do this is to lay them eighteen inches thick on the floor of a loft and cover with a foot or so of hay. Thus arranged they will not freeze until severe weather sets in and will remain frozen until spring. They may also be put in water-proof bins in the field where grown and treated in the same way. They should never be handled when frozen, as they are apt to bruise. Freezing and thawing several times seriously injures them, but if kept frozen and gradually thawed out they come out in very nice condition. After thawing out, they will not keep well, but quickly start to grow, and should be disposed of at once. They Prizetaker and similar kinds are an exception to this rule and are liable to be ruined if frozen.

Onion Sets is a term applied to small onions which are planted out in the spring instead of seeds. If onions under 
three-fourths of an inch in diameter are planted out in the spring, they do not go to seed as do larger onions, but form a new bulb, and form it much earlier than they are formed when grown from seed. Taking advantage of this fact, it has become a common practice to raise these small onions (sets) and plant them out for early summer use. It does not matter how small the set is, and one the size of a pea is as good as one much iarger. The size generally preferred is about one-half an inch in diameter.

Planting Onion Sets.-The method of planting sets is to have the land in the same condition as recommended for onion seed and plant the sets as soon as the soil can be worked in the spring. In doing this mark off the land in drills twelve inches apart and push each set down firmly three inches deep into the mell.ow soil, leaving them three inches apart. This is done by hand, and each set is handled separately, so as to have them right side up. The drill is then closed in with the feet or rake, so that each set is entirely covered up. If the ground is dry, it is sometimes rolled to make it still more compact around the bulbs, but it is generally quite moist when the sets are planted in early spring. As soon as the rows can be seen, the wheel hoe is used, and the plants liept free from weeds and the soil well stirred. By this method we will have onions of good table size by the first of July, and some may be marlieted in bunches in a green state in June. Onion sets seldom, if ever, fail to produce good crops and are well adapted for use in the home garden and by those who will not take the pains necessary to grow onions from seed. No matter how poor the soil or the cultivation where the sets are planted, they always increase in size and ripen early. There is no danger of their being injured by freezing after being planted. From six to ten bushels of sets are required per acre, depending on their size.

The raising of onion sets is carried on to a large extent in some localities, and it is a crop that requires much skill in handling. Sandy soil of rather inferior quality but free from weeds and in fine tilth is best for this purpose. To keep the sets from growing too large, it is customary to plant from thirty to fifty pounds of seed per acre, and not plant it until the latter part of May. This treatment crowds the seedlings so 
that they cannot grow large. In sowing the seed, it is best to go over the rows with the seed sower three or four times, sowing only a part of the seed each time. This spreads the seed out in wide drills and permits of more even work than would be possible were it attempted to sow all the seed by going over the rows once. If onion sets grow too large it is often almost impossiole to use them for any purpose, since they are too small to sell well except for pickling, and the demand for this purpose is very limited. On this account, if it is feared the sets

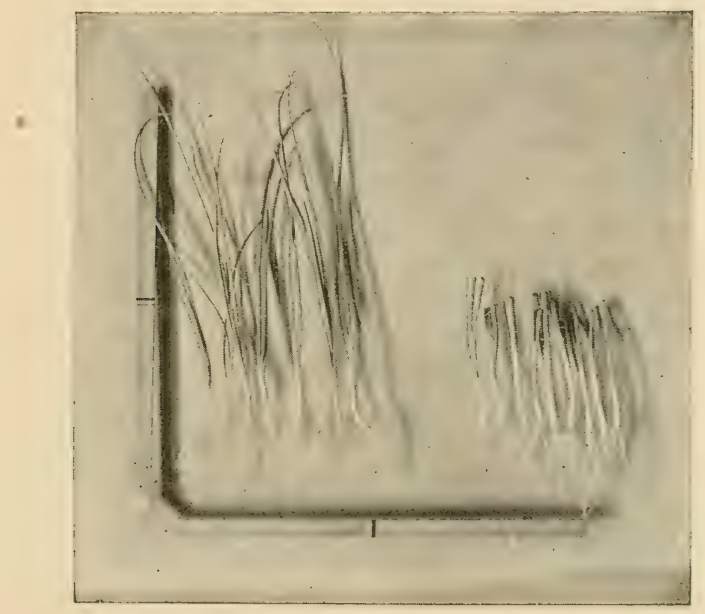

Figure 52.-At the left: onion plants as dug. On the right: onion plants trim med and ready for transplanting.

will grow too lirge, they are pulled when of the proper size, even if still quite green. The further cultivation of plants for sets is the same as for a field crop of onions. The sets should be taken up in August, or as soon as ripe, with a rake or onion set puller. When dry they should be stored, tops and all, about four inches deep, in a loft, where they should be covered with a foot of hay or straw on the approach of hard frost and left until wanted for planting in the spring. In other words, they should be kept 
frozen all winter: Treated in this way they will require to be cleaned in the spring, and this is done by rubbing them in the hands to loosen the dirt and tops and then running them through a fanning mill. After this they are run over a screen with a three-fourths inch mesh, and only those that go through it are sared for sets. This work of cleaning may be done in autumn before storing and the sets mixed with chaff to aid in keeping them over winter.

Transplanting Onions.-Within a few years some market gardener's have adopted a plan of raising onions by sowing the seed in March in a hotbed and then transplanting the seedlings

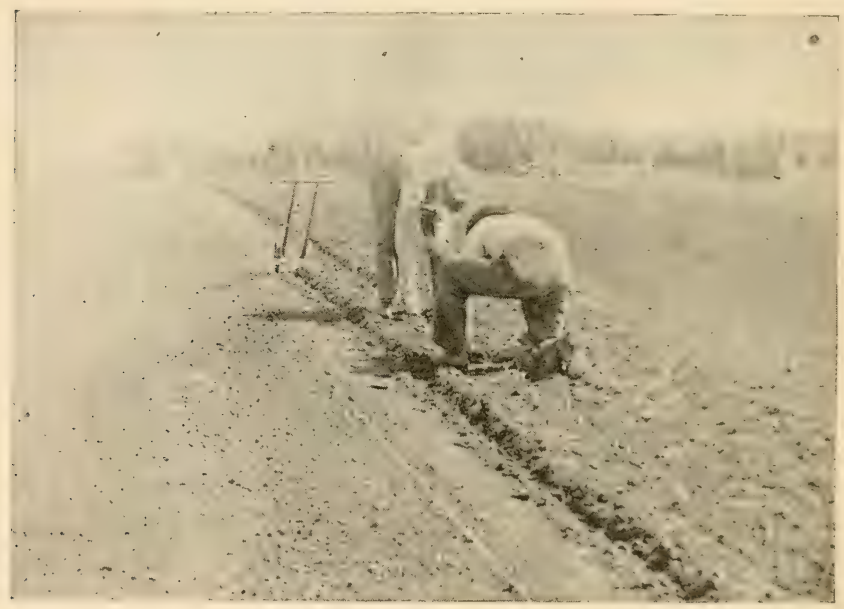

Figure 53.-Transplanting Onions in the Fiela.

to the open ground as soon as it works well. This system has the merit of doing away with the first few weedings in the open ground, reduces the expense of seed to a minimum and makes it possible to raise some of the more delicate foreign varieties of onions, which command the highest price in the market. It is, however, very doubtful if the common field onions can be raised at a profit under this method, but it is desirable if the 
Spanish kinds are to be raised in this section. The selection and preparation of the land for this purpose is the same as for a field crop. The seed is sown in a hotbed in rows three inches apart, or on a small scale a few plants may be raised in a box in the window of the living room. The soil for this purpose should be a somewhat sandy loam of only moderate quality, and that which has no manure in it is most certain to grow healthy plants. If very thick in the row, the plants must be thinned out so as not to crowd one another too much, but still they may be grown very thickly; as many as twelve to fifteen plants to the inch of row is about right, and to secure this amount about twice as many seeds will have to be sown to the inch. Too much importance cannot he attached to the raising of strong plants, since those that are weak and spindling are very certain to fail when moved.

For a week or two previous to setting out the plants, they should have plenty of fresh air, and it is a good plan to remove the sashes entirely from over them except when there is danger of frost, so that the plants may become hardened off, as otherwise they are liable to serious injury by freezing when moved to the open ground, although they stand some freezing when hardened off. They do not transplant so well when soft and succulent as when properly hardened. The land and preparation required is the same as for a field crop of onions. The plants should be set two or three inches apart in rows twelve inches apart. Before setting them out the tops should be mostly cut off, and this is especially important if they are weak and spindling, as they are then very sure to turn yellow and die. If the roots are excessively long, they may be shortened to faciltate transplanting. The plants are generally set in small furrows opened with a hand cultivator or with a marker. The lower part of the bulb should be about an inch deep in the ground. Ine plants are easily moved, and if the soil is well firmed they are very sure to live. About 150,000 plants are required for an acre, and it is a big job to transplant them. For this purpose children can generally be employed at low wages and they will do the work very well if carefully looked after. The expense of transplanting is variously estimated at from $\$ 25$ 
to $\$ 50$ per acre. Subsequent cultivation is the same as for a field crop of onions.

Marketing.-In a general way the directions for marketing onions apply to any other crop. They should be sold as soon as a fair price can be obtained for them and not stored unless there is a good chance of a rise. In some lncalities there is a large demand for onions for bunching purposes before the bulbs are formed. In these places it will sometimes pay to pull and sell the crop before the tops have died down, but generally it should be allowed to ripen. The foreign kinds, such as can only be raised here by the transplanting method, are generally highest in price in early autumn and should then be sold. The tops should always be removed before the bulbs are marketed, and all small bulbs should be picked out and sold separately for pickling purposes. Most markets prefer onions of medium size, globular rather than flat in shape, and yellow or white in color rather than red. Very large onions of the common type are not so salable as those of medium size; but of the foreign kinds, the larger the better, and good specimens sometimes weigh as much as two pounds.

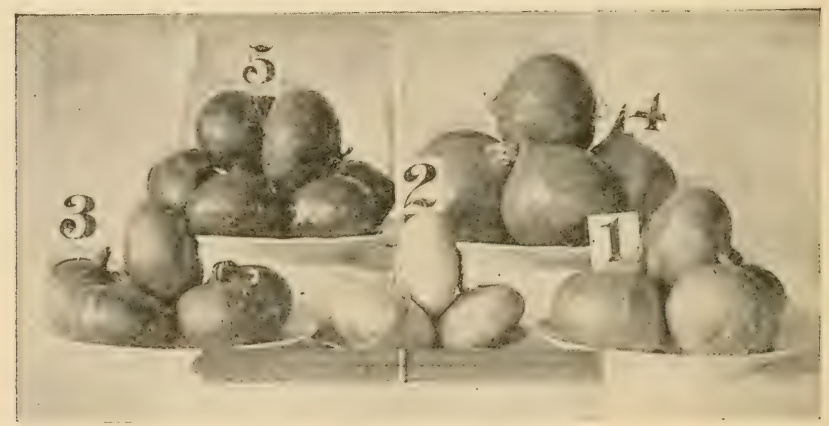

Figure 54.-Varieties of Onions. 1-Southport Yellow Globe. 2- Silver Skin. 3-Red Globe. 4-Prizetaker. 5-Yellow Danvers.

Onions for the Home Garden should be raised partly from seed and partly from sets or transplanting. The small onions picked out from one season's crop may be used as sets the next 
year, when they will give a much earlier crop than those grown from seed.

Varieties.-For general field crops in this section no onion is more certain than Red Wethersfield. The Yellow Danvers is the best yellow kind for this purpose. The earliest maturing large kind is Extra Early Red. For raising sets the Yellow Dutch, called also Yellow Strasburg, is the best kind, but any variety may be used for this purpose. For growing in hotbeds, greenhouses or window boxes to be transplanted to the open ground, the Prizetaker and Southport Yellow Globe are most in demand.

Potato Onions and Shallots are always grown from the bulbs, which increase in size and also produce a cluster of bulbs (cloves) around the one that is planted. They are especially adapted to early marketing in the same way as onion sets.

Egyptian, or Perennial Tree, Onion.-This kind is perfectly hardy and does not form bulbs, but the bleached stem is used in a green state. It produces no seed, but instead has a small cluster of bulblets where the seed cluster should be. These bulblets are planted in September in the same way as recommended for onion sets and are ready for use as bunch onions very early the following season.

Top Onions is a name applied to a class of onions that produce no seed, but where the seed should be have a cluster of small bulbs. These small bulbs when planted grow into large common onions and when these common onions are planted they produce a crop of sets.

Onion Seed is raised by planting out the bulbs in the spring in rows four feet apart, and for this purpose, bulbs of the greatest excellence are used. It is best to set the bulbs about six inches deep and six inches apart in each furrow, and to do this planting out very early in the spring. The seed stalks will attain a height of about three feet. The seed clusters ripen somewhat unevenly, but should be gathered before they are quite dry, or the seed will shell out and be lost. When gathered, they should be dried in airy chambers and afterwards threshed out and cleaned with a fanning mill or they may be cleaned by being thrown into water. The latter method secures the best seed. 
All the seed that is full and plump will sink in water, and as

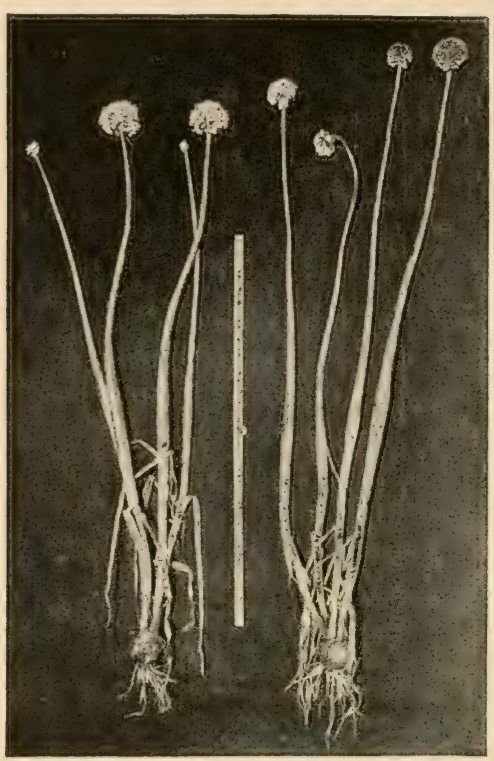
the chaff and lighter seeds float they are readily separated from the good seed Some of the seed that floats will grow, but it is not very desirable for planting. The same land that grows a crop of onion seed is sometimes used for growing a crop of cucumbers or melonsat the same time, since the onions do not shade the land or take much nourishment from it except early in the suring.

Figure 55-Onion plants in flower.

COMMON GARLIC. (Allium sativum.)

Native of southern Europe.-Perennial.-All parts of the plant have the well-known strong burning taste. The bulbs or beads are composed of about ten cloves enveloped by a very thin, white or rose-colored membranous skin. The plant hardly ever flowers and is grown by means of the cloves, for which purpose those on the outside of the cluster should be used. These should be planted in good rich soil in about the same way as onion sets. They should be gathered after the bulb clusters are well formed. This vegetable is scarcely used at the north, while in southern European countries it is quite common. It is said that it has a much stronger burning taste 
when grown at the north than when grown in the soutll. What, is known as common garlic is the kind most generally used.

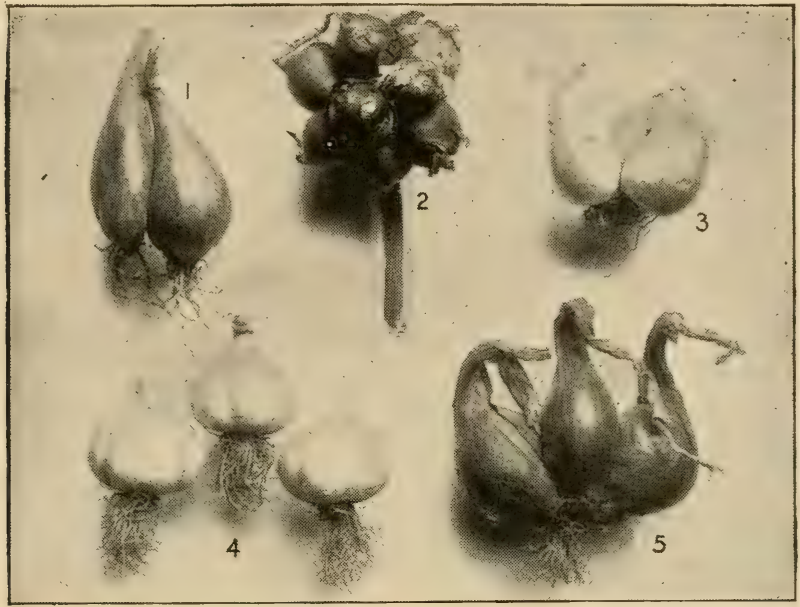

Figure 56.-1-French Shallots. 2-Top Onions (red). 3-Jersey Shallots. 4-Garlic. 5-Potato Onions.

LEEKS. (Allium porrum.)

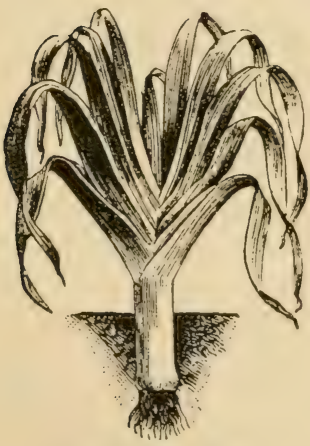

Figure 57-Leek.

Said to be a native of Switzer. land.-Biennial.-The leek is closely allied to the onion, which it resembles in flavor, color of seed and flower. However, it does not form a bulb but a straight bunch of leaves, that are used almost entirely in a fresh or uncooked condition. The leaves are flat instead of round and hollow, as is the case with onions. As yet this vegetable is little grown in this country, except around the large cities.

Cultivation.-Its requirements are about the same, and it may be cultivated in much the same way as the onion, but it is more 
common to sow the seed early in spring and transplant in summer, settling plants very deep, as the market value depends on the blanched condition of the stem; and for the same reason in hoeing the soil is drawn up over the stem. They transplant very easily when the soil is moist, but should have the tops trimmed off as recommended in transplanting onions. If they are not transplanted, especial care should be taken to draw the soil towards the plants in hoeing. They may be stored in the same manner as celery, and are marketed in bunches the same as green onions.

Varieties.-There are several varieties which vary in form and color.

Large Flag leek is a popular sort and, perhaps, more largely grown than any other.

Scotch Flag or Musselburgh leek is longer than the above, but not quite so thick.

\section{CHIVES. (Allium schoenoprasum.)}

Native of Europe.-Perennial.-A hardy plant growing in thick tufts. Bulbs oval, scarcely as large as a hazelnut, forming compact masses; leaves very numerous, grass-like in appearance and hollow. Flower stems in terminal clusters of violetred flowers and usually barren. The tops have an onion-like flavor and are used in seasoning.

Culture.-Chives are propagated by dividing the tufts. They are not much used and are generally grown as edgings for beds in the garden. Of the easiest culture.

THE BUCKWHEAT FAMILY. (Order Polygonaceae.)

The buckwheat family includes herbs which alternate entire leaves and stipules in the form of sheaths above the swollen joints of the stem. Flowers mostly perfect with a one-celled ovary bearing two or three styles or stigmas. Fruit usually an achene either flattened or three or four-angled or winged. Sometimes agreeably acid as in sorrel and sometimes cathartic as the roots of rhubarb. Only rhubarb is here discussed, but other familiar plants that belong to this order are Sorrel, Bitter Curled and other docks, Knotwood, Smartweed, Bindweed or Wild Buckwheat and Field Buckwheat. 
RHUBARB OR PIE PLANT. (Rheum rhaponticum.)

The cultivated varieties of rhubarb are generally supposed to have come from Mongolia, though it is quite possible that some varieties may have sprung from a North American species. The plant is an herbaceous perennial whose leaf stalks are used for sauce, pies, etc. It sends up a flower stalk often four feet high, and produces a large amount of seed each year. It is perfectly hardy in gardens, even in very severe situations, and when once planted continues to yield abundant crops for many years. The seeds are large and triangular.

Culture--Rhubarb is readly increased from the seed, which germinates quickly. Seedings vary considerably but not enough

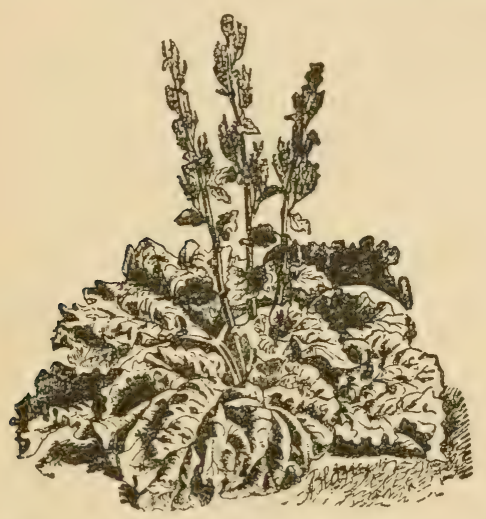

Figure 58.--Rhubarb plant in flower.

to prevent this method of propagation from being the one most commonly practiced. They attain good transplanting size in one year. It is customary to sow the seed in rows three feet apart early in the spring, and set out the plants when one year old where they are to grow; the plants may also be thinned out and a few allowed to remain where the seeds are sown. When it is desired to propagate the specially valuable qualities of individual plants, it is done by dividing the roots, using care to take at least one good bud with each piece of root. This is the only sure way of getting the best plants.

it is preferable to set the plants out in the fall where they are to grow, but spring planting is often followed. They should be set in the richest of land four feet apart each way. The stalks should not be pulled up until the spring of the second year and then only to a small extent; the third year they should give a good crop, The only culture needed is to keep the ground 
free from weeds and loose, and to use plenty of manure. In gathering rhubarb the stalks should be removed from the crown by a jerk downward and sideways, and care should be taken not to be so rough about it as to pull the buds from the crown at the same time. There is little danger of pulling more leaves than the plant can stand without injury, but in the case of a young plantation it would not be well to remove more than onehalf of the leaves at any one time. The stalks are most in de-

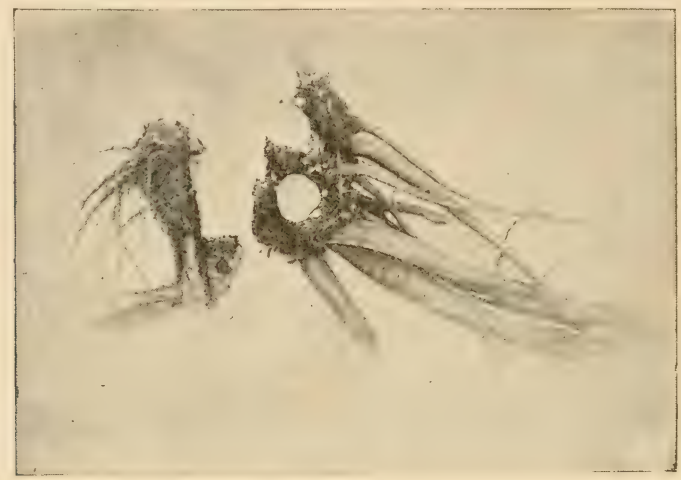

Figure 59-Pieces of rhubarb roots cut off for planting out.

mand early in the spring, but there is more or less call for them all summer. The seed stalks should be cut off as soon as they appear, so as to throw their strength into leaves and to prevent the formation of seed, if the largest amount of stalks is wanted.

Forcing Rhubarb.-For winter and spring use rhubarb is often forced in greenhouses and cold frames. The roots of any age are taken up in autumn, crowded together under the benches in greenhouses or placed in boxes or barrels with a little soil between them, and put in any convenient place in the greenhouse or a warm light room or cellar where they start into growth in February. They are also planted out in warm sheds. Still another way of fcwcing rhubarb is by putting a cold frame over the plants in the early spring where they are growing in the open 
ground. This method may be improved by heavily mulching the plants so as to keep out the frost in winter. The roots are sometimes lifted in autumn, planted close together in a deep cold frame and covered with leaves to keep out frost. In March the leaves are removed and the sashes put on. This method has the advantage of using the sashes to the best advantage, but roots that are dug and then forced are worthless for further planting. In order to increase the length of the stalks it is a common practice where but a small amount is grown to put headless barrels over each plant in the spring when the leaves are starting into growth, and in striving to reach the light the leaf stalks naturally grow long and tender. An old sash laid over the barrel is an improvement on this method.

Varieties.-There are several varieties, but the following kinds are the most highly esteemed:

Myatt's Linneus.-An early sort having deep green stalks and attaining to a large size.

Myatt's Victoria.-A much later kind than the preceding. Stalks red, very thick and large.

\section{THE GOOSEFOOT FAMILY. (Order Chenopodiaceae.)}

The Goosefoot Family includes chiefly homely herbs, with inconspicuous greenish flowers. The ovary is one-celled and oneseeded. Leaves chiefly alternate. Besides the beet, mangel wurtzel, Swiss chard and spinach, whose cultural directions are here given, it includes such weeds as Russian thistle, goosefoot and lamb's quarter or pigweed.

\section{BEET. (Beta Vulgaris.)}

Native of Europe.-Biennial.-This plant in the first year of its growth forms a fleshy root, and goes to seed the second year. The seed stalk is about four feet high. What is usually sold and planted as beet seed is in reality a fruit and is made up of several seeds imbedded in corn-like calyxes; the seed itself is very small and kidney-shaped, with a thin brown skin. The roots vary greatly in form and size and in color from a reddish white to a deep dark red. Some varieties have special qualities for table use, while others are valuable for feeding stock or for sugar only.

The garden beet is easily grown and is a very reliable crop. 
It prefers a very rich, sandy, well-worked soil, but will grow in any land that is fit for corn. For early use some early-maturing kind should be selected and the seeds should be sown in rows sixteen inches apart in the open ground as soon as the

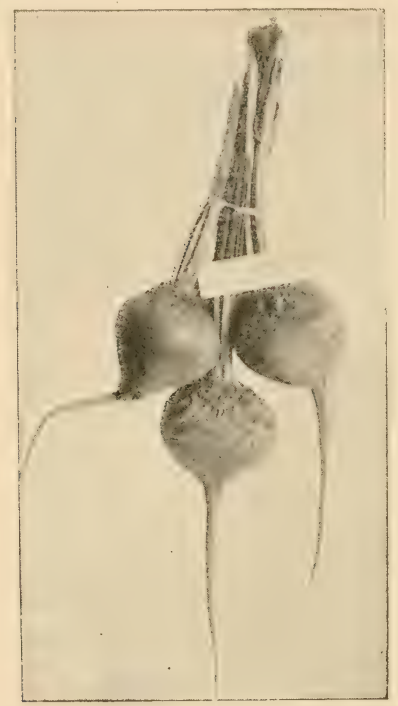
soil can be worked in the spring. Ten seeds should be sown to each foot of row and covered one inch deep. The young plants will stand quite a severe frost without injury. As soon as the seedlings appear they should ise cultivated with a wheel hoe, and the cultivation repeated at frequent intervals. When they are eight or ten inches high, thinning should be commenced and continued until the plants are six inches apart in the rows. These thinnings make excellent greens. If sown as recommended, they will be large enough for table use in June and will Figure 60.-Bunch of Eclipse beets. be good for use the rest of the summer. For winter use, the seed should not be sown until the last of May or first of June. For late planting some growers prefer to put the rows two feet or more apart so that when the plants are nicely started they can be cultivated by horse power. Stock and sugai beets should be sown in rows about thirty inches apart, to allow of easy cultivation. These should be sown from the middle to the last of May ard covered somewhat deeper than is recommended for early table beets, perhaps one and onehalf inches deep. The importance of very early and constant cultivation cannot be too strongly insisted on. Beet seed may be sown by a machine seed sower, but most of the sowers in use will need a little more careful watching when sowing this 
than with most other seeds, as the rough seeds (fruit) are liable to clo's the feed hole. There are a few beet seed sowing machines adapted for horse power that it will probably pay one to use where a large amount of land is to be cultirated in beets. About six pounds of seed is required per acre, and it is always a good plan to sow an abundance of seed, as it does not start very uniformly.

Forcing Beets.-Beets are easily forced by sowing the early maturing kinds in February or March in hotbeds, where they may be left to mature or may be transplanted when of proper size. It is, however, best to allow them to grow to table size without transplanting, as this always puts the plants back, and they recover from it slowly.

Harvesting and Keeping Beets.-On the approach of severe weather-in this section about the middle of October-beets should be pulled and the tops cut or twisted off, but the top of the root should not be cut off. Light frosts do not hurt them much especially when they are protected with a heavy growth of foliage, but when the surface of the ground freezes hard there is danger of permanent injury to the roots. Beets are easily kept in a cold cellar. It is generally best to put them outside when dug and allow them to remain there until severe weather sets in. If the air of the cellar is very dry the beets should be covered with earth after being put in bins, or they will wilt and become corky. Beet seed is grown by planting out the roots about the middle of May, two feet apart in rows three feet apart. The seed ripens in the summer and is generally threshed off as soon as ripe.

Varieties.-There are many varieties of garden beets, and they vary considerably in size, form and color, time of maturing and other characteristics. Among the most valuable are the following:

Eclipse-A very early dark-red turnip-shaped beet of good quality. Valuable for early or late sowing. A favorite with market gardeners.

Egyptian.-Valuable for early sowing.

Bastian's Early Turnip Beet.-A valuable early sort, tender, sweet and good in every way; one of the best for early or late planting. 
Dewing's Improved Blood Turnip Beet.-A first-class beet in every respect; valuable for winter or summer use.

Diseases of Beets.-The beet is subject to several diseasen, and it is most healthy when grown on new land.

Beet Scab is a disease which ruptures the skin of the beet in a manner similar to scab on potatoes. Recent investigations show that this disease is the same as potato scab. On this account, beets should not follow potatoes on land that has grown a scabby crop unless there is an interval of several years between them. Beets are sometimes subject to a rust that injures the foliage, but seldom very seriously.

Stock Beets (often called Mangel Wurzel). Stock beets are gross feeders and prefer rich soil. They require the same care as table beets, but the rows should be thirty inches apart, so

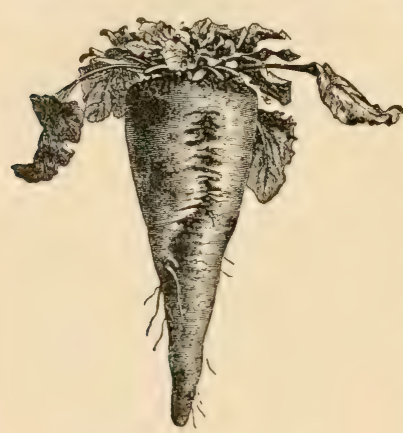

Figure 61.-Sugar Beet. as to allow of cultivating them with horse implements. The seed may be sown with any common garden seed drill after first laying off the rows with a marker, or it may be sown with a common grain drill by stopping the flow of seed through a part of the holes. It is a very good plan to sow radish or rutabaga seed with the beet seed, as it starts quickly and the line of the row is thus easily seen, so that cultivation may be started early. This is very important in land that is somewhat weedy. About six pounds of seed to the acre will give about twelve seeds (fruits) to a foot.

There are many good varieties of stock beets. Among the best are Long Red, Yellow, or Golden Tankard, Yellow Globe and American Sugar. The latter is not a true sugar beet, but is much richer in sugar than the ordinary varieties of stock beets and, possibly, of better feeding value.

Sugar Beets, from which is made a large amount of the sugar of commerce, are grown in a similar way to stock beets, but on a large scale require a rather different and special 
treatment. There is no trouble about raising them with a large percentage of sugar in any of the northern states, but the drawbacks to its becoming a more general industry are the very expensive machinery required to extract the sugar economically on a large scale, the small margin of profit and the low price the manufacturers have been willing to pay for the beets. Sugar beets grow entirely below ground, which makes them difficult to dig, and they do not grow to large size, seldom weighing more than four pounds. The part of a beet above ground does not contain much sugar. It is recommended to sow about $18 \mathrm{lbs}$. of seed of sugar beets per acre.

\section{LEAF BEET OR SWISS CHARD.}

Native of Southern Europe.-Biennial.-This appears to be exactly the same plant as the

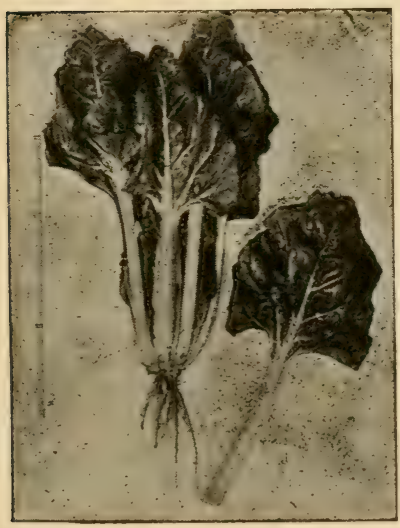

Figure 62.-Swiss Chard. beet root, except that in its case cultivation has developed the leaves instead of the root. The botanical characteristics, especially those of the fruit seed and flowers are precisely alike in both plants. The root is branched and not very fleshy, while the leaves are large and numerous, with the stalk and midrib fleshy and very large. The plants vary in color from deep red to nearly white. The fleshy leaf stalks are cooked and served like asparagus.

Culture.-The plants are grown in the same manner as the common table beets. Among the best varieties is one known as the Silvery Swiss chard.

\section{SPINACH. (Spinacia oleracea.)}

Properly a native of Western Asia.-An annual plant cultivated for its leaves which form popular spring and early sum- 
mer greens. It has a seed stalk about two feet high. The varieties are divided according to their seeds into round and

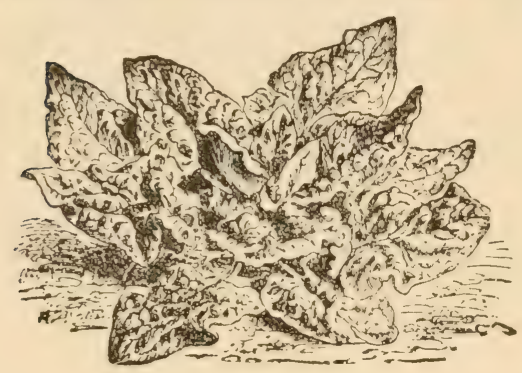

Figure 63.-Spinach. prickly-seeded sorts. The latter have sharp, hard prickles on the seeds. This division is so pronounced $\mathrm{that}$ some botanists have treated these classes as distinct species. The prickly-seeded sorts are considered the hardiest, while among the roundseeded kinds are perhaps the most desirable varieties for table use, but this difference is not always very clear.

Culture.-The seed of spinach may be sown in hotbeds or cold frames very early in the spring or outdoors as soon as the ground can be worked. It is of the easiest culture. A supply may be had during the whole growing season by making a succession of sowings at intervals of about two weeks. Under good conditions it will be ready for table use in about six weeks from the time of sowing the seed. In planting it outdoors the rows should be about twelve inches apart. The seed should be covered about one inch deep and about forty seeds or more sown to the foot or row. It is well to use plenty of seed and since it often starts poorly in dry weather extra precautions are taken when sowing it at that time. The plants may be thinned out when too thick, and, no matter how small they are they form a good regetable. Spinach is often sown in the spring between early peas, cabbage, potatoes or other slow growing crops. For early spring use the seeds of the hardiest kinds should be sown in this section in the latter part of August. The plants should grow well and attain a good size during the cool weather of autumn, and on the approach of winter they should be covered with about two inches of straw, hay or similar material. When thus treated the crop generally comes through the winter in this 
section without serious injury and after making a little growth in the spring is marketable. It is harvested by cutting the plants off at the top of the ground. For this purpose a short push hoe is run under the plants. They are then freed from dead leaves, and after being washed are ready for marketing. Spinach requires a very rich soil and plenty of well-rotted manure. To secure the best results from early spring sowings, it will pay those raising it for market, to use nitrate of soda on the land in small quantities, say, two applications at the rate of seventy-five pounds per acre at intervals of two weeks after the crop has started. This material has a wonderful effect on early leaf crops. Where nitrate of sorla is not used hen manure is very desirable The effect of nitrate of soda on this crop is very marked and often results in more than doubling its size. Spinach generally is very free from insects and fungous diseases.

Varieties.-There are a number of varieties of spinach differing in earliness, hardiness and in the time they remain in edible condition, as well as in many minor matters. Among the best are the following:

Long Standing.-An excellent sort for spring and summer sowing, since it stands longer than any other sort before going to seed.

Prickly, or Winter.-A prickly seed variety that is very popular. It will withstand very severe weather without serious injury if lightly protected by hay or straw and is probably the best sort for autumn planting in this section.

Bloomsdale.-A nice hardy sort with long, curled leaves of excellent quality. Very hardy.

\section{THE CABBAGE FAMILY. (Order Cruciferae.)}

The cabbage family is made up of herbaceous plants having watery juice, a pungent (penpery) taste, and floral envelopes arranged on the plan of four, with their petals generally spread out in the form of a cross. Stamens six, two of which are shorter than the other four. Seed all embryo. This is a large family and includes besides the cabbage, caulifiower, Brussel's sprouts, irale, kohl-rabi, horseradish, cress, water cress, whose cultural directions are given under this head, among common weeds, the mustard, French weed, false flax, pepper cress, shepherd's purse 
and many garden flowers such as nasturtium, gillyflower, candytuft and alyssum.

\section{CABBAGE. (Brassica oleracea.)}

Native of Europe and Western Asia.-Biennial.-It grows naturally to the neight of three or four feet and scarcely resembles any of our cultivated kinds. The part eaten is termed the head and is simply a cluster of leaves enwrapping the top of the stem, or in other words, a large bud. It attains the height of three or four ieet when it goes to seed. The flowers are generally yellow in color and conspicuous, though uot large. There are three great groups of cabbages distinguished respectively by their (1) red leaves, (2) smooth leaves and (3) wrinkled leaves. Red cabbages are chiefly esteemed for pickling. The varieties with smooth, light green leaves (common cabbage) are com.

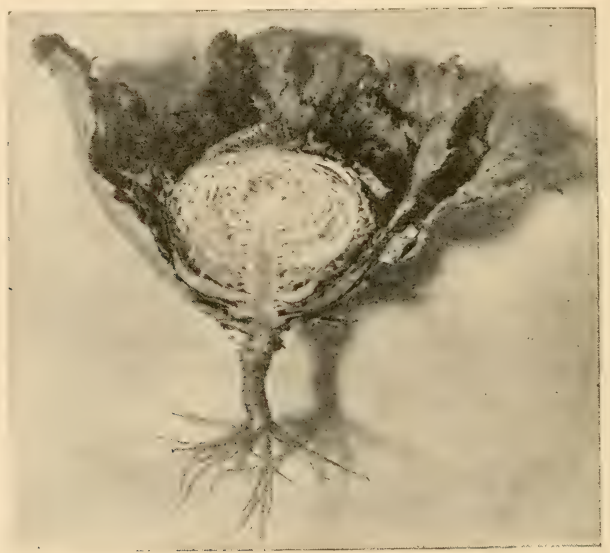

Figure 64-Cross section of cabbage head, showing arrangement of stem and leaves and that it is simply a big terminal bud.

monly cultivated, while the Savoy cabbage, which has wrinkled leaves, and is of the best quality, is little grown because it does not produce so abundantly as the common kinds. The original species from which the cabbage has sprung is also the parent of the cauliflower, kale and Brussel's sprouts. The seed of the cab. bage is dark brown in color, smooth and round. 
Soil.-The best soil for cabbage is a rich alluvial or prairie loam, moist, yet well drained and in fine condition. While some varieties will mature on poor soil yet they all require the highest cultivation for the best development. This is especially true of early cabbage, which needs mucil richer soil than the late crop. It is a good plan to occasionally change the land used for cabbage; in some eastern sections it is necessary to do this each year on account of the prevalence of the disease called clubroot, which is not yet found in this section.

Manure.-The cabbage is a gross feeder and needs lots of rich manure. Most of our best grower's apply manure broadcast, but when there is a necessity of economizing with the manure, it may be applied to better advantage in the hill, providing the land is in good condition. In growing eariy cabbage it is an excellent plan to apply a handful or so of dry hen manure aroun? the hills when the plants are half grown. This should not be put close to the plants, but scattered over a radius of a foot or more from the plants and then cultivated into the soil.

Early Cabbage.-The methods of cultivating adapted to the growing of early cabbage are quite different from those followed in raising late cabbage, and the subject of cultivation naturally groups itself under these heads. The soil preferred for early cabbage is a light, rich, sandy loam, well drained and sloping to the south, providing it is not too liable to injury from drouth. In milder sections of the country it is customary to sow the seed for early cabbage in September, and winter the plants over in cold frames. This method is impracticable in the extreme Northern states, and the best plan to follow in such sections is that of sowing the seed in greenhouses or hotbeds from the middle to the last of February. As the plants need room they are transplanted so as not to be crowded. If they are kept growing freely they will be large enough to transplant to the open ground by the first of April.

Setting the Plants.-Cabbage plants will grow at a low temperature, and it is a great adrantage to plant them out early in the spring, although the weather may be damp and cold. At this season of the year they may not show any great increase in leaf surface, but they form roots rapidly, and these are a great 
help in providing a vigorous growth later in the season. As a rule, early cabbage should be set out as soon as the frost is out in the spring and the ground nicely settled. It is important to set the plants deep in the ground at this season, and since the stem is the part most liable to injury from hard frosts, it should be set deep enough to bring the base of the leaves below the ground. This is very important and frequently mikcs the difference between success and failure in growing the early crop. I severe weather is threatened after the plants are set out, it is § good plan to draw a hoe-ful of earth over each plant, for if frozen when they are covered with earth they will not be injured, and they can remain buried in the ground several days in cold weather without serious injury. However, the earth should be removed as soon as good weather is assured. The distance between the plants will depend somewhat on the varieties to be cultivated; under ordinary conditions the large, early kinds should be set out two feet apart in rows three feet apart. This arrangement permits of horse cultivation both ways when the plants are young and one way when they are full grown.

Cultivation s'lould commence as soon as the rows can be clearly seen, and should be repeated after each rain or at least once a week until the crop is grown. For this purpose a finetooth horse cultivator is the most desirable instrument, and if the work is carefully done there will be very little need of hand hoeing. It is a good plan to draw the earth slightly toward the plants when they are about half grown.

Harvesting the Crop.-Treated in this way, under ordinary conditions they will be nicely "headed up" by the first of July and ready for marketing. The season for marketing, however, will depend largely on the kinds grown. If the land is at once plowed when the crop is harvested, it can be used for growing some late crop, as late beans, spinach or celery. By care in sowing and the selection of varieties early cabbage may be continued till late cabbage is in the market.

Retarding the Heading of cabbages may be accomplished by starting the roots on one side of the head or by slightly pulling the plant so as to break some of the roots. This is very important some seasons, as it is not uncommon to find the market overstocked with this vegetable just as the crop is full grown, and 
if the plants are allowed to remain growing when once a hard head is formed they are very sure to burst and be spoiled. By starting the roots a little, the growth is checked and heads may be kept from spoiling for a week or more.

Late Cabbage is a term generally given to cabbage grown from seed sown in the open ground. It may be ready for use in September or in the late autumn and be kept all winter.

Soil.-Any land that will produce a good crop of corn is in good condition for late cabbage, but the richer the land the better the chances of success. Less manure is required for late than for early cabbage. Late cabbage is generally raised by sowing the seed in the hills, or by sowing it in a seed bed and setting the plants in the field when of sufficient size. Each of these methods has its advantages and will be referred to separately further on.

Sowing Cabbage Seed.-Late cabbage may be raised by sowing the seed in a seedbed, in rows twelve inches apart, in the spring, and when the plants are large enough transplanting them to the field where they are to be grown. This is the common way of growing cabbage. Its advantages are that the plants may be set out o: land that has grown some early crop, as peas, or on sod land after cutting the hay. It also ensures having the plants all together in a small space, where they can be easily cultivated and guarded when they are young and most liable to serious injury from cut worms, flea beetles and other insects and from dry weather. It has the disadvantage of requiring the plants to be mored during the dry weather of early summer, when they are very liable to fail from lack of water in the soil. Sowing the seed of cabbage in the field where the plants are to mature and then thinning out to one plant to a hill, has the advantage of not requiring the transplanting of the plants during dry weather, and as the plants are not set back by transplant. ing they mature in a shorter time than transplanted plants. This makes it practicable to sow the seed later than when the plants are to be removed and is sometimes an advantage. It has the disadvantage. however, of having the plants scattered over a large area when they are small and are liable to serious insect enemies, and they are more difficult to cultivate than when 
in a seed bed. The thinnings from the land where seed is sown in the hill may be set elsewhere.

Raising Cabbage by Transplanting.-If the plants are to be r'aised in a seedbed and then transplanted to the open ground the seed of such varieties as Late Flat Dutch should be sown about the 10th of May; but if Fotler's Improved Brunswick or other second early kind is to be grown, the seed should not be sown until at least ten days later; and such large, early heading varieties as Early Summer may be successfully raised for winter use when its seed is sown as late as the first of June. In any case the plants should be ready to set out by the last of June, when they should be carefully transplanted. The land should be thoroughly pulverized and marked out three feet apart each way, unless it is to be manured in the hills, when it should be furrowed out one way and marked the other way. The plants should be set at the intersections of the marks, but it is not a good plan to sei them on top of the manure, but rather to put them a little to one side of it. This is especially important if the manure is not well rotted. The cultivation and after treatment are the same for late as for early oabbage.

Cabbage from Seed Sown in the Hill.-If the seed is to be sown in the hills, the land should be treated as recommended when the plants are to be transplanted. It is generally necessary for success to have the soil moist wren the seed is sown. After the land is marked out, seven or tight seeds should be sown at each intersection covered with about half an inch of soil and pressed down with the sole of the foot. The plants generally come up inside of a week and should be hand-hoed at once, and when large enough cultivated with a horse implement. When big enough to stand alone take out all but one plant from each hill and treat as directed for those that have been transplanted.

Harvesting Late Cabbage may be done by selling directly irom the field or by storing for marketing during the winter. If the heads are nearly ready to burst they cannot be kept long and should be disposed of at once. There is generally a good demand in the late autumn for this vegetable for general marketing and also by the pickling factories for making sauer kraut. Cabbages will stand ten degrees or more of frost, but severe 
freezing is very injurious; they are seldom injured by frost unless the stump is frozen solid. If there is danger of severe freezing before the crop can be marketed or stored, it is a good plan to pull the plants and put them into piles, with the stumps inside, and cover the whole with straw litter. Piled and covered this way, they may be left in the field until severe freezing weather and will generally be safe in such a condition in this section until the first of December. At harvesting there may be some heads that are quite too loose for marketing, and such cab. bage will often improve very much if stored as recommended for seed cabbage.

Storing Cabbage.-In order to have cabbage keep well far into the winter, they must not be headed very solid when gath-

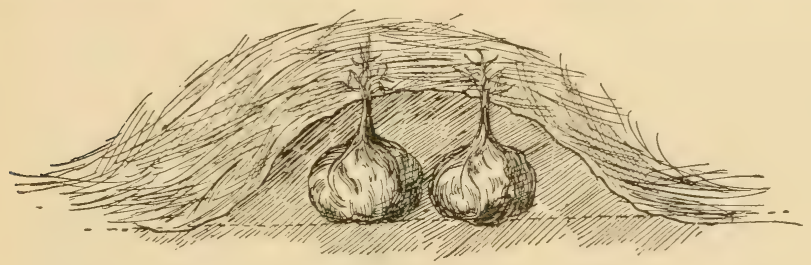

Figure 65.-Cabbage pitted for winter.

ered but should be a trifle soft, but there is quite a difference in the keeping qualities of the different varieties. If late varieties are sown too early, they will not keep well and if early varieties are sown late so as to be in good keeping condition when harvested they often keep very well. In order to store cabbages successfully, they must be kept cold and moist but never allowed to get warm or wet. Providing the cabbage is in good condition for storing it will generally keep until spring if the heads are set together with the roots up, in a trench and covered with from six inches to a foot of soil and mulch enough to prevent hard freezing. If they are frozen while buried and thawed out in the ground they are seldom seriously injured. In this section, however, a better plan is to keep them in a cold, damp cellar, stored in bins about four feet wide so as to allow a circula. tion of air through them. For commercial purposes, it is a good 
plan to build store houses, half in and half out of the ground; in a small way, they may be liept by burying the heads in sand in a cellar, or a few cabbages for home use, may be heeled in by the roots in the cellar-but it should be borne in mind that decaying cabbage is dangerous material to have under a dwelling house, and it should not be permitted under any circumstances. In storing eabbage the loose outside leaves should be removed and the stumps always left on, except when they are to be stored in bins.

Cabbage seed is a somewhat difficult crop to raise in this section, the trouble being in lieeping the plants over winter. Howerer, it may be done if care is used. For this purpose heads should not be permitted to get very hard: they should be gathered before the stumps have been frozen and be set close together, heads up, in a trench and covered with about a loot of scil and mulching enough to prevent severe freezing. (Cabbage

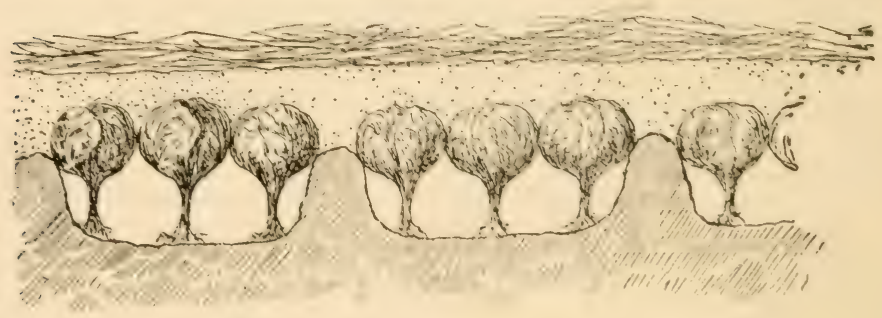

Figure 66.-Seed cabbages pitted for winter.

seed may be raised from the stumps after the heads are cut off. and this is a very simple matter as the stumps (an be buried like turnips or even kept in bins, providing they are covered with earth and kept cold, but such seed is not desirable. as the evidence seems to show that there is a tentency to increase the length of the stump at the expense of the head under such treatment. It is generally agreed among our best seed girowers that cabbage seed should be saved from the terminal buds of the stem which are in the cabbage head. Providing the seed cabbage are successfully wintered over, they should then be planted about the 1 st of May in deep furrows about three feet apart, in 
rows four feet apart. Sometimes the seed stalk cannot burst

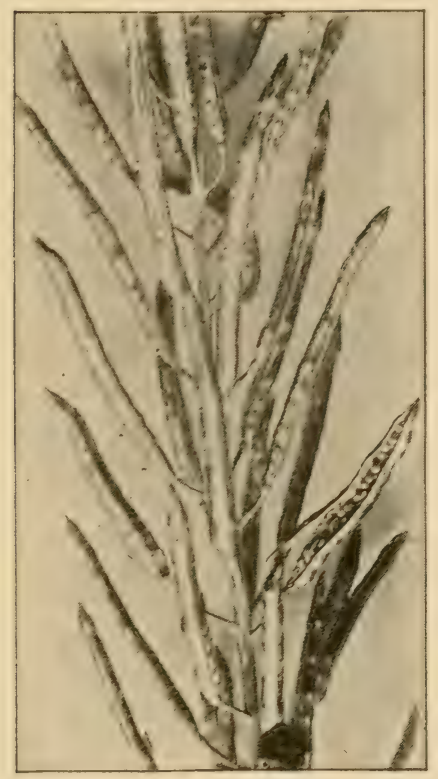

Figure 67.-Part of cabbage seed stalk showing seed pods. (After Landreth).

through the head leaves,

* and it is a good plan where the outer leaves are very thick and tough to cut through the outside leaves on the top of the head a little so as to allow it to push through. The seed is gathered branch by branch as the pods begin to turn yellow, and it generally takes several cuttings to harvest the seed pods. These are dried in buildings having tight floors and the seed is then threshed out.

Varieties. - For very early use the Early Jersey Wakefield is perhaps the most popular variety, but the head is quite small. For second early the Early Summer is perhaps the best and is generally more profitable than

other early kinds, since the head is of good size. The Early Winningstadt is a very desirable variety, forming very solid heads. It is the most reliable of ai! varieties for early or late use in unfavorable situations. Fotler's Improved Brunswick is a valuable variety for

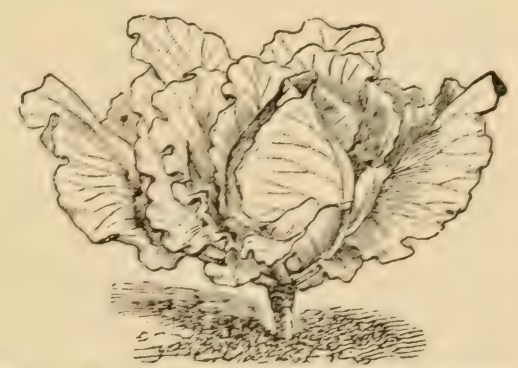

Figure 68.-Early Winningstadt cabbage. 
second early use or for winter use, and it is the earliest of the large heading kinds.

Flat Dutch and Stone Mason are desirable winter sorts and are good keeper's. The best red cabbage is perhaps the Mam-

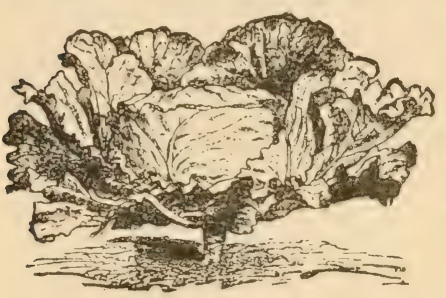
moth Red Rock. The Savoys are of better quality than the ordinary drumheads but do not produce so heavily. Iney are desirable for home use. The best of this class is the American Drumhead Savoy.

Insects.-The insects injurious to the cabbage are the flea Fig. 69-Premium flat Dutch cabbage. beetle, cabbage worms, cut worms and flea, for treatment of which see chapter on insects.

Diseases.-There are very few diseases that seriously injure the cabbage. The most common is club-root, also called clubfoot. The life history of this disease is not known. It attacks the roots of cabbage, cauliflower, turnips and other plants of the same family, causing them to form large irregular swellings. The plant is checked in growth and often dies from the effects of the disease. This is not yet a common disease in this section, but in some of the Eastern and Middle states it is very common. The best way of aroiding it is to not use the same land for cabbage or similar crop without at least three years intervening, during which time it is preferable to have the land in grass or clover. This disease is also transmitted by Pepper Cress, Shepherd's Purse, Candytuft and similar plants. This disease may also be distributed in manure from animals fed on diseased plants.

Sauer Kraut.-The following recipe for sauer kraut is a very excellent one: Slice cabbage fine in a slaw cutter; line the bottom and sictes of an oaken barrel or keg with cabbage leaves, put in a layer of the sliced cabbage about six inches in depth, sprinkle lightly with salt, and pound with a wooden beetle until the cabbage is a compact mass; add another layer of cabbage etc., repeating the operation, pounding well each layer until the barrel is full to within six inches of the top; cover with leaves then a cloth, next a board cut to fit loosely on the inside of the 
barrel, kept well down with a heary weight. If the brine has not raised within two clays, add enough water with just salt enough to taste to corer the cabbage; examine every two days and add water as before, until brine rises and scum forms, then lift off the cloth carefully so the scum may adhere, wash well in several cold waters, wring dry and replace, repeating this operation as the scum arises, at first every other day, and then once a reek, until the acetolis fermentation ceases, which will take three to six weeks. Up to this time keep warm in the kitchen, thew remore to a dry, sood cellar unless made early in the fall, when it may be at once set in the pantry or cellar. One pint of salt to a full barrel of cabbage is a good proportion; some also sprinkle in whole black pepper. Or, to keep until summer: In April squeeze out of bine and pack tightly with the hands in a stone jar, with the bottom lightly sprinkled with salt; make brine enough to well corer the krant in the proportion of a tablespoon of salt to a quart of water; boil, skim, cool and pour orer; corer with cloth, then a plate, weight and another cloth tied closely down; leep in a cool place, and it will be good as late as June. Neither pound nor salt the cabbage too much, watch closely and lieep clear from scum for good sauer kraut.-Buckeye Cook Book.

Black Rot of Cabbage is a disease that has not attracted much attention until the last few years but has during that time caused much damage to cabbage and cauliflower.

The first indication of this disease is upon the outer leares of the plant which turn yellow and die in spots usually near the margins. Such leares are also liable to wilt and careful examination will show that the reins in and near the dead areas are blackener. These spots enlarge and gradually involve the whole leaf. from which it passes to the stem and to the rest of the plant, causing it to rot. The dark colored reins in the freshly cut stem and leares are the best indications of this disease and are its characteristic marks.

Cabbage that is even slightly affected will not keep, for this rot spreads rapidly in stored cabbage, and in selecting cabbage for storage, the stems and outer leares should be examined for the blackened vein so characteristic of this disease. 
The germs of the disease may pass the winter in the soil and reinfect cabbage, cauliflower, turnips or similar crops and even such nearly allied weeds as Pepper Cress and Shepherd's Purse the following season. If diseased cabbage is fed to stock the disease may be distributed by the manure.

Remedial Measures.-In view of the above facts, it seems reasonable to take the following precautions: (1) Do not plant cabbage a second year on land where the disease is observed without several years intervening, during which no nearly allied crop has been grown on it. The seed bed should also be made in new soil each year as the plants may become diseased when vary young. (2) Do not use manure for cabbage crops from animals that have been fed uncooked diseased cabbage. (3) Since the disease may be spread by insects which fly from one

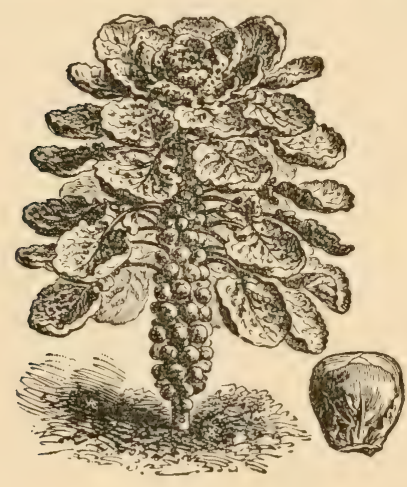

Figure 70.-Brussells Sprouts. plant to another, they should be kept in check as much as possible. (4) When the disease appears the field should be gone over systematically and all diseased leaves removed and destroyed as soon as they appear. If the disease has entered the stem the whole plant should be destroyed This destruction should consist of burning or deep burial. (5) Since this disease may be continued on Wild Mustard, Pepper Cress, Shepherd's Purse and other allied plants, they should be carefully kept out of

land that has been once infested if it is intended for cabbage. BRUSSELS SPROUTS. (Brassica oleracea.)

Native of Europe.-Biennial.-This is one of the many variations which the cabbage has taken on under cultivation. In this case where the head of the cabbage is ordinarily found there are loose green leaves and seldom a head. The stem is generally two feet or more high, with leaves, and at the base of each leaf is a small cabbage which seldom attains a diameter of over two inches. These little cabbages are the parts eaten; they are 
much more delicate than the common cabbage and highly esteemed by many. The plant requires the same treatment as cabbage except the plants can be grown nearer together. While easily grown it is doubtful about its becoming a popular vegetable. since in most of our markets very little attention is paid to quality, and the common cabbage will probably continue to take the place of this vegetable on most tables. The variety most esteemed is known as Dwarf Brussels Sprouts.

CAULIFLOWER. (Brassica oleracea.)

Native of Europe.-Biennial.-Cauliflower is a form of cabbage in which the inflorescence becomes fleshy and distorted.

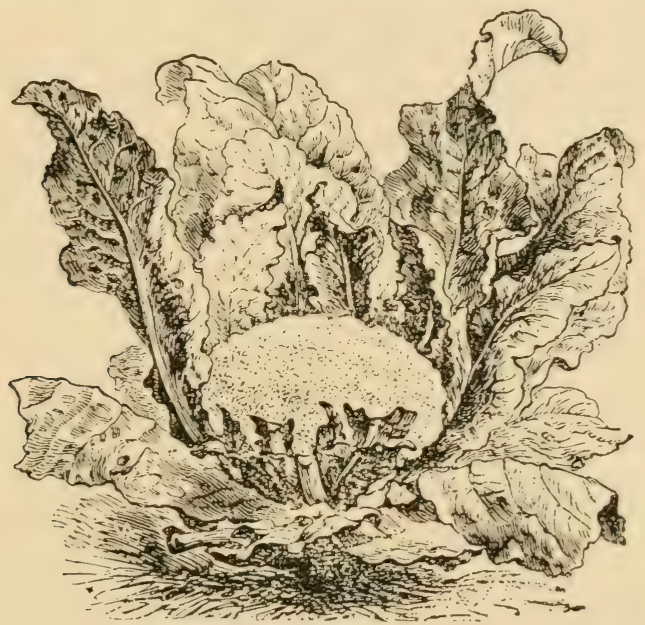

Figure 71-Snowball cauliflower.

It is, however, considered much more delicate than cabbage and brings a higher price. It is grown in much the same manner as cabbage; the plants, however, are not so hardy in resisting cold weather as cabbage, are more sensitive to adverse condi. tions and should have more manure in the soil. As soon as the head commences to form, the outsicle leaves of the plant should be drawn together over the head so as to keep the sunlight away from it. Treated in this way the heads will be nearly snow 
white, while if not protected they become brown in color and are

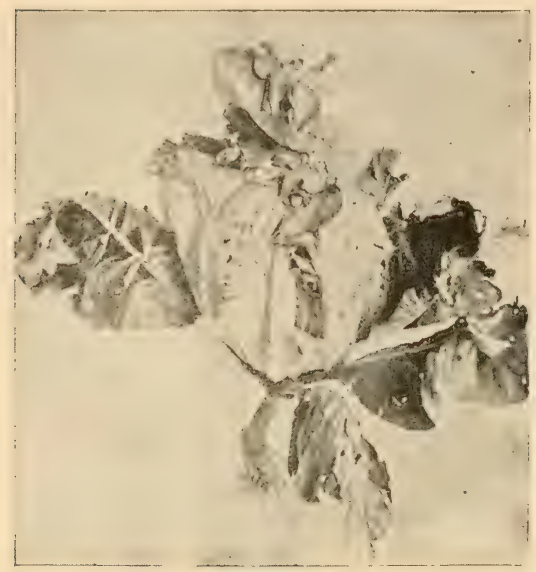

Figure 72.-Cauliflower plant with leaves tied together to keep the sunlight off the head. This should be done as soon as the head can be seen, and the leaves should remain tied until the head is cut out. not as salable. The crop ripens somewhat irregularly When danger of hard frost is apparent the immature heads should be pulled with roots and leaves and be planted out in a cold cellar or cold frame, where many of them will form good salable heads. The insect enemies are the same as those of the cabbage.

Varieties.-There are many varieties, but perhaps, the most desirable are the Snowball and the Early Dwarf Erfurt.

KALE, or BORECOLE. (Brassica oleracea var.)

Native of Europe and Asia.-Annual or biennial.-The seed is like that of the cabbage or kohl-rabi. Under this head is grouped a number of vegetables closely related to the cabbage and kohl-rabi that are used for greens. None of them are sufficiently hardy in the extreme north to stand out over winter. They are here cultivated in the same

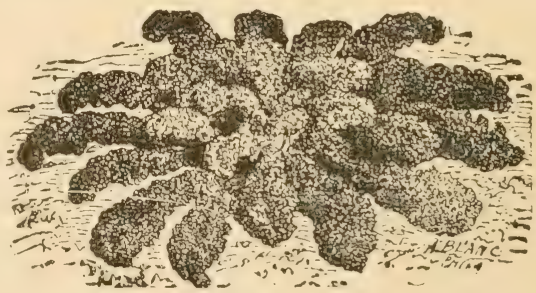

Figure 73.-Dwarf Purple Kale. manner as turnips. In sections where the winters are mild, some of them are esteemed for planting in autumn for early spring use. 
KOHL-RABI. (Brassica oleracea var.)

Kohl-rabi has been derived from a plant nearly allied to the cabbage, and its seed resembles cabbage secd. Its peculiarity is its swollen stem just above the ground, which is used for the same purpose and grown in the same general way as the turnip.

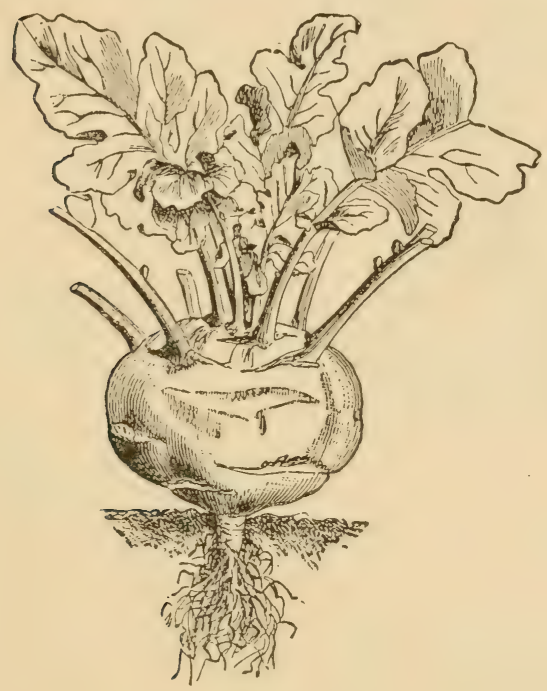

Figure 74.-Kohl-Rabi.

It is more highly esteemed than turnips for early summer use where well known. Like turnips it should be sown where it is to mature and used when young and tender. It may be stored in winter like turnips.

Varieties.-There are small tender varieties especially designed for table use and others that grow to large size and are valuable for feeding stock. Two of the best for table use are the White and Purple Vienna.

TURNIP (Brassica napus) and RUTABAGA, or SIVEDISH TURNIP (Brassica campestris.)

Native of Europe or Asia.-Biennial.-Cultivated for their swollen, fleshy roots. The varieties of turnip and rutabaga rary much in form, size and color of the skin, and the flesh is white or yellow, pungent or slightly acid. There is more difference in the varieties of the turnip than of the rutabaga. The flower stalks are produced the second year and bear a large number of yellow flowers. The seeds are smooth and round like the seed of the cabbage and cauliflower and in similar shaped pods. 
Turnip.-The turnip is essentially a cold weather plant and does best when most of its growth is made during the autumn. It is grown to some extent in the spring, but there is very little call for it until cool weather.

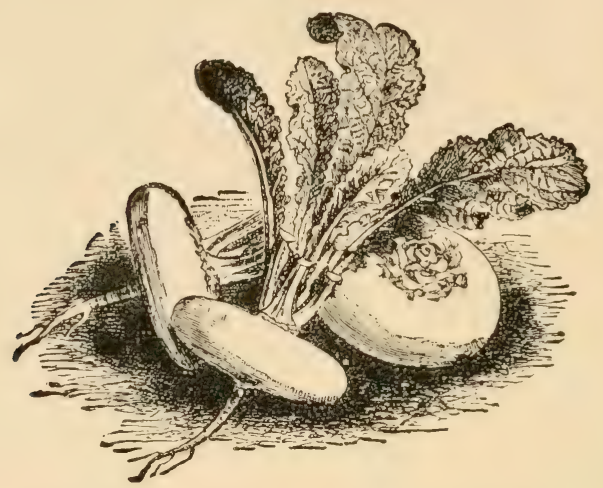

Figure 75.-White Strap Leaved Turnip.

Culture.-The turnip needs to be grown very rapidly to have the best quaiity. The best soil for it is a friable, rich, sandy loam, free from fresh manure; sod land that has been recently broken up is excellent for this purpose, but on old land, i. e., that which has been cultivated for several years, or where there is fresh manure, the roots are often wormy. When grown for early use some quick maturing kinds should be planted as early in the spring as the soil can be worked in rows fifteen inches apart. The seed should be sown rather thickly and the seedlings thinned out two or three inches apart after all danger from the flea beetle has passed. (This insect is the same as that which attacks the cabbage.) Turnips grown for late use generally come in as a second crop after grain, strawberries, early potatoes, cabbage or other crop that is off the land by the first of August, since after this time a good crop of many varieties of late turnips will mature before winter, though some of the large kinds need to be sown earlier in the season. The seed is sometimes sown broadcast just before a shower or else it is harrowed 
in. It is also grown in rows about two feet apart and cultivated by a horse cultivator, or the rows may be put nearer together and a hand cultivator used.

Varieties.-Some of the best varieties of turnips are: Early Flat and Extra Early Milan for early use; Red Top Strap Leaf and White Egg or White Globe for autumn use.

Rutabagas, (also called Swedish Turnips), are grown in the same manner as the common turnips, but require about four

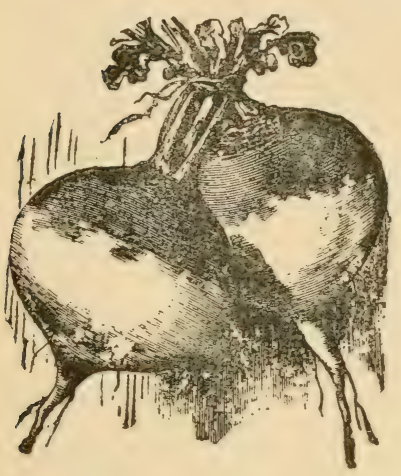

Figure :6-Rutabaga. weeks longer to attain edible size, and, on this account, should be planted by the middle of June or first of July. They are grown in rows thirty inches apart and cultivated with a horse hoe. Rutabagas are sometimes grown in beds and transplanted, but this is seldom, if ever, done with turnips.

The seed of both turnips and rutabagas is so smooth and fine that it is generally sown too thick. Mixing the seed with flour is a good way to prevent its running too rapidly through the seed sower. The crop should be allowed to stay in the ground until the approach of severe cold weather. They will stand some little freezing without injury, but will not live in the land over winter. They should be stored in frost proof pits or cellars. In dry cellars they should be covered with a few inches of sand or other material to prevent wilting. (See directions for keeping carrots.)

Varieties.-Improved Purple Top Swede, and White Rock, are both excellent varieties of rutabagas.

HORSERADISH. (Nasturtium armoracia.)

Native of Europe-Perennial,-Flowers white and small, in 
long clusters; seed vessels small, rounded and almost always barren. Propagated by cuttings of the roots.

Cultivation.-This plant delights in deep, moist soil, but will grow in almost any situation and is very hardy. For home use it is customary to let it remain in some neglected corner; where it kills out everything else, and though treated in this way it yields sufficient roots for home use; yet the roots aie so crowded that they are scarcely salable. When grown as a marliet crop it is planted anew each year. Straight pieces of roots six or eight inches long, called "sets" are planted about twelve inches apart, in rows two feet apart early in the spring. The roots must be set right end uppermost or they will not grow smooth or straight. An iron bar is the most convenient tool for planting the "sets." The top of the sets should be about two inches below the surface. It is customary to grow horseradish as a second crop after peas or cabbage, by setting the roots between the rows of the first crop and cultivating the soil without regard to them until the first crop is harresterl. It does not seem to hurt horseradish "sets" much if they are cut off a few times in cultivating early in the season. When the first crop is gathered the land is thoroughly cultivated, and the horseradish plants given good care. This plant makes its greatest growth in autumn and is dug on the approach of winter or can be left until spring. It must never be left two years on the same land, or else great labor will be required to get rid of it. and the roots will be so crooked as to be almost unsalable. Horseradish is used almost entirely after grinding or grating the roots and mixing with vinegar. It will keep for any lengtlı of time when thus prepared and kept in air-tight packages. It is also gromnd and dried, and the young leaves are sometimes used for greens. The demand is limited, though considerable quantities are sold each year. Under some conditions it is a paring crop, but the business is very apt to be overdone. There are no varieties.

\section{WATER CRESS. (Nasturtium officinale.)}

Native of Europe.-Perennial.-An aquatic plant with long stems, which readily take root in moist soil or water. It is esteemed for use as a salad on account of its pleasant pungent flavor. Leaves are compound, with roundish divisions; flowers 
small, white, in terminal spikes; seeds, usually few, very fine, in slightly curved pods.

Culture.-It can only be cultivated successfully in moist situations and generally does best along the edges of streams, where it grows partially in the water. It may, however, be grown successfully in any moist soil, even in a greenhouse. It is rery hardy, but for best results should be covered with water during winter. Most of the supply for our markets comes from along the courses of natural streams. In Europe, trenches from 16 to 20 feet wide for growing water cress are often excavated, into which running water may be turned at pleasure. In the bottom of these trenches, the roots of the cress are planted. The water is then let in, and the plants are not interfered with until they have grown strong enough to yield a crop of leaves. It is often practicable to make narrow beds about springs or slow running streams for this purpose.

CRESS, or PEPPER GRASS. (Lepidium sativum.)

Native of Persia.-Annual.-An early spring vegetable, used as a salad and for garnishing, and of the easiest culture. It should be sown very early in the spring in the hotbed or outdoors in rows one foot or less apart. As it quickly runs to seed, a succession of sowings should be made every eight or ten days. It is only in demand in the early spring or in winter. It can easily be grown in a window box in a dwelling house. Flowers white and small; seeds comparatively large.

RADISHES. (Raphanus sativus.)

Probably a native of Asia.-Annual or, in the case of the winter radish, biennial.-The flower stalks are branched, about three feet high and have white or lilac-colored flowers, but never yeliow. The seed is roundisis or oval, but somewhat flattened and much larger than cabbage or turnip seed and much more variable in size. Some recent experiments show that the large radish seeds gerumate better and produce marketable roots sooner and more uniform in shape than small seed.

Culture.-The radish is a vegetable of very easy culture. The roots of some kinds reach edible size in three weeks when grown in best conditions and are a farorite vegetable of early 
spring. It is a common practice to sow the seed of early kinds in hotbeds between rows of lettuce and outdoors between, or in the rows of beets, carrots, parsnips, etc. They will grow in almost any soil, but new land is best for them. The seed may be sown as soon as the ground can be worked in the spring, and if sowings are made once every two weeks thereafter a succession of tender roots may be had.

Winter radishes are grown and stored in the same manner and fully as easily as turnips. The seed is sown in June or July.

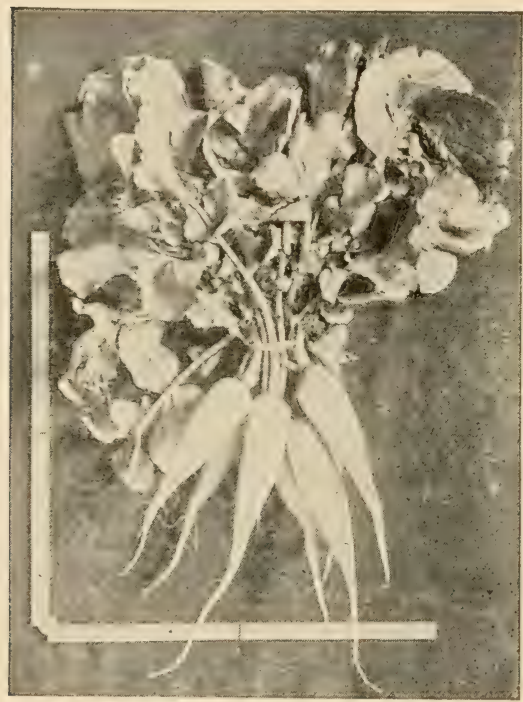

Figure 77.-White Strasburg Radish. and the roots gathered in autumn and stored in cellars or pitted outdoors. They keep very well. Winter radishes closely resemble the errly kinds in quality, but are firmer in texture. The cabbage flea bee. tle affects the young radish plants in the late spring and summer. (See chapter on insects for remedies.) The roots are sometimes infested with maggots, but these are seldom troublesome except where fresh manure is used or in land where radishes have been grown for several year's. It is 'jest. not to manure the land for radishes but use rich soil that has been put in good order by some previous crop.

Varieties.-There are many kinds, differing from each other in color, form, size time of maturity and taste. They are generally divided into early or forcing varieties, summer and au- 
tumn varieties and winter kinds. A few of each are here mentioned:

French Breakfast.-One of the best very early radishes for the market, but small. It remains in good condition for only a short time, consequently is not desirable for the home garden.

Early White Tipped Scarlet Turnip Shaped.-A handsome,

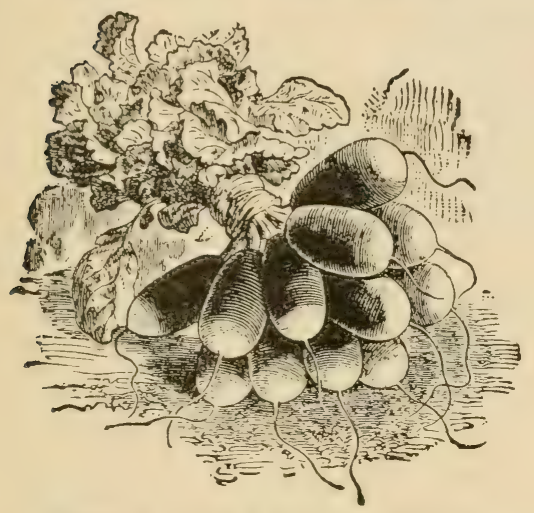

Figure 78.-French Breakfast Radish. round, early, popular radish, maturing very quickly.

Early Deep Scarlet. -Very early, round and of deep scarlet color.

Long Scarlet Short Top.-A well known desirable early kind having long scarlet roots.

\section{White Strasburg.-} One of the finest half long kinds for summer use. Grows to good size; white and tender.

Rose.-The most popular of the winter sorts. Skin pink.

Black Spanish.-Skin very black, flesh white, firm, tender but very pungent. A good winter sort.

\section{THE CLOVER FAMILY. (Order Leguminosae.)}

The Clover family is made up of trees, shrubs or herbs which with few exceptions have a butterfly-shaped corolla, 10 stamens, 9 of which are generally grown together. The fruit is known as a legume and is a pod that opens like the pea or bean pods. The leaves are alternate, chiefly compound, and have stipules. Besides the beans and peas, whose cultural directions are here given, the following are members of this family: Clovers, Vetch, Alfalfa and Lupine among farm crops, and the Common Locust. Kentucky Coffee Tree, Honey Locust and Yellow Wood among trees. 
Annual. The common beans in this country are natives of the warmer parts of South America. They are sometimes referred to as kidney or French beans (P. vulgaris). Besides

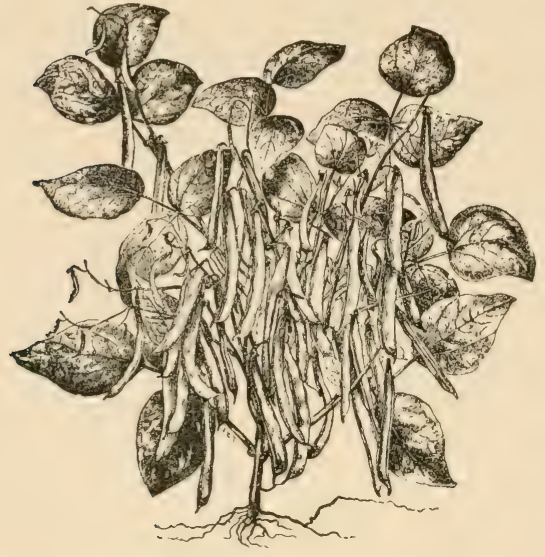

Figure 79.-Bush Bean. these, the Lima beans (P. lunatus) are cultivated to a limited extent. The common broad bean of Europe is an entirely different vegetable from the kinds generally grown here and is not sufficiently prolific in this section to make it worthy of cultivation. There are many varieties of beans, and the varieties of each species readily cross together, the flowers being especially adapted to crossing. They vary from one another in many particulars; some are low, bushy and erect, while other's are twining and have stems that grow ten or more feet in a season.

There are many gradations between these extremes, as well as in size, color and shape of seed and plant. The twining ster kinds always twine from right to left around any support they can lay hold of. Horticulturally, beans are divided into the bush and pole varieties. Under the first class are included all the field varieties that are grown to be used as shelled beans and some snap and string beans. They have stout, erect or slightly running stems. Under pole beans are classed all the kinds that have twining stems and which are benefited by having support of some kind. There are. however, dwarf bunch beans having the same general features as the pole kinds except the tall stem. While this division is by no means distinct, yet the methods of cultivation adapted to each growth are different. Alf 
beans are quite tender and should not be planted untiil the soil is warm and all danger of frost is over. They are sown for early use about the time for general corn planting. For the main crop they should be planted about the first of June.

Bush Beans.-These are very easily grown and are adapted to a great variety of purposes. For a field crop on a large scale, the seed is generally sown with a horse drill or with a hand garden drill, in rows three feet apart. It is sometimes best to mark out the land first and then follow with the drill in the marks. Seed should be sown two or three inches deep. On a smaller scale, the land may be furrowed out with a one-horse plow or with a wheel hoe and the seed sowed by hand. After culture consists in keeping the land well cultivated with a horse hoe and free from weeds. Varieties of dwarf beans for use in a green state, such as string or snap beans, may be sown at any time from the middle of May to the first of August and with good prospects of a good crop of green pods even at the latter date. Some kinds have edible pods in less than six weeks from the time the seed is sown.

Harvesting 3eans.-For use in a green state, the pods of some kinds of beans are picked as soon as large enough to use and when they are tender and fresh; in other cases the beans are used when still fresh, but not until they are large enough to shell from the pods. Field beans are harvested by being pulled by hand or gathered with a bean gatherer when they are ripe, laid in rows until dry enough for threshing, then threshed at once or stored for threshing later on. Great care should be taken in storing the pods to prevent molding of the beans, and in threshing nor to break the beans. In a small way beans may be threshed out by hand, but on a large scale any common threshing machine may be used, providing suitable changes are made in it so it will not break the beans.

Varieties of Bush Beans.-There are many varieties of bush beans having desirable qualities, but only a few of the most valuable are mentioned here:

Field Beans.-White Marrow, Burlingame Medium, Navy and Snowflake. 
Waxen Podded Beans.-Dwarf Golden Wax and Dwarf Black Wax.

Shell and String Beans.-Yellow Six Weeks, Early Mohawk, Cranberry and Dwarf Horticultural.

Japanese, Soy or Soja Beans.-These are easily grown, but on account of their inferior quality are not much used here.

Dwarf Lima Beans are highly esteemed by those who know them and, although smaller in size than the pole Limas, are supplanting them in this section and coming into quite general use, on account of their being more certain to mature well

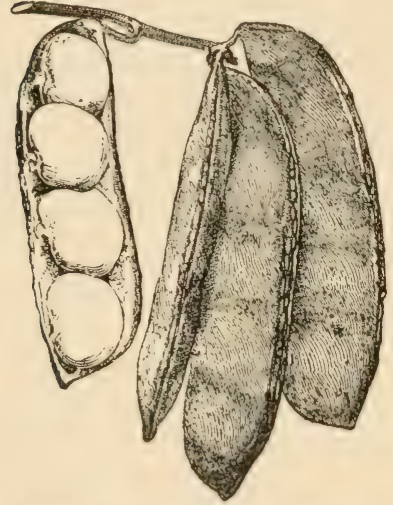

Figure $80-$ Dwarf Lima beans. and requiring less labor in cultivation. They require the same methods of cultivation as other dwarf beans but should not be planted until the land is thoroughly warmed. The best varieties are known as Henderson's Dwarf, Durpee's Dwarf, Jacksun Wonder (black spotted) and Kumerle Dwarf Lima. The common dwarf shell beans are early, productive and good, but not so rich in quality as these.

Pole Beans.-The twining varieties of beans are little grown in this section, as the improved dwarf kinds take their place to a great extent. However, tall Lima beans are highly esteemed by many and the dwarf varieties of this class are not so desirable as the pole kinds. There is also a demand for such shell beans as the pole Horticultural, Cranberry and Caseknife varieties. Pole beans require stronger land than do the dwarf kinds. The ordinary way of growing pole beans is to set poles six feet long in hills four feet apart each way. It is customary to put a shovelful of good compost or rotted manure in each hill if the land is poor. Seed should not be planted till the ground is quite warmthe pole varieties are more particular in this respect than the dwarf kinds. About six seeds should be planted two or three 
inches deep around each pole. In the case of Lima beans the general belief is that the beans should be planted edgeways with the eye downwards, but good results are often obtained by sowing the seeds without regard to this matter. This latter method is customary in sowing the dwarf Lima, and some who sow the large Lima beans in furrows and train them to trellises pay no regard to the position of the seed in the soil, but sow an abundance of seed so as to be sure of a good stand. Lima beans are generally shelled by hand when fresh but full grown and are sold by the quart. In warm climates they are sold in large quantities after being dried. The Cranberry and Horticultural kinds are generally sold in the pod. As soon as the seedlings commence to "run," it is customary to assist them in getting started, and some seasons it is necessary to tie the Lima beans to the poles until they are well started. Lima beans require an extra warm location and soil.

Beans may be Transplanted if removed with much care when the soil is moist. Some very successful gardeners find that it

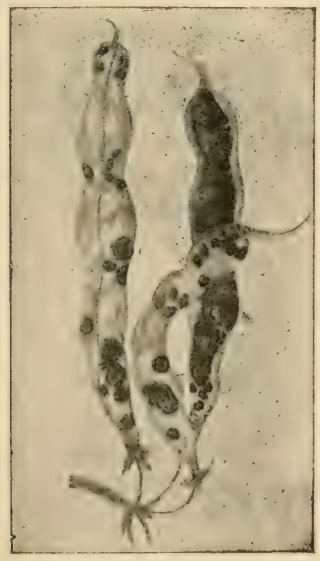

Figure 81-Anthracnose of bean pod. pays them to start their pole Lima beans on pieces of sod or in pots or boxes in hotbeds and in this way they advance the period of ripening two weeks or more. This is a very desirable practice with pole Lima beans in this climate, since the short season often fails to mature much of the crop when the seed is planted in the open ground. The varieties of pole Lima beans best adapted to this section are probably the Large Lima and Dreer's Lima; both of these are of fine quality and productive. The small Lima or Sieva bean is sarlier than those mentioned but of inferior quality.

Preserving Beans in Salt.-String beans are easily preserved 
in salt for winter use, using about seven pounds to the bushel

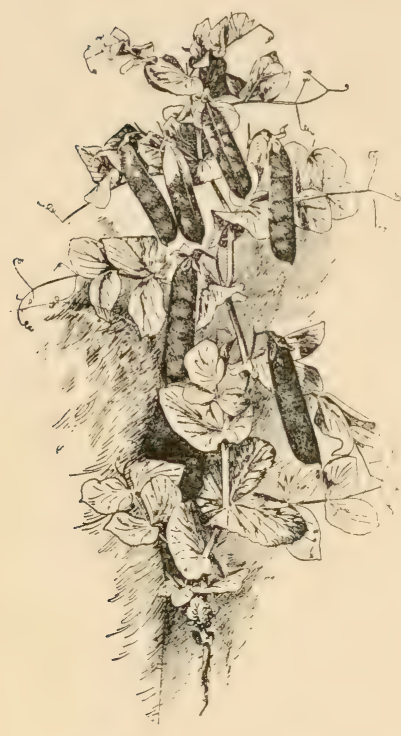

Figure 82-Nott's Excelsior pea. of pods. In doing this the fresh tender pods are put at once into the brine as they come from the field. When wanted for use, they should be freshened out and cooked in the ordinary way. They are very good, and are nearly as desirable as the best canned beans.

Diseases and Insects.-Beans are quite free from the attacks of any injurious insects or diseases. Anthracnose of the bean (Gloeosporium lindemuthianum) shows itself by black spots on the stems or pods or both. It is sometimes very injurious in moist weather, but only in occasional years have we anything to fear from it. It is not generally considered profitable to ise any of the fungicides, such as Bordeaux mixture, which would readily prevent it. Beans grown in locations where there is a good circulation of air are less liable to injury than those protected from a good circulation of air.

\section{PEAS. (Pisum sutivum.)}

The pea is an annual plant of uncertain origin, but probably a native of central Europe. The flowers are either white or violet colored, but the most desirable garden kinds, almost without exception, bear white flowers.

Varieties of peas are divided into three classes, those having wrinkled seed, those having round, small seed, and those having edible pods. Wrinkled seeded varieties do not germinate as well as the smooth skinned or round sorts, nor do their germinating powers last so long, nor are they so hardy in resisting the adverse conditions of early spring. On account of the latter reason, gardener's plant the round seed first in the spring, and 
do not plant the wrinkled kinds until the soil is in best condition and somewhat warm. The wrinkled kinds are better in quality than the round and smooth rarieties. Peas having edible pods are not popular in this country, probably because of the ease with which string beans are grown.

Culture.-Peas may be grown successfully in almost any good soil; they even do well on rather poor soil. The kinds having smooth seeds should be planted as soon as the ground can be worked in the spring-even a hard freeze does not hurt the plants as they are coming out of the ground, and they will stand considerable frost when well up The distance between the rows and the seeds in the row depend somewhat on the kinds grown. Some kinds branch out far more than others and, consequently, need more room in the row. They also vary in length of stem from a few inches to six or seven feet. The tall kinds require the rows to be five or six feet apart, while dwarf varieties are generally planted in rows thirty inches to three feet apart. The growing of tall kinds is mostly confined to private gardens, where it is customary to use brush or other material in the rows for support. Formerly, among tall varieties, were those far excelling in quality anything found among those of a dwarf habit, but recent introductions of the latter kinds have shown a great improvement in quality, until now the dwarf sorts are generally grown, even by the most fastidious. In common practice, the seed is sown about four inches deep, in rows three feet apart, putting about ten seeds to each foot of row. It is best to sow plenty of seed in order to secure a good stand. The land should be well cultivated between the rows. Unleached wood ashes or some other fertilizer rich in potash and phosphoric acid is most beneficial for this crop. As it belongs to the leguminous section of plants, it is a nitrogen producer and, consequently, does not need much nitrogen in the soil. Early peas as generally grown are out of the way in time to allow the land to be used for late cabbage or string beans. When it is desired to extend the season of table peas, successive showings should be made at intervals of two weeks, up to the tenth of June. During the summer the vines are too liable to mildew to make late spring planting successful. The pea is distinctively a cool weather plant and on this account 
it will often do well when sown in the latter part of summer for use in autumn.

The Canning of Peas is an important industry in some sections and could be more generally introduced into this section to advantage. In sowing peas for canneries it is the practice in some sections t- sow them with a common grain drill, leaving a path between each strip for the pickers.

Varieties.-Of the many varieties only a few of the best are referred to here. For very early use, almost every seedman has a strain of smooth, round peas, which he sends out under his own peculiar name. The early sorts are generally derived from the old Daniel O'Rourke, and among them are varieties known as the First and Best, Earliest of All and Improved Extra Early. As a rule, these should be used for first planting only, to be followed by plantings of the wrinkled sorts.

American Wonder is a very dwarf early pea of unsurpassed quality and very hardy for a wrinkled sort. A rich soil and extra cultivation are required to get the best results from it. If only one variety is to be grown, this is perhaps the best to plant.

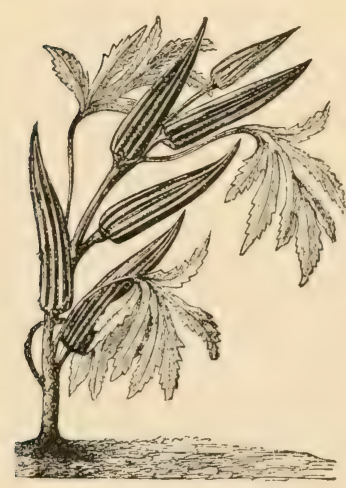

Figure 83-Dwarf Okra.

Stratagem.-Very productive and justly very popular, having remar:ably large pods filled with rich, sweet peas. It does better on light than on heavy soils.

Yorkshire Hero.-An excellent variety.

Marrowfat.-Among the most pop. ular of the old varieties.

Champion of England.-A tall growing, popular sort, of best quality, that does best when supported by brush or wire netting. Late.

Telephone.-Of excellent quality. Pods and seeds large. One of the most productive and, consequently, very popılar. Late. 
Bliss's Abundance.-Half-dwarf, branching, of excellent quality and very productive. Late.

Nott's Execlsior.-A new, very productive, early dwarf variety that is becoming very popular, and in some sections much preferred to the American Wonder.

\section{THE MALLOW FAMILY. (Order Malvaceae.)}

The mallow family is known by its numerous stamens which have their filaments grown together and are attached to the base of the petals. The petals are twisted together in the bud. Seeds kidney-shaped. Herbs or shrubs mucilaginous with very tough fibrous bark, none of them poisonous. Okra is the only plant of this family which is frequently grown in gardens, but the common cotton plant also belongs here as well as the abutilon mallow, hibiscus, althaea and hollyhock of our gardens.

\section{OKRA. (Hibiscus esculentus.)}

Native of South America.-Annual.-The seed is round and of medium size. It is cultivated for its green seed pods, which are highly esteemed for soup. Little grown except at the south. It is of the easiest culture. The seed should be sown about two inches apart in rows two feet apart and in rich, warm soil, at about the time for planting beans. The pods are produced abundantly but are perhaps not as tender when grown in our dry atmosphere as they are in the south. The flowers are large, yellow and very pretty.

The varieties known as Dwarf Green and Long Green are best for our climate.

\section{THE PARSNIP FAMILY. (Order umbelliferae.)}

The parsnip family is made up of herbaceous plants some of which are aromatic and others that are acid-narcotic poisons. 
The flowers are small and generally arranged in compound um. bels; no calyx, but in place often have five minute teech, five petals, five stamens and two pistils. The dry fruit

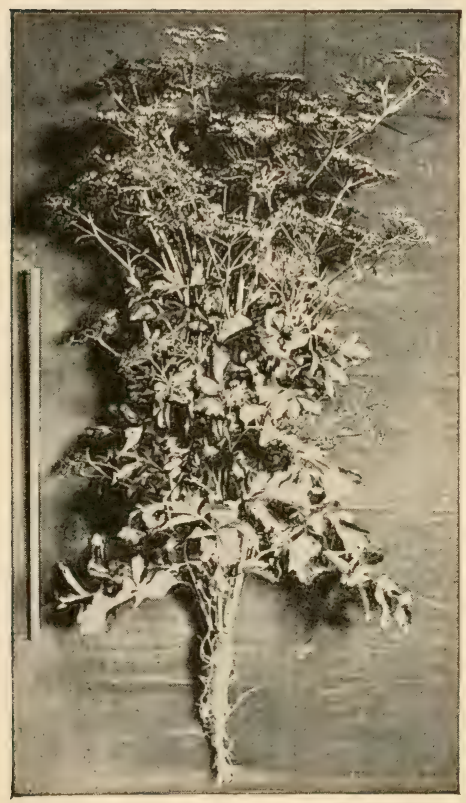

Figure 84.-Parsnip plant in flower. usually splits into two parts and the seed of most species has oil tubes. The leaves are alternate and more commonly compound or decompound. Besides the parsnips, parsley, carrot, celery, whose cultural directions are here given, dill, anise, caraway, coriander and fennel will be found under the head of garden herbs.

\section{PARSNIPS.}

(Pastinaca sativa.)

Native of Europe.-Biennial.-Cultivated for its long, tender root. Seeds light brown in color, flat and marked with five raised lines or ridges. Seed stalks three to five feet

high with large umbels of greenish flowers.

Culture.-The parsnip is grown in the same manner as the carrot, but is rather more particular about the soil on which it grows. Then, too, in manuring the land for this crop, it is important to use only manure which is well rotted, as the application of fresh manure seems to encourage the formation of side roots. Also on hard land. there is often a tendency for the roots to form side roots, and, as what is desired is a rather thick tap root, side roots are to be avoided. It is important t- 
sow the seed early and quite thick and then to thin out in order

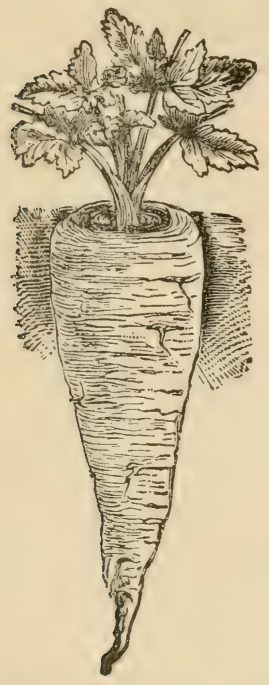

Figure 85-Holluw Crown Parsnip.

to be sure of having a good stand of plants. The seed germinates rather slowly. It is a very hardy crop and may be left in the ground until late autumn or even over winter. In fact, many believe that freezing parsnips in the ground improves their quality. They may be safely pitted outdoors by putting them in heaps, covering with a few inches of hay or straw and then a foot of earth. Treated in this way, they can be taken out at any time during the winter or early spring. It is not advisable to leave the crop in the ground over winter, since it cannot then be dug out until the frost is out of the ground in the spring, by which time the demand for parsnips will have considerably lessened. If kept in an ordinary cellar, they should be covered with earth or sand to prevent wilting.

In marketing the parsnip, it is often customary after trimming off all side shoots, to sell them by the basket without washing. A sar better and more equitable plan is to sell them by weight. In some of the best markets, the roots, after being carefully washed and trimmed, are packed evenly in boxes, sixteen inches square and eight inches deep, which hold just a bushel. Packed in this way, they present a very neat appearance.

The Hollow Crown or Student Parsnip is the best kind to grow for table use.

Turnip Rooted Parsnip, which is short and round, is used to some extent. It is a good form on light soils, but for rich land the Hollow Crown is to be preferred.

PARSLEY. (Carum petroselinum.)

Native of Sardinia-Biennial.-The leaves of some varieties of this plant are used in a fresh state for garnishing and seasoning, and in the case of a few kinds the fleshy roots are used. In 
habit of growth parsley resembles the parsnip, to which it is closely related. The leaves, however, are variously cut and divided. A few varieties are grown for their fleshy roots.

Culture.-Parsley is grown in much the same manner as the parsnip, and, like, it, its seed germinates rather slowly. The seed is often sown for winter and early spring use in greenhouses and hotbeds. The leaves may be used as soon as big enough. The roots may be taken up in autumn and grown in a

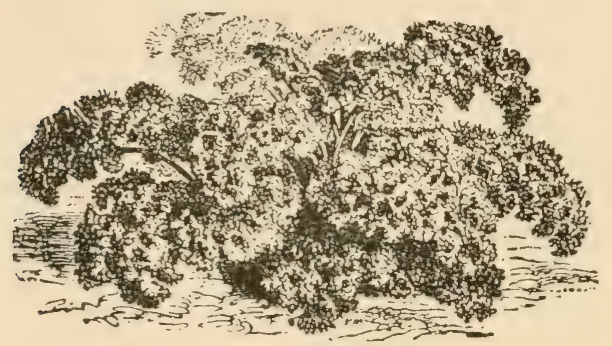

Figure 86.-Fine curled parsley. greenhouse or in a box in a sunny window for a winter supply. The demand is quite limited. It is sold in small bunches and may be found in the larger markets at any season of the year. It seldom comes through our winter's safely when left exposed outdoors but sometimes does so when well protected.

The Varieties commonly grown are the Double Curled and Fine Leaved, either of which makes a border that is pretty enough for a flower garden, and it is often used as an edging for small kitchen gardens.

\section{CARROTS. (Daucus carota.)}

Native of Europe.-Biennial.-In the wild state this root is valueless, being slend $\uparrow$ and woody, and the plant is a bad weed. Under cultivation it exhibits the widest difference in shape, size and color. Some kinds have roots that are broader than long and extend not over two or three inches in the ground, while others attain a length of two feet, and still others may be found having the various intermediate forms between these extremes. There are also varieties having red, white and yellow flesh. The leaves are very much divided and deeply cut. The flowers are white and crowded together in compound umbels on stalks two to five feet high. The roots of the cultivated kind will stand con- 
siderable frost, but not severe freezing. Two seeds are produced by each flower; they are flat on one side and convex on the other, and are partly covered by minute bristles. When sold, the bristles have generally been removed. Carrots are used to some extent as a table vegetable, but they are especially valuable as a food for horses and other stock.

Cultivation.-The carrot is of the easiest culture. It requires a fine mellow, rich, upland soil. On moist land the roots are apt to branch and are much liable to dis-

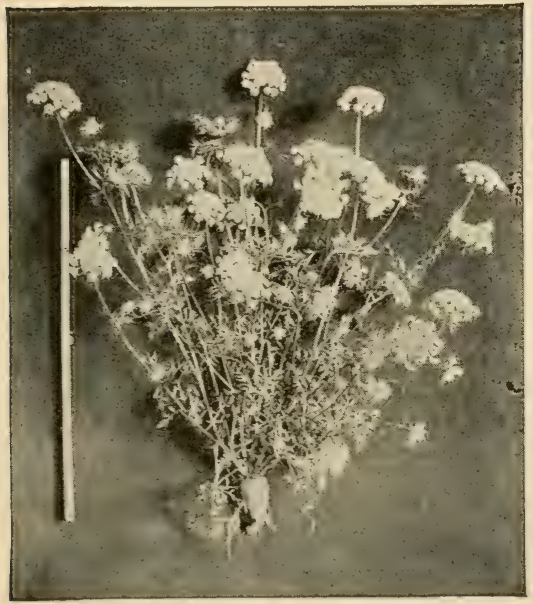

Figure 87-Carrot plant in flower. ease. The seedlings are quite delicate when they first come up and every precaution should be taken to have the land clean, so that the small seedlings will not be overrun with weeds; the surface soil should be kept loose and mellow throughout the season. It is a good plan to sow a few radish seeds with the carrot seed so that cultivation may be commenced early, as the latter start slowly. If the seed of the small kinds are sown very early in spring they will produce roots big enough for table use by early summer; but for the main crop the seed should be sown about the middle of May in rows fourteen inches apart. A fair crop may be expected even if the seed is not sown until the middle of June, although the dry weather which generally prevails at that time of the year is liable to prevent or retard the germination of the seed or to burn up the seedlings just as they are pushing out 
of the ground. The crop is sometimes sown in rows two feet apart and cultivated with a horse implement. If the seed is good, two pounds per acre, or about fourteen seeds to the foot of row, is plenty to sow. Very thick seeding is not desirable, as the cost of thinning in such a case is considerable. It is best for the experienced grower to have all the conditions just right and then to sow the seed so that little, if any, thinning will be necessary. However, the beginner will very likely find it safest to sow a large amount of seed, perhaps three pounds per acre, and thin out so that the plants will stand three inches apart in the row. The richer the soil the more room the roots require in the row; if small roots are wanted they may be left an inch apart in the row.

Gathering.-One of the greatest outlays in raising carrots is in gathering and topping the crop. The topping may be done

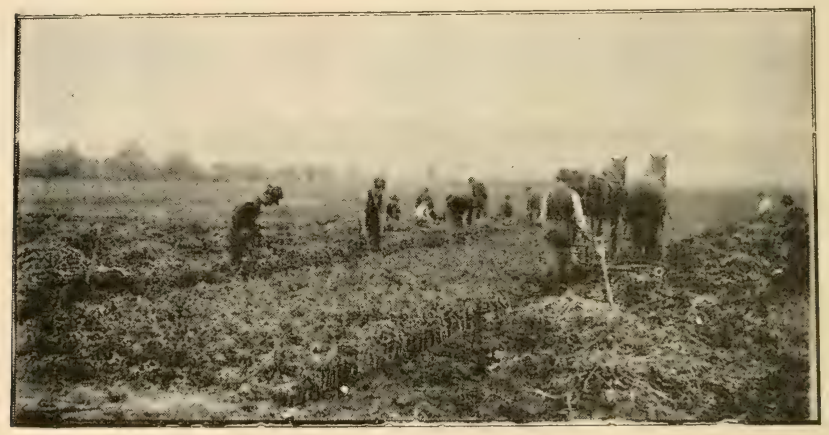

Figure 88.- - Harvesting long carrots and parsnips by plowing the eartn away on one side, and then pulling the roots by hand.

by hand, after being plowed out, but hand labor is very costly. Some growers go over the rows and cut the tops off with a sharp hand hoe. If the tops of the roots are cut off a little no harm is done, as it does not increase the liability to rot as is the case with beets. The roots are, perhaps, most easily dug by plowing close to each row and then pulling them out by hand. For this purpose a subsoil plow is best, but any good plow will answer the purpose fairly well. If a short rooted variety is grown and 
CARROT.

the land is mellow, the plow may often be run so as to turn the roots out on top of the furrow slice.

Storing.-Carrots are easily kept over winter in cellars,

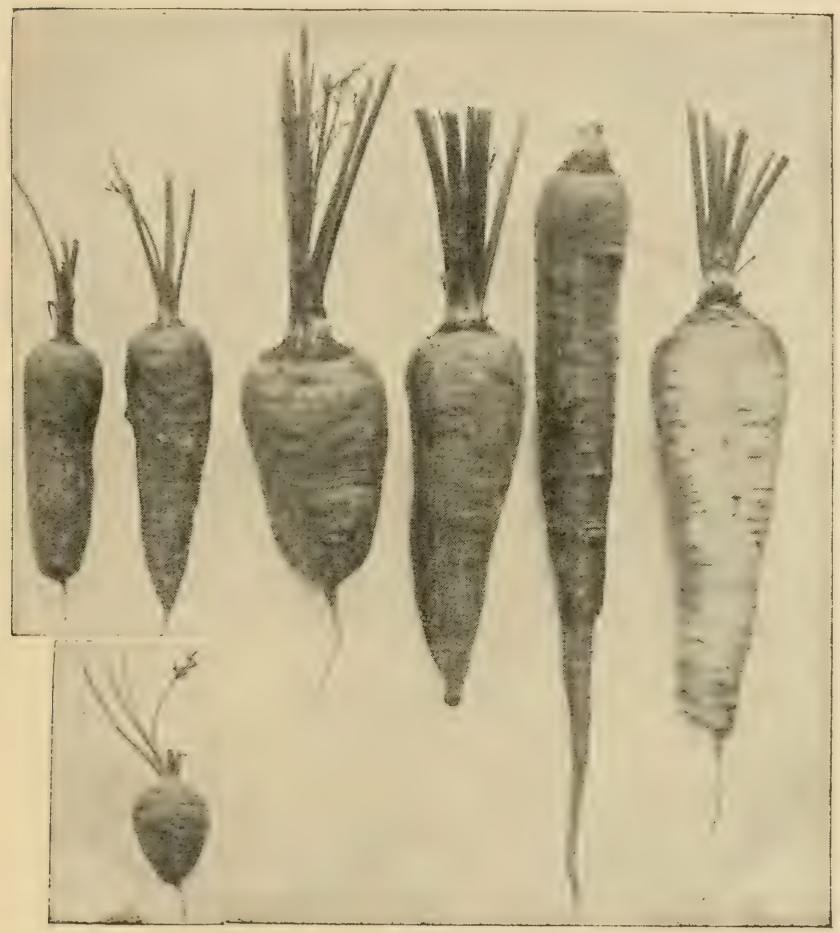

Figure 89.-Varieties of Carrots. 1-White Belgian. 2-Long Orange. 3-Orange Danvers. 4-Ox-Heart. 5-Pointed-Rnoted. 6-BluntRooted Horn. 7-Extra Early Forcing. (After Landreth.)

providing they are in a temperature near the freezing point anil are not too ripe when dug. If the seed has been planted too early, the roots will ripen up early in the fall and will cease to grow, and many of the leaves will turn yellow. Such roots do not keep well, but are liable to sprout badly long before spring, 
even if kept cold. To have the roots keep best they should be growing rapidly when dug. In dry cellars, it may be necessary to cover with loam or sand to prevent those on top of the bin or pile from wilting. If they are to be fed early in the winter, they may perhaps be piled in the barn and covered with chaff and straw sufficient to keep out the frost until used.

Carrot seed is raised by planting out the roots in the spring, about two feet, apart, in rows four feet apart. The seed heads ripen irregula:!y and are gathered as they ripen and threshed when dry. The seed is generally rubbed against a sieve having a fine mesh to take the bristles off, otherwise it would be a difficult matter to sow it in a machine.

The torcing of carrots is carried on to a limited extent, for which purpose they may be sown between rows of radishes in the hotbed or greenhouso.

Varieties.-For very early table use the Short Scarlet is best. For general use in summer and for winter use, perhaps there is no better variety than the Danvers. The Guerande Half Long, or Oxheart, is a variety that is very thick and short and yields nearly as much as the Danvers. It has the advantage, moreover, of being easily pulled by hand without any digging. The White Belgian is a large cropper, but on!y of value as food for stock. Thirty tons of carrots are sometimes raised on one acre, but in ordinary practice seldom more than half that amount is raised.

\section{CELERY. (Apium graveolens.)}

Native of Europe.-Biennial.- The plants are grown for the fleshy leaf stalks, which are very tender when blanched; one form is also grown for the large fleshy roots. The whole plant has a pleasant aromatic flavor. The seed stalks are branching and grow from two to three feet high, and have very small yellowish or greenish flowers in compound umbels. The seed is small, triangle and five-ribbed, having the characteristic aromatic flavor of the plant.

Celery is a crop that is very liable to suffer from the want of rich, nitrogenous manures and from a superabundance of or a lack of moisture in the soil. On this account it should be 
grown on retentive, yet well drained, rich land. Well drained bog land with the water about eighteen inches from the surface is often excellent for this purpose.

Early Celery.-The seed for early celery is generally sown

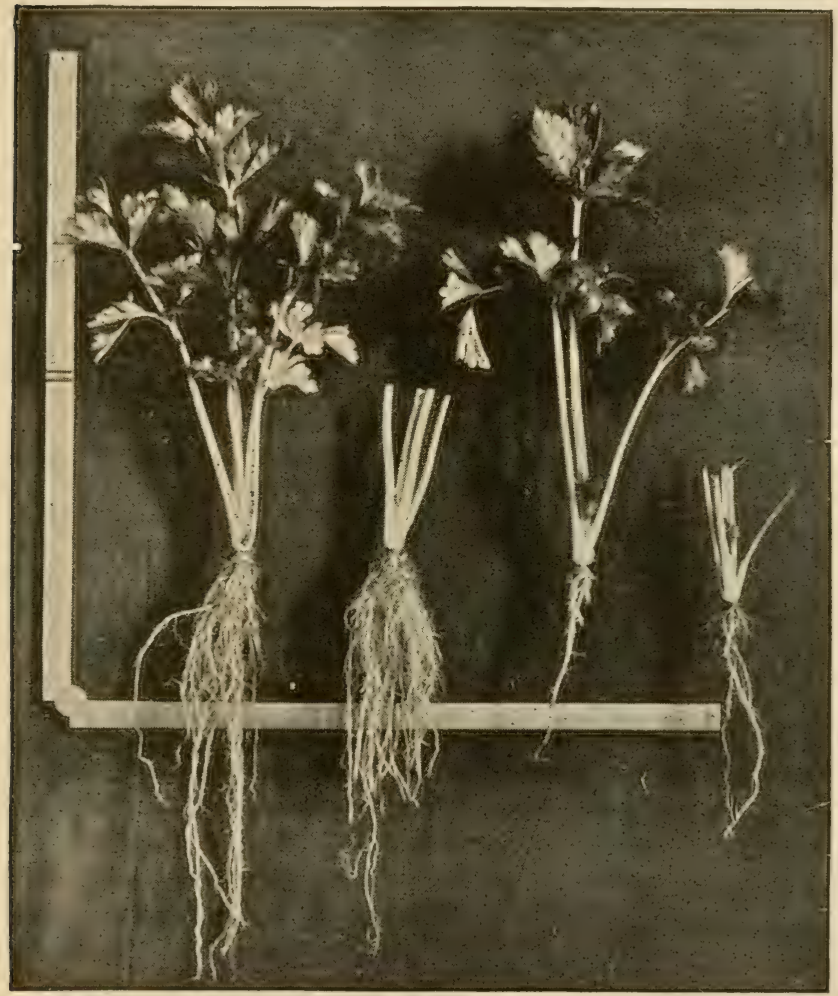

Figure 90--Cclery plants. 'Those on left have been transplanted and show in consequence an improved root system for planting out. Those on right were only grown in seed bed without transplanting and have not as good roots for planting out. The plants with tops trimmed are ready for planting out.

the latter part of February or early in March in boxes in a greer- 
house. As soon as the plants are of sufficient size to handle well, they are pricked out into other boxes or into hotbeds, where they remain until large enough for planting out, which is sometime in May. The tops of the plants should be sheared off once before they are pricked out and again before they are planted to the open ground, as this makes them stocky and helps them to recover from transplanting. If the leaves are all left on the plants when they are set out, they generally dry up an in so doing take away much moisture from the roots. The plants should be hardened off before being set out. Early celery should be bleached by being covered with boards or with boards and straw, since the ordinary way of bleaching it by banking with earth is liable to bring on disease in warm weather.

Late Celery.-The greatest demand for celery is during the

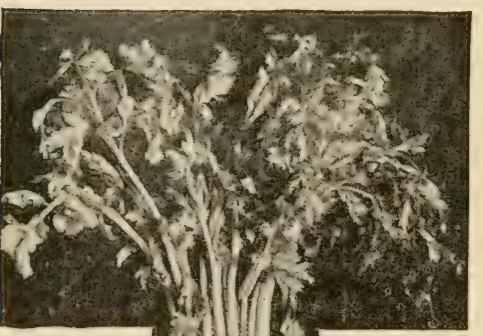

a u t u m n and winter months, and very little is marketed during the summer. The seed for autumn and winter celery is generally sown in April in the open ground, although some of our best growers sow the seed in hotbeds or cold frames e a r ly in worked at of fine rich sow $n$ in quarter inch after coverery seed at down with ger of the April, before the land outdoors can be all. If the seed is sown outside, a piece land is generally selected. The seed is drills about nine inches apart and onedeep, and the soil is well firmed over it ing. Some growers do not cover celall, except by rolling or patting it the back of a spade. If there is danseed drying out, some growers shade the bed with Fig. 91. - White cotton cloth or with a lath screen raised a b o $u t$ Plume Celery. one foot from the ground and so made as to keep off about one-half the sunlight. Another plan is to cover the bed with burlap after sowing the seed and water the seed through it; in this latter case, however, it is very im- 
portant to watch carefully and remove the cloth covering as soon as the plants appear. The seed germinates slowly. The seedlings are quite weak and should receive almost constant cultivation. The tops should be sheared off once or twice, as recommended for early celery, to make the plants stocky; they should also be thinned out so that there will not be over twenty or thirty plants to the foot of row. When sufficiently large, they should be moved to the field where they are to grow. Treated in this way, the plants will be strong and stocky; if left to crowd one another, they probably will be weak and poor. Some successful growers prefer to transplant once to narrow rows before setting in the field where the crop is to mature. This makes the final transplanting most certain by increasing the fibrous roots, but is not generally necessary, although a good plan under unfavorable conditions.

In the growing of celery plants it will often be a good plan at the first transplanting to make up a special bed for them. This should be done as follows: A place feur feet wide and of any length should be selected, the top soil to the depth of about three inches thrown off, and then rotten manure such as that which comes from spent hotbeds or similar material put in to the depth of about three inches. The top soil should then be returned and the plants set out in it. Treated in this way the young plants will develop a compact root system in the manure, and may be transplanted with a ball of roots almost as well as if they had been grown in pots. Plants grown in this way are especially desirable when transplanting must be done in a dry time, but seedbeds require much water.

Planting.-Having good plants, the next thing is to set them so as to get a good crop. It is quite a common practice in some sections to grow celery as a second crop after early peas, lettuce, cabbage or beets. In such a case the plants, perhaps, had better not be set out until the first crop has been gathered; but where only one crop is to be grown the plants may be set as soon as big enough. This will generally be from the middle to the latter part of June anc. for latest use the latter part of July. The land should be thoroughly plowed, harrowed and smoothed off. Furrows six inches deep should then be made where the plants are 
to go, and in these about three inches of fine, well-rotted manure or compost should be placed. This manure should be thoroughly mixed with the soil, and the furrow nearly filled. For mixing the manure and soil perhaps there is no better imple-

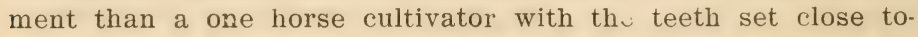
gether. If the land is unusually rich in plant food, there is no need of going to this trouble, but the plants may be set right after the marker. In any case the rows should be four or five feet apart for the common kinds that have to be bleached by banking up with earth, but the self-bleaching and dwarf kinds can be managed in rows three feet apart. The plants should be about six inches apart in the rows.

Before the plants are dug from the seedbed, it should be thoroughly soaked with water; the plants should have the tops cut off, trimmed, and the roots dipped in water. If the roots are very long they should be shortened so they may be easily handled. The place where they are to be planted should be moist, and every precaution taken to prevent the plants drying out when they are being moved. Special attention should be given to planting on freshly plowed land and to firming the soil around the roots. If the land is dry it must be watered before it is safe to set out celery plants, and if the weather is very hot and dry the plants must also be shaded from the sun. The ground should be kept clean and mellow between the plants with a horse cultivator throughout the season.

If, while the crop is growing, it is thought the plants require more food, it may be supplied by plowing a shallow furrow away from them on one side and putting in fine well-rotted stable manure, hen manure or compost and covering it with soil. This treatment supplies the food directly to the roots and is very effective. Nitrate of soda or other nitrogenous fertilizer may also be used to advantage in this way.

Celery and Onions Together.-In some sections celery is grown as a second crop with onions. In this case every fourth or fifth row is left vacant when the onion seed is sown, and this space is set out to late celery plants at the proper time. If the onion seed is sown by the 20th of April, almost any of the wellknown commercial sorts like Yellow Danvers or Red Wethers- 
field will be ripe by the middle of August. when they can be harvested; and then the celery can occupy all the land during the cool weather of autumn, when it makes its most rapid growth.

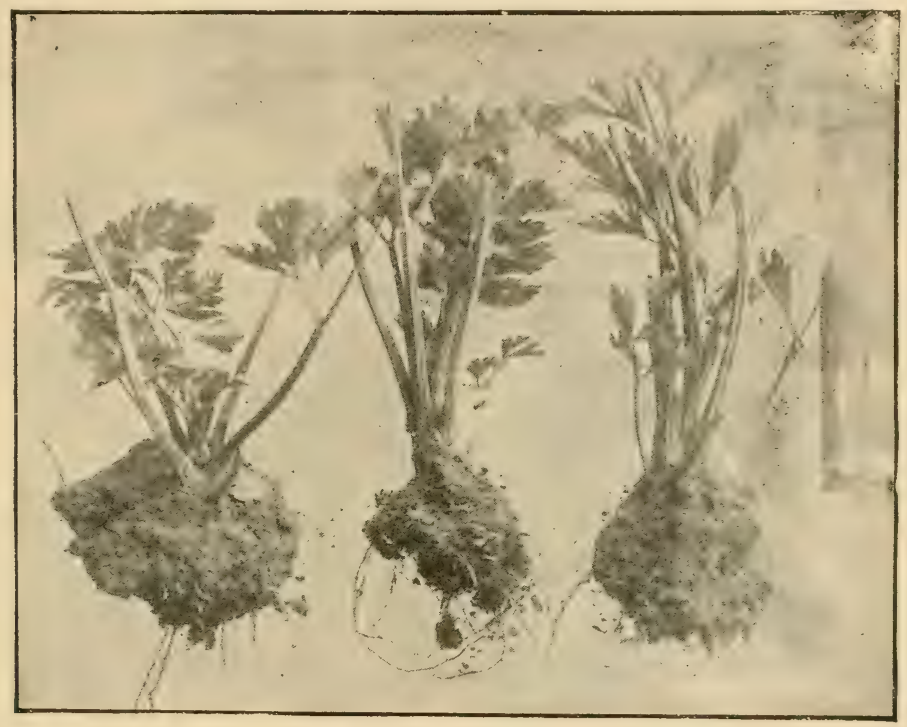

Figure No 92.-Celery plants which have been transplanted from the seed box into moist soil that is rich in rotted manure. Thus treated, the celery forms a close, compact root system, to which the soil adheres in lumps when taken up, and on this account the plants are very sure to start well when set out permanently in the field.

Handling.-As celery grows naturally it spreads on the surface of the ground, like the carrot. The term handling refers to the process by which the leaf stalks of each plant are drawn together and some earth pressed firmly around them by the hands, to hold them in an upright position. After this is done more earth is drawn towards the plants with a hoe, until there is enough to prevent their spreading open. All celery plants should have this upright form before being stored, and it is all 
the bleaching treatment necessary for the self-blanching kinds. The land should be thoroughly cultivated and a furrow turned towards the plants on each side of the row before the handling process is begun, so there may be plenty of loose earth to work with.

Bleaching with Earth or "Banking."-If the celery is intended for marketing previous to the first of December, it should be banked up or otherwise bleached in the field. Sanking up is done immediately after "handling." It consists in plowing earth against the celery to begin with and then finishing it off with a shovel or wide hoe until the earth is banked up to the full height of the celery. This had better be done in several operations as the plants grow and need it.

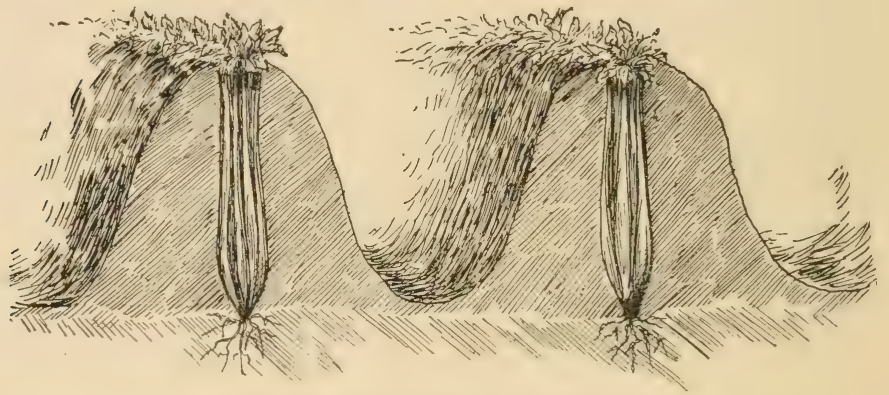

Figure 93-Celery banked up for bleaching.

Bleaching with Boards.-Celery that is to be marketed early should be bleached with boards, because if "banked" with earth it is more liable to become diseased. Boards ten inches wide are the best but narrower boards may be used nearly as well, providing the earth is first drawn towards the plants for them to rest on. The plants are generally handled before the boards are put on, but this is not absolutely necessary, although desirable. A board should be put upon each side of the row quite close to the plants and be held in place with $x$ peg. If for any reason there are vacancies in the row or the plants are not close enough to exclude light from the stalks when the boards are put up, the vacancies may be filled with hay or straw. For 
late autumn use it is probably best to bleach the plants with earth, as it also protects from frost and is much cheaper than bleaching with boards when the first cost of the boards and the handling of them is considered. In fact, almost all growers use earth to bleach their late celery.

Planting in Beds.-Some growers prefer to plant celery in beds four feet wide and to have the plants set ten inches apart each way in the beds; in which case a four foot path is left

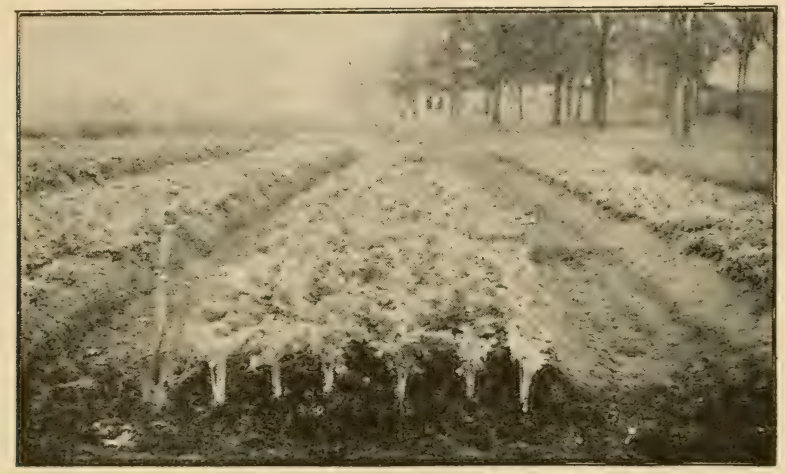

Figure 94-Celery grown in beds and earthed up to bleach.

between the beds for convenience in cultivation and weeding. In this way a very large amount of celery can be grown on a very small piece of land. By putting boards up on both sides of the paths, the plants will take on the upright form, so that handling will be unnecessary. For late use the plants may be taken directly from the bed to the cellar without banking, but it will generally be found a good plan late in the fall to pack the spaces between the plants with hay or fill them with earth from the paths, as they will then be protected from frosts. If the celery is to be blanched in the bed, this, of course, would be necessary. To grow plants so close together successfully requires the utmost care in the preparation of the land. It should be covered with fine rich manure, preferably in the spring; the plants also require to be frequently and heavily watered, since the land will be free of roots. 
Digging Celery.-Celery will stand many light frosts, but hard freezing is liable to injure it, and it should never be handled when frozen. It is seldom safe to allow it to remain unprotected in the ground in this section after the middle of October, but by covering the plants with straw or other material they may often be safely left in the field until the middle of November if well banked up. The plants are generally lifted with a spade after a furrow has been plowed away from the row on one side. Most of the soil should be shaken off the roots and the old outside leaves removed before storing. In this section, to keep well, celery should be stored in a cold, moist cellar or frostproof shed. If it does not whiten quickly enough the plants may be watered and kept warm and thus started into growth, which results in forming the tender white shoots very quickly.

Storing Celery.-For home use a good way to keep celery is to pack the plants closely together, upright, in boxes twelve to eighteen inches wide, with the bottom covered with several inches of moist sand, a little of which should be worked in among the roots. There is no need of having sand between the plants. These boxes, when packed, should be kept in a cold, damp cellar. In storing for market use, where there is plenty of storage room, the plants are sometimes "heeled in" in sand on the floor; the cheapest practicable way, however, is to pack them between boards about nine inches apart. To do this, place the first board on one side of the cellar or shed nine inches from the wall, with its upper edge at a height from the floor a little less than the length of the cellar. The boards may be supported by stakes and should not rest on the ground. In this narrow division the celery should be packed upright, as described for packing in boxes. As soon as the first tier is filled, erect another board division at nine inches from the first, and so continue until the whole surface is covered. No soil or sand is packed among the stalks of celery, but three or four inches of either is placed on the floor, into which the roots are bedded. The temperature of the celery should be kept very low, and even a little frost in the cellar will not hurt it. If dry, it must be watered, but water must not be put upon the leaves, as it may bring on rot. If celery is wanted for immediate use, it may be stored in 
barrels or troughs containing an inch or two of water. This is also a very good way of hastening the bleaching process.

The green stalks of celery do not become white, and the term "bleaching" is a misnomer. The "bleaching" of celery is simply the result of the plant making growth in the dark. Bleached celery will keep but a short time and should be used as soon as white. Celery for use in the latter part of winter should be quite green in color when put into winter storage; for early winter use it should be partly bleached when stored. For winter use celery should be left out as late as is safe in the fall, so that the cellar or pit where it is to be stored may be thoroughly cooled off before it is put in.

The Time Required for Bleaching Celery in the field will depend upon whether it is growing rapidly or not. During the first part of September, when it is making a rapid growth, it will probably be fit to use in three weeks from the time it is banked up; while later on, when the weather is cool and the celery is growing slowly, four weeks will be found necessary. The same conditions affect the bleaching process after storing. In an ordinary frost proof cellar, it may easily be bleached in three weeks by watering it and then raising the temperature to fifty degrees.

Celery Seed is raised by wintering the roots and planting them out in the spring, in much the same way that seed of the carrot and other biennial plants is grown.

Diseases.-There are two diseases, rust and leaf blight, that sometimes seriously injure celery, but they are not commonly very troublesome. As a rule, celery grower's do not attempt to fight them, but select the healthiest varieties and trust to good cultivation to enable the plants to resist them. The diseases referred to are described as follows:

Leaf Blight. (Septoria Petroselini var. apii.) All parts of 'he celery plant except the roots are liable to the attacks of this iungous disease. Watery spots appear on the stems and leaves, vhich soon show small, black dots. This disease may be spread hy the seeds, which are likely to become infected.

Treatment.-The first precaution is to plant clean seed. That which is spotted or speckled with the black spots of disease 
should be avoided. In addition it would be a good plan to spray the young plants with Bordeaux mixture on the first appearance of the disease.

Celery Blight, Rust or Sun-Scald. (Cercospora apli.-[Fries.])

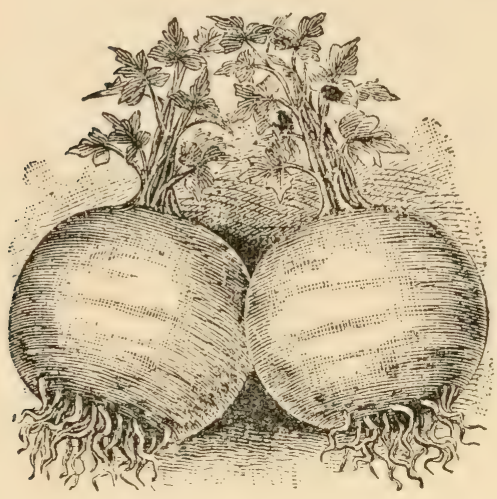

Figure 95-Turnip-rooted celers or celeriac.

The first indication of this disease is the appearance of yellowish spots on the leaves. These finally run together and turn the entire leaves yellow and then brown.

Treatment.- Secure as healthful conditions as possible. Where the plants are somewhat shaded, they are less liable to the disease than if in the full sunlight. This disease is especially bad in very dry locations. It is reported that the Bordeaux mixture and other standard fungicides will entirely prevent it.

Varieties of Celery.-The dwarf kinds are the best to grow; the red varieties are of excellent quality but do not take well in the markets. For early marketing the White Plume is highly esteemed and probably the most profitable variety for general marketing. Its stalks and leaves are white without going through the bleaching process but are not of as good flavor as when bleached. Golden self Blanching is another similar variety, that is considered by some growers superior to White Plume. One of the best flavored as well as best keeping kinds is the Golden Dwarf, or Golden Hearted Dwarf. Other good varieties are the Perfection, Hartwell, Giant Pascal and the Boston Market.

Celeriac, or Turnip-Rooted Celery, is a form of celery cultivated for its roots, which are eaten either cooked or raw. The stalks are generally hollow and quite worthless. The plants are raised by the same method as that for celery but may be planted 
In rows not over twelve inches apart. The roots are generally kept by storing them in moist sand the same as carrots.

Marketing.-Celery is marketed when well blanched. In preparing it for market most of the roots are trimmed off and the green and decaying leaves are removed. About a dozen roots are generally tied together for a bunch, although the size of the bunch varies in different markets. Celery can be easily shipped long distances when trimmed and packed in tight boxes. Much of that which is supplied to the markets of this section comes from Kalamazoo, Michigan, where it is raised on drained swamp land.

\section{THE MORNING GLORY FAMILY. (Order convolvulaceae.)}

The Morning Glory Family includes mostly twining, trailing or rarely erect plants (some tropical species are shrubs or trees, ours are herbs.) Commonly with some milky juice, alternate leaves, no stipules, regular gamopetalous flowers; fruit a 2-4valved capsule. The Sweet Potato is the only vegetable that occurs in this group which is here mentioned. This family also includes the Morning Glory, Bindweed and Man of the Earth.

\section{SWEET POTATO. (Ipomea batatas.)}

Native of South America.-Perennial, but cultivated as an annual.-It is a near relative of the morning glory and scarcely resembles the common potato in any particular. It probably cari. not be profitably raised in the extreme northern states, but may be grown in a small way in warm, sandy soil as far north as Minnesota and will produce even there very large tubers. The plant never flowers at the North and is never cultivated from seed.

Culture.-The sweet potato is raised from sprouts, which are produced abundantly if the tubers are planted in a hotbed in the early spring. The sprouts are carefully pulled from the tuber's and are planted out after the soil has become warm. They should be set two feet apart in rows four feet apart. They need considerable care until started, after which they require good cultivation only and are easily grown. The vines spread on the ground and have a tendency to root at the joints, which should be discouraged by moving them at every hoeing. They are very susceptible to cold weather and should be pulled as soon 
as the tops are frosted. There are many cultivated varieties in the South. For the northern states, Early Carolina is perhaps the best.

\section{THE POTATO FAMILY. (Order Solanaceae.)}

The Potato Family is made up of mostly herbaceous plants with rank-scented herbage (this and the fruit more commonly narcotic-poisonous,, colorless juice, alternate leaves, regular flowers with the parts usually in fives. There are many poisonous plants in this group, which fact led to the tomato being re-

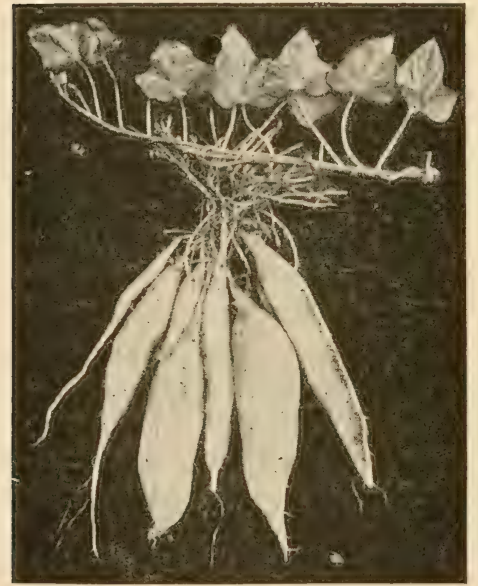

Fig. 96-Sweet potatoes and piece of vine. garded with much suspicion for many years and the tops of potatoes and even tubers that have become green by exposure to sunlight contain a poisonous principle. Besides the potato, tomato, egg plant, pepper and strawberry tomato, whose cultural directions are here given, the Tobacco, Petunia, Nightshade, D a t u r a, Salpiglossis, Jerusalem Cherry and Nierembergia of the gardens, belong to this family.

\section{POTATO. (Solanum tuberosum.)}

Native of the high mountain regions of South America.Grown as an annual, but truly a perennial through its tubers. Its stems are more or less four angled.

The flowers vary ir color from white to purplish. Many kinds do not flower, and most varieties seldom if ever produce fruit. The fruit is a round. ish or slightly oval berry, of a green color or tinged with violet brown and averaging about an inch in diameter. The puip is 
green and very acrid. The seeds are white, kidney-shaped and flat. The seed is never sown except for producing new varieties. Seedlings vary greatly and often do not obtain full size

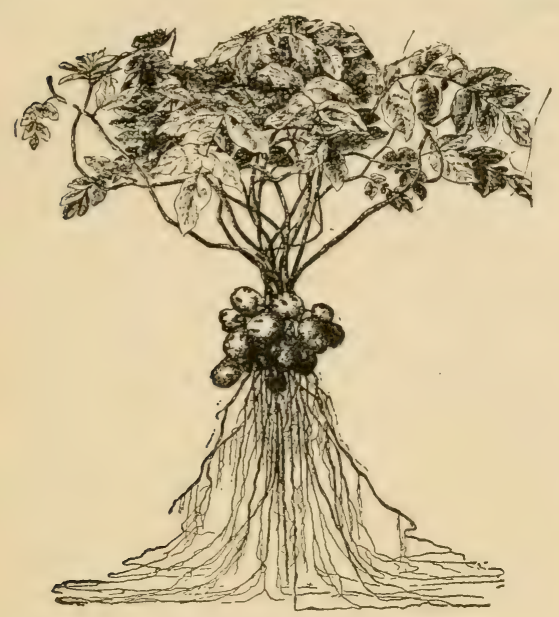

Figure 97-Potato plant showing tubers and roots until three years old. The tubers are commonly referred to as "seed," but they should be regardedas cuttings or sets; they are only swollen underground branches filled with starchy matter. They vary much in size and shape and in color of skin, from white to almost black, including yellow, red and blue. There are a thousand or more of named varieties, but many of $t_{\Perp}$ em are scarcely distinguishable from other named kinds.

Origin of the Modern Potato.-Fifty years ago potato rot ran over western Eurowe and the United States to such an extent as to bring starvation in regions where potatoes were the principal article of diet; no one knows where the potato came frcm that was cultivated previous to that time. Rev. Chauncey Goodrich, of Utica, N. Y., urged before agricultural societies and the agricultural committees of the New York legislature that potato rot resulted from lowered vitality of the potato plant, due to its being grown under high cultivation and in climate; and soils not wholly congenial to a sub-tropical plant, native to a small section only of the earth's surface; and he claimed that the way to restore its vigor would be to get varieties from the part of South America that was the home of the potato. His theories were laughed at by scientific men, and the legislative committee told him he knew more about theology than about plant diseases. 
Being thus repulsed, he attempted on his own account what he felt should be undertaken by the state. Mr. Goodrich commenced his experiments about 1848 and at various times for many years imported potatoes from South America, and from these and their progeny he raised many seedlings. Among eight kinds reeived at one importation (probably from Chili) was a variety that he called the Rough Purple Chili. It ripened late in the season and was generally hollow, but it had flesh of fine texture and was free from rot. From seed saved from this he raised the Garnet Chili, which was a popular variety for many years in New York state. The Garnet Chili was parent of the Early Rose and of Brazee's Prolific and other Brazee seedlings and, indeed, of nearly all of the desirable varieties of Europe and America which have been prized for half a century. Although from some of his other importations he also raised a few very good sorts, yet the progeny of the Rough Purple Chili gave him the most valuable kinds. Among Goodrich's other seedlings were Gleason, Calico, Harrison and Early Goodrick. The latter was the parent of the Chicago Market.

Mr. Goodrich is said to have raised about sixteen thousand seedling potatoes from 1848 to 1864 . Out of this large number he found only about one in a thousand that he thought enough better than the old sorts to make it appear probable that they would be desirable for cultivation. The work that he did in this line has been of great value to Europe and America.

Soil and Manure.-If given proper treatment, potatoes can be grown on soil of almost any composition, provided it is well drained, but a light, rich soil is best. The kind of soil to some extent affects the quality of the tubers; grown on sandy soil, they are generally of better table quality than on clay soils, and when grown on muck land the skin is generally dark colored and the flesh not mealy. New soil is most desirable, and in it the tubers are generally healthy; sod land is most excellent for this crop, but the "seed" should always be under the sod anit not on top of it. If planted on the sod the crop is very certain to suffer from drouth in dry seasons. It is not generally advisable to manure the land the season of planting potatoes, but preferably to apply it to some previous crop, but if manure is to 
be applied, it should be well rotted. Raw stable manure is generally to be avoıded, unless it can be applied a year in advance. In applying manure, it is very important not to use that from animals which have been fed on scabby potatoes, as such manure is liable to cause scabbiness in the crop.

The Sets (commonly called "Seed.")-The tubers for planting should be sound and not sprouted-though if sprouted they may do well; sprouting injures the vitality of the potatoes and is harmful. We should regard the potato much as we do a willow or other plant that grows freely from dormant cuttings if it has the right soil conditions, for the tuber is truly a stem. Given good sound seed potatoes for planting and good soil conditions, it matters little how the sets are cut, provided that every eye that grows is on a piece of potato large enough to nourish the young sprout until it has a good root system and enough expanded leaves to gather and digest its own food. In practice the "sets" should have one, two or three eyes according to whether the tubers have few or many eyes. Varieties with few eyes such as the Rural New Yorker No. 2, should be cut to about one eye to a piece, while those having many eyes should have two or three to each piece. Very small seed pieces will not give a full crop, consequently large pieces are desirable. The biggest crops are not likely to come from the planting of whole tubers, but such sets generally give a larger proportion of small potatoes than cuttings made as recommended. The constant use of small tubers for sets undoubtedly causes varieties to "run out," and, although it is a practice that may be occasionally followed without serious results, it should generally be avoided.

Varieties of potatoes seldom retain their pristine vigor and productiveness many years except in very favorable locations. On some land, even with the best of care, they are apt to "run out," and, as a rule, it is a good plan to occasionally get seed stock from locations very favorable to the best development of the potato or, at least, to change for seed potatoes grown on a different kind of lend.

In saving potatoes for seed, it is desirable to select them in the field from hills having the largest number of marketable tubers, as there is then a tendency to fix this desirable quality. 
When selecting from the bin, take smooth, even, medium-sized potatoes; the largest tubers will not necessarily give the largest yield. If planting is done on a small scale it will probably be found more economical to cut them by hand. Some of the automatic seed potato cutting machines leave a good many pieces without eyes, and on this account hand fed potato cutters are most desirable for general use, although where land is very cheap the automatic feed machines may sometimes be the more economical.

Early Planting.-For early use potatoes should be planted as soon as the ground is nicely settled. Light, sandy loam is best for this purpose. The tops are quite sensitive to frost, but, as they start slowly, they seldom get up until all danger from frost is past. If when pushing out of the ground there is danger from frost, the tops are easily protected from it by covering them lightly with loose earth from between the rows, through which they soon pish again. If frozen off when several inches high the crop is generally seriously lessened, even though new sprouts take the place of those injured. For early crops, the ground may be plowed several times in the spring to expose it to the air and to warm it before planting. The sets for the early crop should not be covered quite so deep as for the main crop, but in other particulars the crop should be treated the same way, and the quickest maturing kinds only should be planted. If the tubers for early sets are spread out in a light, warm room for three or four weeks before planting, healthy green sprouts will start from the eyes, and, if in cutting these sprouts are carefully handled so as not to break them off, the crop will be much earlier than if the sets were not thus started; they may also be started in a hotbed before or after being cut and afterwards transplanted to the open ground; but these methods are seldom practiced except is a very small way, although in some sections they might perhaps be made profitable.

Main Crop.-For the main crop of potatoes, it is desirable to have the seed in the ground pretty early. It is customary in this section to plant from the middle of May to the first of June. When planted later they are liable to suffer seriously from drought, and earlier planting is more desirable. The results of many experiments show that the sets should be planted about 
four inches deep, at sixteen inch intervals, in rows three feet apart. This work may be done by furrowing out with the plow or horse hoe, planting by hand and covering the sets with the plow, though when planted on a large scale the work is generally done by a potato planter. There are several excellent potato planters on the market. Some good growers prefer to plant the sets in check rows three feet apart each way when the land is weedy, but so much space between the plants is not generally desirable, since under ordinary circumstances thorough harrowing when the crop is young will destroy all weeds. If the sets are planted four inches deep, very little hilling up is required; if planted much deeper the digging is quite difficult; if planted nearer the surface, the tubers are liable to push out of the ground and require to be hilled up, which is not desirable. The land should be harrowed or thoroughly cultivated with a Breed's Weeder as soon as the smallest weedis can be seen or a crust forms on the land after planting. It is entirely practicable to harrow potatoes at least three times, the first time just before the plants show, the second when they are just above ground and the third when the plants are three or four inches high. Little if any harm will be done the plants by this work, providing a slanting tooth harrow is used. Such treatment will do more to remove weeds than a good hand hoeing, and the expense of the operation is almost nothing. If the work is properly done, there is seldom any need of hand work with this crop. Subsequent cultivation should consist in keeping the soil loose between the rows, and a little earth should be thrown against the plants. For this purpose a good horse hoe will do excellent work, but a still better implement is a two-horse cultivator that works both sides of the row at one operation. It is not a good plan to hill up potatoes, and it should not be done unless they are pushing out of the ground, when they will turn green if not covered up. Cultivation should be thorough when the plants are young but is not desirable after the tops have made most of their growth.

Digging Potatoes.--Early potatoes are generally dug as soon as they are big enough for cooking if there is a good market for them; for winter use it is very desirable to have the tubers well ripened; if not ripe the skin will peel off when handled, and they do not look well. When potatoes are high in price it may 
pay to dig them by hand, for which purpose tined garden forks are clesirable; the best potato digger's, however, do as good work as can be done by hand, and are generally used by those who raise this crop on a large scale. When potatoes are cheap, they should be dug with a potato digger or plowed out; though when pluwed out some tubers will get covered up, most of these may be brought to the surface by the use of a straight tooth harrow. If the tubers are keeping well in the ground, it is a good plan to delay the digging until the cool weather of autumn, when they may be carried directly from the field to the cellar. If they are rotting in the ground or are "scabby," they should be dug at once, and if the cellar is cool they may be put at once into it, but, otherwise, it is a good plan to pit them in the field until cool weather comes.

Pitting in mild weather is done by putting the tubers into heaps and covering them with straw or hay and a few inches of loam. The straw should be allowed to stick out along the top

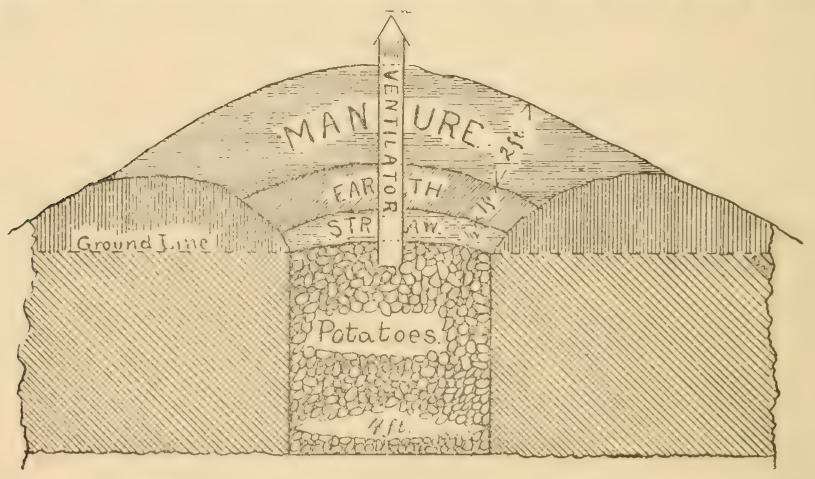

Figure 98.-Potatoes pitted for winter.

of the heap for ventilation, so as to allow the moisture to pass off. In the colder weather of late autumn, the covering, of course, shoulit he heavier, and when potatoes have ceased to sweat there is no necel of ventilation. In milder sections, potatoes are stored through the winter in such pits, but it is imprac. ticable here. IInwerer, cren in Minnesota, potatoes may be safe. 
ly kept over vinter in trenches or pits made below the ground, although a good cellar is a more desirable place. For this purpose the pit should not be large; a good size is four feet wide and deep and not more than six feet long. It should be filled heaping full with the potatoes and corered with six inches of straw and eighteen of soil. Ventilation is giren until cold weather sets in and the potatoes are cooled off. The whole pit should then be covered with enough litter or manure (generally about two feet) to keep out the frost. Such pits can only be opened in mild weather. If this work is well clone, the potatoes will be in fine condition in the spring, but beginners are rery apt to fail of success in this method of storing: and they should attempt it only on a small scale. It is better to make several pits close

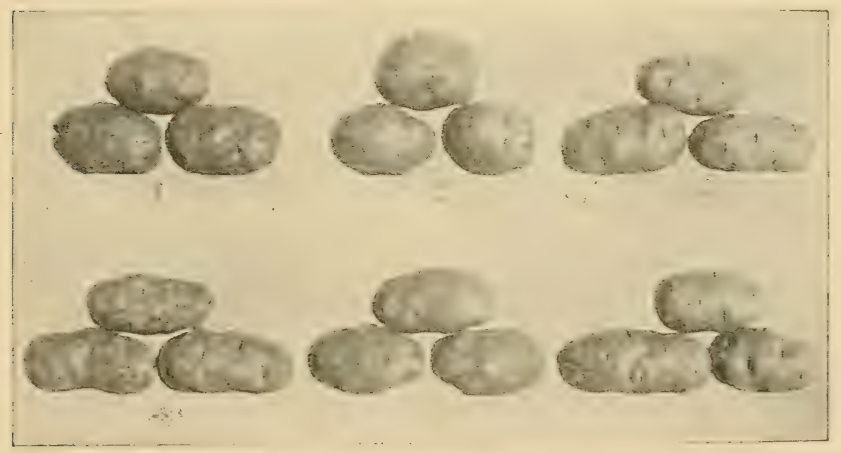

Figure 99.-Six good varieties of early potatoes. 1-Ohio Jr. 2-Ear1y Ohic 3-Burpee's Extra Early. 4-Early Harvest. 5-Freeman. 6-Good News.

together rather than one large one, since in a large one the potatoes are more likely to sweat. The sunlight should not be allowed to shine on them for any length of time, since it causes them to turn green and derelops a poisonous substance in them. If kept in a cellai, the bins are improred by having slatted floors and sides, so that there may be some circulation of air through them to prevent heating at the bottom. The bins should not be large nor more than fire feet (ieep. There is a great difference in the keeping qualities of rarieties; as a rule the early kinds are 
hard to keep from sprouting in the latter part of winter, and the late kinds keep the best.

Starch.-When potatoes are low in price, they can often be profitably worked into starch, but for this purpose starch factories must be near by. Such factories are not expensive and should be more common in this section.

The demand for potatoes seems destined to increase very much. There is a growing demand each year from the eastern and southern states for northwestern grown potatoes. Under ordinary cultivation, in this section, they seldom yield more than 150 bushels per acre of marketable tubers, and the average even in favorable years is probably not over 120 bushels per acre. There are, however, recorded yields here of 800 bushels per acre, and they often yield over 400 bushels.

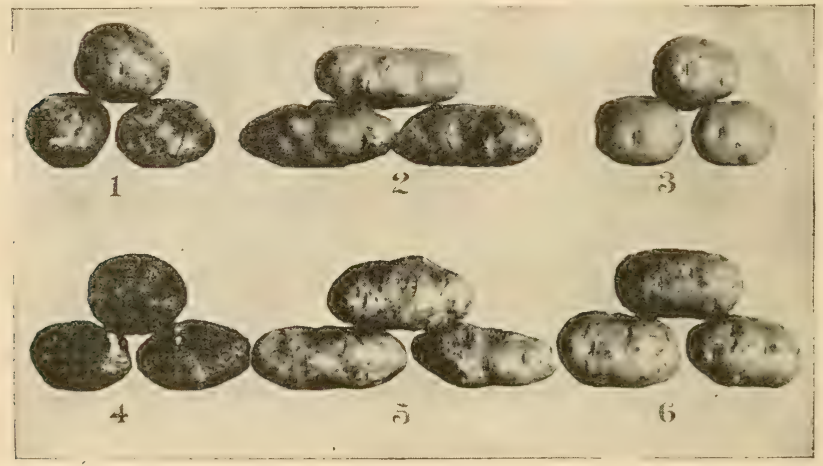

Figure 100.-Six good varieties of 1ate potatoes. 1-Rural New Yorker No. 2. 2-A merican Wonder. 3-Irish Cobbler. 4-World's Fair. 5-Woodbury White. 6-Carman No. 1.

Varieties.-There is a very great difference in varieties, but many kinds closely resemble one another. There is quite a difference in the adaptability of varieties to soils. The large coarser kinds are good for starch but not desirable for table use. Most markets prefer a white or pink potato, rather long, oval in form and smooth, but the fashions change and vary considerably. Some of the varieties at present regarded with much favor are the following: 
Early Ohio.-The most popular early kind and a good solt for the general crop, productive and very early.

Burbank, or Burbank's Seedling, is an excellent late kind and a good keeper, but seems to be running out in some sections. It cooks a little soggy until winter, when it is of excellent table quality. Form long and round.

Rural New Yorker No. 2.-Form flat, roundish oblong, very productive. Quality a little inferior and sometimes inclined to se hollow. Very popular in some sections. It is undoubtedly much influenced by the soil in which it grows.

Early Rose is the progenitor of most of our good kinds. It was introduced into cultivation about 1868 and is still productive in the best potato districts of this section but is not now adapted to general use.

Other varieties of special merit of the early kinds are Early Acme; of medium and late kinds are American Wonder and White Prolific.

Note on Propagation.-New varieties of potatoes are generally high in price, and it is desirable to increase them rapidly. This may be done as follows: Place the tubers in rich soil in boxes or in pots, without cutting them, in a warm, light room, hotbed or greenhouse. As soon as the sprouts are nicely furnished with roots, break them off at the surface of the potato below the roots and plant separately in pots. New sprouts will start from the eyes again, and the process may be repeated until the tuber is exhausted. By another way, the tubers are cut up and planted in good rich loam. As soon as the shoots are six inches or more high, about three inches is cut off the top of each. These pieces are put in moist sand, watered frequently and allowed all the sunlight they will stand without wilting and treated the same as it is common to treat cuttings of house plants. In two or three weeks they will be rooted and may be potted in rich soil. These shoots may again be cut when nicely started, and so on. The plants thus grown are planted out when the weather is settled in the spring. For best success with these methods of propagation, the work should begin in the late winter or very early spring.

Insects.-There are but few insects that do serious injury to 
the potato in this section, and the most important of these is the Colorado potato beetle, or "potato-bug," but it may also be injured by blister beetles, wire worms and white grubs. (For remedies for these pests, see chapter on insects.)

Diseases.-There are several diseases that sometimes injure the potato. The most common of these are known as the scab and the blight. Scab is a term used to refer to the rough patches with which potatoes are frequently covered. Potatoes so infected are lessened in yield, and on account of being unsightly and rough do not sell readily. The term blight refers to a disease that kills the tops.

Scab of Potatoes is caused by a fungous plant working in the surface of the potato. The germs of it are very abundant and live for many years in the soil and also over winter on the potatoes. If these germs are fed to stock they undoubtedly grow in the manure, and the use of such manure may often be the cause of infection. Also they may be spread in the soil by natural drainage and land receiving the drainage from infected fields may become infected with tne disease without ever having had pota. toes on them. Scabby seed potatoes when planted on new or old potato land will generaıy produce a scabby crop, but the amount of the disease will generally be much more on the old land than on the new.

Perfectly clean seed potatoes planted on land which is free from the scab fungus will always and in any season produce a crop of smooth, clean potatoes, no matter what may be the character of the soil; but apparently clean seed potatoes may have the germs of the scab fungus on their surface. This is often the case where they have been sorted out from a lot that is somewhat infected with scab. In this latter case the tubers should, at least, be thoroughly washed in running water to remove any germs that may be present or, what is better yet, be treated with corrosive sublimate (mercuric bichloride) as recommended below.

Land infected by the germs of potato scab will produce a more or less scabby crop, no matter how clean and smooth the seed used.

Scabby potatoes should be dug as soon as mature, since the 
scab fungus continues to grow on the potatoes as long as they are in the ground.

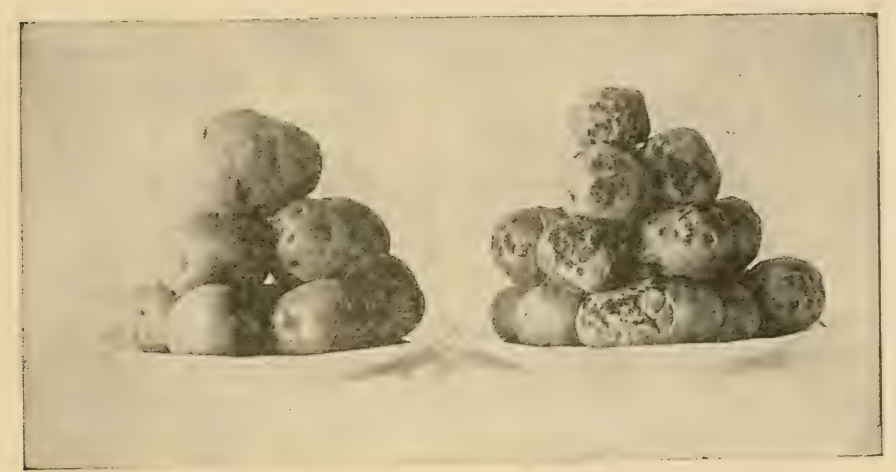

Treated. Figure 101-Potato Scab. Not Treated. Both plates grown from the same lot of scabby seed.

Scabby potatoes may be safely used for seed provided they are first treated in such a way as to destroy the germs of the scab that adhere to them. There are many methods of doing this but the most practical now used are as follows:

Corrosive Sublimate Treatment.-Procure from a druggist two ounces of powdered corrosive sublimate (mercuric bichloride); put this into two gallons of hot water in a wooden or earthenware vessel and allow it to stand until dissolved. Place thirteen gallons of water in a clean barrel, pour in the solution of corrosive sublimate and allow it to stand two or three hours, with frequent stirrings in order to have the solution uniform. Select potatoes as nearly free from scab as can be obtained; put the seed potatoes into bags, either before or after cutting them, and then dip them into the corrosive sublimate solution and allow them to stay in for an hour and a half. If seed potatoes are treated in this way and then planted on land free from scab, the resultant crop will seldom be seriously injured by scab. The expense of this treatment, including labor, should not exceed one dollar per acre, as the material may be used repeatedly. 
But the treated potatoes should never be fer to animals, as corrosive sublimate is a deadly poison.

Formaline Treatment.-This material should be mixed with water at the rate of eight ounces (one half pint) of commercial formaline to fifteen gallons of water. The potatoes should be soaked two hours in it. If this method is used the seed should be planted within two or three days after treatment. This material gives equally as good results as corrosive sublimate. It is slightly more expensive, but the expense is light in any case. It has, however, great advantages over the latter in that it is not poisonous and being a liquid is easily diluted for use and may be placed in any kind of a receptacle. This material does not in any way injure the tubers or make them langerously poisonous. One pound of formaline, costing not more than 50 cents, will make thirty gallons of the disinfecting solution and is enough to treat fifty bushels of potatoes. If the solution stands a long time it will probably lose strength.

Exposing to Light.-If the tuber's are exposed to the full sunlight for several weeks before planting the scab germs will be largely destroyed. It would be a good plan to turn such potatoes occasionally in order to expose them fully to the light.

Blight of Potatoes is a disease which attacks the leaves and stems of potatoes, and sometimes even the tubers are affected. It is most prevalent during moist, warm weather, when sometimes the fungus may be seen as a delicate white mildew on the stems and leaves of the potato vines. In seasons favorable to it, the tops of an entire field may be killed in a few days from the time the disease was first noiced; at other times the tops die so gradually that it is mistaken for a natural dying of the vines. Rotting of the tubers often follcws the dying of the tops. It has been quite clearly shown that this disease may be kept in check or the trouble entirely prevented by spraying the tops with the Bordeaux mixture occasionally. It is, however, somewhat doubtful about the benefits being sufficiently certain in this section to justify the expense; but should this disease become more abundant it may prove to be a paying operation. The cost of treating one acre with the Bordeaux mixture is about $\$ 5$. There is little use of applying this material after the damage from the dis- 
ease is apparent, as it must be used as a preventive and used before the disease is seen.

Bordeaux Mixture is made as follows: Dissolve five pounds of blue vitriol (sulphate of copper) in ten gallons of water in a wooden or earthenware vessel. As this substance dissolves very slowly in cold water and solutions of it are very heavy, it is well to suspend it near the top of the water. (It dissolves more quickly in hot water.) In another vessel, slake five pounds of good fresh quicklime in ten gallons of water. When the mixture is wanted, pour the blue vitriol and lime slowly at the same time into a barrel containing thirty gallons of rater, stirring all the time. When thoroughly stirred the mixture should be of a clear sky blue color. After being mixed for a day or two the mixture loses much of its strength, so it is well to use only that which has been mixed for a short time. There are many formulas used, which vary as to the amount of lime and water, but the above gives good satisfaction when used properly.

Internal Brown Rot is the name given to a disease which has recently appeared in a few potato growing sections of this country. It is first noticed by the darkening more or less of the starchy portion of the tubers, without any manifestation of its

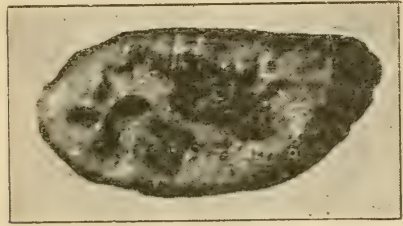

Figure 102.-Internal brown rot of the potato. presence on the outside; later on the potato rots. The life history of this disease is not known, nor are any remedies known for it. Ordinary prudence, however, would indicate that seed potatoes in the least affected with this trouble should not be planted.

\section{EGG PLANT. (Solanum melongena.)}

Native of South America.-Annual.-Stem erect and branching; flowers solitary and violet in color; seeds flat, of medium size. The egg plant is but little used in this section, but can be grown to perfection in our hot, dry summers. The seed must be sown, even earlier than tomato seed, in the greenhouse or hotbed, but when only a few plants are wanted it will be found best 
to buy the plants, as they require delicate handling. The plants

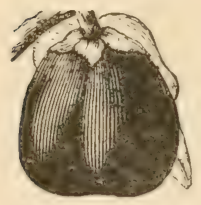

Figure 103.-Egg Plant. are set in rows three by two feet apart, after the ground is well warmed up, which is seldom before the 10 th of June.

The fruit attains marketable size by the last of August. The plants are very liable to the attacks of the potato beetle. The best variety is the New York Purple, but the variety grown as the Long Purple is somewhat earlier.

\section{TOMATO. (Lycopersicum esculentum.)}

Native of South America.-Perennial, but generally treater as an annual.- The tomato is a branching plant, generally with flexible stems that require support to grow erect. Its flower's are yellowish and grow in loose clusters on the stem, opposite or nearly opposite leaves, not axiliary; fruit, a true berry, red, pink or yellow in color; seed, kidney-shaped, flat, with a roughened surface. In many parts of this section, the tomato can be successfully grown as a market crop, and there is no place where it cannot be grown in sufficient quantities for home use. The cultivation of this vegetable for canning purposes is already occupying the attention of farmers in a few localities in this section, and it is an industry that is destined to greatly increase in the future. It is one of the easiest and surest rrops to grow, providing one has good plants to start with.

Growing the Plants.-It is especially important to sow the seed before the first of April, and the middle of March is thought about the right time by most growers. The seed grows easily but needs considerable heat and rich soil to do its best. The plants should be transplanted after they have their second leaves and again when they get crowded, so that they may become stocky and strong. The seed may be started in greenhouses or hotbeds; it is also easily grown in window boxes. If too close together, they grow weak and poor. It is very important that the plants should be well hardened off before they are set in the open ground.

The land preferred for tomatoes is a rich, retentive sandy loam, but they will do fairly well on almost any well drained 
soil, and even if on rather poor soil will do better than most crops. A southern slope is preferable, but they will ripen almost anywhere if properly managed. The tomato pre-eminently needs a rarm place, and if rich manure is plowed into the soil it is beneficial, since by its fermentation it raises the temperature of the land.

Transplanting and After-cultivation.-The plants should be moved to the open ground as soon as all danger of severe frost is past, which will renerally be about the 20th of May in southern Minnesota and not until the 1st of June in more northern sections. They should be set about five feet apart each way and about six inches deep. If the stems of the plants when planted out are very long, they should be partly buried under ground. They need thorough cultivation, which can best be given by a horse cultivator on a large scale.

Pruning and Training.-Tomato plants under field cultivation

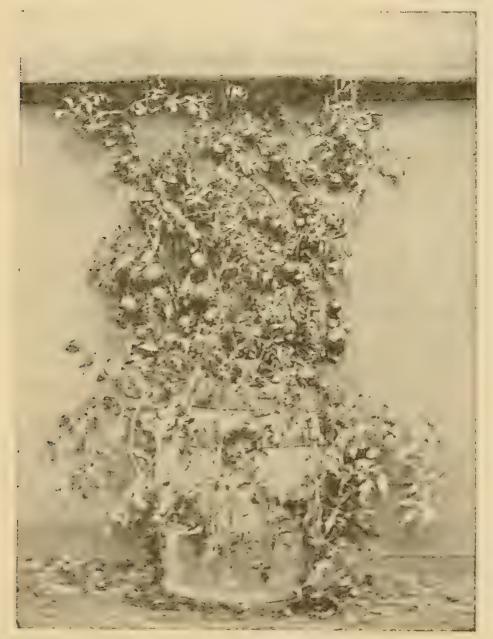

Fignwe 101.- Tomato plant growing in a bar'el and trained against side of building.

are generally allowed to run over the ground in any direction and are nottrained; but even under this method of management it is a good plan to cut off a foot or more of the ends of all growing shoots about the middle of August if they are growing rapidly, so that all the strength of the plant may go toripen the fruit that is well formed and still green. Some growers advise pruning off all but one main stem and two or three laterals and training to a stake, and then pinching off all flower cluster's after a few have set iruit. The result of this practice here is still some- 
what doubtful. It is a good plan in a small garden to cover the land under the vines after they set fruit with a little hay, so that the fruit may be kept from getting dirty in case they are not trained. This covering should not be heavy enough to keep the ground from getting plenty of sunlight.

Tomatoes in Very Severe Locations.-When there is danger of frost in August, a sufficient supply of tomatoes for family use may be grown on the south side of a house, wall or other protec-

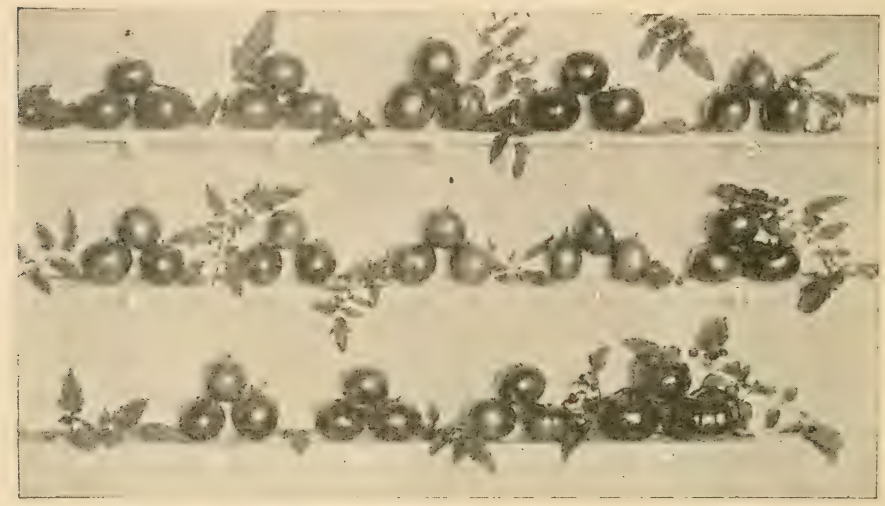

Figure 105.-Varieties of Tomatoes. 1-Dwarf Champion. 2-New Imperial. 3-Thorburu. 4-Virginia Corker. 5-Landreth's 110 Days. 6-Landreth's 95 Days. 7-Landreth's 100 Days. 8-Landreth's 105 Days. 9-Landreth's 115 Days. 10-Waldorf. 11-Laudreth's 105 Days. 12-Fordhook First. 13-Early Wilcox. 14-Clover Crest Giant.

tion, especially if the plants are covered on cold nights. Where this seems to be impracticable, a most excellent way is to grow a few plants in barrels placed in warm corners about the buildings. To do this, at planting time select a barrel as large as a coal oil barrel, bore three or four holes in the bottom, sink the barrel about one-third its depth in the ground and pack the earth around it. Fill it about half full of fresh horse manure well tramped down and pour a bucketful of hot water on this manure. Then put on eight inches of good soil and then a mixture of wellrotted manure and rich black loam in about equal quantities, until you reach within about twelve inches of the top of the 
barrel; then heap up manure around the outside. Set three plants in this and trim to two shoots each. Train one of these shoots from each plant to stakes or near-by building, but allow the other three shoots to grow naturally over the sides of the barrel. Be careful to give plenty of water daily-a gallon each day will be none too much. Three or four old barrels treated in this way and placed in sunny exposure will produce all the tomatoes needed by a family of four or five persons.

Prolonging the Tomato Season.- In autumn the tomato season may be prolonged by pulling the plants with the unripened fruit on them and hanging them in a shed, where they will continue to ripen fruit for some time. The larger tomatoes will ripen very well if picked off and kept in a shady place.

Saving Tomato Seed.-Tomato seed should be saved from the best tomatoes from vines producing the largest amount of good fruic. The tomatoes should be thrown into a barrel as fast as they ripen and be allowed to ferment until the seed separates readily from the pulp, when they should be put into water and thoroughly stirred. The skin and pulp being lighter, the seed is readily separated from it. The seed should be dried at once by spreading it out thinly in a dry place.

Varieties.-There are many varieties of tomatoes adapted to general cultivation. Among the best of these are Acme and Dwarf Champion, which are early, smooth kincls having a pink skin. Of the red-skinned sorts Perfection and Beauty are very good. The earliest rarieties are not always the best to grow for a general crop, as they are inferior to the varicties mentioned. However, in many unfavorable locations it may be best to grow them, as they do very well for home use. Of these the earliest is called Earliest of All, but there are several other very early kinds.

Insects.-The tomato is subject to few insect pests. It is sometimes attaclied by the potato beetle. The remedy is Paris green and water, as recommended for the same insect when it attacks the potato.

Tomato Rot.-There are several diseases that attack the tomato when grown in greenhouses, but only that known as the "rot" is often seriously injurious to plants grown in the open 
field. This is a fungous disease, the germs of which lodge in the end of the fruit when it is very small, probably often just as the flowers fall off. By their growth, they rot the end of the tomato and often cause much loss.

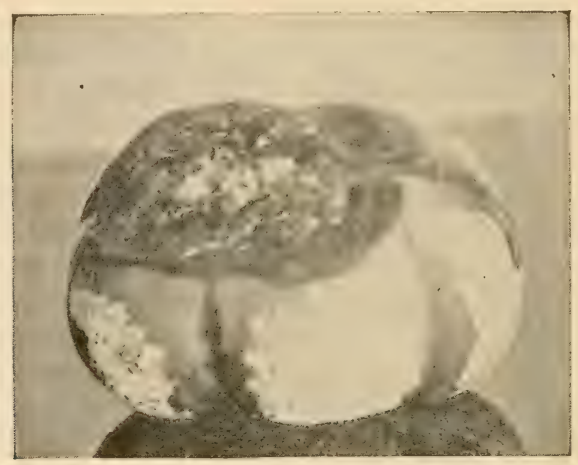

Figure 106-Tomato rot.

Remedies.-The disease lives over winter in the ground where the rotten tomatoes have fallen. The diseased fruit should therefore be gathered and burned or buried a foot or more deep, where they will not be disturbed in the spring. Some varieties are much more liable to rot than others. The Dwarf Champion is perhaps less affected than many other kinds. Experiments with spraying the young fruit with Bordeaux mixture or a solution of sulphide of potassium at the rate of one-half ounce per gallon, are said to lave given good results in some cases, but it is generally considered impracticable to do this, on account of the labor necessary to do the work well. They are less liable to rot when growing on new lanr than on land that has been used for several years in tomatoes.

GROUND CHERRY, or STRATWBERY TOMATO. (Physalis sp.)

Native of North and South America.-Perennial.-There are several species of Physalis that produce edible fruit. Among those indigenous to northern United States is one quite common in old timber land in northern Minnesota and elsewhere. The 
fruit resembles a tomato but is about the size of a cherry and is enclosed in a husk formed of the calyx. The seed is dark colored, flat and round. The fruit is used for preserves and sauces.

Culture.-It is a plant of the earliest culture and when once sown generally covers the ground in following years from self sown seed. The seed should be planted about the first of May. The plants spread about thirty inches.

\section{PEPPERS. (Capsicum annuum.)}

Native of South America.-Perennial, but in cultivation grown as an annual.-There are many varieties, differing chiefly in the shape of their fruit. All of them have erect, branching stems, which become almost woody. The leaves are spearshaped; flowers, white, star-shaped, solitary in the axils of the leaves; fruit generally hollow with a somewhat fleshy skin, at first dark green, but when ripe turning yellow, red or dark violet. The seeds are flat, and, like the flesh of the pods, have a very acrid, burning taste, for which the plant is cultivated and used in giving flavor to pickles, etc. Their germinating power lasts about four years after being separated, but if left in the pods they will keep much longer without injury.

Culture.-Peppers need practically the same cultivation as the tomato or egg plant, except that they may be planted two feet apart, in rows three feet apart.

Varieties vary much in the shape of the pods and the acridity of their juice. The kinds most commonly grown are as follows:

Ruby King.-Fruit very large, bright red, smooth, mild flavored and prolific. The best for general use. 
Long Red Cayenne.-Fruit long and slender. Very pungent.

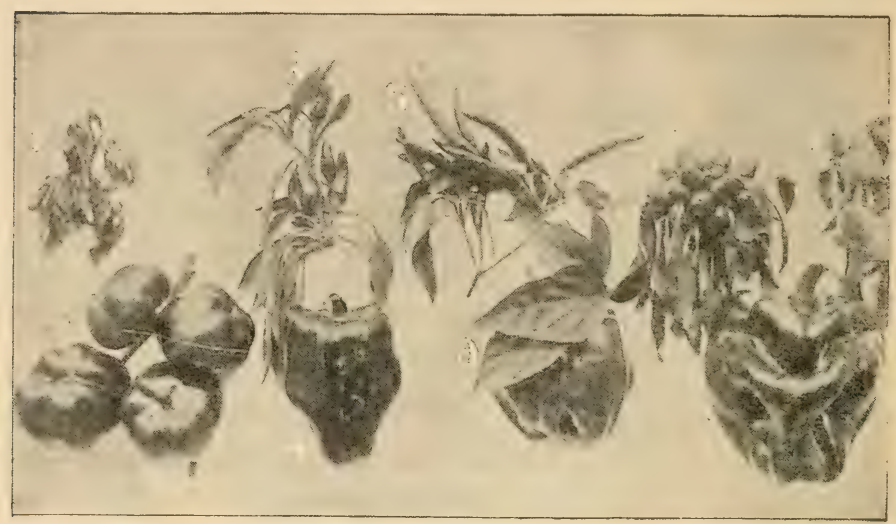

Figure 108-Varieties of Peppers. 1-Bird's Eye. 2-Tomato Shaped. 3-New Orleans. 4-Golden Bell. 5-Very Small Cayenne. 6-Sweet Spanish. 7-Cluster. 8-Ruby King. 9-Celestial. (After Landreth.)

THE MARTYNA FAMILY. (Order Martiniaceae.)

MARTYNIA. (Martynia probosidea.)

Native of southwestern United States.-Annual.-A coarsegrowing, spreading plant, having a peculiar shaped fruit that is used for pickles. The flowers are large, irregular and rather

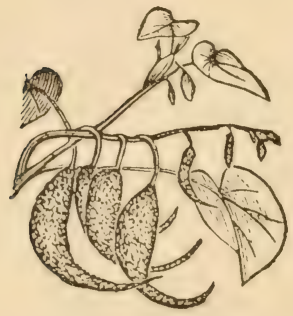

Figure 109-Martynia. pretty. The fruit is tender when young but is nearly as hard as horn when ripe. The seeds are black with a rough surface.

Culture.-This is a plant of the easiest culture. The seed should be sown as soon as the soil settles in the spring, in hills about three feet apart each way. Where seeds are allowed to ripen, plants usually appear the following spring. There is only one kind.

\section{THE GOURD FAMILY. (Order Cucurbitaceae.)}

The gourd family is made up of mostly tendril bearing herbs, 
with succulent but not fleshy herbage, watery juice, alternate palmately ribbed and mostly angled or lobed leaves, pistillate and staminate flowers separate and both kinds generally on the same plant. Calyx grown to ovary, petals commonly united, stamens usually three, of which one has a one-celled and the others two-celled anthers, but commonly the anthers are much twisted and often all combined into a head and the filaments are sometimes grown into a column. The fruit is unusually fleshy and the seed is flat and made up entirely of emuryo. It is commonly believed that some of the species in this group readily cross, but if it occurs at all it is but rarely, and squash and pumpkins have never been successfully crossed with melons. Besides the squash, pumpkin, muskmelon, watermelon and cucumbers, whose cultural directions are here given, there occurs here the gourds and wild cucumbers of the gardens.

\section{SQUASH. (Cucurbita.)}

The term squash does not signify any botanical division, but is an American name that is applied to a large number of varieties of gourds which in common parlance have come to be classified separately. The term often includes what are sometimes called pumpkins.

The term gourd is applied to all the members of Cucurbita pepo and includes the Scallop and Crookneck Squashes, field pumpkins and the small, very hard-shelled fruits of many shapes and color's borne on slender vines that are grown chiefly as curiosities under the name of gourds. The latter are what are commonly known as gourds.

Pollenizing the Flowers.-The flowers resemble those of the cucumber and melon, being separate on the same vine. The pistillate flower is produced at the end of the miniature squash; the staminate flower is often called the "false blossom," and its office is to produce pollen only. They are naturally pollenized by insects.

The crop is made more certain by having bees near by to pollenize the flowers. In some places, the absence of many insects is the reason why cucumbers, melons and squashes, which are similar in the construction of their flowers, fail to produce much fruit, though the vines may grow freely. This is it 
common complaint in some new prairie sections, as there is often a deficiency of pollenizing insects in such places. Where small cucumbers, squashes and melons fall off and fail to mature,

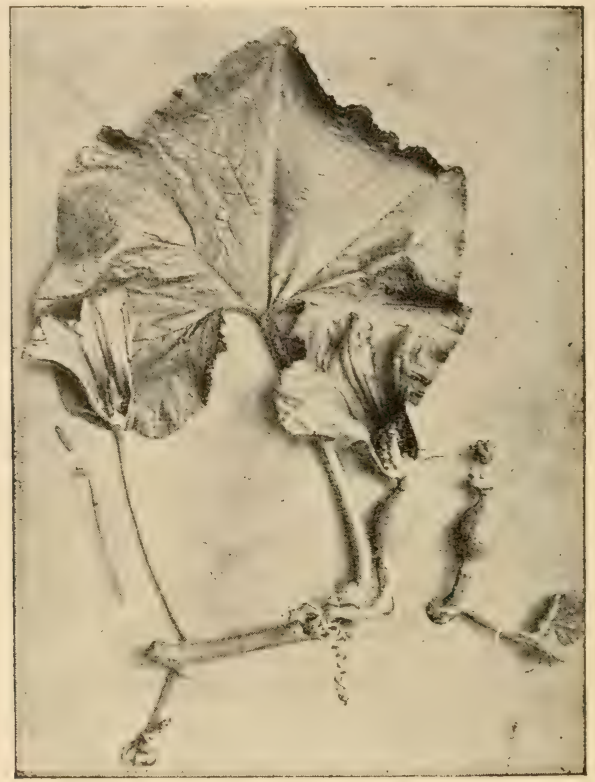

Figure 110.-Flowers on the Squash. To the left two staminate (male flowers; to the right two pistillate (female) flowers.

this matter of pollenization should be closely looked into, and if insects are not present the work can be quickly and easily done by hand. For this purpose a rather large camel's hair brush is used which can be filled at one time with enough pollen from a few male flowers to pollenize twenty or more female flowers.

The seed is oval and flat generally white or yellow, but varies greatly in size. There is a common belief among gardeners that vines from old seed do not grow so strong as those from new seed and produce more fruit. This seems to be borne out by some experiments.

Cultivation.-The cultivation of the squash and the pumpkin 
is much the same as for cucumbers. About six seeds should be put in each hill. The hills should be eight feet apart each way for the longer growing kinds and five feet apart for the bush sorts. The plants should be thinned out after they are established so as to allow two plants to each hill. They are affected by the same insect pests as the cucumber and the same remedies are in order. In addition, however, to these, some kinds are affected in the eastern states by a borer which works in the stem, and by the squash bug. (See chapter on insects.)

The early varieties of the squash are sometimes started in hotbeds or cold frames to advance them and thus avoid serious injury from the striped beetle.

Harvesting.-Summer squash are not grown for storing and are not desirable for table use except before the skin hardens, when they are used entire. Winter squash are excellent for use in a green state but are not gathered for storing until the skin is hard. They should always be gathered upon the approach of frosty weather, as a very little frost injures their keeping qualities, although the injury may not be apparent when gathered. It is a good plan in harvesting them to place them in piles in the field, leaving them exposed to the sun during the day and covering them with the vines or other material every frosty night until they are thoroughly dried and the skins have become hard and flinty. In gathering, cut the stem off not over an inch from the squash, for it the stem is left on it is liable to be used as a handle and be broken off and thus leave a spot that is very sure to start to rotting. Squashes should be handled with the greatest care if they are to be kept successfully, and each one should be placed in the wagon or on the shelf separately; if handled roughly they will not keep. They should be carried in a spring wagon or on a bed of hay or straw.

Storing.-Winter squash keep best in a dry atmosphere and at a cool temperature. They will, however, keep well in a warm or even hot cellar or room, providing it is dry, but will quickly rot in a moist atmosphere. They will shrink more in weight in a warm than in a cool place. They should be laid on shelves one tier deep, and never piled up if it is desired to keep them 
long. When well hardened without exposure to frost before storing and kept dry, many of the winter sorts are easily kept until March.

The quality of squash varies somewhat according to the land on which it is grown. Sandy loam is generally believed to produce the best flavored dry flesh squash, but the quality also varies according to the season.

Summer Varieties.-(Cucurbita pepo.)-Summer Crookneck

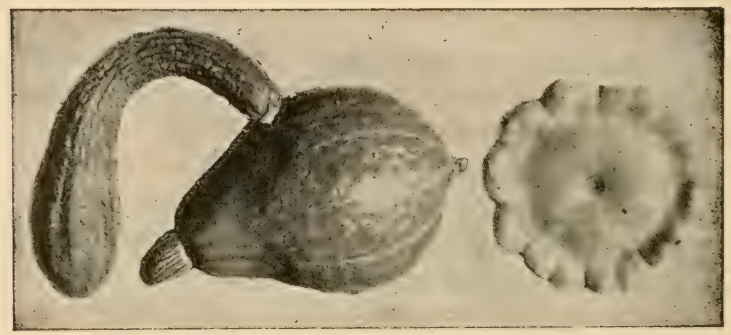

Figure 111.-Varieties of summer squashes.

Crookneck.

Boston Marrow.

Scalloped.

is a summer sort, generally with a crooked neck, that is highly esteemed. A form of this with a straight neck is also grown.

Bush Scalloped.-Yellow and white varieties of this for summer use are much grown by market gardeners, differing from each other only ir color of the skin. They are round-flat and have a scalloped edge.

Boston Marrow.-Much grown for marketing and very highly esteemed for summer and fall use.

Orange $\mathrm{M}_{1}$ arrow-A form of the Boston Marrow.

Fall and Winter Varieties.-(Cucurbita maxima.)-Hubbard.-This is the best known and most largely grown of the winter varieties. It varies somewhat in form, is generally dark green in color and sometimes marked with red. When well grown it has a rough shell of flinty hardness and thick, heavy flesh that cooks dry. The quality varies much according to the quality of the land on which it is grown, sandy loam generally producing the best. 
Marblehead is a variety that resembles the Hubbard in quality of flesh, and by many is considered superior. It differs from the Hubbard in form and color, is ashy gray and the flesh is

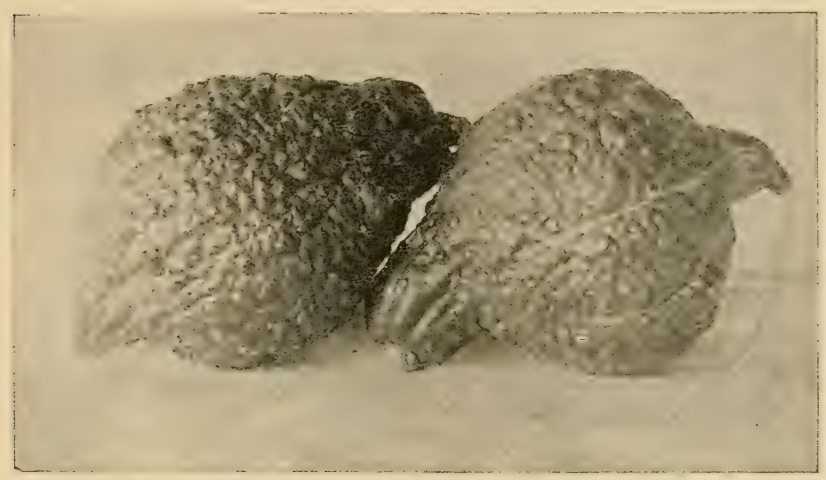

Figure 112-Hubbard Squash.

much thinner. It yields less in weight but generally produces more squashes per acre.

Essex Hybrid.-Very fine grained, rich, sweet, and a good keeper; excellent for autumn and winter.

Bay State.-A good variety.

Miscellaneous Varieties.-Winter Crookneck.-One of the hardiest, most reliable and best keeping squashes, but in quality no better than some of the pumpkins. Very little in demand for marketing, but popular in some sections for home use.

Cocoanut, Perfect Gem and Chestnut are varieties producing a large number of small squashes of excellent quality and are very easily raised.

PUMPKIN. (Cucurbita pepo.)

Native of warm climates.-Annual.-Under the name of pumpkin are grouped a number of gourds, greatly varying in shape, color, size and quality. Some of them are very good for cooking purposes, but they are not generally esteemed for table 
use by those who have become accustomed to the better kinds of squashes; some of them are great yielders and are used for feeding cattle. They may be grown as recommended for squash

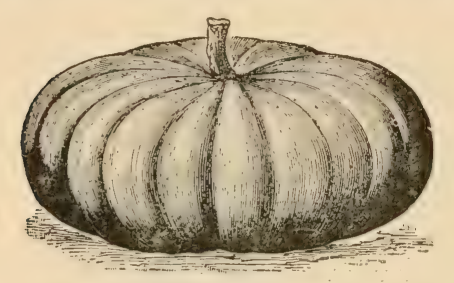

Figure 113-Cheese Pumpkin. or, as is most commonly practiced, grown amongst the corn, where the seed is planted as soon as warm weather is assureá. The seed varies much in size. For remarks on its flowers - and pollination see squash with which they are nearly identical.

The variety most generally grown is known as Connecticut Field, which is of large size and is used mainly for feeding stock. Sugar and Cheese pumpkins are varieties much grown for cooking purposes.

\section{MUSKMELON. (Cucumis melo.)}

Native of the warm parts of Asia.-Annual.-Cultivated from a very remote period of antiquity. It resembles the cucumber in habit of growth, and, like it and the squash, the different sexes of flowers are separate on the same plant and in nature require the agency of insects to pollenize them; however, they may be pollenized by hand, and the directions for pollenizing cucumber flowers apply here. In quite a few cases the flower's of the muskmelon are perfect, that is, have both stamens and pistils; but it is likely that even in these cases cross-fertilization is necessary. The seed resembles cucumber seed in size and form. The fruit varies in shape but is commonly round or oval. The flesh varies in color from nearly white to deep orange. This is one of the most healthful and delicious of fruits, and our warm, bright summers are especially favorable to its growth. As far north as Minneapolis, this fruit is often so plentiful as to glut the markets in September.

Culture.-The culture of muskmelons is practically the same as that recommended for cucumbers, and the insect pests are also the same. A warm soil is, if anything, more desirable for this crop than for cucumbers, and in moist seasons it does 
especially well on very sandy land, providing it has been well manured. It is a good plan to pinch off the ends of the vines after they have grown several feet for the purpose of forcing out the laterals on which the fruit is borne, although this is not customary in growing them on a large scale. Late settings of fruit may be removed to advantage in September, as they then have not time to mature. The fruit is not ripe until the stem separates easily from it. Fruit ripened on the vine is of the best

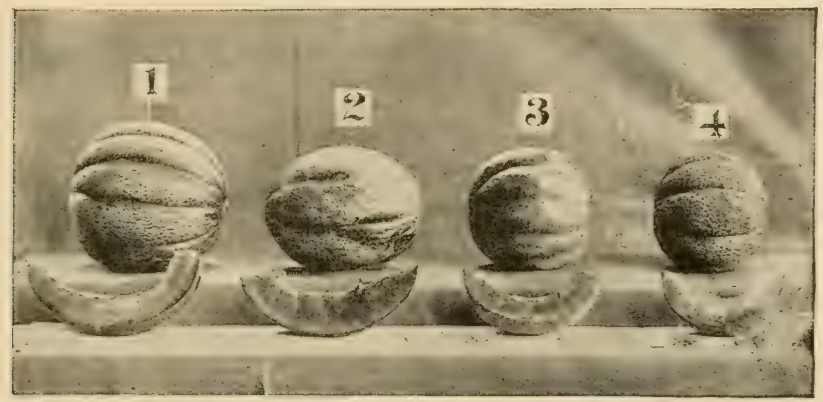

Figure 114-Muskmelons. 1-California Citron. 2-White Japan. 3-Miller's Cream. 4--Extra Ear1y.

quality, but for shipping purposes it should be picked when still green. Almost without exception, melons with finely netted skins are of better quality than those with smooth or coarsely netted skins. So true is this that buyers often refuse to buy the smooth kinds. In order to make the fruit ripen earlier and to avoid the attacks of the striped beetle, the plants are often started in pots and on sods in hotbeds or frames, as recommended for cucumbers. It is a good plan also to place a piece of glass or board under the melons when those of the best quality are desired, since this keeps them off the ground, and they ripen more evenly in consequence.

Varieties.-Melons vary much in size, form, color of skin and flesh and in quality. There are many kinds, but only a few are referred to here.

Christiana, or Early Christiana is a popular melon, of extra good quality, with salmon colored flesh. 
Osage, or Miller's Cream.-A large melon having firm salmon colored flesh, very productive and highly esteemed for the market and home garden. Perhaps, the best shipping sort now grown.

California Citron muskmelon is a variety especially popular in some northern markets for home market and for shipping.

Emerald Gem is a very prolific melon, with smali but very superior fruit that is valuable for home use.

WATERMELON. (Citrullis vulgaris.)

Native of Atrica.-Annual.-A vine of the same general habit as the muskmelon, but the leaves are deeply lobed,

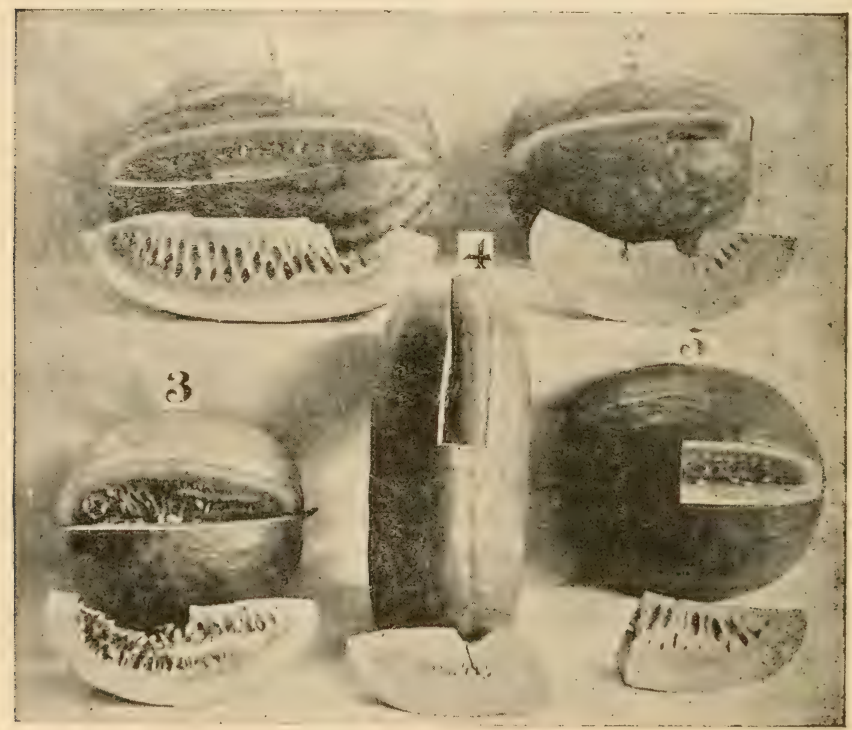

Figure 115-Varieties of Watermelons. 1-Iron Clad. 2-Cuban Queen. 3Light Ice Rind. 4-Monte Cristo. 5-Dark Ice Rind.

and the whole plant is covered with soft, grayish hairs that give it a grayish aspect. The flowers are the same in general structure as those of the cucumber or muskmelon. The seeds are 
large but vary much in size, color and markings. The fruit varies in color of skin from pale yellow to deep green and is often mottled; the flesh varies from white to pink or yellow. Some are tasteless and insipid and others are sugary and refieshing. The fruit often weighs as much as fifty pounds in gool seasons when grown in favorable locations, even in the extreme northern states.

Culture.-The method of culture is the same as for the cucumber and muskmelon, with the exception that the vines should not be pinched, and they require rather more room in which to grow. They should be planted about eight feet apart each way.

Varieties.-There are many kınds of watermelons offered by seedsmen, diiffering from one another in many particulars. Several of the most esteemed are the following:

Dark and Light Icing, or Ice Rind.-The best two varieties for general use. Well adapted for home use or marketing.

Hungarian.-A melon of good quality, adapted for the home garden.

Volga.-An early variety with light colored skin and very red flesh. Fruit rather small but of excellent quality and very productive.

Citron, or Preserving Melon.--Resembles watermelon, but the flesh is hard and only fit for preserves. There is but a limited demand for it.

\section{CUCUMBER. (Cucumis sativus.)}

Native of the East Indies.-Annual.-A creeping plant with angular, flexible stems, rough to touch and furnished with tendrils. The Howers are yellow, in the axils of the leaves, some male, others female; the latter flowers are on the ovary, which later becomes the cucumber. The plants produce flowers and fruit in succession over a long season, and these are naturally 1.ollenized by insects. The seed is long-oval in form and yellowish-white in color.

Cultivation.-The land for cucuinbers should be a deep, ricb. iscrnewhat retentive loam, and yet this vegetable will do very well with only moderately favorable conditions. For ordinary use and for the home garden, cucumber seed should be planted after 
the ground is warm, say from the middle to the last of May, but it may be planted with good results as late as the middle of June. $\mathrm{ft}$ is quite customary to furrow out the land six feet apart one way, mark crossways of the furrows with a six foot marker, and put a shovelful of well rotted manure or compost in each intersection. Cover this manure with soil and plant the cucumber seed. Of course, when the land is in the best condition, it is not necessary to put manure in the hills; in such cases, all that is necessary is to mark out both ways and plant at the intersections. About ten or a dozen seeds should be put in each hill and covered about one inch deep, and the soil packed over the seeds. As soon as the plants are up, and after each rain, they should have the soil loosened around them They should also be kept dusted until well established with Paris green, land plaster or some other dust, to keep off the striped beetles, which are often very troublesome and may destroy the plants when they are small unless preventive measures are used. (See chapter on insects.) The land should be cultivated both ways until the vines prevent it, so that very litle work will have to be done by hand. About three good plants are enough for each hill, and the rest should be removed after the danger from serious insect injuries has passed.

Gathering the Crop.-If for table use or for marketing in a green state, the cucumbers are gathered when full grown but still green; if for pickles, the cucumbers are gathered as soon as of the required size, which is generally when they are about three inches long. Some factories put up larger and some smaller pickles than this size. To gather them of just the right size requires that the whole bed be picked over about once in two days. This is a matter of much labor and is generally paid for by the piece. No cucumbers should be allowed to go to seed if pickles or table cucumbers are wanted, for as soon as seed is ripened the plants commence to die off, while if constantly gathered when green and not allowed to ripen, the plants will continue bearing a long time. In the vicinity of pickling factories, cucumbers for pickles are often raised in large quantities as a farm crop and are contracted for at a specified price per thousand or per hundred pounds, for the season. For home use or for storing and 
marketing in the winter, the cucumber's are packed in salt or salt brine when gathered. Growers generally use about seven pounds of salt to a bushel of cucumbers. They may also be packed in dry salt in layers, which has the effect of taking the water out of the cucumbers, causing them to shrivel up and lie in their own juice. When wanted for use they are freshened out in water, which causes those that are shriveled to swell up plump; they are then put in vinegar. Cucumber pickles are easily kept until the following spring in this way, but when kept later than spring they get soft and are not so desirable. Cucumbers will stand z great amount of dry weather without injury, if frequently cultivated.

Starting Cucumbers in cold frames and hotbeds and then transplanting them to the open ground when all danger of frost

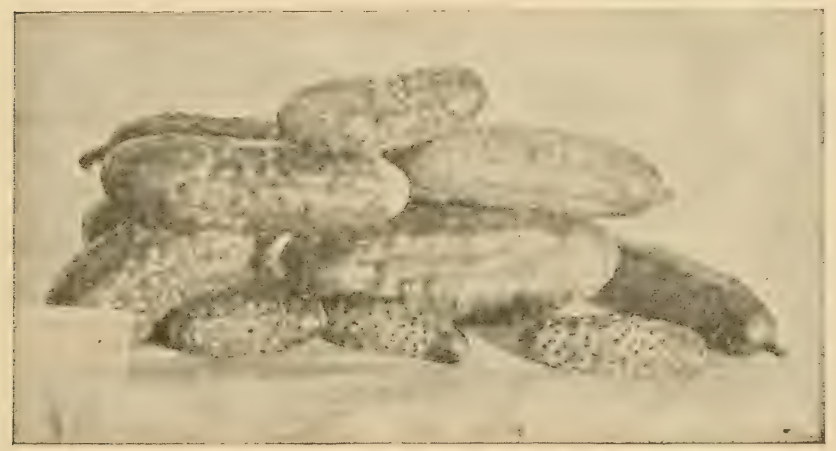

Figure 116-Chicagc Pickling Cucumber.

is over is a common practice where they are wanted for early use. Under this system the seed is sown in old strawberry boxes; tomato cans, flower pots, etc. Square pieces of inverted sod are also used for the same purpose, four or fire seeds being sown on each piece five inches square and covered with good soil. The plants in this latter case root into the sod and are easily moved. Starting cucumbers this way has the merit of adrancing the period of maturity of the plants, and as they are well started 
when set out there is little danger of attacks of the striped beetle, and the fruit is earlier than when sown in the open ground. In following out this plan, the seed should not be sown before the first of May, or the plants will be too large to move well. Before the plants are removed from the frames to the open ground, they should be exposed without the sash for several days until well hardened off. When these plants are moved to the open ground, they should be set rather deeper than they grew in the frames. They then are cultivated the same as plants from seed sown in the hill. Another way for advancing the cucumber season when hotbed sash is used is by planting a hill of them very early, in the center of each sash of the hotbed, while the rest of each sash may be used for an early crop. The cucumbers will not need much room for several weeks, which will give time to grow the early crop and get it out of the way of the cucumbers. The sashes should be removed when warm weather comes, and the vines allowed to grow in the frames all summer.

Insects.-The cucumber has a serious enemy in the striped beetle and is also liable to injury from the cut worm. (For remedies see chapter on insects.)

Seed.-Cucumber seed is easily raised, and in some locations it is a product of some importance. In raising seed it is important to save it from the early fruit, which in a small way are easily saved; on a large scale, however, the fruits are allowed to ripen but not to rot on the ground. When the vines are dead, the ripe cucumbers are split open, the pulp scooped out with the seed and allowed to ferment for a few days, when it readily separates from the seed. The whole mass is then thrown into a sieve with a mesh small enough to not allow the seeds to pass through, and the pulp is washed through the sieve, leaving the clean seed, which is carefully dried. If the cucumbers are allowed to get rotten before the seed is taken out, the skins will become mixed with the seed, and the seed will be discolored, and such seed is very liable to sprout in the cleaning and curing process.

Varieties.-For general home use and marketing, the White Spine is a favorite variety. For pickles the most profitable kinds are those producing many small cucumbers, such as the variety 
known as the Boston Pickling. There are many gond varieties of cucumbers and they are offered under various names. For earliest use the Early Russian is perhaps the best, but it is small and seedy.

\section{THE SUNFLOWER FAMILY. (Order Compositae.)}

The sunflower family (order compositae) is the largest group of flowering plants, yet it has given us only a very few garden vegetables and those are of little importance. Its plants are distinguished by what the older botanists termed the "compound flower." This consists of several or many flowers in a head, surrounded by a set of bracts. Stamens as many as the lobes of the corolla (generally five), their anthers grown together by their edges. Ovary one-celled, inferior, containing a single seed. Besides the artichoke, lettuce, salsify, endive, and dandelion, whose cultural directions are here given, there occur here the tansy, sunflower, daisies, corn-flower, ageratum, cineraria, chicory, burdock, thistle, wild lettuce, compass plant, ragweed, fireweed, chrysanthemum, marigold, goldenrod, aster, yarrow, zinnia, dahlia and many other well known plants.

\section{LETTUCE. (Lactuca sativa.)}

Native of India or Central Asia.-Annual.-Flowers yellow, on seed stalks two or more feet high; seeds small, flat, white or black, but sometimes yellow or reddish brown in color. The shape and size of the leaves also vary greatly; sometimes they form a head like the cabbage and again only a loose bunch. The foliage is generally of some shade of green, but some varieties have leaves of a reddish color.

Cultivation.-Lettuce is largely grown in greenhouses during the winter, in hotbeds and cold frames in the early spring and outdoors in the late spring and until severe weather in autumn. It is a very important crop for the market gardener, as there is some demand for it at all seasons of the year and a large call 1or it in the spring. Some growers making a specialty of this crop have it in marketable condition every month of the year. In some sections, the plants may be started in September and when of good size transplanted to a cold frame, where they may be safely wintered over. In the spring 
they are used for planting in hotbeds and in the open ground. In the extreme Northern states, however, although plants frequently come through the winter safely when thus protected, it is not a method to be depended upon. It is customary here to raise the plants for spring planting, in greenhouses or early hotbeds. Lettuce may be transplanted to the open ground as

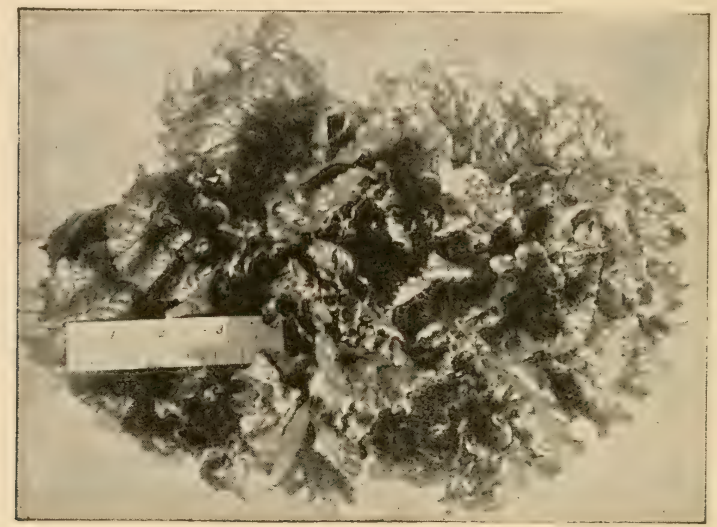

Figure 117-B1ack-seeded Simpson Lettuce. (TJ pica1 curley sort.)

soon as the soil will work easily in the spring, but it should be well hardened off before being planted out; it will, however, stand quite a severe freeze if properly hardened off, and, as is the case with many other crops, the plants may be protected with earth on the approach of hard frost, providing it does not remain over them more than a day or two. In the open ground, lettuce plants should be set out about twelve inches apart each way. It is frequently grown between rows of early cabbage, cauliflower or other plants where it fills up otherwise unoccupied space and comes off the land long before other crops need the room it occupies. For late use, the seed is often sown in the open ground in drills one foot apart and the plants thinned to the same distance apart. It is customary also in the home garden to sow the seed and then cut off the young plants as soon as they are 
large enough to use; such lettuce, however, is not nearly so good as head lettuce where the center is white, crisp and tender. It is a far better plan to thin out the young plants so that they stand three or four inches apart in the rows and in cutting con-

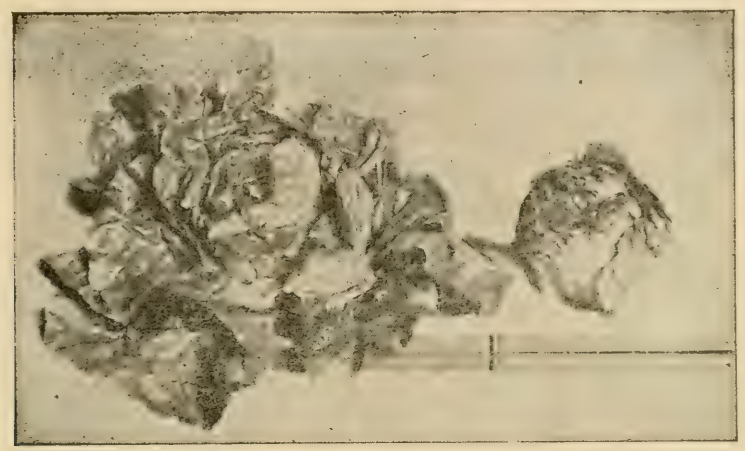

Figure 118-Head Lettuce.

tinue the thinning process so that the later plants will form good heads. Of course, it is necessary to make successive sowings of lettuce in order to have it fit for table use over a long season. Like all leaf crops, lettuce needs plenty of rich, easily available nitrogenous manure and responds very quickly to small ap. plications of nitrate of soda.

Varieties.-There are many varieties and each year finds many additions to the list of those offered by seedsmen. In the matter of quality, those forming a head like the cabbage have the preference. Varieties that form only a bunch of leaves are largely raised by market gardeners to supply the common demand, since they are more easily grown and are less liable to injury in handling than the heading varieties. Some of the most desirable kinds are as follows:

White Tennis Ball, or Boston Market.-A very popular market variety adapted for hotbed and early spring use only. It forms a solid head of medium size but quickly goes to seed in warm weather. 
Hanson.-Forms large solid heads and is a general favorite; excellent for spring or summer use.

Black-Seeded Simpson.-A popular forcing variety that stands well without going to seed and does not form a head but a mass of curled leaves.

Grand Rapids.-A very desirable lettuce for forcing. It resembles Black-Seeded Simpson, but is a better shipping variety.

Black-Seeded Tennis Ball.-A popular sort for forcing or early garden culture. It forms large, solid heads and is highly esteemed.

Salamander.-A good heading sort for summer use.

Buttercup.-Bright chrome yellow in color, very beautiful; tender and desirable. A popular new sort.

Insects and Diseases.-There are few insects or diseases that seriously affect the lettuce when grown outdoors. In the greenhouse and occasionally in the hotbeds, it is sometimes attacked by the aphis and mildew. For remedies for aphis, see chapter on insects.

Mildew frequently injures the lettuce crop when it is grown in greenhouses in winter. It is most liable to be caused by overwatering and especially by frequent watering in cold or cloudy weather, which keeps the leaves wet much of the time. It is a good plan to water heavily when the crop is planted and to avoid repeating it until the soil is quite dry and then water heavily again in the morning of a bright day, so that the foliage may dry off before night. Sub-irrigation has been used with excellent success for this crop in greenhouses in winter.

SALSIFY, OR VEGETABLE OYSTER. (Tragopogon porrifolius.)

Native of Europe.-Biennial.-A plant with long fleshy taproot and grass-like leaves. The flower stalks grow three feet high; the seed is long, ridged, generally curved and pointed at both ends. It is rather difficult to plant with a seed sower because of its peculiar form, but when the points are rubbed off it is often so planted.

Culture.-The cultural directions given for the parsnip apply to this plant. It is very easily grown and hardy, and generally comes through the winter in the extreme northern states without injury; it is safer, however, to dig the roots in autumn, and put in 
pits until spring or for use during winter. The root is highly esteemed and has the flavor of oyster's; it is used for soups, but may be cooked in the same manner as parsnips.

The best variety is the Mammoth Sandwich Island, which is far superior to any other.

\section{ENDIVE. (Cichorium endivia.)}

Native of East India.-Annual.-Endive resembles the dandelion in habit and growth. It is esteemed by some as a de-

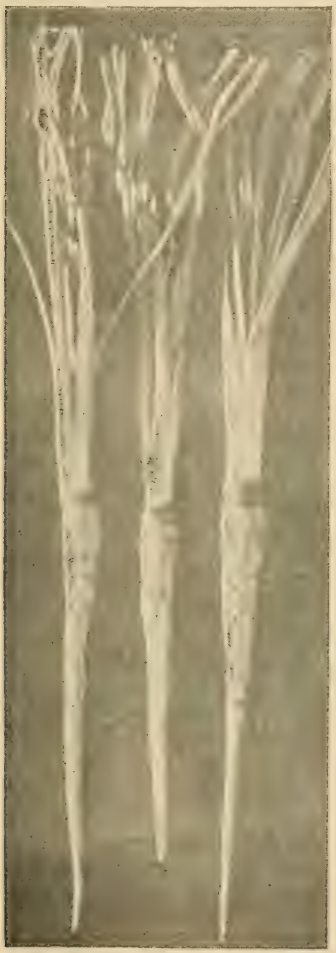

g. 119-Sandwich Island Salsify. sirable fall and winter salad since it has a pleasant bitter taste when blanched. It is of very simple culture and may be grown in much the same manner as lettuce. For summer use, sow the seed early in the spring; for autumn and winter use, sow in July. It is blanched before being eaten. This is accomplished by tying the leaves lightly together when the plants have nearly completed their growth. After this treatment, the leaves in the center of the plant will have become blanched in about three weeks. Do not tie the plants too rapidly, since the hearts are liable to rot soon after blanching, especially if the weather is warm. On the approach of severe weather, the plants may be set in boxes in a cold cellar, where they will continue to produce nice blanched leaves during the early part of the winter.

Varieties.-A variety known as Green Curled Endive is generally grown, but other varieties are offered by seedsmen.

DANDELION. (Taraxacum officinale.)

Native of Europe.-Perennial.-The dandelion is a familiar 
pisnt to almost every one. It is now of spontaneous growth here

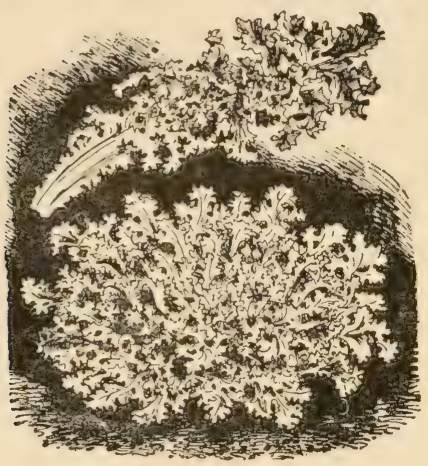

Fig. 120.-Curled Endive. and is used for greens in its wild state; but the cultivated varieties are quite an improvement on the wild plants. The best method of growing it is by sowing the seed in the spring in drills ten inches apart and thinning out the plants to three inches apart in rows. The seed is somewhat difficult to start, and it is a good plan to go over each row twice with the seed sower, so as to mix the seed up with the soil, since by this method some of it will be sure to be properly covered. It is sometimes used in the fall, but

not generally until spring. It is often forced by covering the bed with the hotbed sash or by transplanting to hotbeds or cold frames. It is sometimes blanched and used as a salad, for which purpose it is much like endive. While the plant is a perennial, yet only one crop should be harvested from each sowing, since after the first cutting there are many sprouts produced from each root so that none of them are large enough for good market plants. The plants should always be plowed in before they ripen seed unless seed is to be

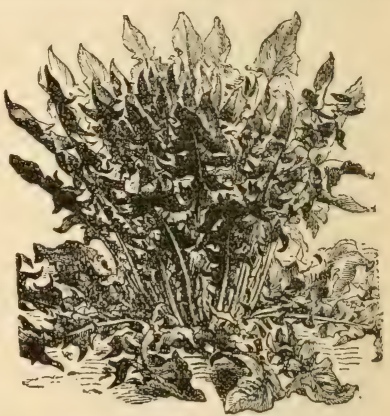

Figure 121.-Dandelion. saved, to prevent its scattering and becoming a nuisance. A variety called the Improved Thick-Leaved is the most esteemed.

JERUSALEM ARTICHOKE. (Helianthus tuberosus.)

Native of North America.-Perennial.-Stems herbaceous, six or more feet high, roots tuberous. Flowers yellow, resembling those of the common sunflower, but comparatively small. 
For best results the artichoke requires exceedingly rich soil. It can be grown from the seed, although this is seldom attempted, but it is customary to grow it by planting the small tubers whole or cut the large tubers in the same way as potatoes. They should be planted about four inches deep at twelve inch intervals in rows three feet apart. They are used chiefly for feeding stock and are often harvested by turning hogs into the field. They will frequently remain in the land many years even if not cultivated. They are easily injured by frost when not covered with earth but in the ground they are perfectly hardy.

\section{GLOBE ARTICHOKE. (Cynara scolymus.)}

Native of Barbary and South Europe.-Perennial.--A large thistle-like plant growing two to three feet high, producing large flower heads, the scales of which are large and thick, and are highly esteemed as a garden vegetable in England and Southern Europe. It has, however, never become popular in this country and is rarely grown. In Southern Europe it is grown by divisions and there are many varieties. It may also be grown from seed, but seedlings are generally very much inferior to the best named sorts. The roots must be very carefully protected in order to bring them through our winters.

\section{GARDEN HERBS.}

Under this head are grouped a number of sweet culinary and medicinal plants that are cultivated to some extent in gardens. They are generally easily grown in mellow, open soil. Those having foliage that is esteemed for its aroma should generally be cut on a dry day, just as they reach full flowering stage, and should be dried quickly in the shade. As a rule, herbs should be cut before being frozen, though freezing does not always injure them. When dry they should be kept in dry air-tight boxes or vessels. The demand is very limited for most of them. Only a few of the most common kinds are referred to here. In the extreme northern states, many of the perennial kinds will kill out in severe winters unless protected.

\section{THE MINT FAMILY. (Order Labiatae.)}

The Mint Family includes little other than herbs (with few exceptions) which have aromatic herbage, square stems, op- 
posite simple leaves, 2-lipped corolla and a deeply 4-parted ovary which separates into the same number of seeds. Besides balm,

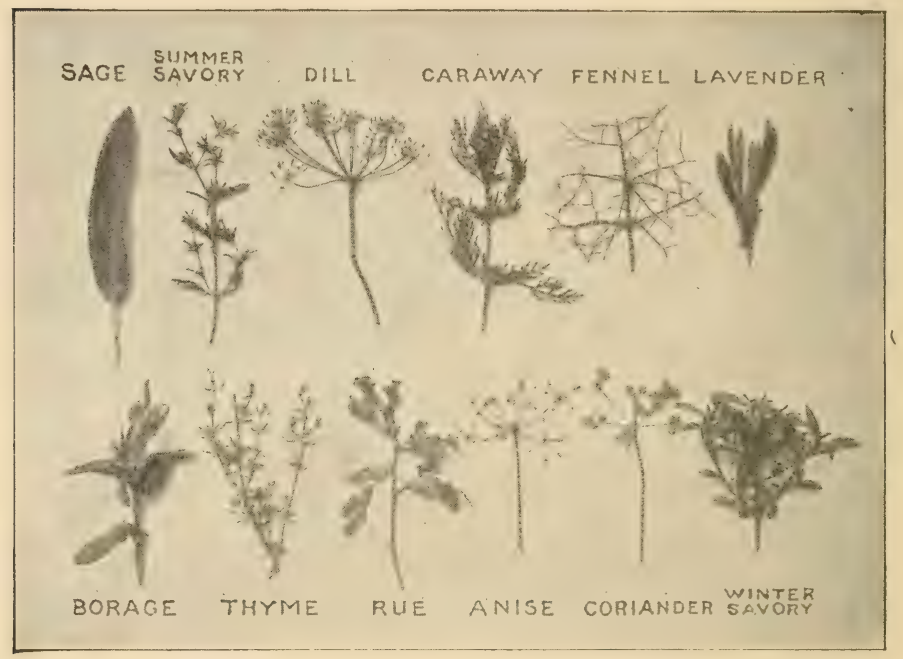

Figure 122-Characteristic portions of garden herbs.

catnip, lavender, peppermint, sage, sweet basil, sweet marjoram, spearmint, summer savory, thyme, and winter sarory whose cultural directions are here given, this order includes garden coleus, hyssop, flowering sage or salvia, and horse mint. The plants of this group are mostly grown for their aromatic herbage.

Balm.-(Melissa officinalis.) - A native of the south of Europe.-Perennial.-A plant growing about eighteen inches high having aromatic herbage. The seed is very small. Sow in spring where the plants are to remain.

Catnip.-(Nepeta cataria.) - Native of Europe.-Perennial.Often a common weed around buildings and along roadsides here. It is used in a small way for seasoning. Easily grown from seed or by division. 
Lavender.-(Lavendula spica.) - Native of southern Europe.Perennial.-A low undershrub grown chiefly for its flowers which are used in the manufacture of perfumery. Generally increased by dividing the old roots. It delights in a fine, rich, rather calcareous soil.

Peppermint.-(Mentha piperita.) - Native of northern Europe. -Perennial.-Propagated by divisions of the stems; occasionally a roadside weed in moist places. It is cultivated in the same way as spearmint. Used mostly for its essential oil which is obtained by distillation. The raising of this plant forms a considerable industry in a few locations in the northern states.

Sage.-(Salvia officinalis.) - Native of southern Europe.-Perennial.-Plants forming broad tufts about sixteen inches high; flowers in heads of three or four in terminal clusters, usually bluish white but sometimes white or pink. The seeds are round and of medium size. Plants come readily from seed, which should

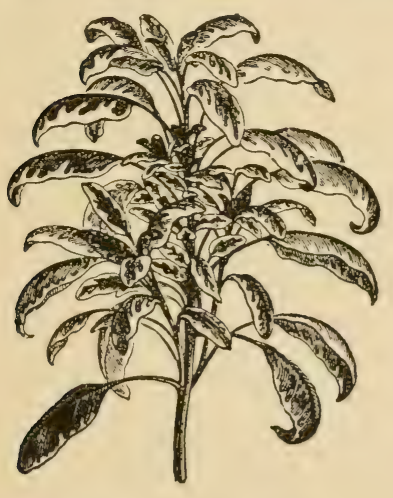

Fig. 123-Branch of sage plant.

be sown in early spring. It is customary in a small way to sow the seed outdoors and allow the plants to remain where they grow for several years. Where it is grown on a large scale, however, the plants are generally put out as a second crop, following early peas or cabbage. There is some uncertainty about its coming through very severe winters in the northern states, but it generally does so in good shape; it is more reliable if banked with earth or covered with litter in winter. Broad-leaved sage is an improved kind.

Sweet Basil.-(Ocymum basilicum.)-Native of India.-Annual.-Stem about one foot high; very branching. The leaves and other green parts have an agreeable aromatic odor and are used in seasoning. Sow indoors in March or April and transplant as soon as the weather is settled. It may also be sown in the open ground early in the spring. 
Sweet Marjoram.-(Origanum marjorana.) - Native of Asia.Perennial but generally grows as an annual.-The leaves and other green parts are used for seasoning. The seeds are very small. Sow early in spring in any good garden soil.

Mint or Spearmint.-(Mentha viridis.) - Native of Europe.Perennial.-A plant with vigorous creeping root stock, very hardy and sometimes a troublesome weed in moist soil. It is grown by planting the roots in the spring. There is a small demand for this plant in winter as well as in summer, which is met by a greenhouse supply. The leaves and young shoots are used for seasoning.

Summer Savory.-(Satureia hortensis.)-Native of southern Europe.-Annual.-A small plant eight or ten inches high. The seed, which is very small, should be sown the latter part of April or in May. The leaves and young shoots are used for flavoring.

Thyme.-(Thymus vulgaris.) - Native of southern Europe.Perennial.-A small plant with small aromatic leaves and stems. It starts easily if sown in early spring. It is customary to sow the seed where the plants are to remain but it may be transplanted. It is in demand for flavoring and is generally hardy at the north. Eroad-leaved thyme is the only variety worth growing.

Winter Savory.-(Satureia montana.)-Native of southern Europe.-Perennial.-Stems woody, at least near the base; twelve to sixteen inches high. Used for the same purposes as Summer Savory. Not hardy here unless well protected.

PARS.VIP FAMILY. (Order Umbelliferae.)

For characteristics see page 172 .

Anise.-(Pimpinella anisum).-A native of Asia Minor.-Annual.-Attains a height of sixteen inches. The seeds are aromatic and used in medicine and confections. Sow in April or May where the plants are to remain during the season.

Caraway.-(Carum carui.) - Native of Europe.-Biennial.Stem straight; two or three feet high. The seeds resemble those of carrots and are esteemed for flavoring. It should be sown in May in drills and does not produce seed until the following season; very hardy and of the easiest culture. 
Coriander.-(Coriandrum sativum.) - Native of southern Europe.-Annual.-Two to two and one-half feet high. Stem leaves much divided. Grown from the seed which should be sown in the spring. ' the seed is used for flavoring purposes; the foliage exhales a very rank odor.

Dill.-(Ane:hum graveolens.) - Native of sou'hern Europe.Annual.-Height, from two to two and a half feet. It is of the easiest culture. The seed is much used as flavoring for pickles of various kinds. It should be sown in the spring in rows about one foot apart and cultivated the same as for carrots. Where the seed ripens, an abundance of plants generally spring up the following year. Probably botanically the same as fennel but the latter is more in use in the green stage for its foliage.

BORAGE FAMILY. (Order Boraginaceae.)

Borage.-(Borage officinalis.) - Native of Europe and North Africa.--Annual.- Twelve to eighteen inches high. Used in the manufacture of cordials. Flowers blue, pretty. Of the easiest culture, growing freely from spring sown seeds.

\section{RUE FAMILY. (Order Rutaceae.)}

Common Rue.-(Ruta graveoleus.) - A bushy herb, woory, or almost shrubby at its base. The leaves are very bitter and some. times used in seaconing. Grown from seed or by division of the roots. 
TABLE I.-WEIGHT OF OУE QUART OF SEEDS AND NUMBER OF SEEDS IN ONE OUNCE.

\begin{tabular}{|c|c|c|}
\hline KIND OF SEED. & $\begin{array}{l}\text { Weight of a } \\
\text { Quart of } \\
\text { Seed in } \\
\text { Ounces. }\end{array}$ & $\begin{array}{l}\text { Number of } \\
\text { Seeds in } \\
\text { One Ounce. }\end{array}$ \\
\hline sparagus & \multirow{49}{*}{$\begin{array}{l}32 \\
20 \\
20 \\
24 \text { to } 33 \\
10 \\
25 \\
25 \\
25 \\
15 \\
9 \\
13 \\
28 \\
25 \\
17 \\
14 \\
20 \\
28 \\
202 / 3 \\
18 \\
20 \\
91 / 2 \\
11 \\
18 \\
12 \\
25 \\
20 \\
151 / 3 \\
23 \\
20 \\
24 \\
101 / 3 \\
13 \\
22 \\
18 \\
\text { to } 281 / 2 \\
\text { to } 281 / 2 \\
\cdots \ldots \ldots . . . \\
16 \\
9 \\
25 \\
281 / 2 \\
3 \text { to } 41 / 2 \\
191 / 2 \\
8 \\
18 \\
15 \\
131 / 2 \\
142 / 3 \\
8 \\
14 \\
151 / 2 \\
23 \\
24 \\
11 \\
24 \\
161 / 2 \\
12\end{array}$} & \multirow{49}{*}{$\begin{array}{c}1,400 \\
56,600 \\
22,665 \\
200 \text { to } 225 \\
1,400 \\
8,500 \\
10,525 \\
8,500 \\
9,915 \\
19,835 \\
26,915 \\
3,400 \\
10,525 \\
70,835 \\
19,830 \\
16,915 \\
12,715 \\
113,335 \\
1,103 \\
3,680 \\
34,000 \text { to } 42,500 \\
25,500 \\
6,520 \\
18,000 \\
8,500 \\
11,335 \\
22,665 \\
113 \text { to 140 } \\
113,355 \\
340,000 \\
565 \\
1,560 \\
425 \text { to } 510 \\
7,080 \\
56 \text { to 142 } \\
142 \text { to 225 } \\
6,605 \\
4,205 \\
700,835 \\
3,400 \\
1,415 \\
7,080 \\
2,835 \\
42,500 \\
70,835 \\
2,550 \\
3,135 \\
113 \text { to } 15000 \\
28,335 \\
2800 \\
\text { to } 340 \\
930 \\
\end{array}$} \\
\hline & & \\
\hline sil, & & \\
\hline & & \\
\hline . & & \\
\hline ecole, or Kale.... & & \\
\hline & & \\
\hline $\begin{array}{l}\text { bbą } \\
\text { raw }\end{array}$ & & \\
\hline $\begin{array}{l}\text { araway,.... } \\
\text { arrot, with }\end{array}$ & & \\
\hline & & \\
\hline & & \\
\hline & & \\
\hline & & \\
\hline & & \\
\hline erican,....... & & \\
\hline $\begin{array}{l}\because \quad \text { common gard } \\
\text { water,............. }\end{array}$ & & \\
\hline $\begin{array}{l}\text { Wacumber, } \mathrm{c} \\
\text { Cucut }\end{array}$ & & \\
\hline p & & \\
\hline andelion,.... & & \\
\hline Plant,... & & \\
\hline Plant,. & & \\
\hline$\cdots .$. & & \\
\hline & & \\
\hline & & \\
\hline ......... & & \\
\hline & & \\
\hline artynia & & \\
\hline $\begin{array}{l}\text { artynia,.... } \\
\text { uskmelon,. }\end{array}$ & & \\
\hline & & \\
\hline & & \\
\hline \multirow{2}{*}{ 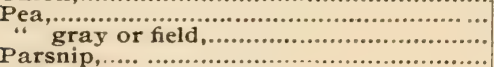 } & & \\
\hline & & \\
\hline Pepper, & & \\
\hline ( & & \\
\hline ................... & & \\
\hline ............ & & \\
\hline .............. & & \\
\hline 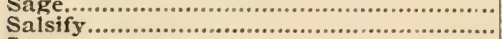 & & \\
\hline & & \\
\hline n.......... & & \\
\hline nach, & & \\
\hline "New 2 & & \\
\hline 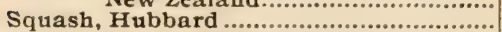 & & \\
\hline (- & & \\
\hline wberry Tomato........... & & \\
\hline & & \\
\hline mato. & & \\
\hline Naterme. & & \\
\hline & & \\
\hline
\end{tabular}


TABLES.

TABLE II.-LONGEVITY OF GARDEN SEED WHEN PROPERLY CURED AND STORED.

\begin{tabular}{|c|c|c|c|}
\hline KIND OF SEED. & $\begin{array}{c}\text { Average } \\
\text { Years. }\end{array}$ & KIND OF SEED. & $\begin{array}{l}\text { Average } \\
\text { Years. }\end{array}$ \\
\hline Balm.................. & 4 & Martynia........................ & 1 or 2 \\
\hline 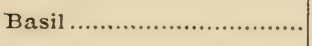 & 8 & Muskmelon..................... & 5 \\
\hline Bean ....... & 3 & Mustard, white or salad & 4 \\
\hline Beet...... & 6 & Okra.......... & 5 \\
\hline Borecole.... & 5 & Onion ................................... & 2 \\
\hline Cabbage ............. & 5 & Parsnip.... & 2 \\
\hline Caraway ............. & 3 & Parsley........................... & 3 \\
\hline Carrot.................. & 4 or 5 & Pea. Garden or field...... & 3 \\
\hline Catmint...... & 6 & Pepper...... & 4 \\
\hline Cauliflower.... & 5 & Pumpkin.................... & 4 or 5 \\
\hline Celery......... & 8 & Radish....... & 5 \\
\hline Chicory.... & 8 & Rampion..... & 5 \\
\hline Cress, American............... & 3 & Rhubarb ................ & 3 \\
\hline "Common Garden.. & 5 & Rosemary... & 4 \\
\hline " Water..................... & 5 & Rue.............. & 2 \\
\hline $\begin{array}{r}\text { Cucumber common ......... } \\
\text { Prickly-fruited } \\
\text { Gherkin........... }\end{array}$ & $\begin{array}{r}10 \\
6\end{array}$ & $\begin{array}{l}\text { Sage } \ldots \ldots \ldots \ldots \ldots \ldots \ldots \ldots \ldots \ldots \ldots \\
\text { Salsify } \ldots \ldots \ldots \ldots \ldots \ldots \ldots \ldots \ldots\end{array}$ & $\begin{array}{l}3 \\
2\end{array}$ \\
\hline Dandelion...... & 2 & Sarory, summer or wint'r & 3 \\
\hline Dill...... & 3 & Spinach, all kinds,......... & 5 \\
\hline Egg-Plant. ...................... & 6 & Squash, Hubbard............ & 6 \\
\hline Endive........................... & 10 & “ Bush scalloped.. & 6 \\
\hline Kohlrabi...................... & 5 & Strawbery Tomato........ & 8 \\
\hline Leek................ & 3 & Thyme........... & 3 \\
\hline Lettnce, common............ & 5 & Tomato.............. & 4 \\
\hline Maize, or Indian Corn.... & 2 & Turnip............ & 5 \\
\hline $\begin{array}{l}\text { Marjoram, Swert.... } \\
., \quad \text { Winte..... }\end{array}$ & $\begin{array}{l}3 \\
5\end{array}$ & Watermelon.... & 6 \\
\hline
\end{tabular}


TABLE III.-AMOUNT OF SEED REQUIRED TO SOW AN ACRE.

\begin{tabular}{|c|c|c|}
\hline KIND OF SEED & METHOD OF SOWING & Amt. per Acre \\
\hline 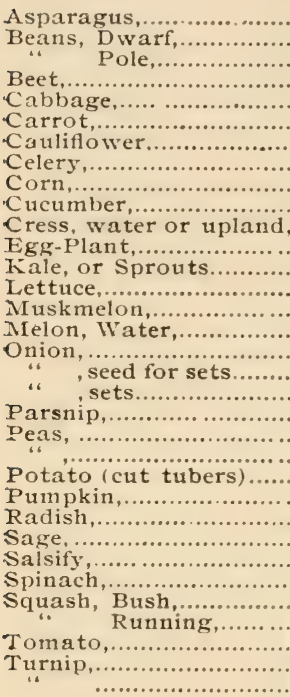 & 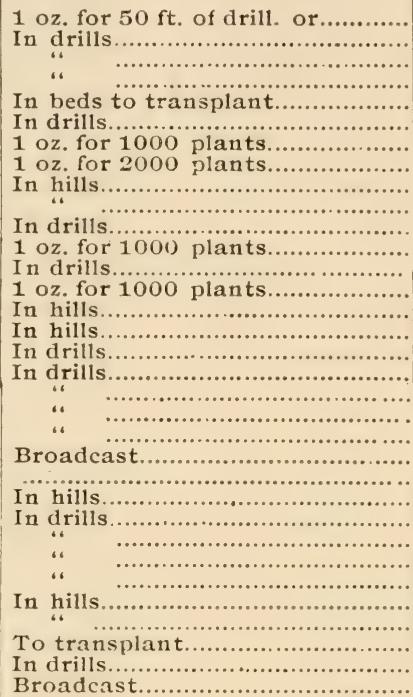 & 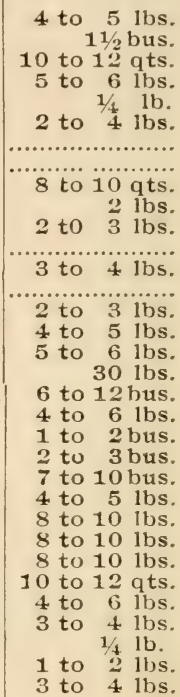 \\
\hline
\end{tabular}

TABLE IV. - AVERAGE TIME REQUIRED FOR GARIEN SEEDS TO GERMINATE UNDER GOOI) CONDITIONS,

\begin{tabular}{|c|c|c|c|}
\hline KIND OF SEED. & No. Days. & KIND OF SEED. & No. Days. \\
\hline 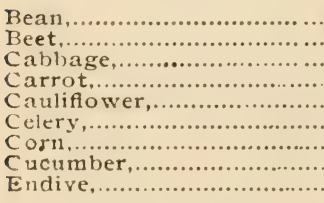 & $\begin{array}{r}5 \text { to } 10 \\
7 \text { to } 10 \\
5 \text { to } 10 \\
12 \text { to } 18 \\
5 \text { to } 10 \\
10 \text { to } 20 \\
5 \text { to } 8 \\
6 \text { to } 10 \\
5 \text { to } 10\end{array}$ & 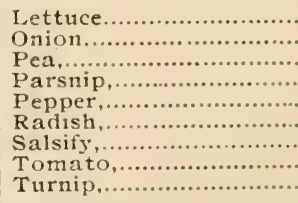 & $\begin{array}{r}6 \text { to } 8 \\
7 \text { to } 10 \\
6 \text { to } 10 \\
10 \text { to } 20 \\
9 \text { to } 14 \\
3 \text { to } 6 \\
7 \text { to } 12 \\
6 \text { to } 1 \frac{2}{4} \text { to } 8\end{array}$ \\
\hline
\end{tabular}




\section{TABLE V.-STANDARDS OF PURITY AND GERIINATION OF AGRICULTURAL SEEDS.}

The United States Department of Agriculture has adopted the following standards as the base for its decisions as to the value of seeds:

The seeds must be true to name, and practically free from smut, bunt, ergot, insects or their eggs or larrae, and the seeds of dodder (Cuscuta spp.), wild mustard (Brassica spp.), wild flax (Camelina spp.), Russian thistle (Salsola kali tragus), Canada thistle (Carduus arvensis), cockle (Agrostemma githago), chess (Bromus secalinus), quack grass (Agropyron repens), penny cress (Thlaspi arrense), wild oats (Arena fatua), and the bulblets of wild onion (Allium vineale). It must not contain more than one per cent of other weed seeds, and should come "ip to the percentages of purity 1 and germination given in the following table:

\begin{tabular}{|c|c|c|c|c|c|}
\hline KIND OF SEED & Purity. & $\begin{array}{l}\text { Gerial- } \\
\text { uation }\end{array}$ & KIND OF ,3EED. & Purity. & $\begin{array}{l}\text { Germi } \\
\text { nation. }\end{array}$ \\
\hline & $\begin{array}{c}\text { per } \\
\text { cent.* }\end{array}$ & Der cent & & $\begin{array}{l}\text { ner } \\
\text { cent. }\end{array}$ & $\begin{array}{l}\text { per } \\
\text { cent }\end{array}$ \\
\hline $\begin{array}{l}\text { Alfalfa. } \\
\text { Asparam }\end{array}$ & 98 & $85-90$ & Nelon, water... ..... & 99 & $85-90$ \\
\hline $\begin{array}{l}\text { sparag } \\
\text { arley.. }\end{array}$ & D? & & Millet, common (C'hae- & & \\
\hline $\begin{array}{l}\text { Barley.. } \\
\text { Beans:. }\end{array}$ & $\begin{array}{l}99 \\
99\end{array}$ & $\begin{array}{l}90-95 \\
90-95\end{array}$ & $\begin{array}{l}\text { lochlont italica)..... } \\
\text { Nillet, hog (Panicum }\end{array}$ & 98 & $85-90$ \\
\hline Beet ... & 99 & $140-150 \dagger$ & mi/raceum)......... & 99 & $85-90$ \\
\hline Blue grass, Canadian & 90 & $45-50$ & Millet, pearl......... & 99 & $85-90$ \\
\hline Blue grass, Kentucky. & 90 & $45-50$ & Oats................ & 99 & $90-95$ \\
\hline Brome, awniess...... & 90 & $75-80$ & Olira................. & 99 & $80-85$ \\
\hline Buckwbeat........ & 99 & $90-95$ & Onion................. & 99 & $80-85$ \\
\hline Cabbage............ & 99 & $90-95$ & Parslay............... & $99^{\circ}$ & $70-75$ \\
\hline Carrot................ & 95 & $80-85$ & Parsnip ............... & 95. & $\begin{array}{l}70-10 \\
90-95\end{array}$ \\
\hline Cauliflower............ & 99 & $80-85$ & Peas ................... & 99 & $\begin{array}{l}90-95 \\
85-90\end{array}$ \\
\hline $\begin{array}{l}\text { Celery. } \\
\text { Clover, }\end{array}$ & 98 & $\begin{array}{l}60-65 \\
75-80\end{array}$ & Pumpkin........ & 99 & $\begin{array}{l}85-90 \\
90-95\end{array}$ \\
\hline & $\begin{array}{l}95 \\
98\end{array}$ & $\begin{array}{l}75-80 \\
85-90\end{array}$ & Rape................ & 99 & $90-95$ \\
\hline Clover, red............... & 98 & $85-90$ & Rye.............. & 99 & $90-95$ \\
\hline Clover, white........ & 95 & $75-80$ & Salsify........... & 98 & $75-80$ \\
\hline Collardi... & 99 & $90-9$ & Sorghum....... & 98 & $85-90$ \\
\hline Corn, field....... & 99 & $90-95$ & Spinach ........ & 99 & $80-85$ \\
\hline Coru, sweet... & 99 & $85-90$ & Squash. & 99 & $85-90$ \\
\hline Cotton............ & 99 & $85-90$ & Timotliy..... & 98 & $85-90$ \\
\hline Cowpea.......... & 99 & $85-90$ & Tomato........ & 98 & $85-90$ \\
\hline Cucumb-r. ..... & 99 & $85-90$ & Turnip.. & 99 & $90-95$ \\
\hline Egg Plant...... & 99 & $75-80$ & Tobacco. & 98 & $\begin{array}{l}75-80 \\
70-75\end{array}$ \\
\hline Fescue, meadow..... & 95 & $\begin{array}{l}85-90 \\
85-90\end{array}$ & $\begin{array}{l}\text { Vetch, hairy.... } \\
\text { Vetch, kidney. }\end{array}$ & 98 & $\begin{array}{l}70-70 \\
85-90\end{array}$ \\
\hline $\begin{array}{l}\text { Lettuce } \ldots \ldots \ldots \ldots \ldots \\
\text { Kafir corn. }\end{array}$ & $\begin{array}{l}99 \\
98\end{array}$ & $\begin{array}{l}85-90 \\
85-90\end{array}$ & $\begin{array}{l}\text { Vetch, kidney.. } \\
\text { Wheal........... }\end{array}$ & 99 & $90-95$ \\
\hline Melon, musk........... & 99 & $85-90$ & ............ & & \\
\hline
\end{tabular}

*Impurity allowed refers to inert matter and one per ceut (on1y) of weed seed other than those practically prohibited, as avore noted.

tEach beet fruit, or "ball," is likely to contain from 2 to 7 seeds. One hundreo" balls should yield 150 sprouts.

This means purity of grain, not purity of stock. 
TABLE VI.-QUANTITY IOF SEED REQUIRED FOR A GIVEN NUMBER OF HILLS:

Corn

1 qt. to 200 hills

Cucumbers

$1 \mathrm{oz}$. to $1: 5$

$1 \mathrm{oz}$. to 60

$1 \mathrm{qt}$. to 100

$1 \mathrm{qt}$. to 150
$1 \mathrm{oz}$. to 50

Pole Beans, Lima

Pumpkin

1 Oz. to 50

Squasl

$1 \mathrm{Oz}$. to 30

66
66
66
66
66

TABLE VII.-QUAN'TITY OF SEED REQUIRED FOR A GIVEN LENGTH OF DRILL:

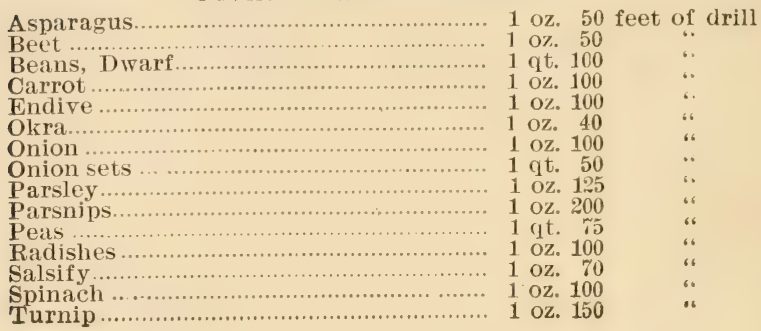




\section{MONTHLY CALENDAR.}

Under this head some of the principal operations of the year in the more northern states are referred to, but these can be regarded only as suggestive, since individual conditions as well as the weather vary from year to year. The point should be borne in mind that it is of the utmost importance, and for the greatest profit, to have all garden work done at the proper time; and to do this considerable planning and studying will be necessary in laying out each day's work, as well as the work of the season, so as to make the most of the opportunities offered by weather and season.

January.-The outdoor work is generally quite at a standstill this month, except that manure may be drawn from the stable to the fields needing it, where it may be piled and forked over. Plan out the work of the season, aiming to have the ground and the time of your help occupied all the time. In doing this it is generally best to plan to raise those crops that will not require a large amount of work at the same season, but rather those that will give a succession of work. Market any celery, squash or other vegetables for which there is a demand.

Send for seed catalogues of leading deaiers. Decide what you are going to want. Test the quality of the seeds you have on hand and get your new stock of seed early. Test the seeds received for planting.

February.-The work of this month differ's but little from that of January, but, in addition, the following may be mentioned: During the latter part of the month prepare manure for early hotbeds to be started the first of March. Inspect tools, wagons, harness, boxes and crates for marketing and hotbed sash, and get them into shape for the busy season. In the greenhouse, cabbage and cauliflower plants may be started; and as 
soon as of transplanting size they should be removed to cold frames, where they should remain until the ground is ready for planting out.

March.-Make up hotbeds and sow in them tomatoes, peppers, cabbage, lettuce, radishes, cress, onions for transplanting, carrots, beets, celery, etc. In the latter part of the month cold frames may be used for the hardy vegetables.

If the ground is fit to work, onion sets may be planted and spinach, hardy peas, and other plants which are generally not sown until April may be sown at this time. Harden off the early cabbage and cauliflower plants.

April.-The hotbeds and cold frames should be in constant use. Plantations of asparagus and rhubarb may be made during this and the following month. Plant onion sets.

Sow hardy (smooth) peas, lettuce, celery, radishes, cabbage, cauliflower, turnips, onions and spinach, and plant early potatoes as soon as the land is fit to be worked. By the end of the month, wrinkled peas, salsify and parsnips may be sown. See that tomatoes sown last month are transplanted into beds or boxes so as to have plenty of room. Transplant cabbage plants for the early crop, putting them in deep enough to completely cover the stems.

In the latter part of the month, all the early planted crops may need cultivating and some of them thinning though but little of this is generally necessary until May. Radishes, lettuce, spinach and onions from sets and from seed sown in hotbeds in March should be fit to eat or to market.

Haul out manure and plow land for planting next month. Transplant onion plants from the hotbeds to open ground.

May is the month when the larger part of the vegetables are planted.

By the middle of the month it is often safe to plant the more tender vegetables, sucu as cucumbers, squash, melons and beans, in the epen ground, although nothing is gainea by so doing if the ground is cold, waen it would be better to wait until ten days later. Corn is frequently planted by the middle of the month, and in early seasons it is a good plan to venture a little, 
of some very early kind during the first week of May. Plant potatoes for general crops.

All the early planted crops need cultivating frequently, and those in drills need tc be thinned.

Plantings for succession may be made of all vegetable seeds and sets put in last month.

Sow cabbage for winter use.

Lettuce, radishes, beets, spinach, asparagus, rhubarb and bunch onions should now be large enough for use.

Harden off tomato plants and set them out the first part of next month.

June.-Set out tomatoes, celery for early use, peppers, egg plant, late cabbage and cauliflower plants and sow winter beets.

Plant cucumbers for pickles and beans for main crop. Plant Lima beans the early part of the month. Market the same vegetables as last month and in addition early peas and, perhaps, early cabbare.

Weeding commences in earnest this month and should begin early, since if neglected it may be cheaper to plow up the whole crop rather than weed it out.

Keep the soil well stirred with the cultivator.

Sow rutabaga turnips.

Stop cutting asparagus by the twentieth of the month. Clean up the bed, manure and plow it.

July.-Plant celery for main and late crop.

Sow string beans, winter radish and rutabaga turnips.

Early potatoes, string beans, cabbage, summer squashes, cucumbers, green corn, onions from sets and cauliflowers are now of edible size in addition to those vegetables nearing maturity last month.

Continued cultivation is necessary to protect from drought and to keep plants growing.

August.-Sow string beans and flat early turnips, spinach for spring use, winter radishes and early peas.

The late crops are now maturing, and we have tomatoes, squashes, the better kinds of sweet corn and egg-plant, onions from early sown seed, and those transplanted are now dry and 
marketable. Lima beans will be ready for use the latter part of the month.

Keep weeds from going to seed.

Sow lettuce for growing in hotbeds or cold frames for Thanksgiving.

September.-The cool nights of this month are especially favorable to such crops as celery, cabbage and cauliflower, and they should be carefully cultivated.

Melons, winter squash and celery are now marketable.

Handle celery; i. e., partially earth up around it.

First frosts may now be expected by the fifteenth of the month, and the half-ripened tomatoes should be picked and allowed to ripen in some shady place. Winter squash should be gathered before it is at all injured by frost.

Dig potatoes.

Transplant lettuce to hotbeds or cold frames. Plant out hardy perennial onions for bunching in the early spring.

October.-Winter celery should be banked up to protect it from severe frosts, and on severe nights it should be covered with straw or hay for protection. It should all be stored away by the end of the month unless plenty of protection is provided in the shape of straw, in which case it is safe to leave it out until the 10th of November. Such crops will not stand with inmunity as much frost in the western states as in the eastern states. Pull and store cabbage, dig beets, carrots, parsnips, salsify and potatoes and store in pits or put at once into the celiar. Some parsnips and salsify may be left on high land to be lug in the spring. Plant out rhubarb roots.

Attend to fall plowing and leave in ridges any very heavy land that is needed for early spring use.

November.-In the more northern states this month generally closes up the work of the season. All the crops should be gathered in the early part of the month.

Clean up the garden, frames and hotbeds and get them ready for spring work.

The lettuce sown in August and transplanted to hotbeds or cold frames should be nt to market this month.

Market all the vegetables on hand that will bring a fair 
price, unless wanted for some special purpose or at an assured price.

Cover winter spinach and hardy onion sets with hay as soon as the ground begins to freeze hard at night, to prevant freezing and thawing.

December.-Clean up the garden and continue the marketing of vegetables if it is not already attended to.

Carefully study the season's work, note the profits or losses on the last crop, and what has been learned that will be useful another year.

At Odd Times the following may be attended to:-Gather manure, make crates and boxes for marketing fruits, vegetables and plants, repair tools, wagons, harnesses, sashes, hotbeds and cold frames. Clean up! 


\section{INDEX.}

Acre inch of water........ 10

Anise ..................232

Artichoke, Globe ........229

Artichoke, Jerusalem.......228

Ash, per cent in vegetables. 15

Asparagus ...............114

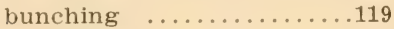

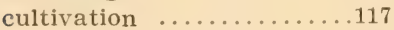

cutting ..............118

forcing $\ldots \ldots \ldots \ldots \ldots \ldots \ldots$

manuring .............119

planting ................. 117

propagation ...................

varieties ............... 120

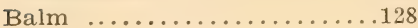

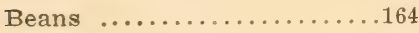

bush ................... 165

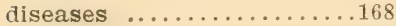

harvesting ................ 165

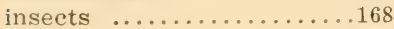

pole ......................

transpanting ...........167

preserving in salt.......167

varieties ...............164

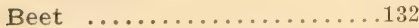

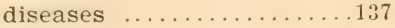

forcing ................. 139

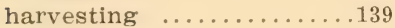

keeping .................... 139

swiss chard ...........141

stock ..................140

varieties $\ldots \ldots \ldots \ldots \ldots \ldots . \ldots \ldots$

sugar ........................

Borraginaceae ...........233

Borage ..................233

Borage Family ........ 106-233

Bordeaux mixture .........203

Borecole ...............156

Botanical classification.....105

Brussels sprouts ........154

Buckwheat Family.......105 134

Cabbage ................144

early .................145
Cabbage-Cont'd.

late ................147

storing ............... 149

diseases ..............152

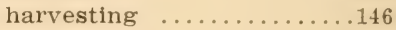

hill sowing ............ 148

insects ............... 152

manure for ............145

pitting ................. 149

retarding heading of .....146

rot ................. 153

sauer kraut ...........152

seed raising ............150

seed sowing .............147

setting plants ..........145

soil $\ldots \ldots \ldots \ldots \ldots \ldots \ldots \ldots \ldots \ldots$

varieties ................ 143

Cabbage Family.........105-143

Calendar, monthly........238

Caraway ...............232

Carbon bisulphide ....... 87

Carrot .................174

cultivation .............175

forcing .............. 178

gathering ............. 176

seed ..........................

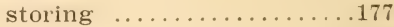

varieties ..............178

Catnip ................230

Cauliflower ...............155

varieties ...............156

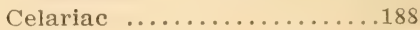

Celery .................178

bleaching with boards. ...184

bleaching with earth.....184

bleaching, time req @d

for ................187

digging .......... . 186

diseases ............. 187

early .............. 179

handling ............ .183

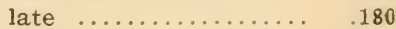

maxketing .......... .188 
Celery-Cont'd. Page

onions with ..........182

planting .............181

storing $\ldots \ldots \ldots \ldots \ldots \ldots 186$

seed ... ...........187

varieties .............188

Citron melon ...........219

Chenopodiaceae ...........137

Chives ... .............134

culture ............134

Classification of Vegetables..104

Clover Family .........105-163

Cold Climate Vegetables.....104

Cold frames (see greenhouses) 65

Cold frames, for early spring use .............6 66 sash for.. ......... 78

Commercial fertilizers .....21

Compositae ............223

Compost heap ...........21

Convolvulaceae ..........189

Corn ................109

classes of $\ldots \ldots \ldots \ldots \ldots 109$

cultivation ..........110

curing seed ..........112

cutting off tassels.......113

diseases .............101

insects .............113

marketing ............111

pop ... ............112

preserving $\ldots \ldots \ldots \ldots . . \ldots 113$

smut ...............113

varieties run out........112

Coriander ............233

varieties ..............111

Corrosive for Potato Scab...201

Cress .................161

water ...............160

Crucifereae .............143

Cucumber ... ..........219

cultivation .........2.219

gathering the crop ......220

insects ..............22

salting $\ldots \ldots \ldots \ldots \ldots 221$

secd $\ldots \ldots \ldots \ldots \ldots \ldots 22.2$

starting in cold frames...221

varieties .............222

Cueurbitaceae .........210
Page

Cultivation, general.....29-33-35

Dandelion .............2.

Dill .................23:

Diseases-

anthracnose of bean.....168

beet scab .............140

blight or rust of celery....18

club root of cabbage......152

leaf blight of celery......187

lettuce mildew .........226

potato blight .........202

potato scab ............200

smut of corn...........113

Egg plant ...........203

Endive ............227

Fennel ..............230

Formaline for Potato Scab...202

Frost Hardy Vegetables......105

Frost Tender Vegetables.....104

Fungi ................106

Garden herbs ..........229

Garlic, common..........132

Glass structures .........65

Germinating apparatus ..... 56

Germination, conditions for

successful ...........42

Gourd ............211

Gourd Family ........105-210

Goosefoot Family ......105-137

Gramineae ..............109

Grass Family .........105-109

Greenhouse hotbed ........71

Greenhouses .......... 74

boxes ... ........... 81

glass $\ldots \ldots \ldots \ldots \ldots, 8$ ?

glazing $\ldots \ldots \ldots \ldots \ldots 84$

heating ........... 75

lean-to..............73

mats ............ 78

miscellaneous notes on.... 78

radiating surface $\ldots \ldots \ldots 77$

sash ............. 78

shading ............ 82

shutters ........... 78

soil ..............81 81

substitutes for glass......81 81

temperature $\ldots \ldots \ldots \ldots .79$ 
Greenhouses-Cont'd. Page ventilation .......... watering ........... so

Ground cherry .........208

IIardening off of plants..... 50

Irerbs ...............229

Horseradish ............ 159

Hotbeds (see also greenhouses) 66

Hotbeds .............66 66

manure for .........6 67

early spring use.......67 67

fire .............. 69

sash for ........... 78

shutters for ......... 78

mats for .......... 78

Humus ............. 10-14

Implements . . . . . . . . . 35

combined drills and cultiva-

tors ........... 37

dibbers ............ 38

hand .............. 36

horse.... .......... 36

marker ............. 38

plank drag ........... 39

potato diggers ......... 39

potato hoe ............ 39

scuffle hoe ........... 39

seed drills ........... 37

spray pumps ......... 39

Insecticides ........... 85

application of $\ldots \ldots \ldots \ldots 88$

carbon bisulphide ........ 87

kerosene emulsion ...... 87

London purple ........ 86

Paris green ......... 86

pyrethrum .......... 85

tobacco ........... 86

Insects ........... 85

aphis .............. 99

bean weevil ............101

cabbage flea beetle.......998

cabbage lice .......... 100

cabbage worms ......... 90

eatching ............ 88

celery caterpillar .......100

chinch bug ............101

cucumber beetle ........ 95

cut worms .......... 93
Insects-Cont' d. Page

corn moth............100

leaf lice ............ 99

maggots ............ 97

May beetle ............ 96

parsley worm .........100

potato beetle .......... 89

pea weevil ............. 101

squash bug .............. 103

squash vine borer ......102

tassel worm ............. 100

white grub ........... 96

wire worms .......... 93

Irrigation $\ldots \ldots \ldots \ldots \ldots$

acre inch of water ..... 10

amount of water need:d... 10

application of water .... 11

cultivation as an aid to... 9

humus, an aid to....... 10

pumping water for....... 10

reservoirs ............ 11

rules for ........... 11

storage capacity for...... 10

sub-irrigation ......... 12

temperature of water..... 11

Kale................156

Kerosene emulsion ....... 87

Kitchen garden .......... 53

Kohl-rabi .............157

varieties .......................

Labiatae ..... . . . . . . 229

Lavender .............230

Leeks . . . . . . . . . . . . 133

cultivation ............ 133

varieties ............. 134

Luguminosae.............163

rettuce.............. . . . 223

cultivation.... . . . . . .223

mildew ............226

varieties ........... 225

Lilaceae ............. . . 114

Lily Family ....... . . 111,-114

Lima beans ............ 166

London purple ......... 86

Malvaceae .............171

Manure pile ............ 20

Manure, hotbed .........67 67

Manures ............. 14 
Manures-Cont'd. Page

action of........... 14

animal $\ldots \ldots \ldots \ldots \ldots 18$

commercial........... 21

effect $\ldots \ldots \ldots \ldots \ldots \ldots 25$

composition of $\ldots \ldots \ldots \ldots 17$

composition of farm...... 10

compost heap .......... 21

cow .............. 20

for early and late crops .. 26

for leguminous crops..... 27

ground blood ........... 22

ground bones ........... 22

heating of $\ldots \ldots \ldots \ldots \ldots 19$

hen $\ldots \ldots \ldots \ldots \ldots \ldots$...... 19

horse .............. 19

humus ............. If

Kainit ................. 24

land plaster ........... 25

lime .............. 25

liquid $\ldots \ldots \ldots \ldots \ldots \ldots 28$

mixing ............ 20

most valuable element in... 14

nitrate of soda ......... 23

salt .............15-24

sheep ............. 20

sulphate of ammonia ..... 24

superphosphates........24

swine .............. 20

tankage ............. 22

use of fresh $\ldots \ldots \ldots \ldots 26$

wood ashes ............24

Mallow Family ........105-171

Manuring growing crops.... 27

Martyniaceae .........210

Martynia ............210

culture ............210

Martynia Family.......105-210

Melon, musk ..........216 culture ...........216 varieties .........2.217

Melon, preserving .......217

Melon, water ...........218 culture .............219 varieties .............219

Mint . . . . . . . . . . 229

Mint Family ........105-229

Mixing varieties .........6 63
Page

Morning Glory Family...105-189

Monthly calendar .........238

Mulching ...........

Mushrooms ...........106

native species or $\ldots \ldots \ldots 107$

Novelties ............58

Okra ...............171

varieties ............171

Onions for home garden.....130

Onions ................120

cultivation ............123

keeping .............125

land for...............121

marketing ...........131

perennial .............131

potato..............131

scallions............124

sets...............125

seed..................131

sowing seed..........122

storing. . . . . . . . . . 125

top $\ldots \ldots \ldots \ldots \ldots \ldots \ldots \ldots \ldots 131$

transplanting ..........128

varieties.... .........131

Oyster plant ...........226

Parsnip Family .........105-171

Parsley ...............173

culture.............174

varieties............174

Parsnip..............172

culture ............172

varieties ............17?

Paris green .......... 86

Peas ..................168

culture.............169

canning of..........170

varieties .............170

Peppers ..............209

culture ...........209

varieties.............209

Peppermint ............231

Pie plant . . . . . . . . . 13.

Plowing .............. 31

subsoil ............. 31

Pollenizing flowers ........ 61

Polygonaceae ............134 


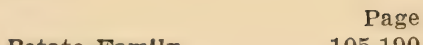

Potato Family ..........105-190

Potatoes ............... 190

blight .............202

digging ............... 195

diseases .............200

early planting .........194

insects ...............199

main crop ............194

manuring ............192

origin $\ldots \ldots \ldots \ldots \ldots \ldots 19 . \ldots \ldots$

pitting .............. 196

propagation, notes on ....199

"running out" of ........193

saving seed ............193

scab ..............200

sets or "seeds" . . . . . . . . 193

soil ................192

starch .............. . 198

use for seed of scabby . . . 201

varieties .............. 198

Protection to newly planted seeds against insects.... 46 against crows and gophers. 46

Pumnkins ..............215

Pyrethrum ............. 85

Radishes..............161

culture ..............161

- varieties .............. 162

Rhubarb .........................

culture .....................

forcing .............. 136

varieties .................

Ridging land ........... 33

Rotating of manures...... 28

Rotation of crops ........13

reasons for........... 13

Rue................. . 233

Rue Family ...........106-233

Rutaceae .............233

Rutabagas .............. 157

Sage.................231

Sauer kraut...........152

Savory, winter ..........232

Shallots............... 133

seed................. 55
Seeds-Cont'a. Page

curing............. 57

germinating apparatus .... 56

germinating standards ...2237

stock .............. 58

storing $\ldots \ldots \ldots \ldots \ldots \ldots . \ldots$

testing ............ 55

Seed sowing ........... 42

depth .............. 42

time ............. 43

firming by feet ........ 45

in stiff soils ......... 43

with machine ......... 44

by hand............. 45

Seedmen's humbugs ....... 58

Seedmen's specialties ....... 58

Seed tables ..........234-237

amount for acre .......236

lon vity ............235

purity standards........237

number of seeds in an ounce.234

time to germinate......236

weight of seeds........234

Seeds, pedigrees of . . . . . 55

novelties............ 58

Solanaceae .............. 190

Soils................ 8

for early crops ........ 8

for late crops.......... 8

elements necessary ...... 14

elements lacking in...... 14

Spearmint .............232

Spinach.................141

culture.............142

varieties .............. 143

Squash ...............211

cultivation ............212

harvesting ..........213

pollenizing flowers ......211

storing ............213

varieties. ............214

Sunflower Family.......105-243

Strawberry tomato ........208

culture ...............209

Sub-irrigation .......... 12

Subsoiling ............ 31

Summer savory ..........232

Sweet basil ............231

Sweet marjoram..........232 
Page

Sweet Potato .............189

Swiss chard ..............141

Thinning plants .........4 46

Thyme ................232

Tillage, galdin .......... 29

general ............... 33

Tomato, prolonging season..207

Tomato .................204

cultivation ............204

diseases .............207

insects .............207

in severe locations.......206

land for ..............204

propagation ............204

pruning ..............205

saving seed ...........207

training ..............205

transplanting ..........205

varieties .............207

Tobacco ................. 86

Transplanting ............ 47

avoiding ..............4 47

conditions of success.....47 47
Transplanting-Cont'd. Page shortening the tops in..... 48 digging plants for........48 48 firming the soil in....... 49 with tomato cans........ 51

Turnip ..................15i culture ................15s

rutabaga ...............159

varieties $\ldots . \ldots \ldots \ldots \ldots$....... 159

Umbellifereae ..........171-23:

Varieties, development of...5 58 mixing of $\ldots \ldots \ldots \ldots \ldots, 63$ distance between ........6. 63

Vegetable oyster (see salsify) $\ldots \ldots \ldots \ldots \ldots \ldots \ldots \ldots 226$

Vitality of seeds..........235

Vegetables, composition of.. 15

Warm Climate Vegetables...104

Weeds ................. 30 cultivation to kill......... 29 killing of $\ldots \ldots \ldots \ldots \ldots, 29$ prevention of $\ldots \ldots \ldots \ldots .29$ seeds in manure......... 30

Winter Savory ............232

Weights of seeds..........234 








FEB $18 \quad 1904$ 



\section{LIBRARY OF CONGRESS}

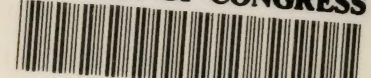
०0009283705 